José Heitzmann Fontenelle

\begin{abstract}
ANATOMIA, TAXONOMIA E DISTRIBUIÇÃO GEOGRÁFICA DOS CARACÓIS-GIGANTES DO "COMPLEXO MEGALOBULIMUS GRANULOSUS" (MOLLUSCA，GASTROPODA，PULMONATA)
\end{abstract}

São Paulo 
José Heitzmann Fontenelle

\title{
ANATOMIA, TAXONOMIA E DISTRIBUIÇÃO GEOGRÁFICA DOS CARACÓIS-GIGANTES DO "COMPLEXO MEGALOBULIMUS GRANULOSUS" (MOLLUSCA, GASTROPODA, PULMONATA)
}

\author{
ANATOMY, TAXONOMY AND GEOGRAPHICAL \\ DISTRIBUTION OF THE GIANT SNAILS "COMPLEX MEGALOBULIMUS \\ GRANULOSUS" (MOLLUSCA, GASTROPODA, PULMONATA)
}

Dissertação apresentada ao Instituto de
Biociências da Universidade de São
Paulo, para a obtenção de Título de
Mestre em Zoologia, na Área de
Malacologia.

Orientador: Prof. Dr. Luiz Ricardo

Lopes de Simone

São Paulo 
Heitzmann Fontenelle, José

Anatomia, taxonomia e distribuição geográfica dos caracóis gigantes do "Complexo Megalobulimus granulosus" (Mollusca, Gastropoda, Pulmonata). VIII, 160 p.

Dissertação (Mestrado) - Instituto de Biociências da Universidade de São Paulo. Departamento de Zoologia.

1. "complexo Megalobulimus granulosus" 2. anatomia comparada 3. taxonomia 4. distribuição geográfica I. Universidade de São Paulo. Instituto de Biociências. Departamento de Zoologia.

Comissão Julgadora:

$\operatorname{Prof}(\mathrm{a}) . \operatorname{Dr}(\mathrm{a})$.

$\operatorname{Prof}(\mathrm{a}) . \operatorname{Dr}(\mathrm{a})$.

Prof. Dr. Luiz Ricardo Lopes de Simone

Orientador(a) 
À Rebeca

"E ainda que tivesse o dom de profecia, e conhecesse todos os mistérios e toda a ciência, e ainda que tivesse toda fé, de maneira tal que transportasse os montes, e não tivesse amor, nada seria" 
Agradeço ao meu orientador, Professor Doutor Luiz Ricardo Lopes de Simone, por ter me aceitado como seu aluno e me iniciado no aprendizado da morfologia comparada, sendo um exemplo de dedicação e comprometimento com o estudo da biodiversidade dos moluscos.

Aos técnicos e colegas que dividiram as bancadas do Laboratório de Malacologia do Museu de Zoologia da USP, Magenta, Eric, Daniel Potter, Isac, Anita, Vanessa, Portuga, Jaime, Daniel Abade, Rodrigo, Cuca, Bárbara e Patrícia, sempre solícitos aos pedidos de ajuda, e aos demais funcionários e docentes do Museu de Zoologia, que se mostraram atenciosos e prestativos quando necessários, registro meus agradecimentos e amizade.

Aos meus pais que garantiram uma criação e educação retos, que são a base do que sou e faço hoje, e em especial à minha mãe, "Dona" Therezinha, que manteve a biologia sempre presente em minha formação e a quem tento me espelhar no seu exemplo de vida como pesquisadora e principalmente do seu exemplo de ser humano, a minha eterna gratidão.

A Prefeitura de Santos e ao Orquidário Municipal de Santos, onde esta dissertação tomou forma com as coletas dos primeiros Megalobulimus no final da década de 1990, agradeço aos administradores, funcionários e estagiários a imprescindível e imensa colaboração. Á antiga chefe da unidade Greicelene pelo grande apoio no início da pesquisa e a bióloga Ana Beatriz que garantiu a "tranquilidade" no setor de zoologia durante as minhas ausências, o meu reconhecimento e agradecimento.

À minha família, Cleide, Rebeca e Pepa, que independente de minha vontade sempre se esforçaram para cuidar de mim, e que nestes anos de correria e prazos me ensinaram que o mundo não pode parar quando queremos, cobrando com direito a minha presença e atenção, agradeço do fundo de meu coração pelo aprendizado, ajuda, tolerância e apoio. 


\section{1) INTRODUÇÃO}

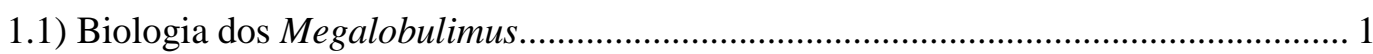

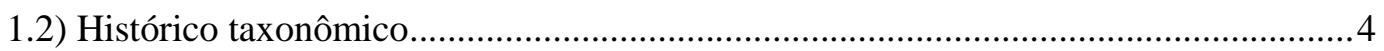

1.3) Os complexos e as espécies selecionadas para este estudo........................................

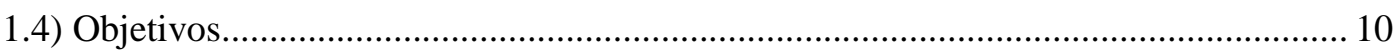

\section{2) MATERIAL E MÉTODOS}

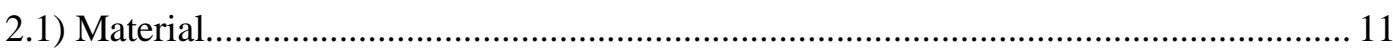

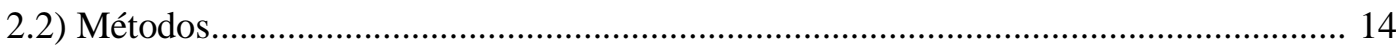

3) RESULTADOS

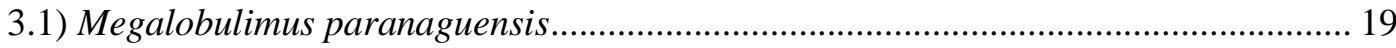

3.2) Megalobulimus granulosus................................................................................ 51

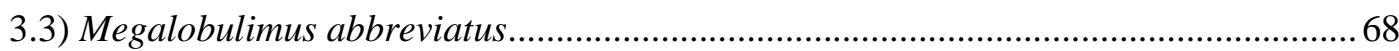

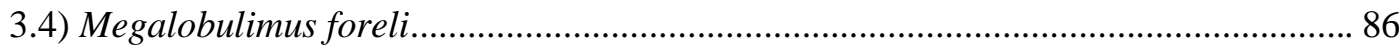

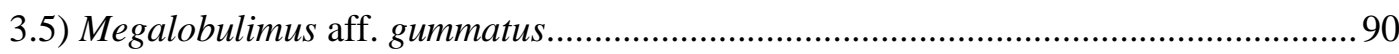

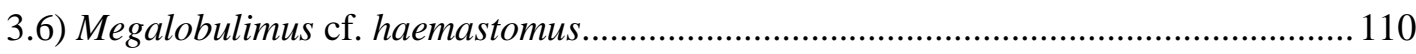

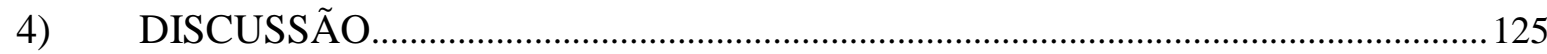

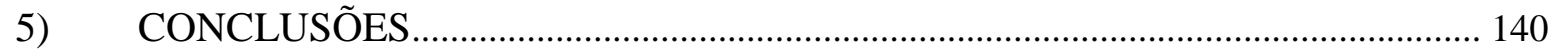

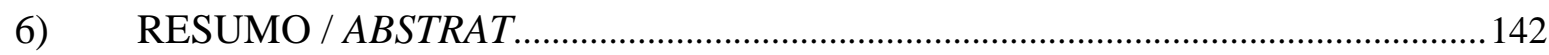

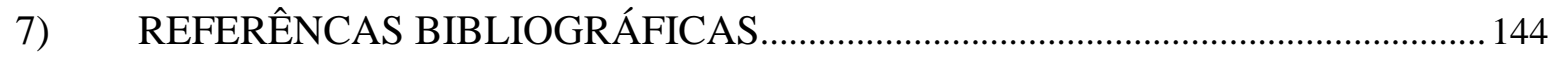

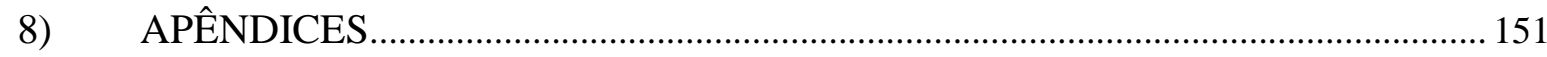


ANSP Academy of Natural Sciences of Philadelphia, PA, EUA

MCZ Museum of Comparative Zoology, MA, EUA

MNCN Museo Nacional de Ciencias Naturales, Madrid, Espanha

MNHN Muséum national d'Historie naturelle, Paris, França

MNHNM Museo Nacional de Historia Natural, Montevideo, Uruguai

MZSP Museu de Zoologia da Universidade de São Paulo, SP, Brasil

PZOMS Parque Zoobotânico "Orquidário Municipal de Santos”, SP, Brasil 


\section{ABREVIAÇÕES USADAS NO ESTUDO MORFOLÓGICO}

\begin{tabular}{|c|c|}
\hline an: & ânus \\
\hline aa: & aorta anterior \\
\hline ap: & aorta posterior \\
\hline av: & apêndice vaginal \\
\hline bc: & bursa copulatrix (bolsa copulatória) \\
\hline be: & bolsa do espermatóforo \\
\hline bm: & borda do manto \\
\hline bt: & bonete da rádula \\
\hline c1, c2 & ramificações do vaso pericárdico \\
\hline ca: & câmara de albume \\
\hline cb: & cabeça \\
\hline cd: & cinta mandibular \\
\hline ce: & complexo subesofageal \\
\hline cf: & canal esofágico \\
\hline ci: & canal intestinal \\
\hline cl: & canal lateral \\
\hline cm: & câmara média do esôfago \\
\hline cn: & câmara anterior do esôfago \\
\hline cp: & câmara posterior do esôfago \\
\hline cs: & câmara essencialmente respiratória \\
\hline cr: & cartilagem radular \\
\hline da: & ducto para a glândula digestiva anterior \\
\hline db: & ducto da bursa \\
\hline dd: & dobra superior da borda do manto \\
\hline de: & dobra inferior da borda do manto \\
\hline df: & canal deferente \\
\hline dg: & ducto da glândula de albume \\
\hline dh: & ducto hermafrodita \\
\hline di: & diafragma \\
\hline dp: & ducto para a glândula digestiva posterior \\
\hline eo: & espermoviduto \\
\hline ep: & epifalo \\
\hline es: & esôfago \\
\hline et: & estômago \\
\hline fl: & flagelo(s) \\
\hline fp: & fundo da cavidade palial \\
\hline ga: & glândula digestiva anterior \\
\hline gb: & glândula de albume \\
\hline ge: & goteira espermática \\
\hline gg: & glândula genital acessória \\
\hline go: & gônada \\
\hline gp: & glândula digestiva posterior \\
\hline gs: & glândulas salivares \\
\hline gu: & goteira urinária \\
\hline in: & intestino \\
\hline li: & lábio interno da borda do manto \\
\hline lp: & lábio do pneumóstoma \\
\hline lx: & lábio externo da borda do manto \\
\hline m1: & músculos extrínsecos longitudinais da massa bucal \\
\hline m2: & músculo retrator da massa bucal \\
\hline m3: & músculo extrínseco transversal da massa bucal \\
\hline m4/m5: & músculos retrator/protator da rádula \\
\hline m6: & músculo inter-radular \\
\hline m7: & músculo núcleo-radular \\
\hline mb: & massa bucal \\
\hline md. & mandíbula \\
\hline c. & músculo columelar \\
\hline
\end{tabular}

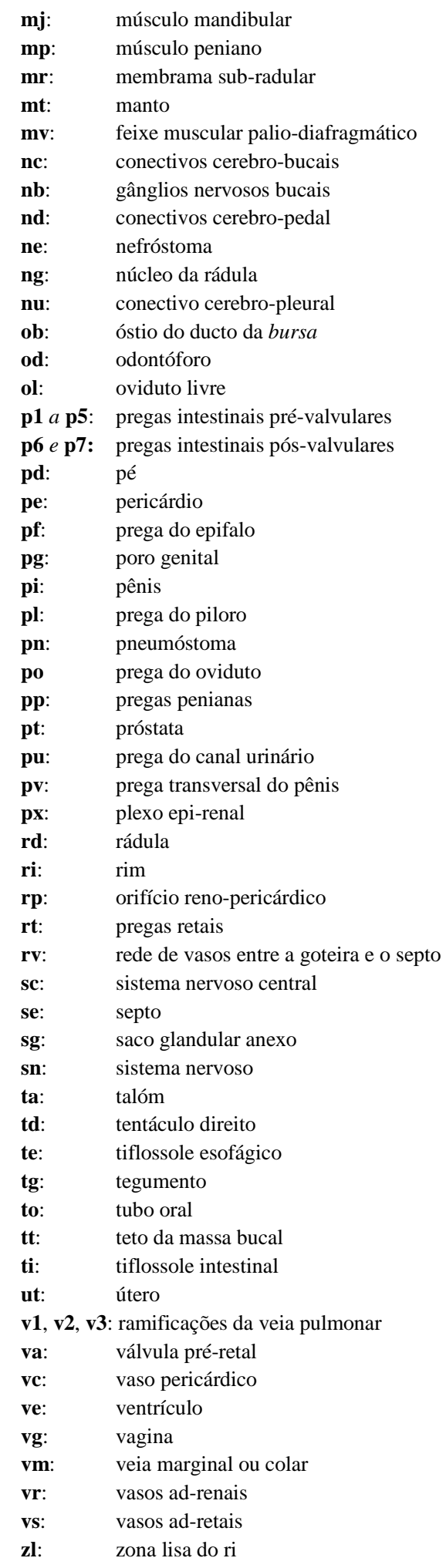




\section{INTRODUÇÃO}

\section{1 ) Biologia dos Megalobulimus}

Conhecidos popularmente como caracóis-gigantes ou aruás-do-mato (Ihering, 1968), os gastrópodes estilomatóforos pertencentes à subfamília Megalobuliminae (Leme, 1973) e ao gênero Megalobulimus Miller, 1878 são os maiores pulmonados terrestres sul-americanos com comprimento de concha variando entre 50 e $160 \mathrm{~mm}$ (Fig. 1).

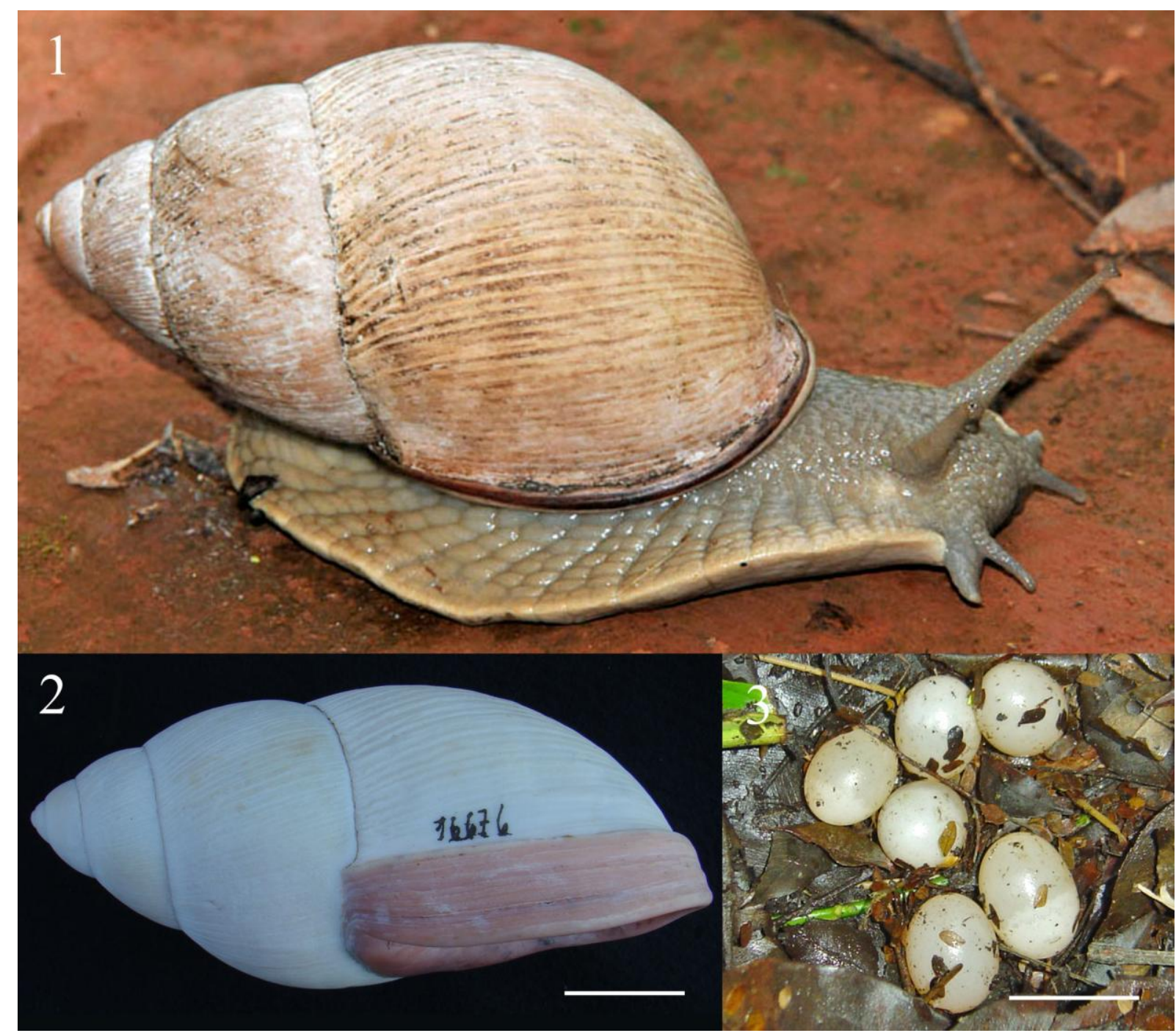

Figuras 1 a 3. Megalobulimus: 1. Megalobulimus aff. oblongus (Serra Negra, Patrocínio/MG, foto: Robson Silva e Silva); 2. Megalobulimus haemastomus MZSP 16676: lábio espessado pelo acúmulo de camadas produzidas pela borda do manto (ESCALA $=10 \mathrm{~mm}$ ); 3. Megalobulimus paranaguensis: postura sob o folhiço no Parque Zoobotânico "Orquidário Municipal de Santos", Santos/SP (ESCALA $=25 \mathrm{~mm}$ ). 
Pelo seu grande tamanho, foram utilizados por grupos humanos pré-históricos entre 10.000 e 2.000 anos atrás como alimento e suas conchas como adorno ou matéria prima para confecção de instrumentos. São encontrados em sítios arqueológicos no litoral e interior do Brasil (Leme, 1975), sendo particularmente abundantes nos sambaquis fluviais na região do vale do rio Ribeira do Iguape em São Paulo (Prous, 1992). Sua utilização cultural como alimento resurgiu na região sul do Brasil, quando eram coletados e assados pelos imigrantes italianos no início do século XX (Valduga, 1985) a semelhança do caracol Helix spp. na Europa mediterrânea. Os caiçaras que vivem em pequenas comunidades na Mata Atlântica ainda utilizam o Megalobulimus torrado e moído para fins medicinais (Hanazaki et al., 2009).

São reconhecidas 61 espécies de Megalobulimus, sendo 50 a 56 registradas para o território brasileiro (Salgado \& Coelho, 2003; Simone, 2006). O principal centro de densidade de espécies são os planaltos e serras do Brasil oriental, entre o Maranhão e o Rio Grande do Sul (Bequaert, 1948). Sob o domínio do Hotspot da Mata Atlântica (Mansur \& Leme, 1996; Myers et al., 2000), esta área possui 35 espécies descritas (Simone, 2006). Entretanto, estes números podem estar subestimados devido ao fato dos gastrópodes terrestres possuírem distribuições restritas, com alto endemismo, com a maioria das espécies ainda desconhecidas pela ciência (Simone, 1999; Monge-Nájera, 2003; Lydeard et al., 2004).

Os megalobulimíneos possuem hábitos noturnos e detritívoros, enterrando-se no folhiço ou solo das florestas úmidas durante o dia e na estação de dormência (Bequaert, 1948; Morretes, 1952). Ocorrem em áreas tropicais e subtropicais desde a Colômbia até a latitude $40^{\circ}$ sul na Argentina, não ocorrendo a leste dos Andes (Bequaert, 1948). Uma de suas espécies, o M. oblongus (Müller, 1774) foi introduzido presumivelmente no início da colonização europeia nas ilhas do Caribe, ocorrendo atualmente na Jamaica (Rosenberg \& Muratov, 2005), Barbados (Chase \& Robison, 2001), St. Vicent, St. Thomas, Grenada, Antígua, St. Kitts e St. Lucia (Bequaert, 1948).

A maturidade sexual é marcada pela inversão do lábio, e a consequente parada no crescimento, entre nove e 16 meses para $M$. aff. ovatus; 12 meses para M. bronni (Pfeiffer, 1847) e 13 a 36 meses para M. mogianensis Simone \& Leme, 1998 (Oliveira et al., 1984; Jacinavicius et al., 2004; Romero, 2004).

Após a inversão do perístoma, ocorre o espessamento progressivo do lábio com a deposição de novas camadas de cálcio (Fig. 2). Utilizando este número de camadas e supondo 
a adição de duas novas camadas anuais, Groh (2005), calculou em 44 anos a idade de um indivíduo de $M$. intertextus (Pilsbry, 1895), enquanto que Fontenelle (2011) calculando a velocidade do espessamento do lábio para o M. paranaguensis (Pilsbry \& Ihering, 1900), determinou a idade de um indivíduo com 6,5 mm em 21 anos.

São considerados moluscos K-estrategistas, iteróparos, com período de postura na primavera-verão nas espécies M. mogianensis e M. abbreviatus (Bequaert, 1948) (Romero, 2004; Rohr et al., 2005) ou no outono e primavera nas espécies $M$. bronii e M. gummatus (Oliveira et al., 1984; Sobreira \& Molina, 2002). Os ovos são grandes e possuem casca calcária (Fig. 3) e, em indivíduos mantidos em terrários, o número médio por postura e a taxa de eclosão variou de; 1,44 / 42,4\% em $M$. aff. ovatus; 2,87 / 36,7\% em M. sp.; 3,71 / 52,6\% em M. gummatus; e - / 30\% em M. bronni (Oliveira et al., 1984; Sobreira \& Molina, 2002; Rios et al., 2004), após um período de incubação de 71 a 112 dias em M. aff. ovatus; e 91 dias para M. bronni (Oliveira et al., 1984; Rios et al., 2004). Apresentaram alta taxa de mortalidade na fase juvenil, entre 95 a 97\% em M. mogianensis (Romero, 2004).

Os moluscos terrestres são táxons extremamente sensíveis, possuindo o maior número de extinções registradas entre os animais terrestres com 291 (42\%) das 693 extinções documentadas desde o ano de 1500 (Lydeard et al., 2004). Embora algumas espécies de Megalobulimus já estejam oficialmente relacionadas na lista de espécies brasileiras ameaçadas de extinção, como M. cardosoi (Morretes, 1952), M. grandis (Martens, 1885), M. lopesi Leme, 1989, M. parafragilior Leme \& Indrusiak, 1990 e M. proclivis (Martens, 1888) (IBAMA, 2003), desconhece-se a situação da maioria das espécies onde o alto endemismo regional torna-as presumivelmente ameaçadas diante da introdução de espécies exóticas, destruição e contaminações ambientais (Leme \& Mansur, 1996; Simone, 1999; Lydeard et al., 2004).

O “caramujo-africano”, Achatina fulica Bawdick, 1822, após sua introdução no final da década de 1980, tem sido incriminado como uma importante ameaça às populações de megalobulimíneos brasileiros (Simone, 1999). As interações interespecíficas observadas em laboratório ainda são inconclusivas, indo desde letargia e óbito dos Megalobulimus após contato com o invasor (Eston et al., 2006), até a permanência do Megalobulimus em seu sítio preferencial, o solo, com o deslocamento e dispersão vertical do invasor (Latoski \& Fischer, 2010). Assim, a diminuição das populações de Megalobulimus relatada pelos moradores de áreas invadidas (Fischer \& Colley, 2005) pode ser interpretada como um efeito direto da 
competição do Achatina fulica, que pode ser ampliado pelas medidas de controle como a contaminação do solo com sal ou hipoclorito de sódio (Fischer \& Colley, 2004) e a captura e extermínio acidental de indivíduos de Megalobulimus durante as campanhas de controle do caracol invasor (Colley \& Fischer, 2009), ou ser apenas o resultado colateral destas medidas contra o Achatina fulica.

O estudo das espécies de Megalobulimus é prejudicado em campo pela dificuldade de localização dos indivíduos pela baixa densidade das populações e pelos longos períodos de inatividade (Cáceres, 1997; Simone, 1999), e, consequentemente, em laboratório pela falta de séries completas com os extremos das variações individuais (Bequaert, 1948). Um exemplo da dificuldade de estudo é que cerca de um quinto das espécies de Megalobulimus são conhecidas apenas pela descrição original, não tendo sido mais encontradas (Mansur \& Leme, 1996).

Diante de um eminente colapso da biodiversidade e da falta de informações biológicas, a preservação deste grupo de caracóis detritívoros e longevos (Fontenelle, 2011) esta necessariamente vinculada a novos estudos taxonômicos, visto que uma espécie só pode ser preservada desde que seja reconhecida pela ciência (Simone, 1999). Atualmente considerada muito mais do que a simples nomeação e organização de nomes, a taxonomia identifica e analisa os caracteres morfológicos, reconstruindo relações, e reconhecendo uma espécie como produto real de um determinado processo evolutivo em um determinado ambiente. Estas construções taxonômicas são a soma das informações morfológicas de concha e dos tecidos moles do gastrópode, com os dados paleontológicos, ontogênicos, moleculares e ecológicos, criando uma taxonomia ampla reconhecida como holística ou holomorfologia (Leme, 1971; Wheller, 2008).

\section{2 ) Histórico taxonômico}

No início do século XIX eram reconhecidas poucas espécies de Megalobulimus, a maioria dentro dos polivalentes gênero Helix na família Helicidae. Posteriormente foram utilizados os taxa Bulimus Scopoli, 1777; Strophocheilus Spix, 1827; Borus Alber, 1850; Cochlogena Férussac, 1821; e Megalobulimus Miller, 1878. O primeiro destes, o gênero Bulimus associado à forma bulimóide da concha, tornou-se um verdadeiro meme científico, sendo utilizado por Pfeiffer (1848) para 632 espécies de gastrópodes terrestres. 
Somente no final do século XIX, quando já eram descritas 28 espécies dos atuais Megalobulimus, que uma sistemática e taxonomia baseadas em caracteres da anatomia dos tecidos moles foram iniciadas com os trabalhos de Pilsbry (1894), que criou a subfamília Acavinae na família Helicidae, a qual foi posteriormente elevada pelo mesmo autor à família (Acavidae) com a subfamília Strophocheilinae para abrigar os gêneros Gonyostomus Beck, 1837 e Strophocheilus, este último incluía no subgênero Borus, os atuais Megalobulimus (Pilsbry, 1902). Os acavídeos foram definidos por terem uma genitália simples com o vaso deferente inserido diretamente no pênis ou ampliado em uma epifalo sem flagelo; ausência de saco de dardo ou glândulas mucosas, mas às vezes com um apêndice alto na vagina; ovos com cascas fortes e jovens muito grandes na eclosão; mandíbula sólida, lisa ou verticalmente estriada; rádula com dentes todos unicúspides; concha embrionária grande, claramente diferenciada do crescimento posterior por escultura, e; concha grande e sólida (Pilsbry, 1894), enquanto que os Strophocheilinae possuíam como caracteres o rim longo; ausência de um ureter tubular; abundante venação na região cardíaca da cavidade palial, e; mandíbula sólida e lisa (Pilsbry, 1902). Posteriormente a família Acavidae foi elevada à superfamília Acavoidea, e a subfamília Strophocheilinae à família Strophocheilidae, sendo esta a sistemática atual (Bouchet \& Rocroi, 2005).

Duas revisões foram realizadas na família Strophocheilidae em meados do século XX. Baseado na análise das conchas e principalmente das esculturas da protoconcha Bequaert (1948) realizou uma extensa revisão da família e dividiu o gênero Strophocheilus em cinco subgêneros: Megalobulimus, Strophocheilus, Speironepion Bequaert, 1948, Microborus Pilsbry, 1926, e Chiliborus Pilsbry, 1926. Para o subgênero Megalobulimus foram relacionadas 48 espécies e subespécies. Na introdução daquela monografia o autor definiu a utilização do status de subespécie para todos os táxons reconhecidos, que além de "verdadeiras" subespécies, poderiam incluir também extremos da variação individual, mutações ou anormalidades, e raças ecológicas sem isolamento genético (Bequaert, 1948), deixando clara a necessidade de estudos complementares.

Uma concomitante revisão nos Strophocheilidae brasileiros, baseada igualmente nas características conquiliológica, foi realizada por Morretes (1952). Aquele autor elevou o táxon Megalobulimus à gênero e definiu quatro novos subgêneros: Megalobulimus s.s., Speironepion, Phaiopharus Morretes, 1952, e Psiloicus Morretes, 1952, reconhecendo 48 espécies (Morretes, 1952). Diante da impossibilidade de acesso e diagnóstico preciso de todos 
os representantes brasileiros da família, Morretes reconhece a possibilidade de posteriores alterações de inclusão nos gêneros e subgêneros propostos.

As divergências entre as classificações de Bequaert (1948) e Morretes (1952), embora utilizando os mesmos caracteres diagnósticos, são decorrentes da semelhança conquiliológica entre as espécies. Espécies com morfologia conquiliológica similar são comuns em moluscos, e a dificuldade em seu reconhecimento é aumentada pela grande variação intraespecífica (Mayr, 1977), que pode resultar na descrição de um número elevado de espécies sinônimas (Monge-Nàjera, 2003), ou a existência de duas ou mais espécies ocultas por um único tipo conquiliológico (Simone, 1995).

Na década de 1970, Leme conduziu um novo estudo sistemático da família Strophocheilidae baseado na anatomia dos órgãos internos (Leme, 1971-1973). O artigo resultou no seu desmembramento, com a criação da nova família Megalobulimidae, reunindo o gênero pregressamente alocado em Strophocheilidae, para abrigar apenas espécies do gênero Megalobulimus. Nas revisões sistemáticas posteriores a família Strophocheilidae manteve-se com duas subfamílias Strophocheilinae e Megalobuliminae (Bouchet \& Rocroi, 2005).

Os principais caracteres da subfamília Megalobuliminae incluem: A) Rim sem qualquer vestígio de ureter primário; B) Válvula pré-retal no intestino; C) Septo na câmara pulmonar; D) Boca com lábios franjados; e, E) Glândula genital anexa (Leme, 1971).

Segundo Leme (1971) a pequena variabilidade dos caracteres nos tecidos moles invalida os subgêneros dentro de Megalobulimus e a definição de outros gêneros dentro de Megalobuliminae. Nesse contexto, Speironepion foi elevado a gênero e realocado dentro da família Strophocheilidae, e Phaiopharus e Psiloicus foram considerados sinonímias de Megalobulimus enquanto as subespécies da classificação de Bequaert (1948) foram elevadas á categoria de espécies (Leme, 1973).

Na comparação entre os caracteres da concha e dos tecidos moles, Leme (1971-1973) também considerou que a concha nos gastrópodes terrestres é mais conservativa e que sua análise é insuficiente para um estudo comparativo entre espécies próximas, pois pequenas diferenças conquiliológicas, passíveis de serem interpretadas como simples variação individual, populacional ou geográfica, podem mascarar grandes diferenças anatômicas 
apresentadas por espécies diferentes. Conclui aquele autor que existe a necessidade de associar à análise conquiliológica, um rigoroso estudo dos caracteres anatômicos das partes moles, principalmente dos sistemas digestivo, reprodutor e excretor (Leme \& Indrusiak, 1995).

Anteriormente, Morretes (1952) havia defendido o valor dos caracteres conquiliológicos, igualando sua importância à anatomia na diferenciação de espécies na família Strophocheilidae. Mais recentemente, Schander \& Sundberg (2001), analisando 28 filogenias morfológicas publicadas em gastrópodes, chegaram a mesma conclusão intuitiva de Morretes ao constatarem que os índices de homoplasia são similares em ambos os conjuntos de caracteres.

Exemplos do uso da anatomia interna para resoluções taxonômicas dentro da subfamília Megalobuliminae incluem as espécies Megalobulimus lopesi, diferenciada de $M$. grandis pela conformação da rádula e anatomia do sistema reprodutivo (Leme, 1989); $M$. parafragilior que apresenta exclusiva diferenciação peniana em porções basal e apical (Leme \& Indrusiak, 1995); M. riopretensis e M. mogianensis Simone \& Leme, 1998, diferenciados de outras afins do "complexo M. oblongus" pela anatomia da câmara palial, sistema digestivo e reprodutivo (Simone \& Leme, 1998).

A anatomia interna também foi utilizada para redescrições de espécies conhecidas unicamente através de suas características conquiliológicas como, e.g., M. lorentzianus (Doering) (Scott, 1939), M. auritus Sowerby, 1838 (Leme, 1993) e M. proclivis (Leme \& Indrusiak, 1995).

\section{3 ) Os “complexos" e as espécies selecionadas para este estudo}

Leme (1971-1973), com o objetivo prático de igualar as espécies para comparação morfológica excluiu os subgêneros e subespécies dentro da família Megalobulimidae. Mas aquele autor reconheceu a existência de grupos relativamente homogêneos de espécies (Leme, 1971-1973), muitas vezes coincidente com os conjuntos de subespécies de Bequaert (1948) ou os subgêneros de Morretes (1952). Concluiu que existe a necessidade de estudos visando a correlação destes grupos em função da sua anatomia, distribuição geográfica e ecologia, 
aceitando a subdivisão de Megalobulimus em "complexos", provisoriamente informais e sem conotação taxonômica (Leme, 1971). Tais "complexos", após estudos complementares, poderão revelar-se subgêneros ou até gêneros separados.

Dentre estes agrupamentos, as quatro espécies que compõem o "complexo Megalobulimus granulosus" foram escolhidas para este estudo anatômico em função da grande disponibilidade de material de uma de suas espécies, o Megalobulimus paranaguensis, coletados no Orquidário Municipal de Santos (PZOMS) e utilizados na aprendizagem das técnicas de dissecção e como parâmetro de comparação para com as outras espécies estudadas, somado ao fato que tanto esta como as demais espécies deste complexo estarem bem representadas na coleção do Museu de Zoologia da Universidade de São Paulo (MZSP). Outro fator que justificou o estudo deste complexo foi a ocorrência de suas espécies em áreas de alta densidade e impacto antrópico (planície costeira das regiões Sudeste e Sul), necessitando de um estudo que as identifique como espécies únicas e os seus limites de distribuição geográfica para que caso necessário possam ser implantadas medidas de manejo e preservação (Lydeard et al., 2004).

O “complexo" engloba as quatro prévias subespécies de Strophocheilus (Megalobulimus) granulosus, da revisão de Bequaert (1948): Megalobulimus granulosus (Rang, 1831); Megalobulimus paranaguensis (Pilsbry \& Ihering, 1900); Megalobulimus abbreviatus (Bequaert, 1948); e, Megalobulimus foreli (Bequaert, 1948). Os caracteres conquiliológicos utilizados por aquele autor para o grupo incluíam: concha larga à alongadaelíptica, com a espira mais atenuada do que a base; concha geralmente com forte microescultura granulosa em linhas espirais; costelas neopiônicas um pouco menos largas do que seus intervalos na segunda volta, mas mais afastadas e espalhadas na terceira volta; voltado-corpo achatada e convexa; concha um pouco saciforme no lado esquerdo de sua base; abertura oblíqua ou semi-elíptica, com lábio inferior abruptamente arredondado na columela; região mediana do lábio externo não endireitado ou acrescido; parede parietal não abaulada; e columela mais ou menos arqueada (Bequaert, 1948).

Na classificação de Morretes (1952) estas quatro espécies pertenciam ao subgênero Phaiopharus do gênero Megalobulimus conjuntamente com as espécies dos complexos “ $M$. ovatus" e "M. bronni", sendo o M. granulosus a espécie tipo do subgênero. Este táxon era definido pelas conchas de tamanho médio ou grande (70 a mais de $100 \mathrm{~mm}$ ), geralmente finas; voltas nepiônicas com finas estrias espirais pontuadas, voltas nepiônicas postglabras 
com costelas longitudinais bem marcadas, de espaço largo progressivamente crescente; fina granulação que pode alcançar o lábio na última volta; voltas postnepiônicas com costela de crescimento mal perceptíveis longitudinais, amareladas, lustrosas ou não; lábio geralmente fino e recurvo de coloração branca à rosa (Morretes, 1952).

Embora as espécies deste complexo tenham em comum caracteres de concha, destacando a microgranulação em espirais, e uma aparente proximidade na distribuição geográfica sugerindo uma unidade taxonômica, já no início este estudo notou-se que também haviam similaridades que as aproximam de espécies de outros complexos, e.g., o Megalobulimus paranaguensis apresenta sobreposição parcial de sua distribuição com Megalobulimus aff. gummatus; о M. granulosus e M. foreli tem algumas características da concha similares ao M. sanctipauli (Pilsbry \& Ihering, 1900), semelhanças estas já observadas por Bequaert (1948); e o M. abbreviatus é facilmente confundido com as espécies do "complexo Megalobulimus oblongus", sendo sua distribuição no Rio Grande do Sul uma incógnita (Buckup \& Buckup, 1957; Sawaya \& Petersen, 1962; Thomé et al., 2007). A própria granulação da concha não é exclusiva do complexo $M$. granulosus, como observou Morretes na definição de seu subgênero, ocorrendo de forma até mais intensa nas espécies do “complexo M. bronni”, e no M. pergranulatus (Pilsbry, 1901).

Por este motivo, nesta dissertação serão também estudados comparativamente a conquiliometria e anatomia interna de algumas outras espécies de Megalobulimus que auxiliarão na definição de possíveis caracteres diagnósticos exclusivos.

Buscar-se-á um diagnóstico anatômico para cada espécie, assim como as prováveis relações morfológicas entre elas que subsidiarão, ou não, a sustentação taxonômica do complexo estudado. De uma forma mais abrangente espera-se que este estudo anatômico contribua para o conhecimento e construção da filogenia dos megalobulimíneos traduzidos em medidas práticas para sua conservação. 


\section{4 ) Objetivos}

- Realizar detalhado estudo morfo-anatômico com a redescrição das espécies do "complexo Megalobulimus granulosus", assim como algumas espécies de outros complexos similares, visando melhor embasamento das comparações da anatomia e da distribuição geográfica;

- Identificar caracteres anatômicos que possam ser utilizados na diagnose das espécies estudadas e na validade e/ou diagnose do "complexo M. granulosus";

- Comparar criticamente os resultados com a anatomia conhecida de outras espécies de Megalobulimus, realizando inferências taxonômicas. 


\section{1 ) Material}

Os lotes examinados para o estudo taxonômico estão relacionados no início da descrição de cada espécie, sendo sua maioria depositados no Museu de Zoologia da Universidade de São Paulo (MZSP) que contém uma das mais completas coleções de Megalobulimus spp., dispondo de 26 tipos para comparação (Dornellas \& Simone, 2011).

Inicialmente foi realizado um levantamento, triagem e organização dos todos os lotes de Megalobulimus no Laboratório de Malacológica desta instituição, que se constituíam, em sua grande maioria, exclusivamente de séries de conchas. Devido a grande similaridade morfológicas destas, cerca de 900 dos 1600 lotes estavam designados genericamente como Megalobulimus sp. Para um diagnóstico específico presuntivo das espécies foram utilizadas as descrições conquiliológicas de Bequaert (1948), e o catálogo de moluscos não-marinhos de Simone (2006), procurando uma coerência e proximidade das localidades de coleta. Mesmo com este esforço, muitos lotes continuaram indeterminados e algumas séries apresentavam conchas que se encaixavam em espécies distintas. Neste sentido Bequaert (1948) já havia concluído que o tamanho, o formato geral da concha, diferenças de coloração, presença ou ausência de bandas subsuturais, cor do perístoma, a forma da abertura e a abertura ou fechamento do umbigo são variáveis até em uma mesma série de conchas.

Após aquele trabalho inicial de curadoria, foram selecionadas os lotes das quatro espécies pertencentes ao "complexo Megalobulimus granulosus" para o estudo e de duas espécies externas ao complexo para comparação. A maioria dos espécimes com tecidos internos fixados já havia sido dissecada previamente e estava fixada em Railliet-Henry. Abaixo segue a descrição sucinta do material estudado e as justificativas para a inclusão das espécies externas ao complexo utilizadas para comparação. A sequência da citação das espécies será a mesma utilizada na descrição dos resultados:

\section{Espécies do "complexo Megalobulimus granulosus"}

A) Megalobulimus paranaguensis: 81 lotes com 246 conchas (via seca) e 40 indivíduos com tecidos internos (via úmida). A sobreposição parcial de sua distribuição geográfica e o 
contorno similar da concha desta espécie com o M. gummatus encontrado na região do vale do rio Ribeira do Iguape e litoral sul do Estado de São Paulo justificaram sua inclusão como espécie externa;

B) Megalobulimus granulosus: 26 lotes com 114 conchas (via seca) e 15 conjuntos de tecidos internos fixados (via úmida);

C) Megalobulimus abbreviatus: 19 lotes com 170 conchas (via seca) e 47 indivíduos fixados (via úmida). A triagem a partir de caracteres da concha e da procedência no Rio Grande do Sul foram insuficientemente para separar o M. abbreviatus de M. cf. haemastomus (Scopoli, 1786) do "complexo oblongus". Assim o estudo anatômico desta última espécie se mostrou importante na delimitação do complexo estudado, sendo incluída;

D) Megalobulimus foreli: 7 lotes com 20 conchas. Não havia espécimes com tecidos internos fixados na coleção, e não foi coletado neste período;

\section{Espécies externas ao "complexo Megalobulimus granulosus"}

E) Megalobulimus aff. gummatus: 57 lotes compostos de 112 conchas (via seca) e 32 indivíduos com tecidos fixados (via úmida);

F) Megalobulimus cf. haemastomus: 11 lotes compostos de 68 conchas (via seca) e 12 indivíduos com tecidos fixados (via úmida).

Adicionalmente para melhor subsidiar a discussão foram realizados estudos biométricos de concha das seguintes espécies: M. gummatus (Hidalgo, 1870) (Figs. 136, 137, 198, Tab. 10); M. ovatus (Müller, 1774) (Figs. 192, 193, 198, Tab.17); M. sanctipauli (Figs. 194, 195, 198, Tab. 18); M. yporanganus (Ihering \& Pilsbry, 1901) (Figs. 196, 197, 198, Tab. 16), a partir dos seguintes lotes:

G) Megalobulimus ovatus (Esta espécie possui uma ampla distribuição pelo litoral do sudeste com grande variação conquiliológica. Neste estudo a amostragem para comparação foi restrita ao litoral de São Paulo e da região sul): BRASIL. São Paulo, Guaratinguetá, MZSP 98188, 1 concha (SUCEN col., xii/1981); Ubatuba, MZSP 3242, 1 concha (E. Garbe leg., 1905), MZSP 16604, 8 conchas (Lange de Morretes col., iv-1v/1950), MZSP 64516, 1 concha (F. Müller Melchers col., vi/1957), MZSP 92418, 1 concha (Jorge Vaz col. xii/1964), MZSP 29365, 1 concha (P. Montouchet col., 31/i/1967), MZSP 29366, 1 concha (P. Montouchet col., 26/i/1968), MZSP 29367, 1 concha (A.V. Boffi col., 27/ii/1968), MZSP 29369, 3 conchas (P. Montouchet col., 22/ix/1969), MZSP 28908, 1 concha (P. Montouchet col., 20/viii/1974), MZSP 29370, 2 conchas (P. Montouchet col., 22/ix/1979); São Vicente, MZSP 
16598, Morro Xixová, 1 concha (viii/1944), MZSP 29373, 1 concha (W.M. Patrocínio col., ii/1973); Itanhaem, MZSP 3241, 1 concha (Zeidler leg., 1906), MZSP 3243, 1 concha, MZSP 8002, 1 concha (1911); Pedro de Toledo, MZSP 92425, 2 conchas (SUCEN col., vi/1974); Peruíbe, MZSP 13370, 2 conchas (R. Spetz col., iv/1926). Paraná, Ilha do Mel, MZSP 64542, 1 concha (I.F. Zanardini col.). Santa Catarina, Luiz Alves, MZSP 29375, 1 concha (C.N. Goffergé col., 1961).

H) Megalobulimus sanctipauli: BRASIL. MZSP 14417, 1 concha, MZSP 65565, 1 concha. São Paulos. Marília, Palmeira, MZSP 16683, 4 conchas (Íris Cordeiro col., 1933); Rio Claro, Horto Florestal, MZSP 16038, 1 concha (J.H. Guimarães col., 25/viii/1964); Ipeuna, MZSP 96546, 1 concha (A.M. Dias col., 1966); Piracicaba, Bairro Pau d'Alho, MZSP 29232, 1 concha (M. Menezes col., 15/iii/1970); São Manuel, MZSP 270, 2 conchas (1898), MZSP 16672, 4 conchas (H. Rugai col., xii/1940), MZSP 29082, 6 conchas (M.M. Valente col., xii/1978); Candido Mota, MZSP 29219, 3 conchas (N. Busearin col., vii/1972); Botucatu, MZSP 7982, 3 conchas (1896), Fazenda Lajeado, MZSP 29113, 7 conchas (J.L.M. Leme col., i/1964), Fazenda Lajeado, MZSP 29220, 1 concha (14/i/1965); Paranapiacaba, E.B. Alto da Serra, MZSP 28682, 1 concha (R.P. da Rocha \& S.A. Casari cols.; 25-26/i/1997).Paraná. MZSP 1310, 1 concha (1900), MZSP 7980, 1 concha (1900), MZSP 16558, 1 concha (Sadamú Noda col., ix/1935); Colorado, MZSP 64554, 1 concha (Inst. Filadélfia de Londrina col.), MZSP 64555, 1 concha (Inst. Filadélfia de Londrina col.); São João Caiuá, MZSP 29272, 3 conchas (M.F. da Silva col., vii/ 1968) MZSP 95086, 7 conchas (M.F. da Silva col., vii/1968); Cruzeiro do Sul, MZSP 29084, 2 conchas (A.L. Agruar col., xii/1967), MZSP 29271, 2 conchas (J. Vaz leg., vi/1968), MZSP 95087, 8 conchas (A. A. da Aguiar col., vii/1968), MZSP 98230, 4 conchas (A.L. de Alencar col., xi/1969); Jacarezinho, MZSP 64552, 1 concha; Londrina, MZSP 64551, 1 concha (Manuel de Barros col.), MZSP 29270, 1 concha (A. Ruffinis col., i/1968); Cambé, MZSP 64558, 1 concha (Manuel de Barros col.); Nova Esperança, MZSP 29307, 3 conchas (Osvaldo \& Nazira Palma cols., i/1969), MZSP 92448, 9 conchas (Osvaldo \& Nazira Palma cols.., i/1969); Assai, MZSP 64550, 1 concha (Manuel de Barros col.); Maringá, MZSP 64545,1 concha (Manuel de Barros col.), MZSP 64547, 1 concha (Manuel de Barros col.), MZSP 64548, 1 concha (Lange de Mooretes col., 1952), MZSP 64566, 1 concha (Manuel de Barros col.); Jandaia do Sul, MZSP 29274, 16 conchas (A.C. Machado col., i/1970); São Gerônimo da Serra, Aguá do Lambedor, MZSP16675, 1 concnha (viii/1939), MZSP 16684 (viii/1939); Floresta, MZSP 64556, 1 concha (Vila Rica col., 20/viii/1959); Maria Helena, MZSP 98234, 2 conchas (A. Pizzaio col., i/1970); Guaira, Sete Quedas, MZSP 92856, 2 conchas (A.L. Aguiar col., xii/1968), MZSP 29269, 2 conchas (G.R. Kloss col., 7/xii/1969); Goioerê, MZSP29308, 4 conchas (O.\&.N. Palma cols.); Três Barras, MZSP 29267, 1 concha (M.R.S Lopoes col.); Toledo, MZSP 15723, 1 concha (H. Nomura col., xii/1961); Curitiba, Guaira, MZSP 64553, 1 (Proftage col., 11/ix/1948); Guarapuava,rio Vivião, MZSP 16554, 1 concha (Sadamú Noda col., ix/1935), rio Guarani, MZSP 16569, 1 concha (Sadamú Noda col., viii/1935), rio das Cobras, MZSP 16565, 1 concha (Sadamú Noda col., ix/1935), Serra do Madeireiro, MZSP 16587, 1 concha (Sadamú Noda col., ix/1935), Serra do Boiman, MZSP 16586, 1 concha (Sadamú Noda col., ix/1935), Porto Piqueri, MZSP 16591, 1 concha (Sadamú Noda col., ix/1935), MZSP 16592, 1 concha (J.P. Machado col., xi/1937 ), Serrra da Jacutinga, MZSP 16599, 1 concha (Sadamú Noda col., ix/1935); Praia do Leste, MZSP 64546, 1 concha (O. de Fiore col.); Nova Prata do Iguaçu, MZSP 48519, 2 conchas (M. Miretzki \& F.C. Straube cols., 12/x/1998); Foz do Iguaçu, MZSP 16600, 1 concha (Sadamú Noda col., viii/1935), MZSP 16553, 1 concha (Sadamú Noda col., 1935), MZSP 16559, 1 concha (Sadamú Noda col., ix/1935); Iguaçu, MZSP 16588, 1 concha (Sadamú Noda col., ix/1935). Santa Catarina. Videira, MZSP 92449, 4 conchas (Irmã Adelina col., x/1973), Iporã, MZSP 29294, 18 conchas (C.N. Goffergé col., xii/1959); Florianópolis, MZSP 15548, 1 concha (S. Mezzalina col., iii/1964), Morro das Pedras, MZSP 16681, 3 conchas (M.J.L. Castro col., 1953), Praia 
de Tapera, MZSP 29243, 18 conchas. Rio Grande do Sul. Taquara, MZSP 16183, 6 conchas (24/vii/1965).

I) Megalobulimus yporanganus: BRASIL. Minas Gerais, Lagoa Santa, Lapinha, MZSP 15588, 6 conchas (1963), Lagoa vermelha, MZSP 20442, 1 concha (1971); Pinheiros, MZSP 42549, 2 conchas. São Paulo, MZSP 5662, 1 concha (Ihering col.), Rio Claro, Assistência, MZSP 92825, 1 concha (A.M. Dias col., 1966); Ourinhos, MZSP 82634, 1 concha (J. Vaz col., 1976); Capão Redondo, caverna Sumidouro, MZSP 15025, 6 conchas (P.E. Vanzolini \& Brandão cols.); São Sebastião, MZSP 924271, 1 concha (Sebastião G.D. de Oliveira col., 13/xi/1968); Guapiará, Gruta do Término, MZSP 29303, 4 concha (CEU col., i/1970), Fazenda Intervales, MZSP 29376, 1 concha (Exp. MZUSP col., iii/1993); Miracatu, MZSP 92822, 6 conchas (Toyomi Naruto col., i/1981); Juquiá, MZSP 29300, 1 concha (P. Duarte col.), MZSP 92829, 1 concha (B.E. Pereira col., xii/1972), MZSP 92830, 1 concha (Luiz Alonso col., x/1975); Registro MZSP 29299, 1 concha, (de Fiore col.); Eldorado, MZSP 92817, 6 conchas (J.P. Sandoval col., 01/xii/1969); Iporanga, MZSP 15604, 15 conchas (J.L.M. Leme \& Papavero cols., 03/xi/1963), MZSP 15593, 17 conchas (J.L.M. Leme col., 01/xi/1961), MZSP 16474, 17 conchas (J.L.M. Leme col., 10/iv/1965), Gruta da Areia, MZSP 16552, 1 concha (C. Pavan col.), MZSP 29306, 2 conchas (CEU col., v/1970), MZSP 64144,1 concha (1901); Iguape, Sambaqui do morro do Bernardo - Jupuvurá, MZSP 14106, 1 concha (1937), MZSP 14108, 1 concha (Lange de Morrets col., iv/1937), MZSP 16606, 12 conchas (Lange de Morretes col., v/1937), MZSP 16649, 1 concha (Lange de Morretes col., iv/1937), MZSP 16650, 3 conchas (Lange de Morrets col., iv/1937), Serrote, MZSP 29301, 1 concha (O. de Fiore), Sambaqui Barranco Alto, MZSP 92821, 4 conchas (J. Vaz col., 02/ix/1982), MZSP 94173, 1 concha (krone leg.). Paraná. Adrianópolis, MZSP 15714,1 concha (H.M. Cartes col., 05/ix/1960)

J) Megalobulimus gummatus: BRASIL. MZSP 94172, 3 conchas. Rio de Janeiro, Cabo Frio, MZSP 34703, 5 conchas (Coltro leg.), MZSP 92424, 2 conchas (L.R. Tostes leg., iv/1979), MZSP 29374, 2 conchas (Marini col., 6/i/1973); Arraial do Cabo, MZSP 73766, 2 conchas (A. Galdino col., ii/2000), MZSP 34420, 1 concha (C. Magenta col.), MZSP 34421, 1 concha (C. Magenta col.), MZSP 34422, 1 concha (C. Magenta col.), MZSP 34223, 1 concha (C. Magenta col.).

\section{2 ) Métodos}

\section{CONCHA}

A descrição da concha segue a terminologia de Bequaert (1948) e Breure (1979), incluindo o contorno (outline); forma da espira e abertura; ornamentação e microescultura da concha neopiônica, penúltima volta, e volta-do-corpo; padrão das linhas de crescimento, largura e convexidade das voltas postneopiônicas com a descrição da sutura e sua angulação na vista dorsal; angulação da columela; coloração do perióstraco e perístoma. Para a biometria foram realizadas três medidas conquiliológicas utilizando-se um paquímetro digital com resultados aproximados em milímetros, e duas medidas de número de volta da concha com aproximação em frações de 1/125 volta: 
1. Comprimento: correspondendo ao maior eixo vertical da concha, medido da ponta da espira até a borda basal do lábio inferior (Fig. 4: A);

2. Largura: com a concha em vista frontal, corresponde ao maior diâmetro transversal, medido perpendicularmente ao eixo vertical a partir da margem esquerda da volta do corpo até a borda mais distante do lábio externo (Fig. 4: B).

3. Altura: correspondendo a espessura dorso-ventral da volta do corpo, medida perpendicularmente ao eixo vertical (Fig. 5: C).

4. Número de voltas totais: corresponde ao número de voltas da concha contados a partir do cruzamento da linha espiral da sutura (Fig. 6: D) com uma reta imaginária perpendicular ao início da espira com precisão de 0,125 volta;

5. Número de voltas da protoconcha: corresponde ao número de voltas da concha neopiônica contados a partir do cruzamento da linha espiral da sutura (Fig. 6: D) com uma reta imaginária perpendicular ao início da espira com precisão de 0,125 volta;

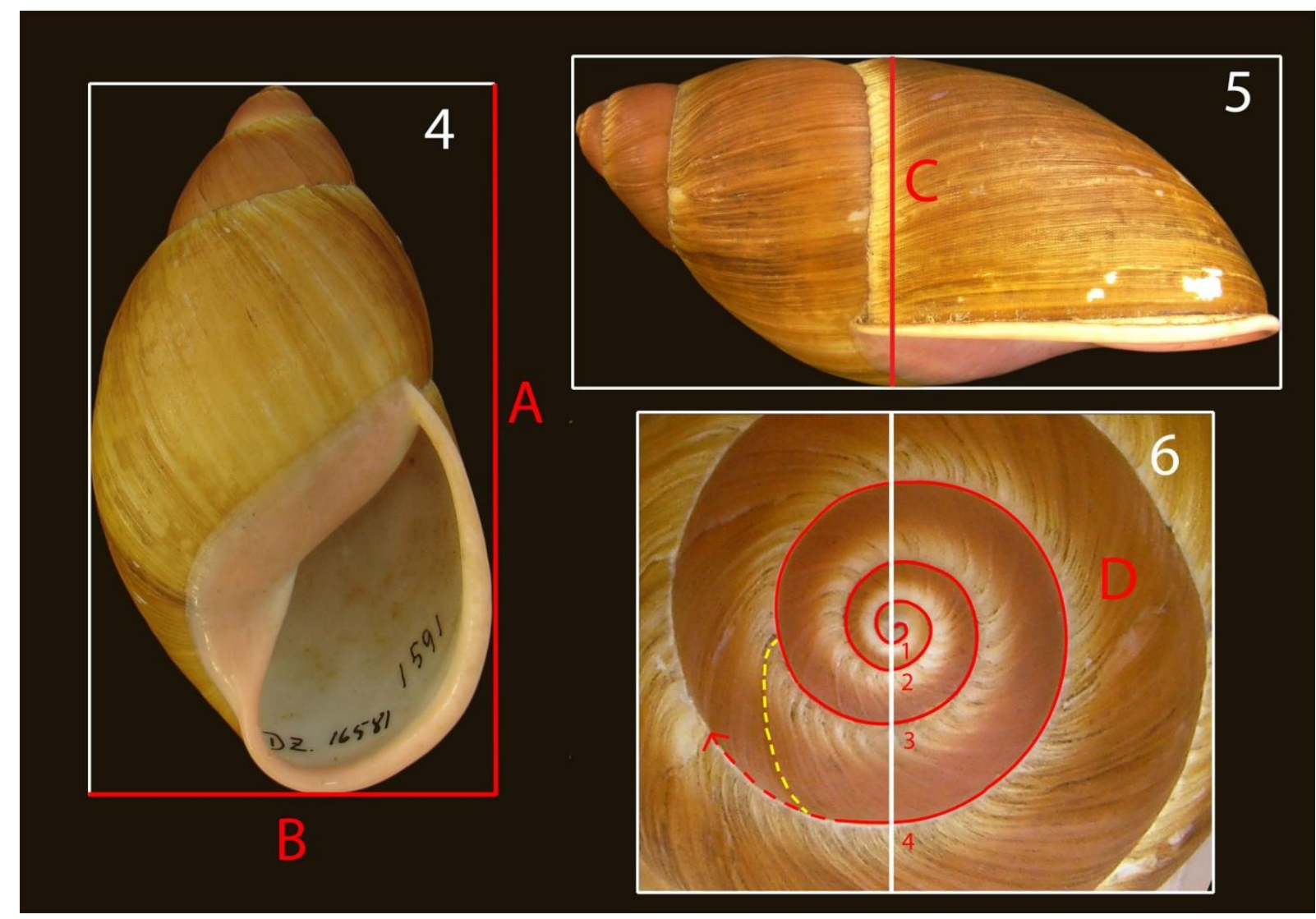


Figuras 4 a 6. Medidas conquiliológicas em um exemplar de Megalobulimus granulosus (MZSP 16851, Piçarras, SC). Fig. 4: Vista frontal especificando o comprimento (segmento A), e a largura (segmento B); Fig. 5: Vista lateral especificando a altura (segmento C); Fig. 6: Vista do ápice especificando a contagem de voltas com o limite da protoconcha delimitado pelo traçado amarelo.

Para comparação entre as espécies, os dados biométricos das conchas foram tratados estatisticamente pelo software Biostatic, sendo apresentados: (a) tamanho da amostra; (b) valor máximo; (c) valor mínimo; (d) amplitude total; (e) média aritmética; (f) mediana; (g) desvio-padrão; (h) coeficiente de variação; e, (i) teste distribuição normal de D’AgostinoPearson, sendo na discussão as medidas e suas relações (comprimento / largura, comprimento / altura, e largura / altura) de cada espécie foram comparadas com as demais pelo Teste $t$ de Student.

\section{ANATOMIA}

Os espécimes pertencentes à coleção do MZSP foram retirados do meio fixador e, quando necessário, extraídos de sua concha com um movimento de rotação anti-horário lento e vigoroso, sendo em seguida lavados em água corrente e escova suave para a remoção do muco coagulado principalmente nas dobras da borda do manto. Os espécimes vivos foram sedados com aplicação de $20 \mathrm{ml}$ de sulfato de magnésio $10 \%$ na hemocela céfalopediosa, sendo posteriormente removidos da concha e fixados em álcool $70 \%$, etiquetados e incorporados a coleção.

Para a dissecção dos tecidos moles foi seguido o método descrito por Leme (1971), complementado por Simone (1995) na dissecção do sistema digestivo e na numeração das pregas longitudinais da superfície interna da região proximal e mediana do intestino a partir do tiflossole em:

- pl) baixa larga, lisa e geralmente encoberta pelo tiflossole;

- $\quad p 2)$ similar a $p 1$, porém, com sulcos transversais;

- p3) estreitas, lisas afastadas entre si, variando em número;

- p4) similar às pregas $p 3$, única com aproximadamente o dobro da largura e altura;

- $p 5)$ similares às pregas $p 3$, variam em número;

- $\quad p 6)$ continuação $p 4$ após a válvula pré-retal, e;

- $\quad p 7)$ pregas dispostas obliquamente do intestino médio. 
Entretanto, para uma melhor visualização e comparação do estômago, nesta dissertação o órgão foi dividido em metades direita e esquerda por um plano de corte que passa longitudinalmente pela curvatura maior e menor.

As mandíbulas foram extraídas após a abertura da massa bucal e fotografadas a fresco em lupa estereoscópica Zeiss Discovery SV-12 com automontagem. As rádulas após remoção dos odontóforos foram tratadas com $\mathrm{KOH}$ saturado em banho-maria por 2 horas, lavados com jatos de detergente neutro (Veja Multiuso), agitadas no ultrassom por quatro minutos, e montadas em stubs, sendo analisadas em microscópio de varredura Leica Leo 440 do MZUSP.

As ilustrações anatômicas foram feitas com auxilio de uma câmara clara acoplada a uma lupa estereoscópica Zeiss SV-6 no MZSP e em uma Nikon SMZ-1000 no PZOMS. Os desenhos inicialmente confeccionados em folha de papel sulfite A4 com grafite $0,5 \mathrm{~mm}$ foram copiados para papel vegetal com nanquim 0,1 a $0,3 \mathrm{~mm}$, para serem digitalizados e finalizados com o software Abode Photoshop Elements 9.

\section{DISTRIBUIÇÃO GEOGRÁFICA}

A área de ocorrência consiste em uma importante informação taxonômica, visto que há uma grande dependência dos gastrópodes terrestres aos fatores ambientais, limitando sua distribuição às condições ambientais específicas que variem dentro de sua faixa de tolerância, garantindo assim, a perpetuação da espécie naquele ambiente. Os Megalobulimus são caracóis de grandes dimensões capazes de despertarem o interesse e simpatia de pessoas leigas que podem coleta-los, mantê-los cativos e por vezes solta-los em uma nova área que não a de origem, introduzindo-os em um novo ambiente. Como exemplo, no MZSP existem lotes de espécies de Megalobulimus com localidade de coleta improváveis, os quais desconsiderando os erros na identificação, representam tal situação de introdução, e cuja sobrevida neste novo ambiente é geralmente desfavorável.

Para a definição de áreas de ocorrência foram confeccionados mapas individuais para cada espécie a partir das localidades de ocorrência informados nos lotes. Inicialmente as localidades foram padronizadas em municípios. Estes foram localizados no software Google Earth e a imagem copiada e tratada pelo software Abode Photoshop Elements, produzindo um 
mapa da metade meridional do Brasil em escala 1:134.000.000 $(1 \mathrm{~cm}=134 \mathrm{~km})$, sendo acrescentadas as unidades geográficas básicas para cada unidade federativa em que as espécies estudadas ocorrem, entre São Paulo e Rio Grande do Sul (exemplo na Fig. 7). Para representar as localidade de ocorrências foram utilizados círculos com 1,5 mm de diâmetro que correspondem na escala adotada a uma área aproximada de $300 \mathrm{~km}^{2}$.

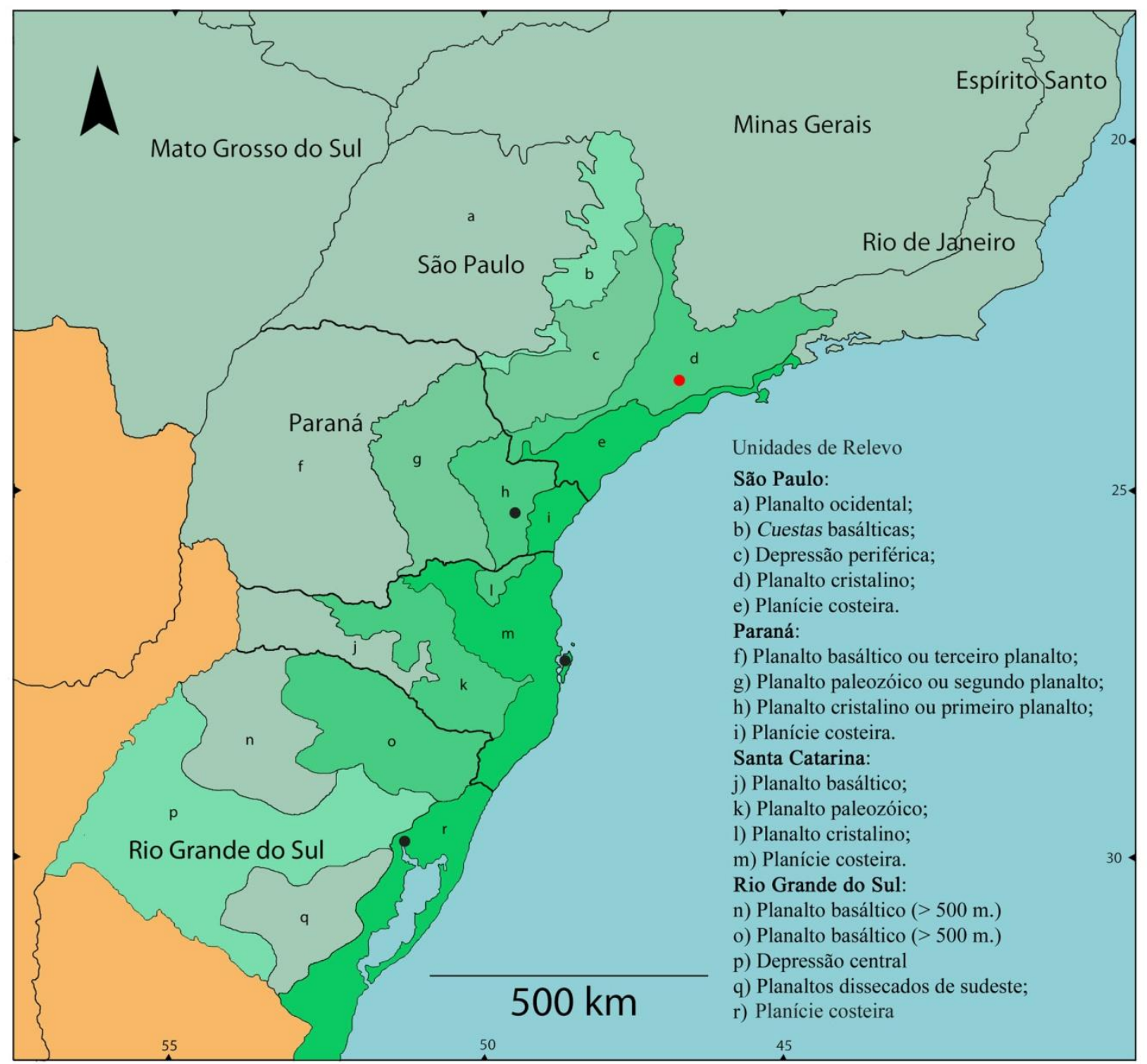

Figura 7. Mapa utilizado para a representação das ocorrências das espécies do "complexo Megalobulimus granulosus" com a identificação das principais unidades do relevo por Estado. Neste exemplo os círculos indicam uma área de $314 \mathrm{~km}^{2}$ sobre as capitais estaduais. O círculo de coloração vermelha indica a localidade tipo (neste caso a cidade de São Paulo). 


\subsection{Megalobulimus paranaguensis (Pilsbry \& Ihering, 1900)}

Strophocheilus (Borus) paranaguensis Pilsbry \& Ihering, 1900: 390 (pl. 11, figs. 1-2);

Pilsbry, 1901: 124 (pl. 16, figs. 1-2).

Strophocheilus (Megalobulimus) granulosus paranaguensis: Bequaert, 1948:164-165 (pl. 5, fig. 4, pl. 26, fig. 2, pl. 30, fig. 4).

Strophocheilus paranaguensis: Morretes, 1949:143.

Megalobulimus (Phaiopharus) paranaguensis: Morretes, 1952:113.

Megalobulimus (Megalobulimus) paranaguensis: Morretes, 1953: 67.

Megalobulimus paranaguensis: Leme, 1973: 15; Salgado \& Coelho, 2003: 158; Simone, 2006: 216 (fig. 823); Thomé et al. 2007: 22.

Tipos: Holótipo - ANSP 72646.

Localidade tipo: BRASIL, Paraná: Paranaguá (costa litorânea).

Material examinado. BRASIL. São Paulo: Taubaté, MZSP 94753, 1 concha (SUCEN col., ix/1982); Ribeirão Pires, MZSP 29276, 1 concha (Leme col.); Santos, MZSP 54629, 2 conchas (J. H. Fontenelle col., 22/viii - 01/ix/1998); São Vicente, Morro Xixová, MZSP 28911, 8 espécimes (W. M. Patrocínio col., ii/1973), MZSP 29108, 3 conchas (W .M. Patrocínio col., ii/1973); Itanhaém, MZSP 94756, 1 concha (H. Nucci col., i/1972); Miracatu, MZSP 34417, 1 espécime (xi/2001); Pedro de Toledo, MUSP 94762, 1 concha (SUCEN col., vi/1974); Peruíbe, MZSP 16580, 3 conchas (L. de Morretes col., 07/ix/1957), MZSP 29281, 3 conchas (J. F. Vaz col., vi/1970), MZSP 48624, 1 concha, MZSP 94750, 2 conchas (M. Nunes col., ii/1967), MZSP 94751, 2 conchas (H. Nucci col., xii/1972); Juquiá, Prainha (entre a foz do Açungui e a cachoeira Lageado), MZSP 16612, 1 conchas, MZSP 16617, 2 conchas (xi/1941), MZSP 94749, 2 conchas (J. Haramura col., vii/1978); Registro, MZSP 85901, 3 conchas (R. A. Fuentes leg., vii/2007); Iguape, MZSP 1170, 2 conchas (R. Krone col.), MZSP 18429, 1 concha (O. de Fiore col., 1939), MZSP 18431, 1 concha, MZSP 18432, 1 concha (O. de Fiore col., 1939), MZSP 18433, 1 concha (O. de Fiore col., 1939), MZSP 29279, 1 concha (Leme \& Biase col., 02/xi/1968), MZSP 29290, 2 conchas (C. P. Carvalho col.), MZSP 48253, 1 espécime (SUCEN col., ix/1989), MZSP 48522, 2 conchas (O. de Fiore col.), MZSP 94748, 1 concha (SUCEN col., ix/1983), MZSP 94783, 3 conchas (A. Fortes col., viii/1982); Cananéia, MZSP 16030, 2 conchas (C. T. Carvalho col., 27/vi/1964), MZSP 18428, 1 concha (C. D. R. Garcia col.), MZSP 64559, 1 concha (Montouchet col., 03/xi/1973), MZSP 28891, 1 concha (J. Cardoso col., ix/1975), MZSP 29277, 5 conchas, MZSP 64532, 1 concha (E. X. Rabelo col., 09/xi/1977), (IOUSP Base Sul), MZSP 28920, 1 concha (C. D. R. Garcia col.), Vamiranga (sambaqui), MZSP 18435, 2 concha (O. de Fiore col.), MZSP 18430, 1 concha (O. H. Leonardos col.), MZSP 15715, 4 conchas (E. X. Rabelo col., 06/i/1961); Ilha do Cardoso, MZSP 15727, 1 concha, MZSP 34944, 1 concha (G. Machado col.). Paraná: MZSP 278, 2 conchas (Bicego col., 
1898); Guaraqueçaba, MZSP 16585, 12 conchas (L. de Morretes col., vi/1934); Antonina, MZSP 273, 1 concha (M. Wacket col., 1907), MZSP 279, 1 concha (Bicego col., 1898), MZSP 7997, 3 conchas (Bicego col., 1898), Itapema, MZSP 16574, 38 conchas (L. de Morretes col.), Cachoeira, MZSP 16583, 7 conchas (L. de Morretes col., viii.1948); Ilha das Peças, MZSP 16593, 2 conchas (L. de Morretes col.); Morretes, MZSP 15713, 1 concha (R. Imaguirre col.), MUSP 16572, 1 concha (L. de Morretes col., 1931), MZSP 16601, 1 concha (E. Sopovisk col., 1931), São João da Graciosa, MZSP 16602, 6 conchas (L. de Morretes col., iv/1934), MZSP 18436, 3 conchas (Zanardini col., 12/ix/1965), MZSP 18437, 12 conchas (Zanardini col., 25/ix/1965), Serra da Graciosa, MZSP 28915, 1 espécime (F. C. do Val \& R. Heyer cols., xii/1978), Serra da Graciosa, MZSP 35391, 3 espécimes (J. Coltro leg., iii/2002), MZSP 48237, 5 conchas (L. de Morretes col., 1940), Serra da Graciosa, MZSP 72378, 1 concha (Galdino col.), Serra do Cadeado (Estação Marumbi), MZSP 83733, 1 concha (V. Fernandes col., 14/xii/2006), Serra do Cadeado (Estação Marumbi), MZSP 83734, 1 concha (V. Fernandes col.), MZSP 94777, 6 conchas (J. Dias col., 10/viii/1976); Ilha do Mel, MZSP 16596, 1 concha; Paranaguá, MZSP 7994, 2 conchas (Ihering col., 1894), MZSP 7997, 2 conchas (Bicego col., 1898), MZSP 7999, 2 conchas, MZSP 16568, 1 concha (L. de Morretes col., 1928), Guaraguaçu, MZSP 16679, 1 concha, Alexandra, MZSP 18434, 1 concha; Praia do Leste, MZSP 64539, 1 concha (O. de Fiore col.); Guaratuba, Sambaqui do Araujo, MZSP 64529 - 64532, 64534 - 64538 e 64540, 9 conchas (L. de Morretes col.), MZSP 64564, 1 concha (L. de Morretes col.), Sambaqui do Araujo, MZSP 64561, 1 concha (L. Morretes col., 1952). Santa Catarina: Garuva, MZSP 16595, 1 concha (L. de Morretes col., vii/1953); Itajaí, MZSP 64533, 1 concha (H. Mayer col., 1945).

\section{CONCHA}

A concha (Figs. 8-11) apresenta forma oval com 5,3 voltas, imperfurada a semiperfurada; com contorno fortemente convexo e saciforme a esquerda da columela; compressão dorsoventral ou em um plano oblíquo; espira curta, larga, arredondada e mamilar; abertura sub-ovalada. Periostraco caduco (Fig. 15) de coloração castanha amarelada com faixas radiais escuras. Concha neopiônica (Figs. 12-13) com 3,3 voltas discretamente convexas, sendo a primeira volta lisa e submersa seguida pelo aparecimento gradativo de discretas costelas a partir da sutura inferior que atingem a superior na $13 / 4$ voltas. Costelas finas prosóclinas, desalinhadas, de sutura a sutura com intervalos irregulares, geralmente maiores que a largura da costela. $\mathrm{O}$ intervalo aumenta entre a $2 \frac{1}{2} 2$ e 3 voltas quando algumas costelas extras, mais finas e incompletas podem ocorrer tanto na sutura superior como na inferior, aumentando o efeito de desalinhamento, finalizando com um adensamento a partir da terceira volta; suturas pregueadas, e banda subsutural amarelada clara que permanece branca na concha rosada com a perda do periostraco. Microescultura (Fig. 13) com granulação em linhas espirais por toda a protoconcha. Penúltima volta e a volta-do-corpo com linhas de crescimento médias à largas (com grande variação nas faixas mais pigmentadas na teleoconcha, resultando em um aspecto irregular), arredondadas, com intervalos mais ou menos constantes, e que podem se dicotomizar e fundir. Mantém o mesmo padrão da microescultura em linhas espirais, sendo este muito mais discreto na teleoconcha. 
Ocasionalmente são observados curtas estrias espirais (striolae) e um aspeto de superfície martelada (malleata). O perfil esquerdo da penúltima volta é convexo (vista dorsal). Lábio interno reto. Columela obliqua formando um vinco na larga parede parietal. Ângulo do lábio externo e parede parietal $<90^{\circ}$. Abertura maior que $1 / 2$ do comprimento. Perístoma refletido, coloração variando, entre um branco levemente rosado a um vinho intenso.

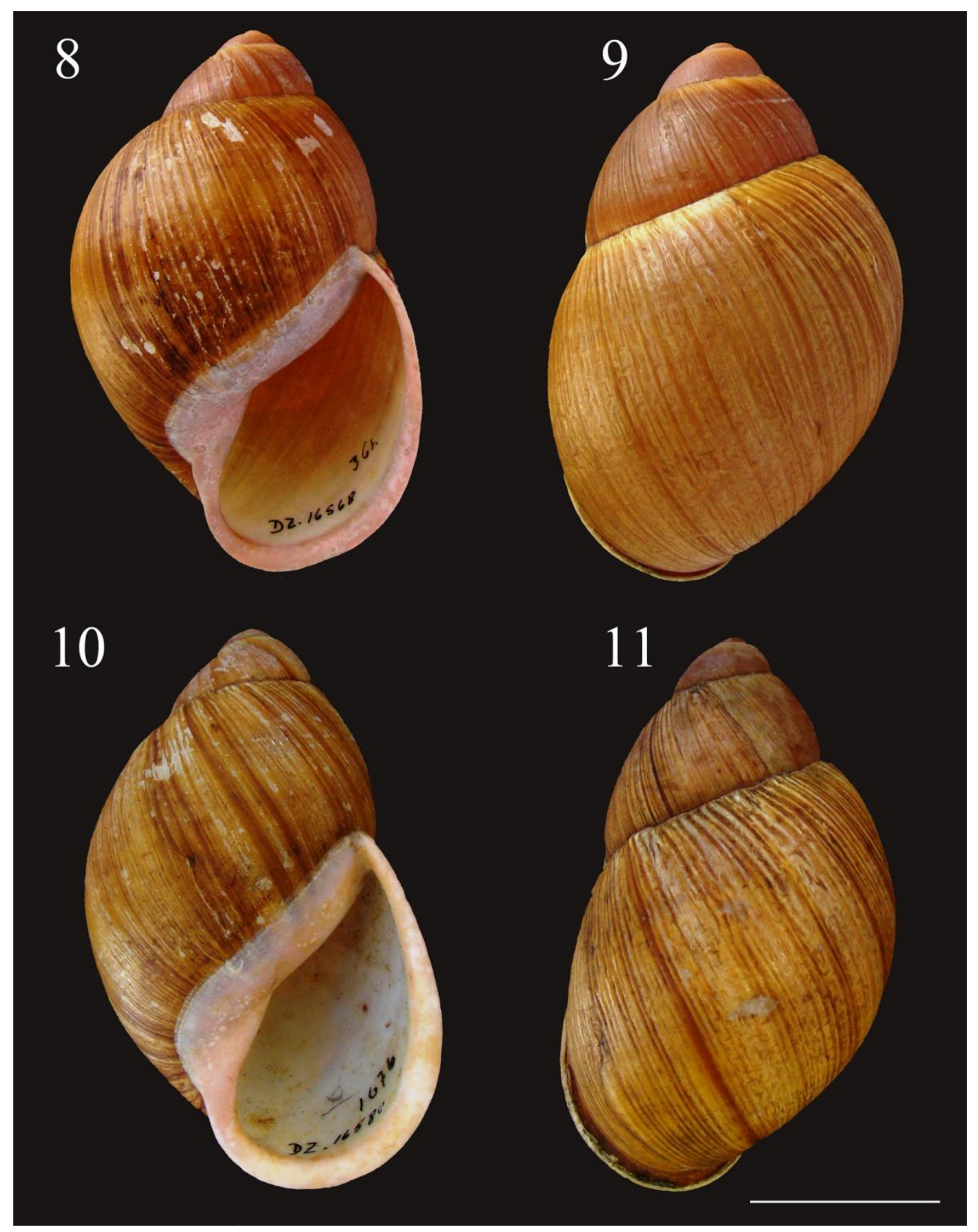


Figuras 8-11. Concha de Megalobulimus paranaguensis: 8. Vista frontal do exemplar MZSP 16568 (Paranaguá, PR), 9. Mesmo exemplar em vista dorsal, 10. Vista frontal de um dos exemplares do lote MZSP 16580 (Peruíbe, SP), 11. Mesmo exemplar em vista dorsal. (ESCALA = $50 \mathrm{~mm}$ )

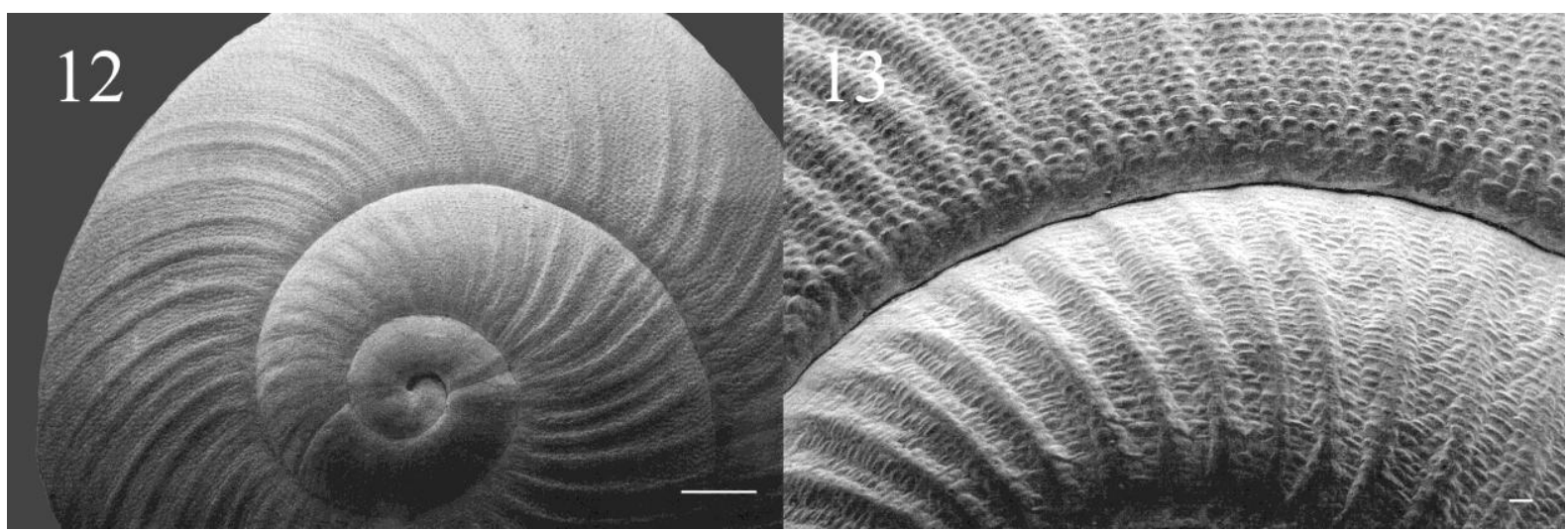

Figuras 12 e 13. Protoconcha de Megalobulimus paranaguensis em SEM: 12. Vista apical da protoconcha $($ ESCALA $=1 \mathrm{~mm}), 13$. Detalhe da escultura $($ ESCALA $=0,1 \mathrm{~mm})$.

Os dados biométricos da concha estão estatisticamente tratados condensados na tabela 1. Duas medidas não apresentaram a esperada distribuição normal ( $p>0,05)$ : a largura e a altura da concha. Isto pode ser devido ao inconstante achatamento dorsoventral que como citado na descrição conquiliológica, muitas vezes assumia uma posição diagonal.

\begin{tabular}{cccccc}
\hline & COMP. & LARG. & ALT. & $\begin{array}{c}\text { VOLTAS } \\
\text { PROTOCH. }\end{array}$ & $\begin{array}{c}\text { VOLTAS } \\
\text { TOTAIS }\end{array}$ \\
\hline $\mathbf{n}$ & 212 & 216 & 214 & 187 & 204 \\
$\mathbf{m a x}$ & 115 & 72 & 59 & 3.5 & 5.5 \\
$\mathbf{m i n}$ & 81 & 48 & 43 & 3.0 & 4.8 \\
$\mathbf{a m p l}$ & 34 & 24 & 16 & 0.5 & 0.8 \\
$\boldsymbol{\mu}$ & 98 & 58 & 50 & 3.3 & 5.2 \\
$\mathbf{m}$ & 98 & 58 & 50 & 3.3 & 5.3 \\
$\mathbf{D P}$ & 6 & 3 & 3 & 0.1 & 0.1 \\
$\mathbf{C V}$ & $6.1 \%$ & $6.0 \%$ & $5.5 \%$ & $3.4 \%$ & $2.8 \%$ \\
$\mathbf{p}$ & 0.2088 & 0.0045 & 0.0338 & 0.5395 & 0.7230 \\
\hline
\end{tabular}

Tabela 1. Biometria da concha de Megalobulimus paranaguensis. Legenda: $n$ : tamanho da amostra; max: valor máximo; min: valor mínimo; ampl: amplitude; $\mu$ : média aritmética; m: mediana; DP: desvio padrão; CV (\%): coeficiente de variação em porcentagem; p: teste de normalidade de D'Agostino-Pearson (distribuição normal nos valores de $p>0,05)$. 
ANATOMIA

\section{Massa céfalo-pediosa}

O tegumento recobre a porção dos tecidos moles da massa cefalo-pediosa (Figs. 14, 15). É superficialmente dividido por sulcos formando padrões geométricos irregulares, com exceção da sola, que é lisa. Coloração uniforme cinza claro, às vezes azulado ou esverdeado. Na cabeça, mal diferenciada do pé, são identificados dois pares de apêndices. Um par de omatóforos dorsais e um par de tentáculos ventrais. Das comissuras labiais se projeta a franja bucal de aspecto franjado.

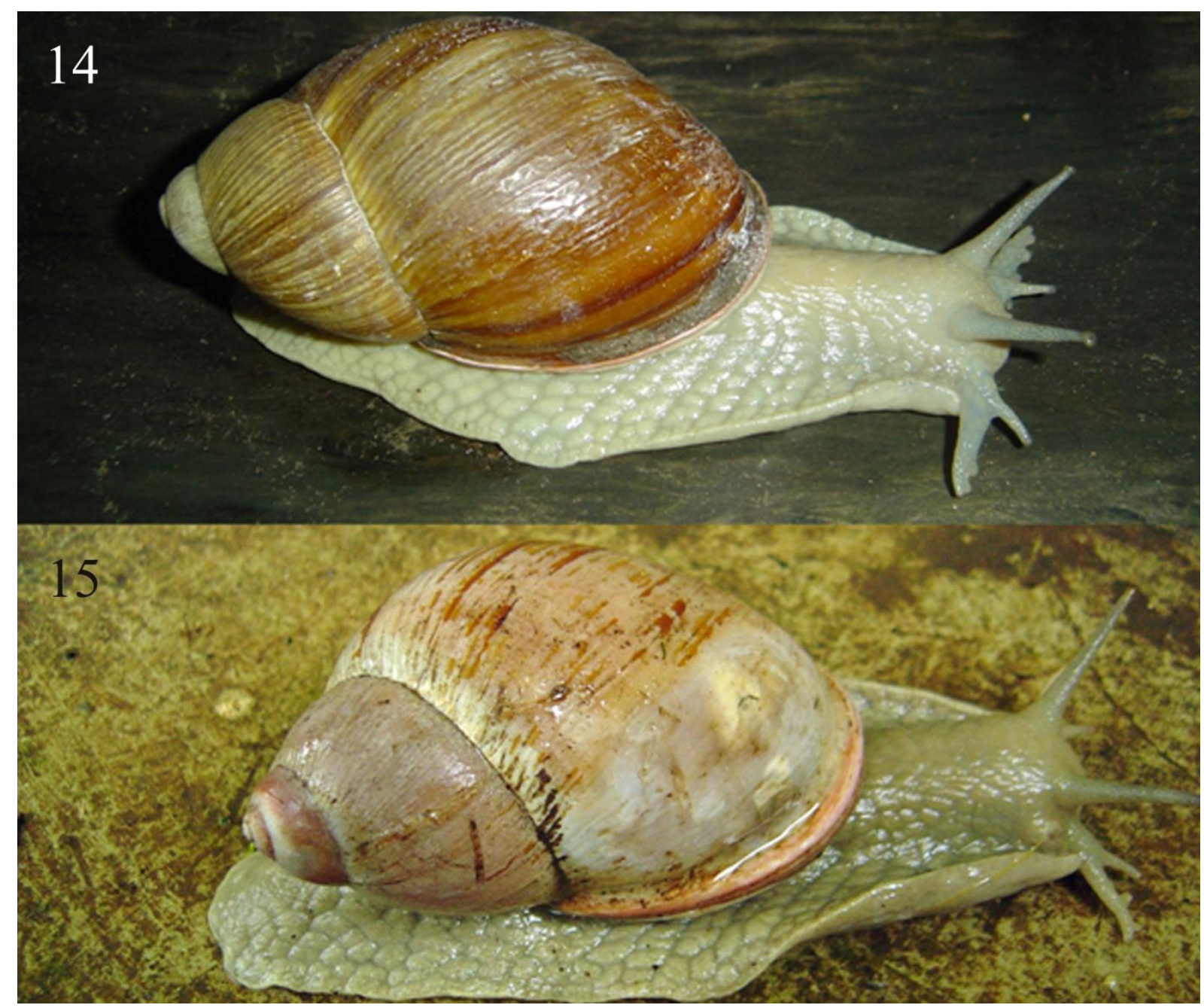

Figuras 14, 15: Megalobulimus paranaguensis, animais vivos rastejando. 14. Concha com periostraco; 15. Concha sem o periostraco (PZOMS, Santos, SP)

A franja labial estende-se lateralmente e cada lado, apresenta nove papilas sensitivas utilizadas na exploração ambiental na margem ventral. Entre o tentáculo superior e a franja 
bucal direita localiza-se o poro genital (Figs. 15, 20), abertura comum do sistema reprodutor, que em determinadas épocas pode estar edemaciado em função da atividade reprodutiva.

\section{Manto}

Com a remoção da concha, observa-se o manto recobrindo toda a superfície parietal da câmara palial e hemocele visceral (Figs. 16-18). Com exceção do espessamento em sua borda (bm), o manto é fino, resistente e semitransparente, possuindo nos espécimes fixados, coloração uniforme cinza com estrias marrons (Fig. 21).

Na maior parte do manto na volta do corpo (Figs. 16-18) podem ser observados vasos em posição radial na porção respiratória da cavidade palial (cs), com origem na região pericárdica e renal (pe/ri). Acompanhando a sutura da concha e paralelas a esta se identificam o septo (se) e o intestino (in), com a goteira urinária entre ambos (gu). Parte dos sistemas digestivo e reprodutivo pode ser localizada no lado esquerdo da volta do corpo (Fig. 16), destacando-se a glândula digestiva anterior (ga) totalmente localizada na volta do corpo, e a glândula de albume (gb) ventralmente na transição entre a volta do corpo e a penúltima. Ventralmente e a direita da penúltima volta também se identifica uma alça do intestino que delimita o fundo da cavidade palial (Fig. 18: in'). No restante da espira, o manto recobre a glândula digestiva posterior $(\mathrm{gb})$. 

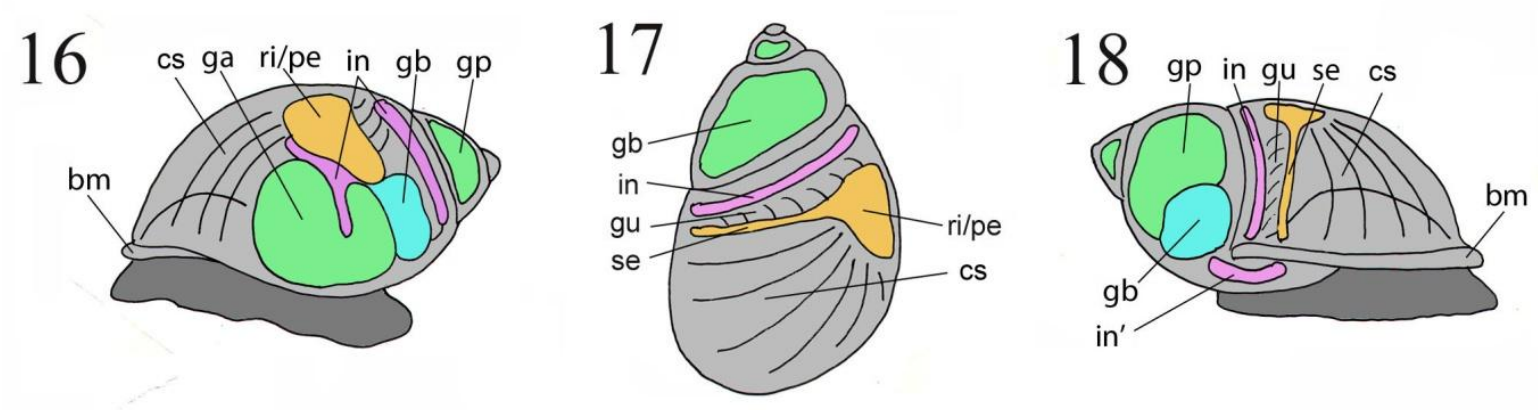

Figuras 16-18: Anatomia topográfica de Megalobulimus paranaguensis. 16. vista lateral esquerda; 17. vista dorsal; 18. vista lateral direita.

A borda do manto (Fig. 21, 29) corresponde ao anel espessado do manto na abertura da concha, na intersecção entre manto, tegumento e diafragma (Fig. 30). Sua principal estrutura é o pneumóstoma, uma abertura muscular e extremamente inervada que comunica o meio externo com a cavidade palial e está localizada na borda angulosa no lado direito posterior da borda do manto (Fig. 22, 28). De sua comissura anterior parte um sulco que delimita o lábio do pneumóstoma (Fig. 29: 1p). Outro sulco circunda externamente o pneumóstoma e percorre quase toda a borda do manto dividindo-o nos lábios interno (Figs. 29, 30: 1i) e externo (Figs. 29, 30: 1x). Na região columelar do lado esquerdo a borda do manto afina e às vezes forma uma prega comprimido pelo músculo columelar (Fig. 23). Durante o período de dormência com a retração cefalo-pediosa ocorre a hiperplasia da borda do manto recobrindo toda a abertura da concha, deixando evidente apenas o orifício do pneumóstoma (Fig. 24). 


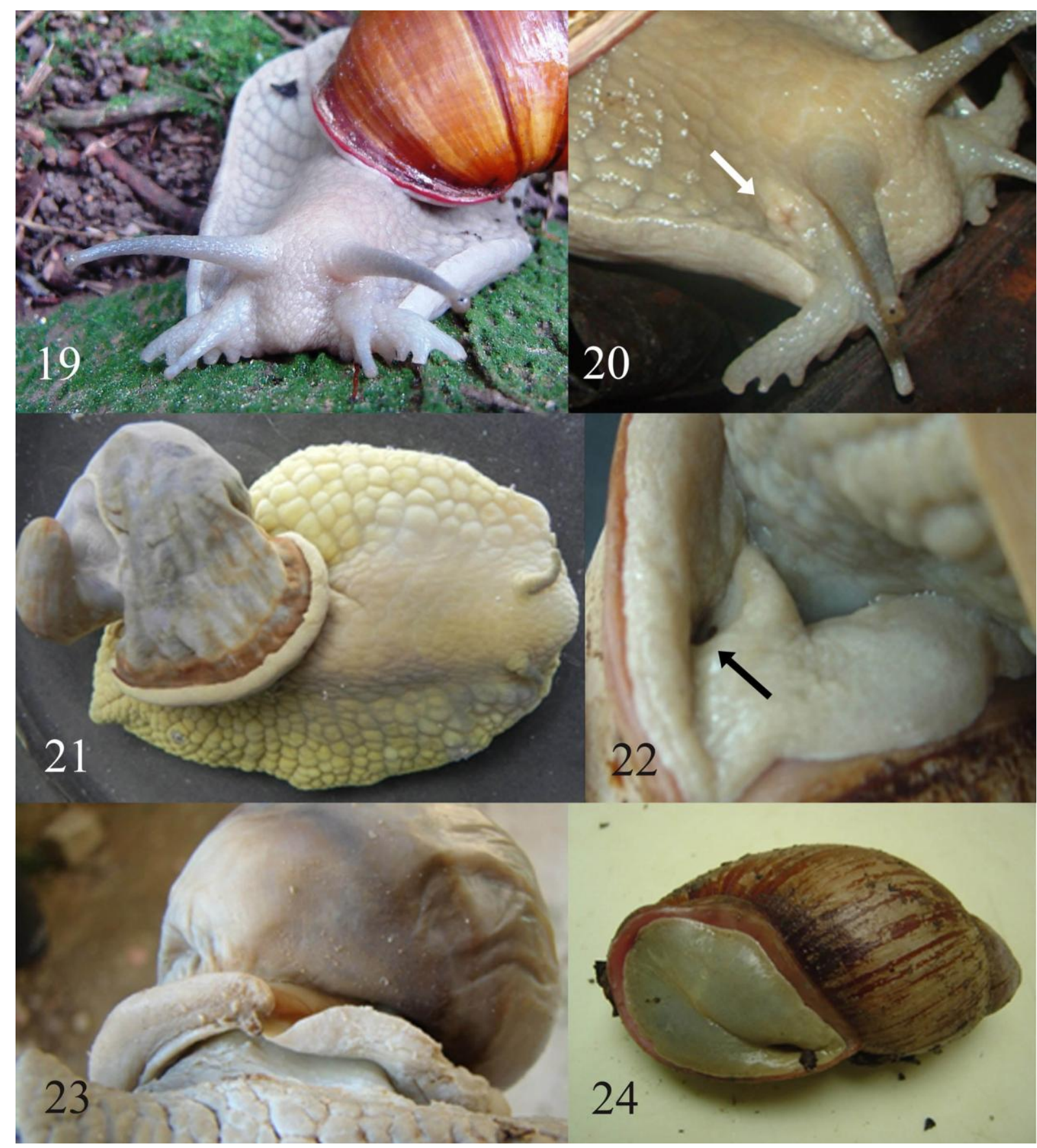

Figuras 19-24: Megalobulimus paranaguensis. 19. Detalhe dos tentáculos cefálicos e da franja bucal; 20. Poro genital edemaciado localizado abaixo do tentáculo superior direito (seta); 21. Superfície do manto e borda do manto expostos após a remação da concha; 22. Pneumóstoma (seta) limitado pelo lábio do pneumóstoma e o lábio interno da borda do manto; 23. Borda do manto afinada e formando uma prega na região columelar; 24. Hiperplasia da borda do manto durante o período de dormência (PZOMS, Santos, SP).

\section{Cavidade palial}


A cavidade palial aberta assume uma forma triangular, tendo a borda do manto como a base à direita (Fig. 28). Nela são distinguíveis quatro regiões. A primeira, essencialmente respiratória (cs), é a maior, com o manto fino e liso e ocupa sua metade direita. É cortada por vasos paralelos com origem alternada entre a veia marginal ou colar que acompanha internamente a borda do manto (Fig. 31: vm) e o vaso pericárdico (Fig. 32: vc). Os três tributários de maior calibre da veia colar estão no seu ângulo direito (Fig. 31: v1, v2, v3), sendo que o $v 1$ e $v 2$ são curtos e terminam no septo, enquanto que o $v 3$ direciona-se de forma retilínea para o vaso pericárdico esmaecendo entre o septo e o primeiro tributário do vaso pericárdico (Fig. 32: c1), que nesta espécie tem uma inserção em comum com o $c 2$.

A passagem da cavidade palial para o meio externo é realizado pelo pneumóstoma (Figs. 28, 29: pn), via comum para os sistemas respiratório, digestivo e urinário, que é melhor observado após a incisão do lábio interno do pneumóstoma (Fig. 31). O ânus (an) está direcionado para o canto superior do pneumóstoma, com pregas que se anastomosam até a borda externa. Ao lado do ânus há uma concavidade lisa, o canal lateral (cl) que parece ser uma importante via de acesso à cavidade palial.

A região do septo pulmonar (Figs. 31, 32: se) corresponde a uma prega de tecido com vasos intensamente anastomosados, dando a este um aspecto esponjoso, que envolve a veia pulmonar e espraia-se a esquerda da cavidade palial sobre o pericárdio e o rim (Fig. 28: ri). A rede de vasos anastomosados também se expande para a região respiratória próxima aborda do manto, envolvendo os $v 1, v 2$ e $v 3$ nesta região.

A terceira região no lado superior da cavidade palial, a excretória, engloba o intestino posterior e goteira urinária. O intestino posterior ou reto (Fig. 33) emerge no fundo da cavidade palial (Figs. 28, 43: fp), após fazer uma inversão de sua direção formando um fundo de saco na altura da transição entre a penúltima e a última volta e direciona-se para o pneumóstoma, acompanhando internamente a linha da sutura da concha paralelamente ao septo (Figs. 32, 33). No espaço entre o reto e o septo está a goteira urinária no lado do intestino (gu) e rede vascular ad-retal do septo (vs). A goteira urinária corresponde a uma faixa forrada por pregas oblíquas entre a face inferior da parede externa do intestino posterior e a parede interna do manto que o margeia. Nas proximidades do ânus as pregas sobre o intestino cessam e as do manto tornam-se mais volumosas, destacando-se da parede do manto para formar o sulco urinário externo (ux). Este possui uma prega em seu lado interno terminando em uma papila (pu) próximo ao canto inferior do pneumóstoma. Os vasos septais 
formam uma rede dendriforme transversal entre o septo e um vaso que margeia a goteira urinária, com vasos mais volumosos no lado septal.

Por fim, a região reno-pericárdica, a mais volumosa de todas, está localizada no lado direito inferior da cavidade palial. O rim (Fig. 28: ri) apresenta forma aproximadamente triangular com seu vértice esquerdo alongado. Encontra-se separado do intestino pelo plexo de vasos paralelos ad-renais (Fig. 32: vr). Nesta margem em seu terço médio apresenta o nefróstoma (ne) parcialmente encoberto pela inserção de um dos vasos ad-renais. A partir do nefróstoma, o plexo ad-renal começa a retrair-se em sentido ao intestino formando o vaso que delimita a goteira urinária. Paralelamente ocorre a expansão dos vasos ad-retais (vs). O plexo de vasos anastomosados, que constitui o septo, espraia-se pela superfície renal, delimitando o plexo epirenal (px), ocupando aproximadamente $3 / 4$ da superfície livre do rim, deixando uma área lisa que margeia a borda inferior (zl).

O pericárdio (Fig. 28: pe; Fig. 32) esta localizado na face direita do rim, conectado em seu polo superior ao septo com uma área de aproximadamente um terço da superfície renal. $\mathrm{O}$ plexo de vasos anastomosados cobre a metade superior do pericárdio, correspondendo internamente ao átrio cardíaco. Do ventrículo (ve) originam-se a aorta posterior (ap) e a aorta anterior (aa). Na parede interna da cavidade pericárdica na altura do terço médio do ventrículo esta o orifício em forma de fissura reno-pericárdico (rp).

Uma larga inserção pode ser observada no feixe muscular palio-diafragmático quando é removido o manto sobre o rim e o intestino médio (Fig. 32: mv). Este músculo conecta a superfície interna do diafragma com a face interna do manto, atravessando a glândula digestiva anterior (ga).

\section{Sistema digestivo}

A mandíbula (Fig. 25) é elasmognata, pigmentada e apresenta cerca de 40 colunas axiais de espessura e distribuição irregulares com linhas transversais de crescimento, sendo o padrão colunas largas e planas. A rádula (Figs. 26, 27) com aproximadamente 108 fileiras de dentes retangulares na proporção 3:2, unicúspides com ápices longos, ocupando metade do comprimento, que ultrapassam a base do dente que o antecede. Dentes centrais ligeiramente menores e com uma ligeira constrição anterior ao ápice. 


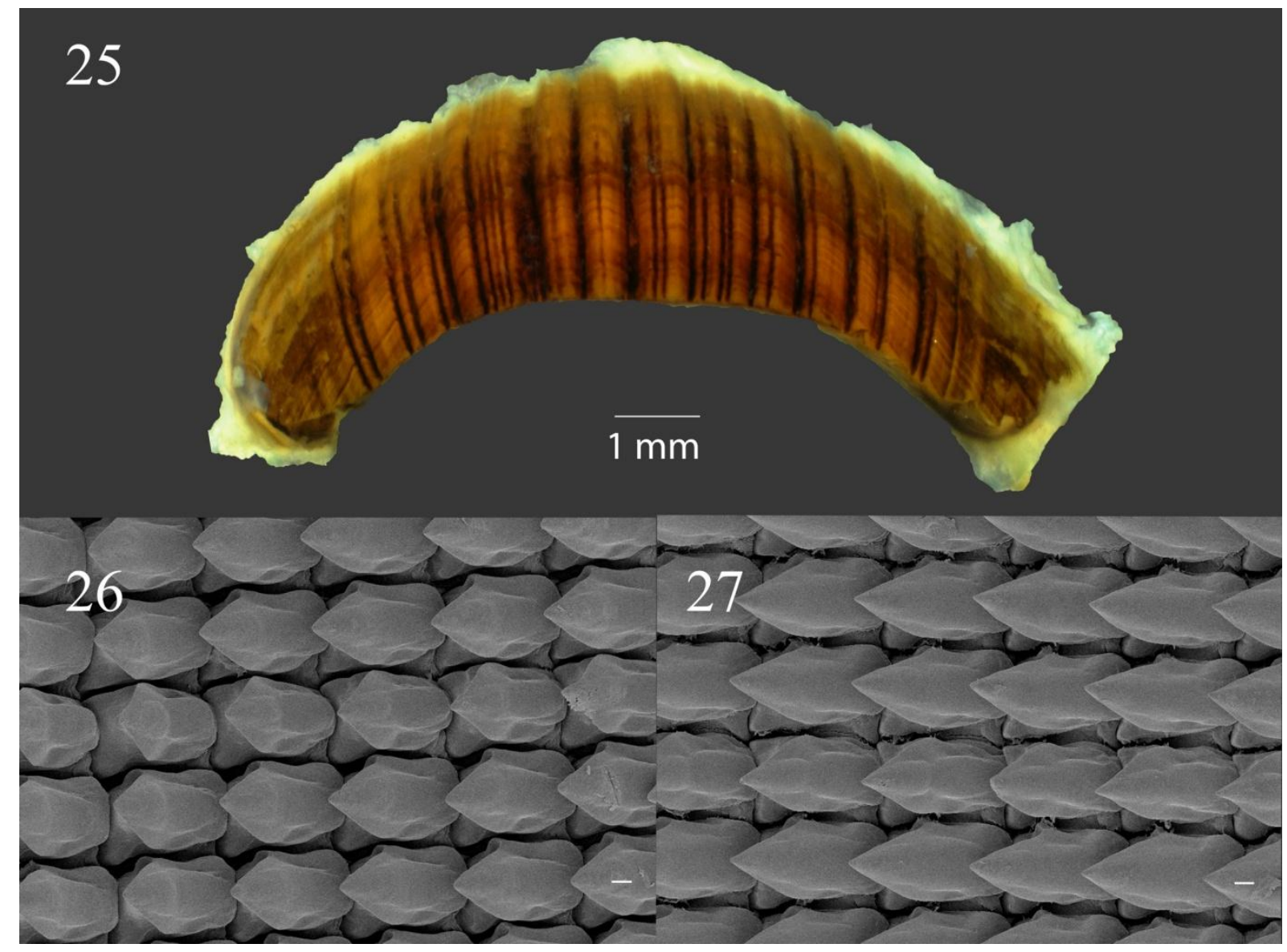

Figuras 25-27: Megalobulimus paranaguensis. 25. Mandíbula (ESCALA = $1 \mathrm{~mm}$ ); 26, 27. Detalhes dos dentes radulares em SEM (ESCALA $=0,02 \mathrm{~mm}$ )

A massa bucal (Fig. 33: mb) apresenta uma forma cilíndrica com aumento de sua altura na parte posterior devido ao posicionamento da rádula, sendo identificadados sobre a sua superfície feixes musculares extrínsecos longitudinais simétricos (Fig. 36: m1); a artéria cefálica (Fig. 38: ac) que se divide em quatro vasos, dois anteriores e dois posteriores antes de penetram na musculatura da parede ventral, sendo que o posterior esquerdo origina a artéria radular (ar); o par de gânglios bucais (Figs. 36: nb), dorsais e posteriores próximos a axila do esôfago, estando encobertos por um feixe muscular do $m 3$ e ambos unidos entre si pela comissura bucal; o núcleo da rádula que se projeta como uma formação arredondada posterior (Figs. 37, 38: ng); o delgado músculo $m 3$ que recobre frouxamente a região posterior da massa bucal incluindo o núcleo da rádula (m3). Ventralmente observa-se o músculo $m 2$, ou retrator da massa bucal, que se insere na massa bucal abaixo do núcleo da rádula (Figs. 37, 38: $\mathrm{m} 2$ ) e a cinta muscular mandibular, que cruza transversalmente a massa bucal inserindo-se nas laterais da mandíbula. Por fim o esôfago se origina posterior e dorsalmente, ligeiramente à esquerda (Figs. 33, 36, 38: es). 
A boca é localizada ventralmente à cabeça com as franjas bucais localizadas em suas comissuras (Fig. 39). O tubo oral (to) é o segmento seguinte e corresponde a uma invaginação do tegumento reticulado e ligeiramente despigmentado. Em exemplares que tiveram uma forte retração da cabeça na fixação, este tubo pode ser ampliado para alguns centímetros. A passagem do tubo oral para o odontóforo é marcada internamente por um sulco transversal dorsal onde uma mandíbula rígida (md) se aloja (Fig. 39). Lateralmente observam-se dois fortes feixes musculares, os músculos mandibulares (Fig. 36, 37), que se originam na cartilagem radular e se inserem na peça mandibular. A mandíbula fixada na musculatura dorsal pode ser observada externamente como uma linha escura e irregular circundando dorso-lateralmente a transição entre o tubo oral e o odontóforo (Fig. 37). Internamente o teto do odontóforo apresenta um largo canal liso que termina na transição com o esôfago (Fig. 39), a superfície sobre o músculo mandibular (mj) apresenta pregas musculares discretas, enquanto que a metade posterior do odontóforo apresenta pregas finas e delicadas, intensamente dobrada com sulcos profundos, onde desembocam lateralmente ao teto da cavidade os ductos das glândulas salivares.

O odontóforo apresenta uma forma arredondada à elíptica e geralmente esta obliquamente retraído, expondo sua superfície ventral. A rádula é mantida unida à cartilagem radular pelo músculo núcleo radular (Figs. 39, 40, 41: m7) que circunda parte da rádula exposta após emergir com esta do canal do núcleo radular. A entrada deste é protegida pelo bonete radular (Fig. 15: bt), uma estrutura rígida e pigmentada, a semelhança da mandíbula, que impede a entrada de partículas ingeridas. Na margem posterior da cartilagem radular junto com a inserção no $m 2$, originam-se os músculos retrator e protrator da rádula $(\mathrm{m} 4 / \mathrm{m} 5)$, nesta espécie são indiferenciáveis, que irão se fixar nas membranas sub-radulares dorsal e ventral, bem como lateralmente na superfície ventral da cartilagem radular, encobrindo parcialmente a origem do mj (Figs. 40, 41). O músculo inter-radular (m6) mantém estável a parte posterior da linha média não fundida da cartilagem radular.

O esôfago (Fig. 42), entendido como a porção do sistema digestivo entre a massa bucal e o estômago, dirige-se dorso posteriormente e apresenta no seu percurso duas pequenas flexuras dividindo-o em três segmentos ou câmaras com comprimento similares. A câmara anterior (cn) inicia-se dorso-posteriomente a massa bucal curvando-se ventralmente em seguida até o núcleo da rádula. Corresponde ao segmento onde se encontram externamente as glândulas salivares (Fig. 33: gs). A mucosa de sua fina parede apresenta pregas longitudinais 
plicadas transversalmente, conferindo a este segmento uma grande capacidade de distensão mesmo no material fixado. Quando distendido por alimentos o esôfago anterior avoluma-se dorsalmente comprimindo o diafragma. Na flexura entre a câmara anterior e média há uma pequena constrição na face inferior. A câmara média (Fig. 42: cm) segue o eixo da massa bucal e relaciona-se com o $m 2$ em direção a columela. É pouco distensível, possuindo paredes espessadas por uma cinta muscular circular externa e internamente pregas espessas e afastadas que podem se anastomosar. No terço médio de seu percurso o esôfago médio passa da hemocele cefalo-pedal para a hemocele da massa visceral.

Na flexura entre a câmara média e posterior, há também uma discreta distensão da parede na face direita (Fig. 43: cp). A parede deste segmento (Fig. 42) é mais fina que a anterior, porem menos distensível que o segmento proximal, recoberto com pregas discretas em sua mucosa. No seu terço distal recebe o ducto da glândula digestiva anterior (da), na face anterior esquerda. A partir de então as pregas avolumam gradativamente em sentido ao estômago, paralelas ao tiflossole esofágico (te) que surge pelo ducto da glândula digestiva anterior.

O par de glândulas salivares (Figs. 33, 36, 37: gs) correspondem a duas massas lobuladas, com os seus lobos achatados e aderidos em uma fina membrana tubular translúcida ao redor da câmara anterior e frouxamente fixada a esta por trabéculas musculares originadas na parede do esôfago. As glândulas estão parcialmente fundidas dorsalmente. A membrana tubular da glândula salivar se funde ao esôfago na transição entre a câmara anterior e média. Os ductos das glândulas salivares (Figs. 36, 37: ds) penetram na massa bucal lateralmente ao esôfago.

O estômago (Figs. 44, 45) encontrado onde o tubo digestivo apresenta uma curva abrupta de 180 graus, passando sua orientação dorso-posterior para ântero-ventral, conjuntamente com forte espessamento muscular de suas paredes. Possui forma arredondada com paredes espessadas pelo aumento da musculatura. Internamente ocorre uma transição suave do esôfago caracterizado pelo intumescimento das baixas e estreitas pregas, que assumem um aspecto aveludado. Na metade anterior do estômago as pregas seguem o sentido da curvatura maior do estômago.

O tiflossole esofágico (te) direciona-se para a curvatura menor da face direita do estômago, onde termina abruptamente ao fundir-se a musculatura do piloro (pl) que ocupa a 
circunferência menor do órgão e circunda a transição do estômago para o intestino na face esquerda gástrica. Feixes de pregas partem desta trabécula e se espalham transversalmente nas faces posterior e direita, onde um conjunto termina perpendicular a abertura obliqua da glândula digestiva posterior (dp). Do canto medial desta abertura um canal liso, o canal intestinal (ci) segue em direção a curvatura menor do estômago e continua paralelo ao início do tiflossole intestinal (ti), enquanto que o canal esofágico (cf) acompanha o tiflossole esofágico (te) circunda a musculatura do piloro (pl) e se junta ao canal intestinal.

O intestino é dividido em três segmentos (Fig. 33): o proximal, compreendido entre o estômago e a válvula pré-retal; o médio mais curto que o anterior, entre a válvula pré-retal e o fundo da cavidade pulmonar, onde o tubo digestivo entra na cavidade palial; e o distal, o mais longos dos três, que corresponde ao segmento do tubo digestivo existente na cavidade palial até o ânus, próximo ao pneumóstoma.

O intestino anterior ou proximal (Figs. 33, 46) inicia-se no estômago paralelo ao esôfago posterior para direcionar-se anteriormente encoberto pela glândula digestiva anterior até os limites da hemocele na altura do pericárdio. Sua parede é lisa, fina e translúcida marcada pelo tiflossole e pregas intestinais. O tiflossole intestinal (ti) corre pela face direita do segmento e apresenta aspecto lobado, destacando um sulco que corre longitudinalmente em seu ápice. As pregas longitudinais intestinais (Fig. 40) incluíram as seguintes quantidades e tipologias: p1: uma prega ao lado do tiflossole apresentando um discreto pregueamento transversal; $p 2$ : uma prega larga com pregueamento transversal em formas trapezoidais; $p 3$ : três pregas lisas e finas; $p 4$ : uma prega larga que apresenta vincos oblíquos; $p 5: 5$ a 6 pregas lisas e finas.

O intestino médio inicia-se com a válvula pré-retal (Fig. 47), característica do grupo, com uma interrupção brusca do tiflossole intestinal e das pregas $p 1$ e $p 2$, e com a gradativa diminuição das pregas $p 3$ e $p 5$. A prega 44 emite ramos laterais que se fundem com as bordas da válvula e passa a ser denominada $p 6$. Após a válvula, a superfície interna do intestino é caracterizada por pregas oblíquas denominadas $p 7$, ao longo da prega longitudinal p6, e um canal liso na intersecção oposta das pregas oblíquas $p 7$.

Este padrão é mantido no intestino posterior até que no seu terço final (Fig. 48), as pregas $p 7$ se tornam longitudinais e se anastomosam formando as pregas retais (rt), mas apenas duas pregas avançam além do limite do ânus sobre o pneumóstoma. A p6 se mantém 
individualizada e é a principal prega na borda livre do ânus. Um complexo desenvolvido de seios vasculares localiza-se entre a parede do intestino posterior e o manto (Fig. 49) responsável pela reabsorção de água do conteúdo intestinal.

\section{Sistema reprodutor}

No sistema reprodutor (Figs. 51, 52), a gônada ou glândula hermafrodita (go) esta imersa no lobo posterior da glândula digestiva. É composta de ácinos digitiformes (Fig. 50) agregados em lobos organizados em uma superfície dobrada sobre si formando um cilindro achatado. Os inúmeros dúctulos dos lóbulos reúnem-se no ducto hermafrodita.

O ducto hermafrodita é um longo ducto branco amarelado e intensamente enovelado exceto em suas extremidades $(\mathrm{dh})$. Conecta a gônada apicalmente ao tálom ou vesícula seminal (Fig. 53: ta), e este ao ducto do saco glandular anexo, de aspecto granuloso (sg). Estas duas últimas estruturas fazem parte do denominado carrefour ou "encruzilhada" e estão localizadas no terço médio da região hilar da glândula de albume $(\mathrm{gb})$, que pode variar muito em tamanho em função da estação reprodutiva do indivíduo. A glândula de albume tem coloração clara e consistência maciça e no material fixado, não sendo identificados ductos internos além de uma extensa fenda longitudinal que percorre internamente toda a glândula (Figs. 54, 55). A parte final do ducto do saco glandular anexo é envolto pelo parênquima da glândula de albume, antes de desembocar na câmara de albume (Figs. 53, 55: ca) que se localiza a direita do polo proximal da glândula de albume e que recebe também o ducto desta glândula (dg) que aparentemente provem de uma das fendas de seu parênquima.

A câmara de albume possui uma parede delicada com muitas dobras, com uma superfície interna quadriculada, lisa com duas pregas largas e baixas (Fig. 58: ca) que se continua no útero (ut) no espermoviduto (eo). Neste segmento tubular, o maior do sistema reprodutivo, os ramos masculinos e femininos continuam juntos mas parcialmente separados, sendo facilmente diferenciados em um corte transversal do órgão (Figs. 53, 57, 58). O útero mantém o mesmo padrão de mucosa da câmara de albume, enquanto que a porção masculina que aparentemente comprime a luz do útero, é representada pela glândula prostática (pt) de consistência firme e identificável externamente por uma coloração mais clara localizada dorso lateralmente à esquerda no espermoviduto; pela glândula genital anexa (gg) de coloração escura e que também é uma característica dos Megalobuliminae, estando quase que totalmente 
envolvida pela próstata; e pela goteira espermática (ge) localizada entre o útero e a glândula genital anexa.

O espermoviduto termina na hemocele céfalo-pediosa em uma forte constrição com a formação do ducto deferente (Fig. 51: df) e a separação dos ramos masculino e feminino. Ao espermoviduto segue o oviduto livre (Figs. 59, 60: ol). Sua mucosa continua reticulada mas, com a formação de fortes pregas longitudinais destacando a formação de uma prega lisa e arredondada, a prega do oviduto (po) na passagem entre o oviduto livre e o espermoviduto e que aparentemente pode obstruir todo o espaço interno e assim controlar a ascensão do espermatóforo ou seu deslocamento para o apêndice vaginal (av). O apêndice vaginal está localizado distalmente após uma dicotomia no oviduto livre. É relativamente curto e arredondado e possui pregas não reticuladas, sendo uma delas maior que as demais.

O óstio do ducto da bursa (Fig. 59: ob) marca internamente a transição entre o oviduto livre e a vagina. Há uma passagem das espessas pregas reticuladas para pregas menores, muitas delas circundando o óstio do ducto da bursa. Na porção proximal as pregas vão se tornado mais superficiais densas até alcançarem um curto átrio genital, por onde também se conecta o ramo masculino, para exteriorizarem pelo poro genital (pg).

O ducto da bursa (Fig. 51: db), arredondado, acompanha pelo lado direito o oviduto livre até e a metade do espermoviduto quando se direciona para o pericárdio sem atravessar o diafragma. A bursa copulatrix (Fig. 56) tem a forma elíptica e sua mucosa é formada por inúmeras pregas que acompanham seu maior eixo.

O seguimento masculino engloba parte do ducto deferente, o epifalo e o pênis. O ducto deferente, cilíndrico e uniforme, origina-se na transição do espermoviduto com o oviduto livre (fig. 51: df), percorre imerso na parede muscular do oviduto livre (Fig. 60: df) antes de surgir aderido na superfície lateral externa esquerda na altura da entrada do apêndice vaginal (av) em sentido a vagina, onde próximo de atingir o átrio genital, lateraliza para a base do pênis. Progride em direção distal até terminar no ápice do epifalo (Figs. 61, 62: df), onde aparenta tracionar o epifalo curvando o pênis distalmente.

O epifalo, paralelo e firmemente aderido ao pênis no seu terço distal (Figs. 61, 62: ep), possui forma fusiforme com uma prega muscular interna dividida por um sulco (Fig. 64: pf). Em seu ápice, onde se insere o ducto deferente não há apêndices ou flagelos. Apresenta em 
sua base na passagem para o pênis um óstio muscular (Fig. 63), e não recebe feixes musculares do músculo retrator do pênis.

O pênis (Figs. 61-64) apresenta a forma de um ponto de interrogação com o epifalo encaixado em sua curvatura interna (ep). Após alcançar sua maior distância da base, o pênis curva-se sobre o epifalo, recebe a inserção de um volumoso músculo retrator do pênis (mp) e forma uma expansão terminal saculiforme, a bolsa do espermatóforo (be), onde foram encontrados espermatóforos em vários exemplares examinados. Em sentido diametralmente oposto a bolsa se encontra a óstio do epifalo. Internamente o pênis apresenta em sua base, inúmeras e discretas pregas musculares longitudinais que se anastomosam e se espessam em sentido distal formando quatro grandes e afastadas pregas penianas (pp), que acabam por se avolumarem em uma cinta muscular transversal. Apicalmente a esta cinta há uma discreta prega transversal do pênis (pv) que parece ser contigua entre o músculo retrator do pênis e uma das pregas penianas que se prolonga por metade do diâmetro interno peniano. Entre a cinta muscular transversa e a prega transversa existe um sulco que se alarga com o adelgaçamento das pregas penianas, formando a bolsa do espermatóforo (be).

\section{Sistema nervoso}

O sistema nervoso (Fig. 33: sn) esta concentrado em um anel periesofagiano que nos exemplares estudados foram todos encontrados circundando o tubo oral anteriormente na massa bucal. Podem-se identificar os gânglios cerebrais dorsais (Figs. 34 e 35: gc) e o complexo subesofageal (ce) firmemente aderido à membrana que separa a hemocele cefalopediosa da glândula pediosa. Neste complexo estão reunidos sete gânglios: dois pediosos, dois pleurais, dois parietais e um visceral. A aorta anterior (aa) ao atravessar o complexo emite dois ramos que acompanham os conectivos em sentido aos gânglios cerebrais e torna-se a artéria cefálica (ac).

Os gânglios cerebrais comunicam-se aos gânglios bucais (Figs. 33, 36, 37: nb), localizados na região axilar do esôfago, pelos conectivos cerebro-bucais (Figs. 34, 35: nc), e ao complexo subesofageal pelos conectivos cerebro-pleural (nu) e cerebro-pedal (nd). 


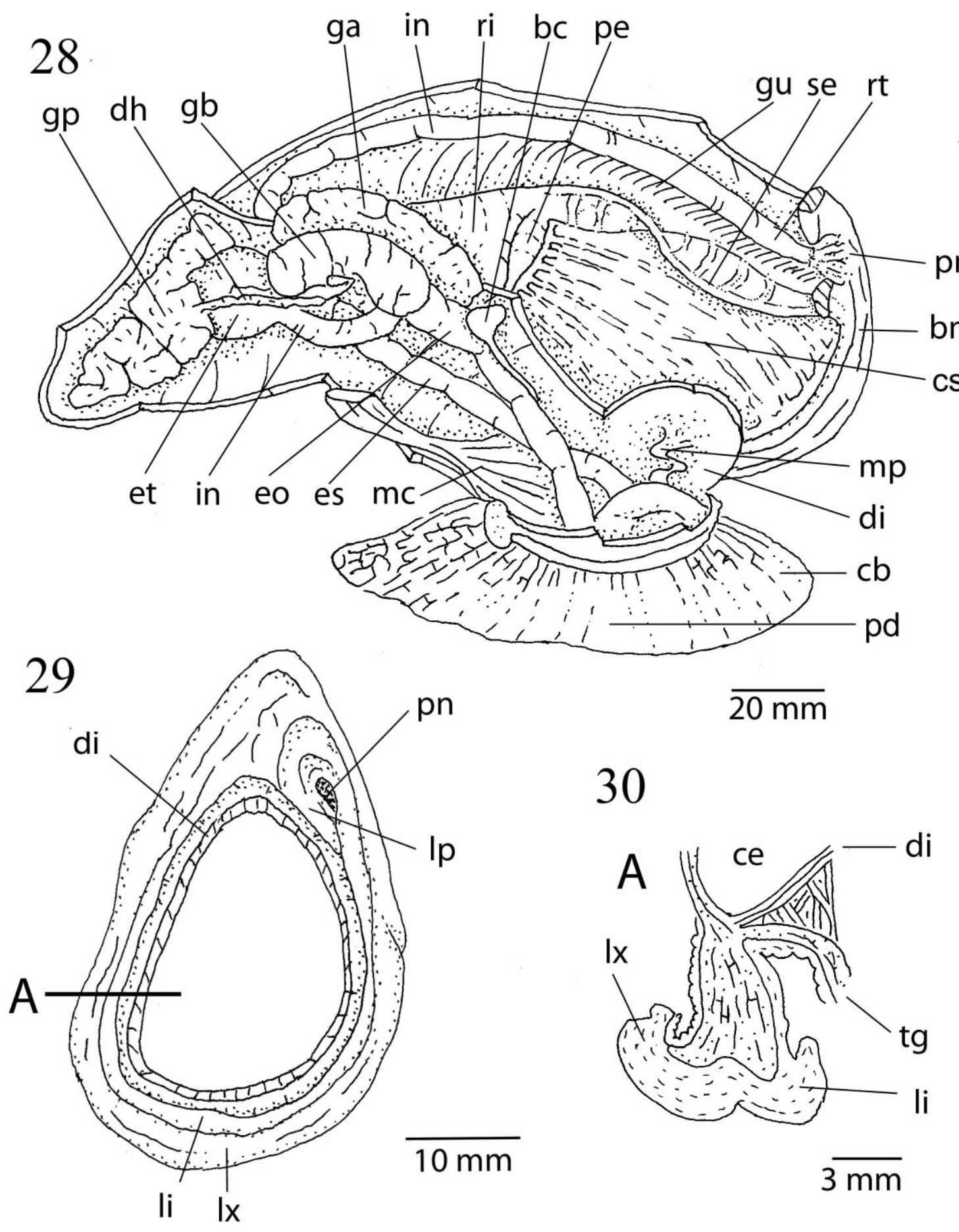

Figuras 28-30. Megalobulimus paranaguensis: 28. Hemocele visceral e cavidade palial abertas após despiralização, vista lateral direita; 29. Borda do manto, vista ventral; 30. Corte transversal da borda do manto. bc: bursa copulatrix (bolsa copulatória); bm: borda do manto; cb: cabeça; cs: câmara respiratória; dh: ducto hermafrodita; di: diafragma; eo: espermoviduto; es: esôfago; et: estômago; ga: glândula digestiva anterior; gb: glândula de albume; gp: glândula digestiva posterior; gu: goteira urinária; in: intestino; li: lábio interno do manto; lp: lábio do pneumóstoma; lx: lábio externo da borda do manto; mc: músculo columelar; mp: músculo peniano; p: pé; pe: pericárdio; pn: pneumóstoma; ri: rim; rt: reto; se: septo; tg: tegumento. 


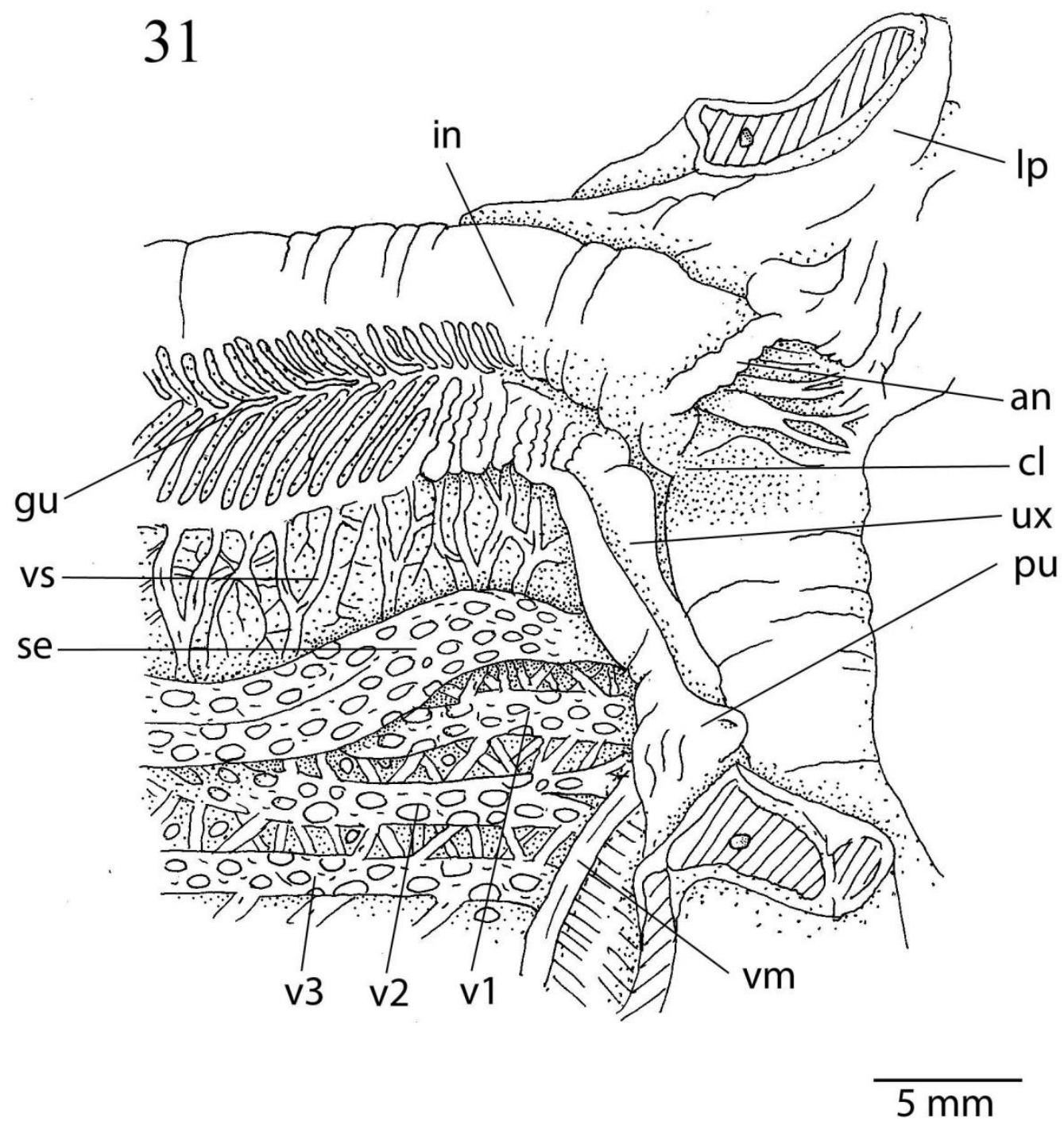

Figura 31. Região distal do septo e pneumóstoma de Megalobulimus paranaguensis após secção do lábio do pneumóstoma. an: ânus; cl: canal lateral; gu: goteira urinária; in: intestino; lp: lábio do pneumóstoma; pu: prega do sulco urinário; se: septo; ux: sulco urinário externo; v1, v2 $e$ v3: ramificações da veia pulmonar; vm: veia marginal ou colar; vs: vasos ad-retais. 


\section{2}

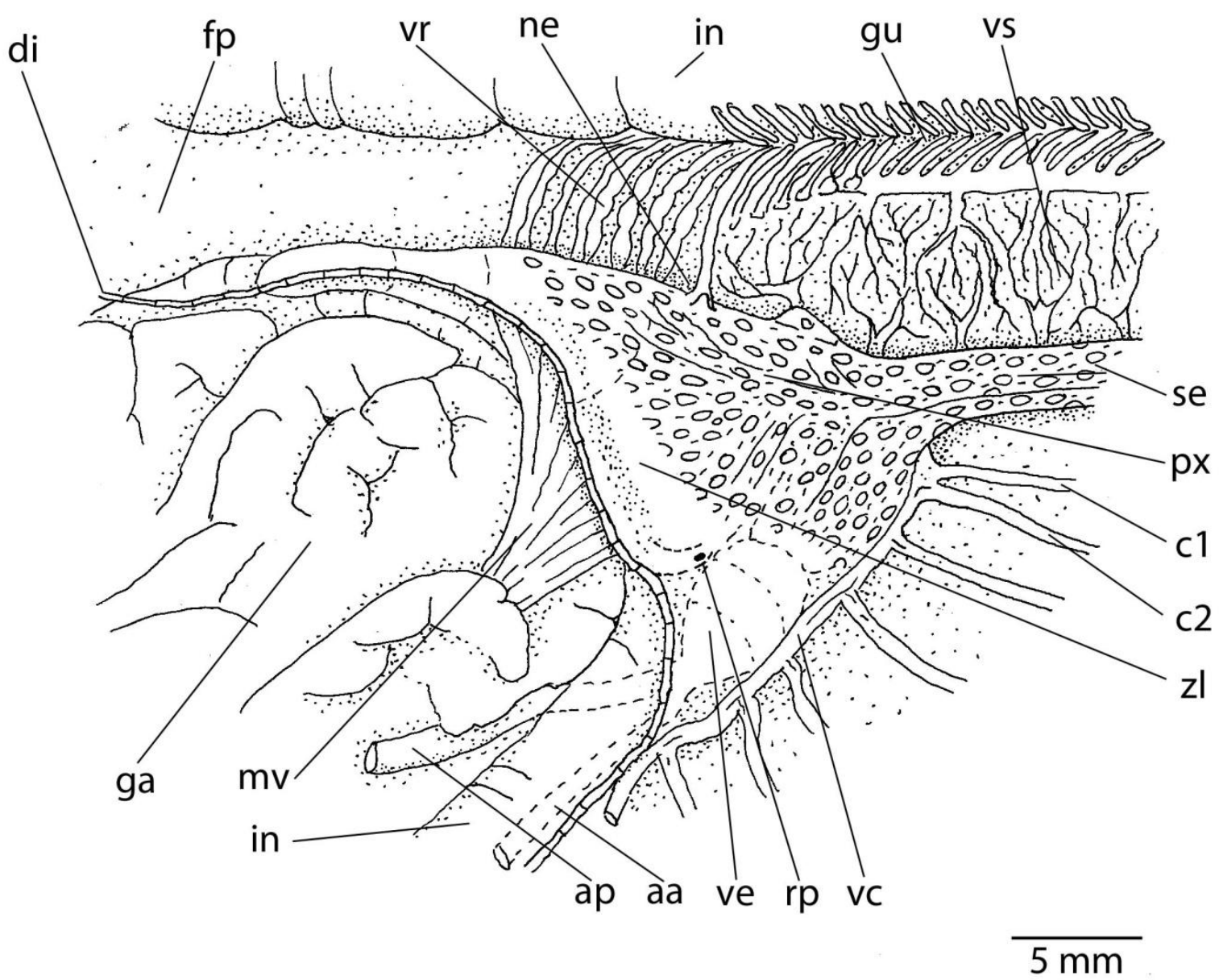

Figura 32. Região reno-pericárdica da câmara palial de Megalobulimus paranaguensis, vista ventral. aa: aorta anterior; ap: aorta posterior; c1 e c2: ramificações do vaso pericárdico; fp: fundo da cavidade palial; ga: glândula digestiva anterior; gu: goteira urinária; in: intestino; mv: feixe muscular palio-diafragmático; ne: nefróstoma; px: plexo epi-renal; rp: orifício reno-pericárdico; se: septo; vc: vaso pericárdico; ve: ventrículo; vr: vasos ad-renais; vs: vasos ad-retais, zl: zona lisa do rim. 


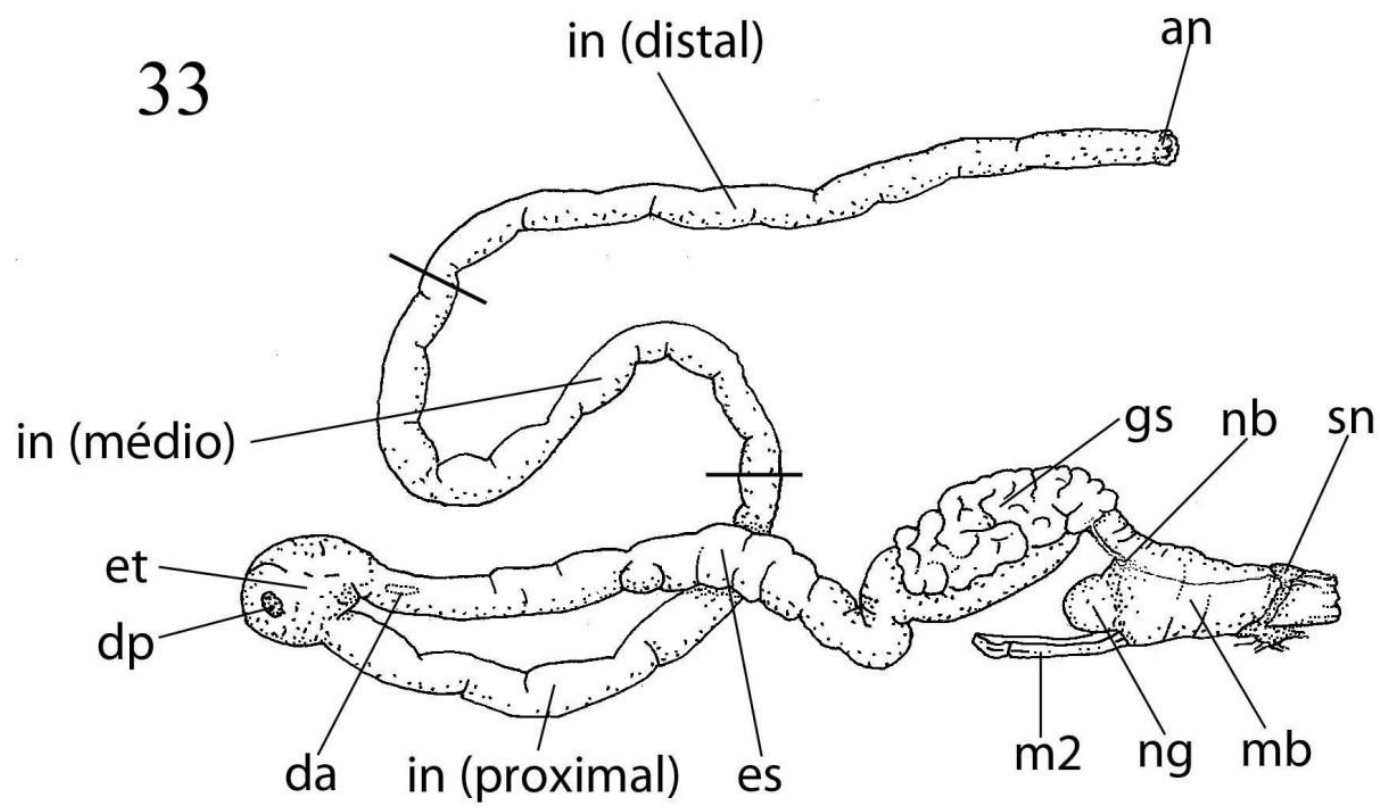

$\overline{10 \mathrm{~mm}}$
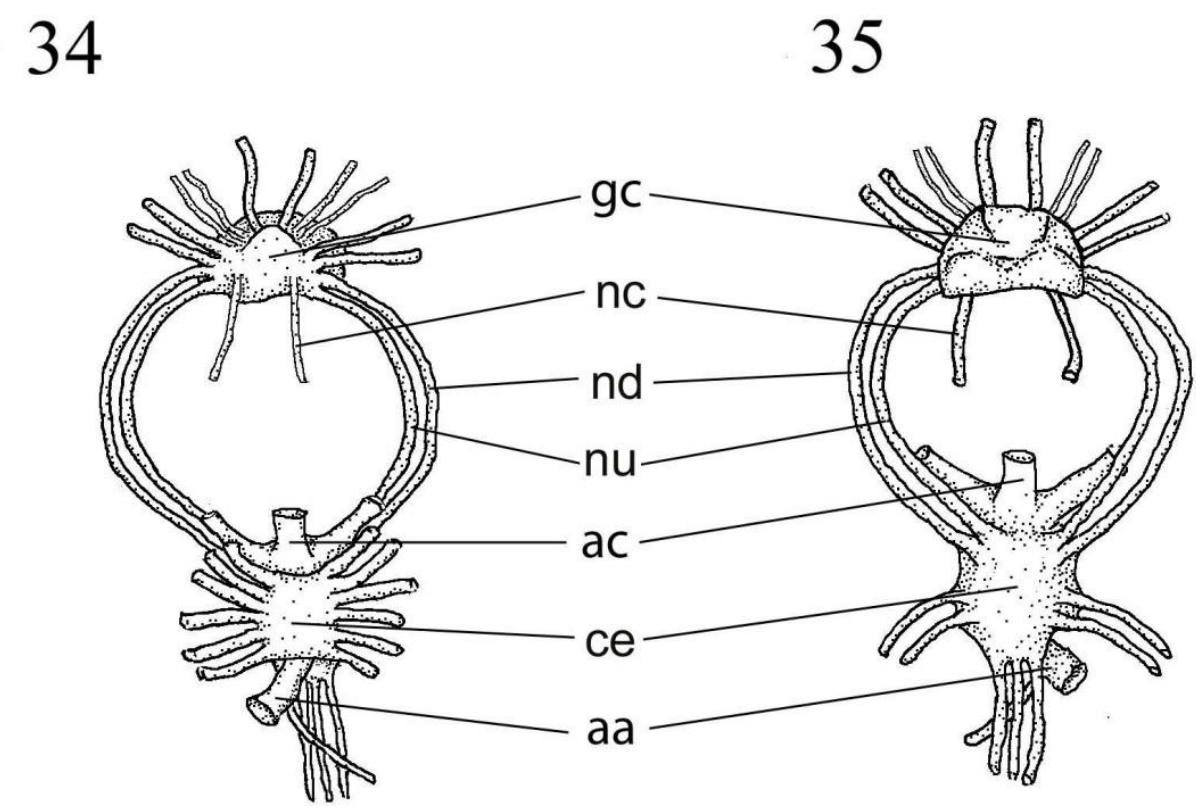

$\overline{5 \mathrm{~mm}}$

Figuras 33-35. Megalobulimus paranaguensis: 33. Topografia do sistema digestivo com a divisão transversal do intestino em seus segmentos proximal, médio e distal, e localização do anel nervoso no tubo oral; 34. Sistema nervoso, lado ventral; 35. sistema nervoso, lado dorsal. aa: aorta anterior; ac: artéria cefálica; an: ânus; nc: conectivo cerebro-bucal; nd: conectivo cerebro-pedal; ce: complexo subesofageal; nu: conectivo cerebro-pleural; da: ducto a glândula digestiva anterior; dp: ducto para a glândula digestiva posterior; es: esôfago; et: estômago; gc: gânglios cerebrais; gs: glândulas salivares; in: intestino; m2: músculo retrator da massa bucal; mb: massa bucal; nb: gânglio bucal; ng: núcleo da rádula; sc: sistema nervoso central. 


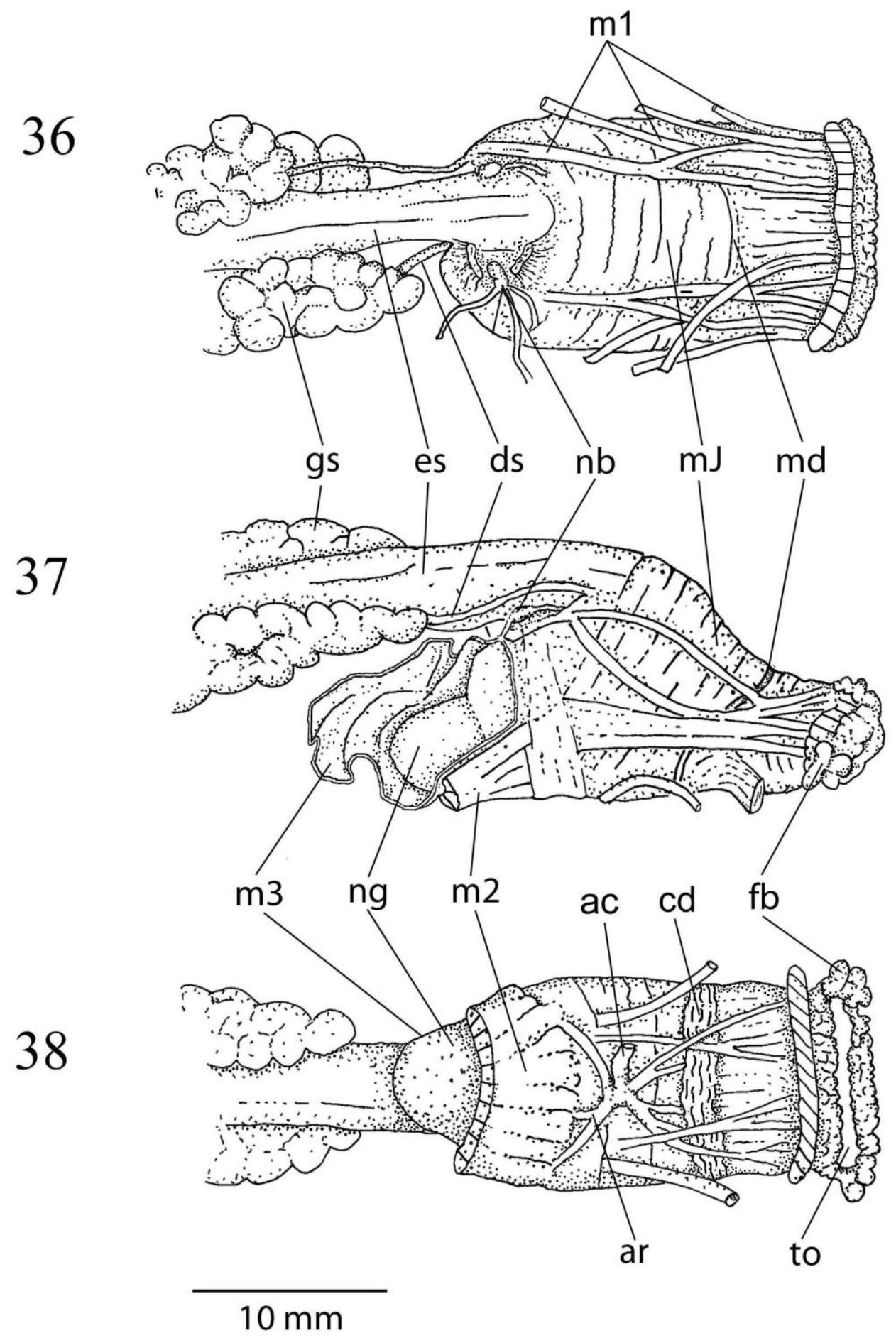

Figuras 36-38. Massa bucal de Megalobulimus paranaguensis: 36. vista dorsal; 37. vista esquerda; 38. vista ventral. ac: artéria cefálica; cd: cinta mandibular; ds: ducto da glândula salivar; es: esôfago; fb: franja bucal; gs: glândulas salivares; m1: músculos extrínsecos longitudinais; m2: músculo retrator da massa bucal; m3: músculo extrínseco transverso; md: mandíbula; nb: gânglio bucal; ng: núcleo da rádula. 


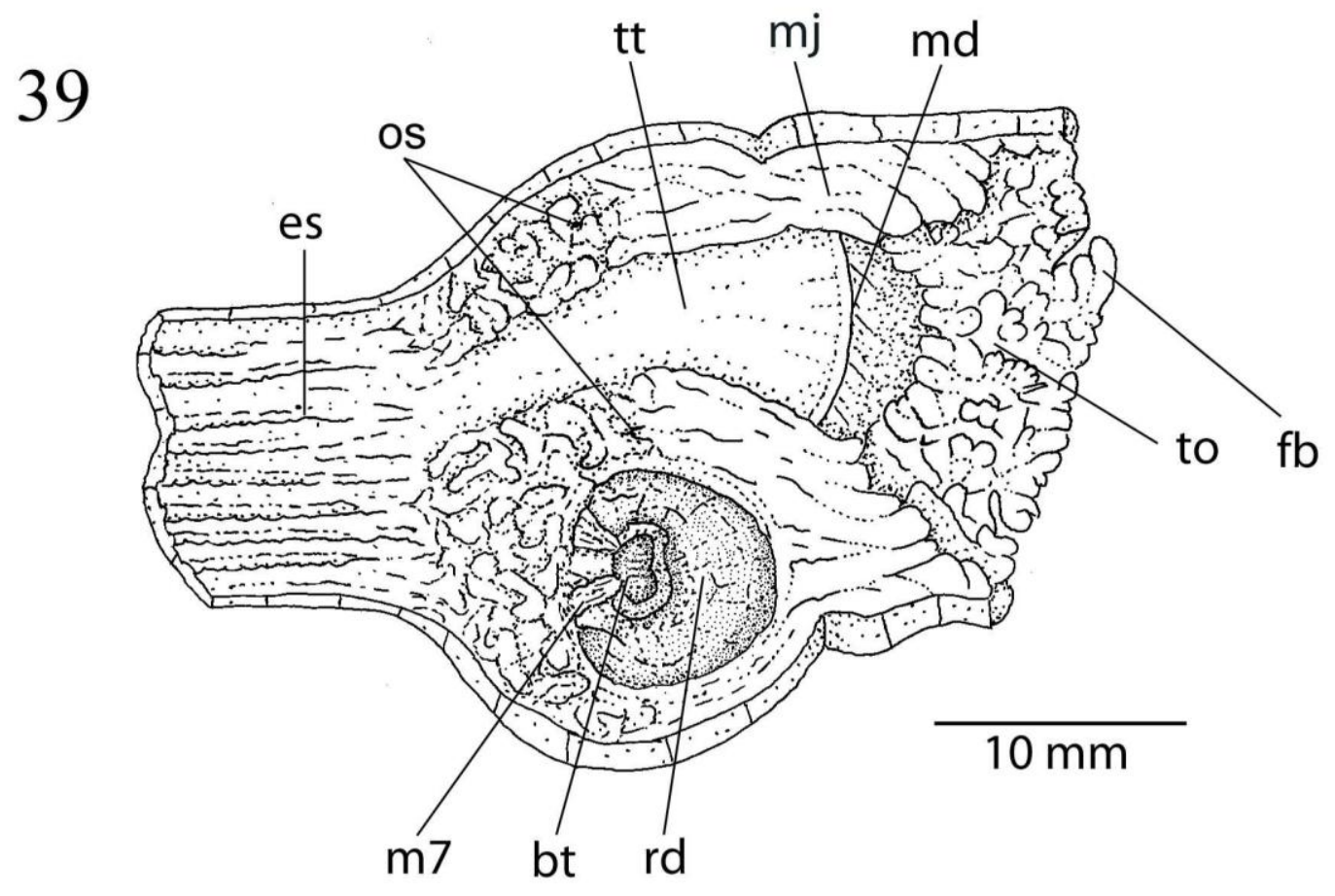

\section{0}

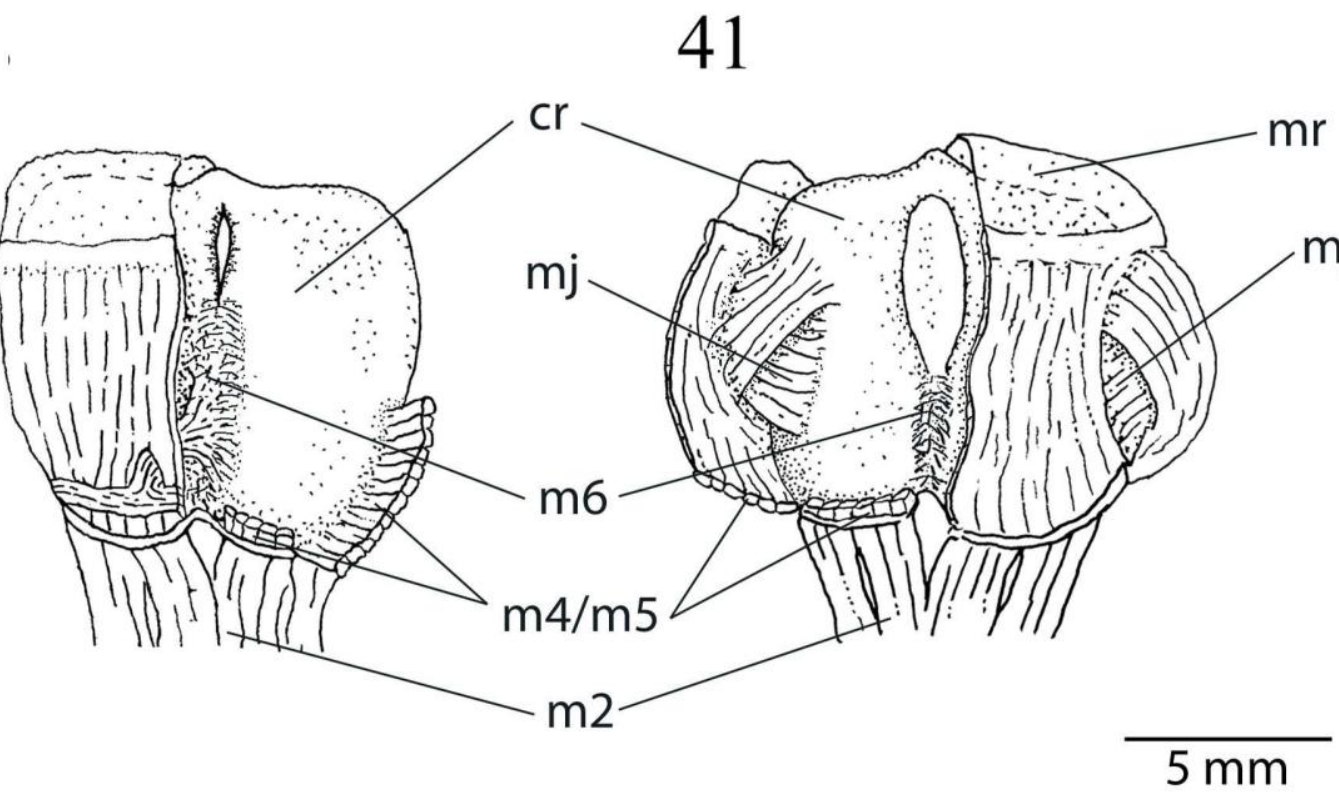

Figuras 39-41. Megalobulimus paranaguensis: 39. Massa bucal; 40. Odontóforo após remoção da rádula em vista dorsal; 41. Odontóforo em vista ventral. bt: bonete da rádula; cr: cartilagem radular; fb: franja bucal; m2: músculo retrator da massa bucal; m4/m5: músculos protrator/retrator da rádula; m6: músculo inter-radular; m7: músculo núcleo radular; md: mandíbula; mj: músculo mandibular; mr: membrana subradular; rd: rádula; te: tiflossole esofágico; to: tubo oral; tt: teto da massa bucal. 


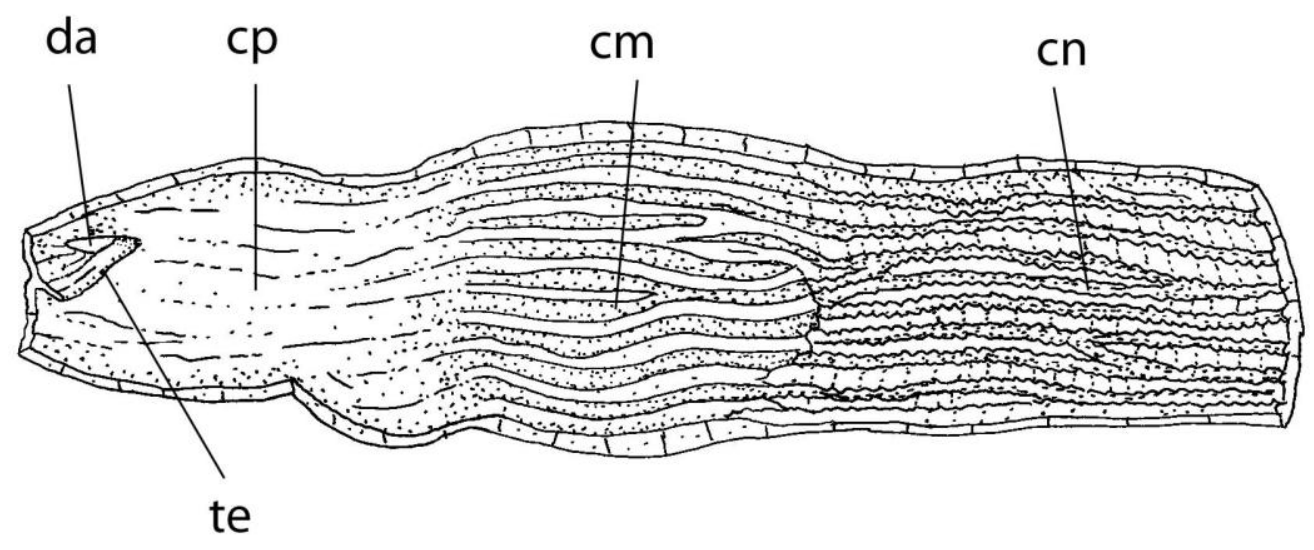

$10 \mathrm{~mm}$

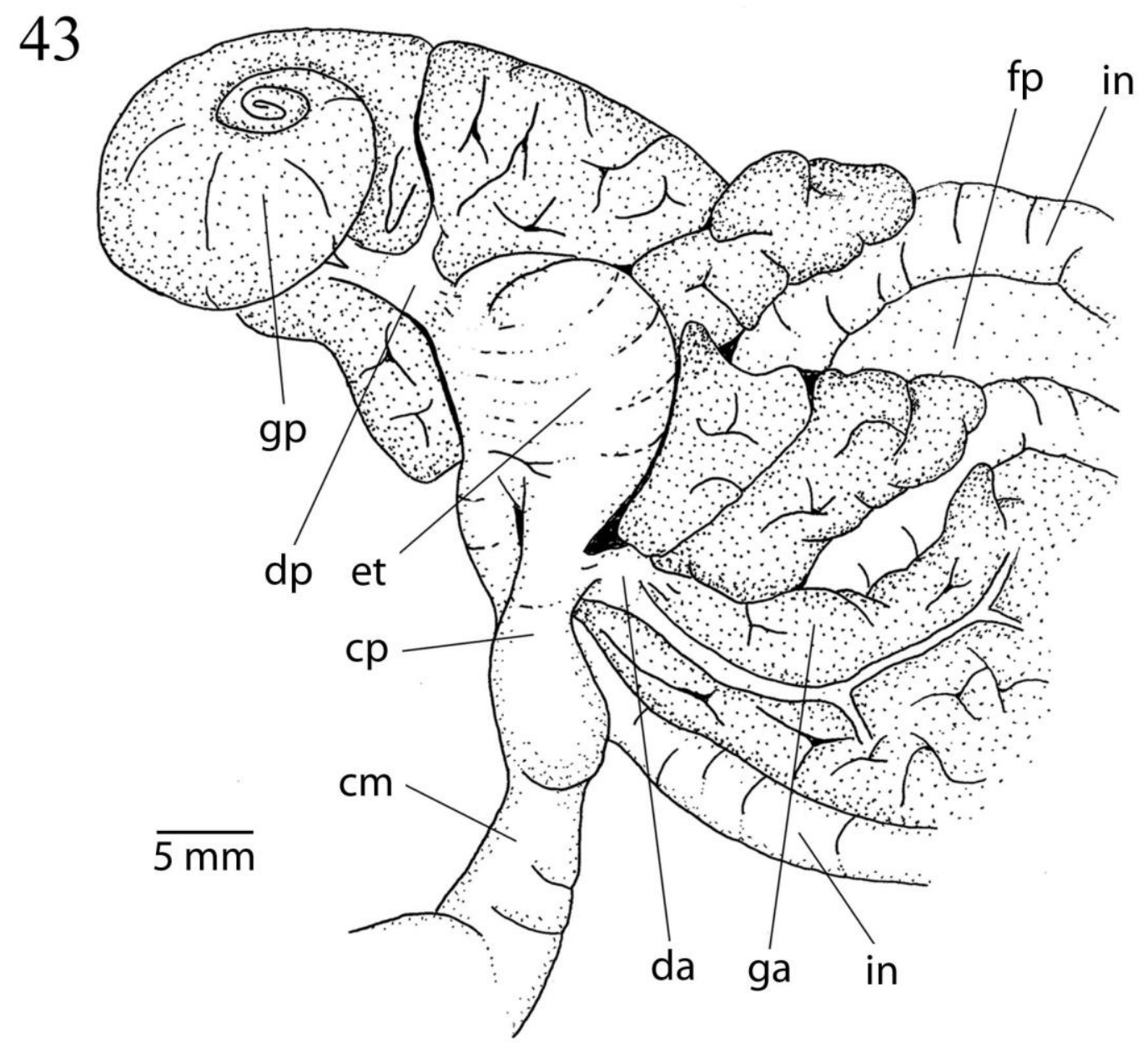

Figuras 42, 43. Megalobulimus paranaguensis: 42. Esôfago aberto longitudinalmente; 43. Sistema digestivo na hemocele visceral após remoção do sistema reprodutivo, lado direito. cm: câmara média do esôfago; cn: câmara anterior do esôfago; cp: câmara posterior do esôfago; da: ducto para a glândula digestiva anterior; dp: ducto para a glândula digestiva posterior; es: esôfago; et: estômago; fp: fundo da cavidade palial; ga: glândula digestiva anterior; gp: glândula digestiva posterior; in: intestino; te: tiflossole esofágico. 


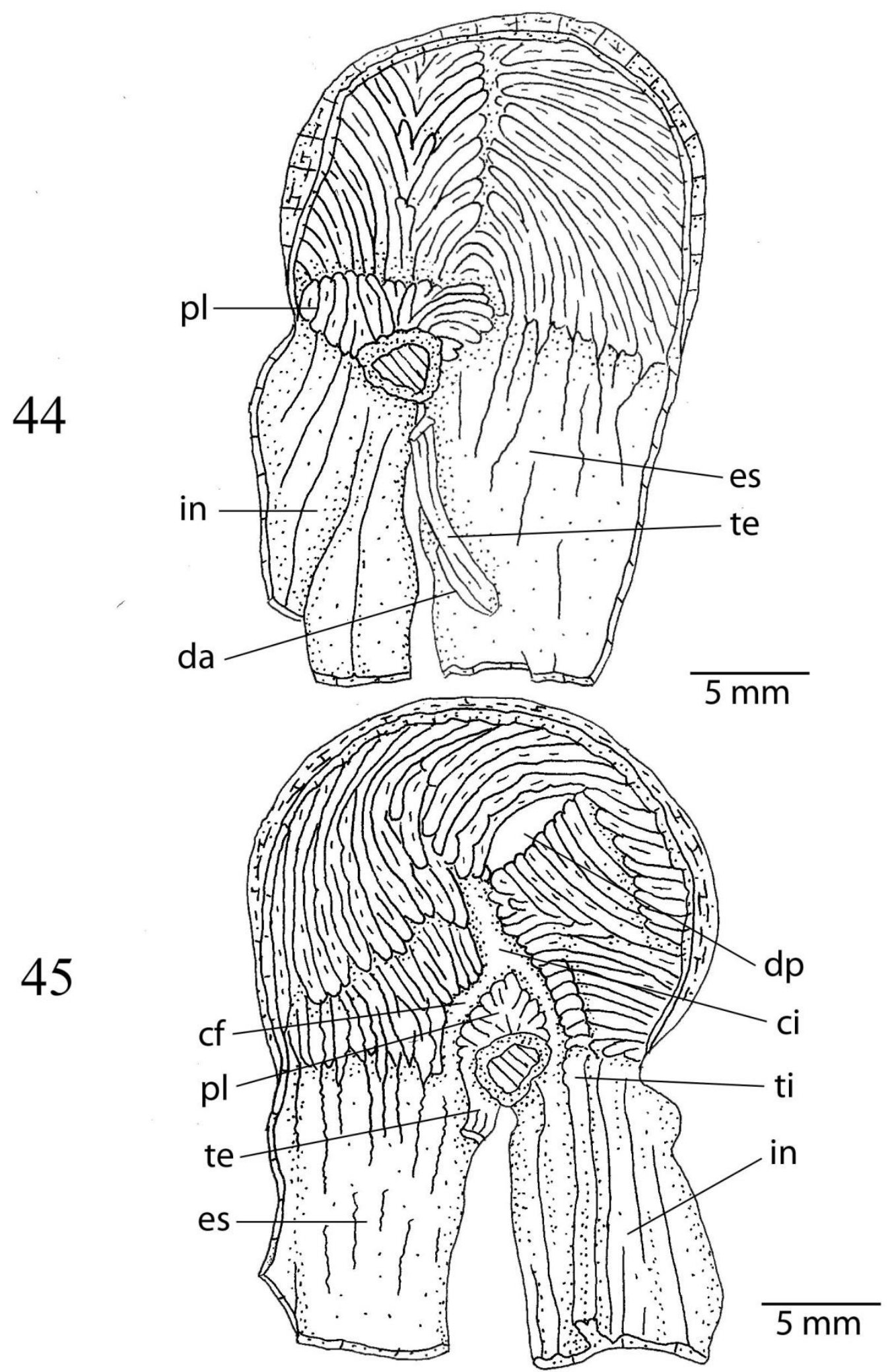

Figuras 44, 45. Estômago de Megalobulimus paranaguensis: 44: Superfície interna do lado esquerdo; 45: Superfície interna do lado direito. cf. canal esofágico; ci. canal intestinal; da. ducto para a glândula digestiva anterior; dp. ducto para a glândula digestiva posterior; es. esôfago; in. intestino; pl. musculatura do piloro; te. tiflossole esofágico; ti. tiflossole intestinal. 


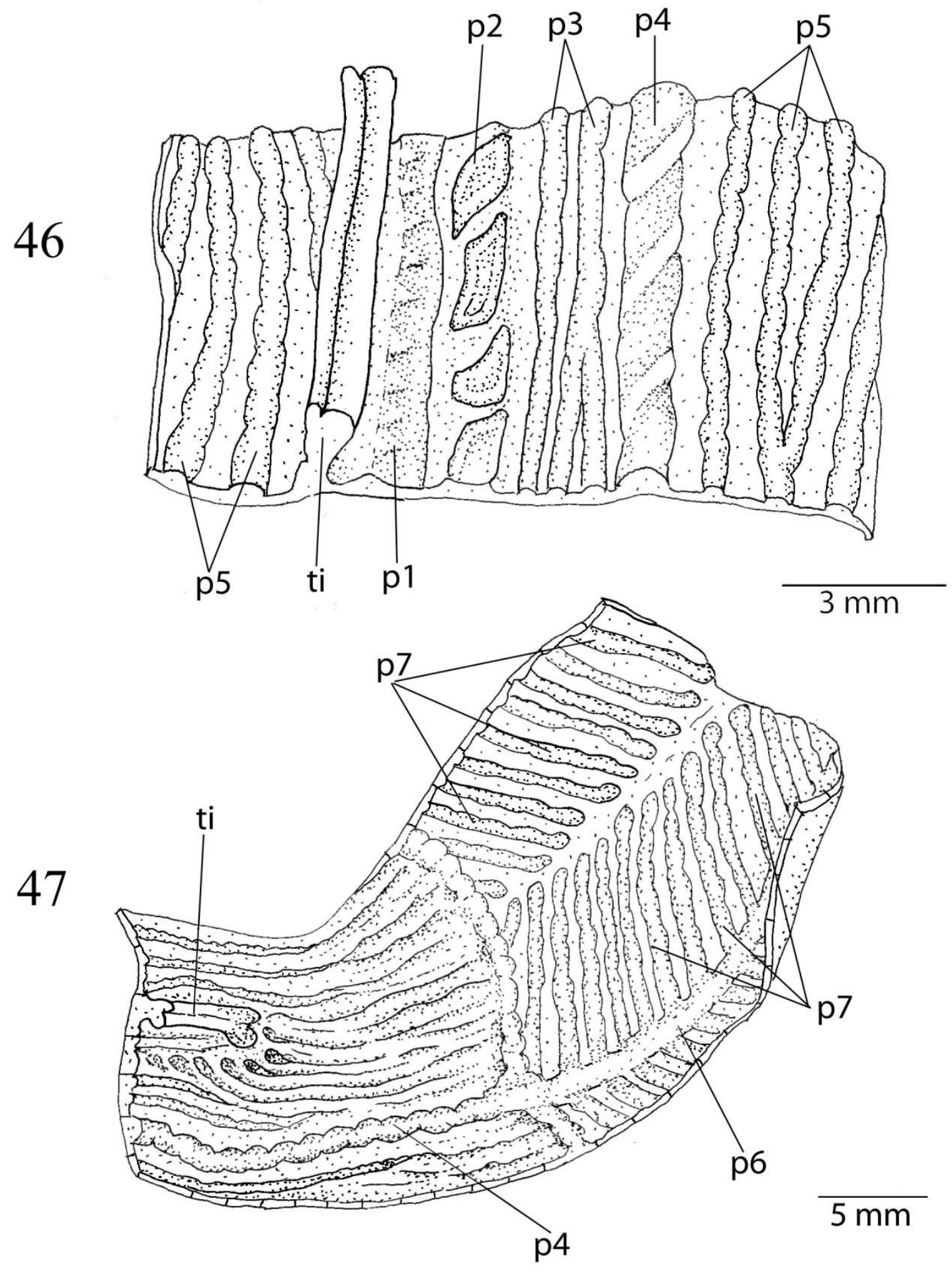

Figuras 46, 47. Sistema digestivo de Megalobulimus paranaguensis: 46. Superfície interna do intestino proximal; 47: Superfície interna da válvula pré-retal no intestino médio. p1, p2, p3, p4 e p5: pregas intestinais pré-valvulares; $\mathbf{p 6}$ e p7: pregas intestinais pós-valvulares; ti: tiflossole intestinal 


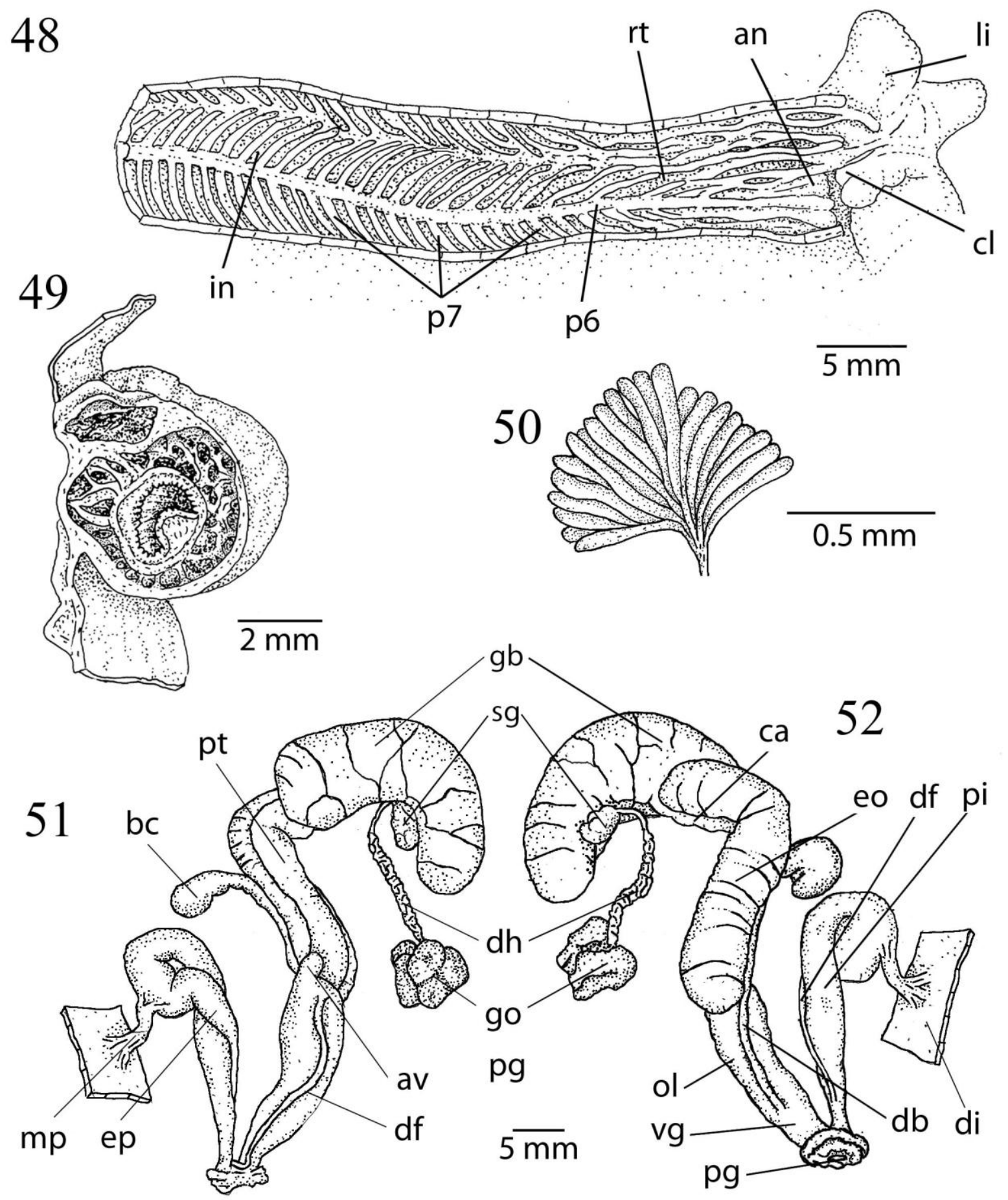

Figuras 48-52. Sistemas digestivo e reprodutor de Megalobulimus paranaguensis: 48. Reto, aberto longitudinalmente, vista ventral; 49. Corte transversal do reto, expondo o sistema de seios vasculares; 50. Ácino da gônada; 51. Sistema reprodutivo, lado esquerdo; 52. Sistema reprodutivo, lado direito. an: ânus; av: apêndice vaginal; bc: bursa copulatrix (bolsa copulatória); ca: câmara de albume; df: canal deferente; dh: ducto hermafrodita; di: diafragma; eo: espermoviduto; ep: epifalo; gb: glândula de albume; go: gônada; in: intestino; li: lábio interno do pneumóstoma; mp: músculo peniano; ol: oviduto livre; p6 e p7: pregas intestinais pós-valvulares; pg: poro genital; pi: pênis; rt: pregas retais; sg: saco glandular anexo; vg: vagina. 


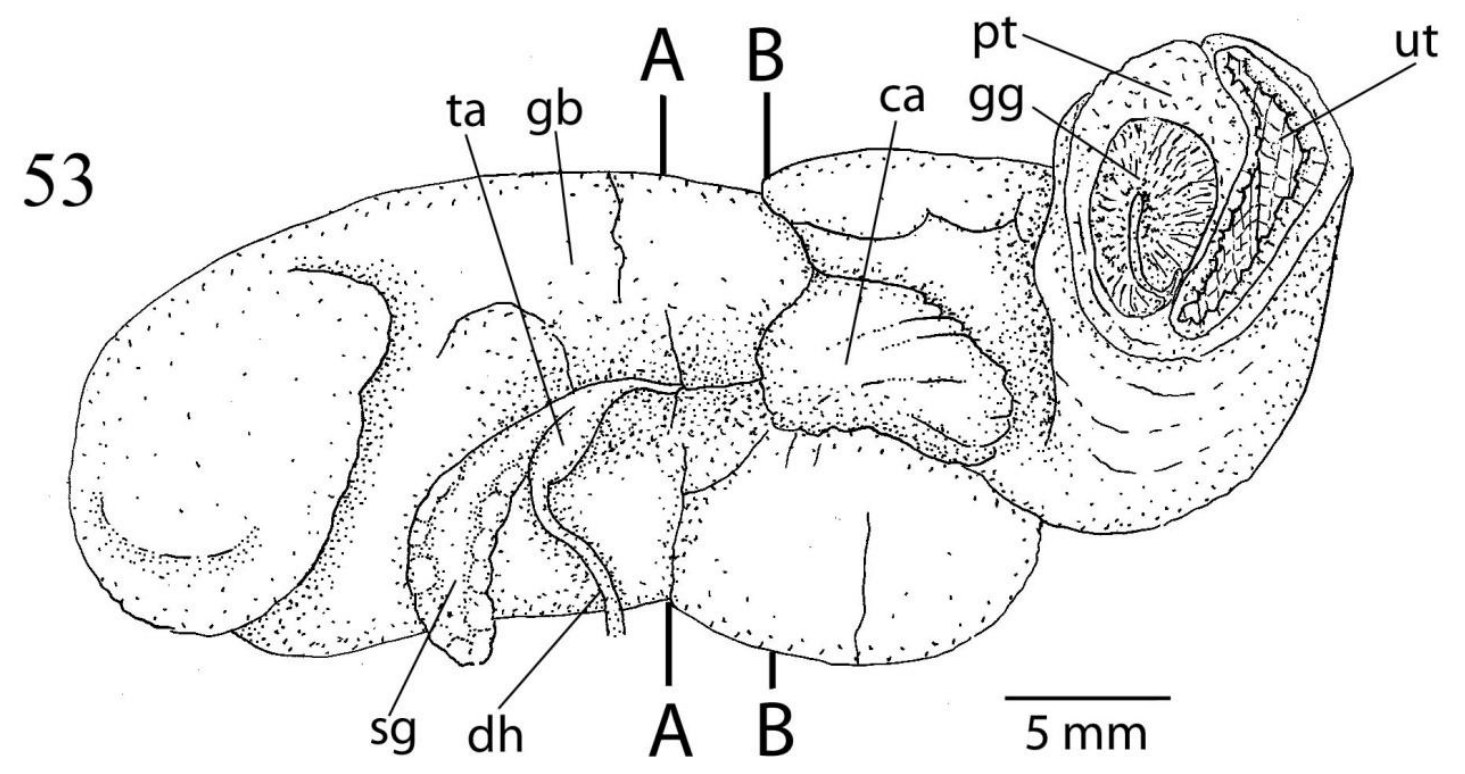

54
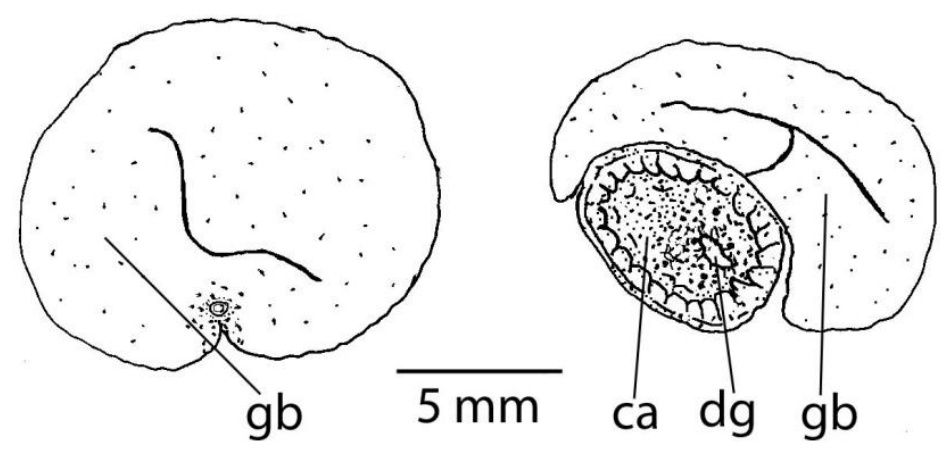

55
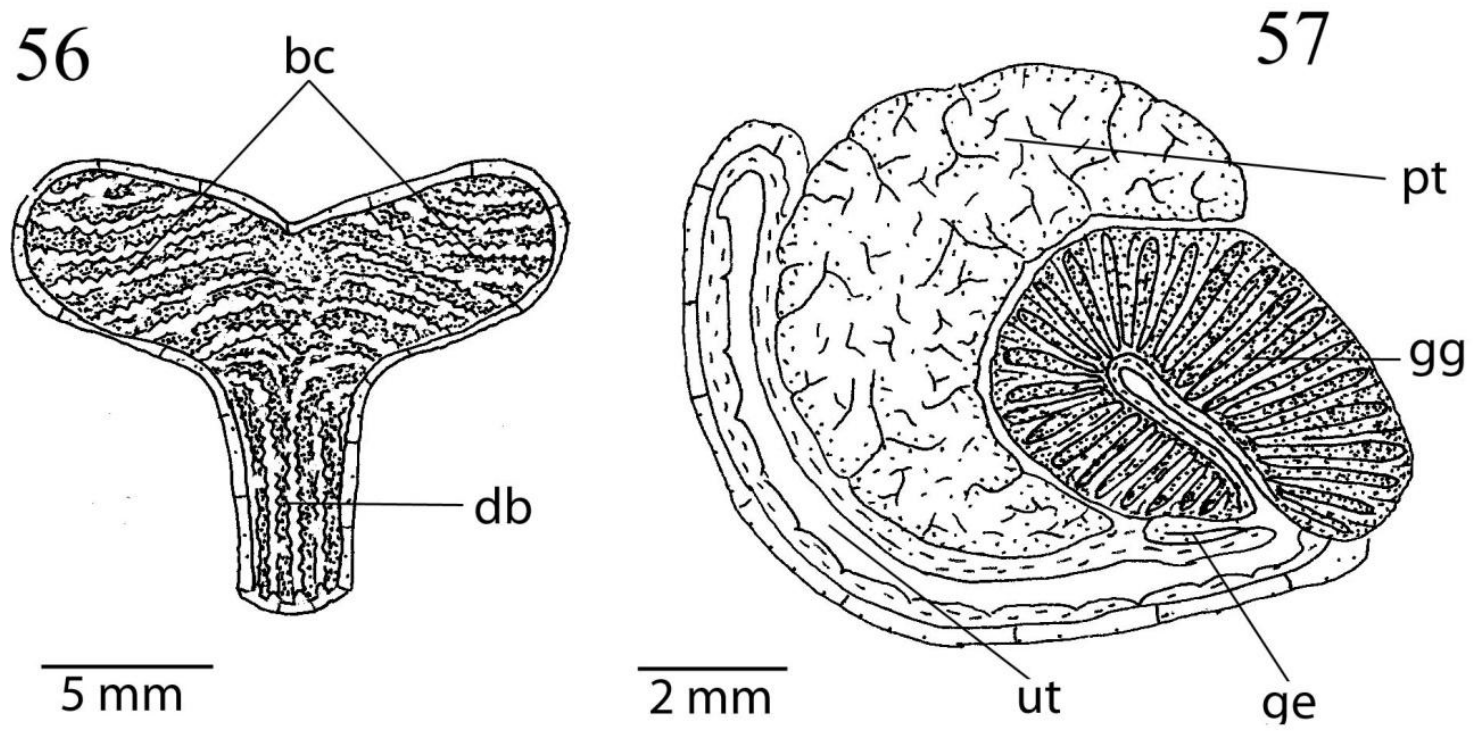

Figuras 53-57. Sistema reprodutivo de Megalobulimus paranaguensis: 53: Glândula de albume e carrefour, lado ventral; 54 . corte transversal da glândula de albume pelo plano A; 55 . Corte transversal da glândula de albume e da câmara de albume pelo plano B; 56. Superfície interna da bursa copulatrix; 57. Corte transversal no terço médio do espermoviduto. bc: bursa copulatrix; ca: câmara de albume; db: ducto da bursa; dg: ducto da glândula de albume; dh: ducto hermafrodita; gb: glândula de albume; ge: goteira espermática; gg: glândula genital acessória; pt: próstata; sg: saco glandular anexo; ta: tálom; ut: útero. 


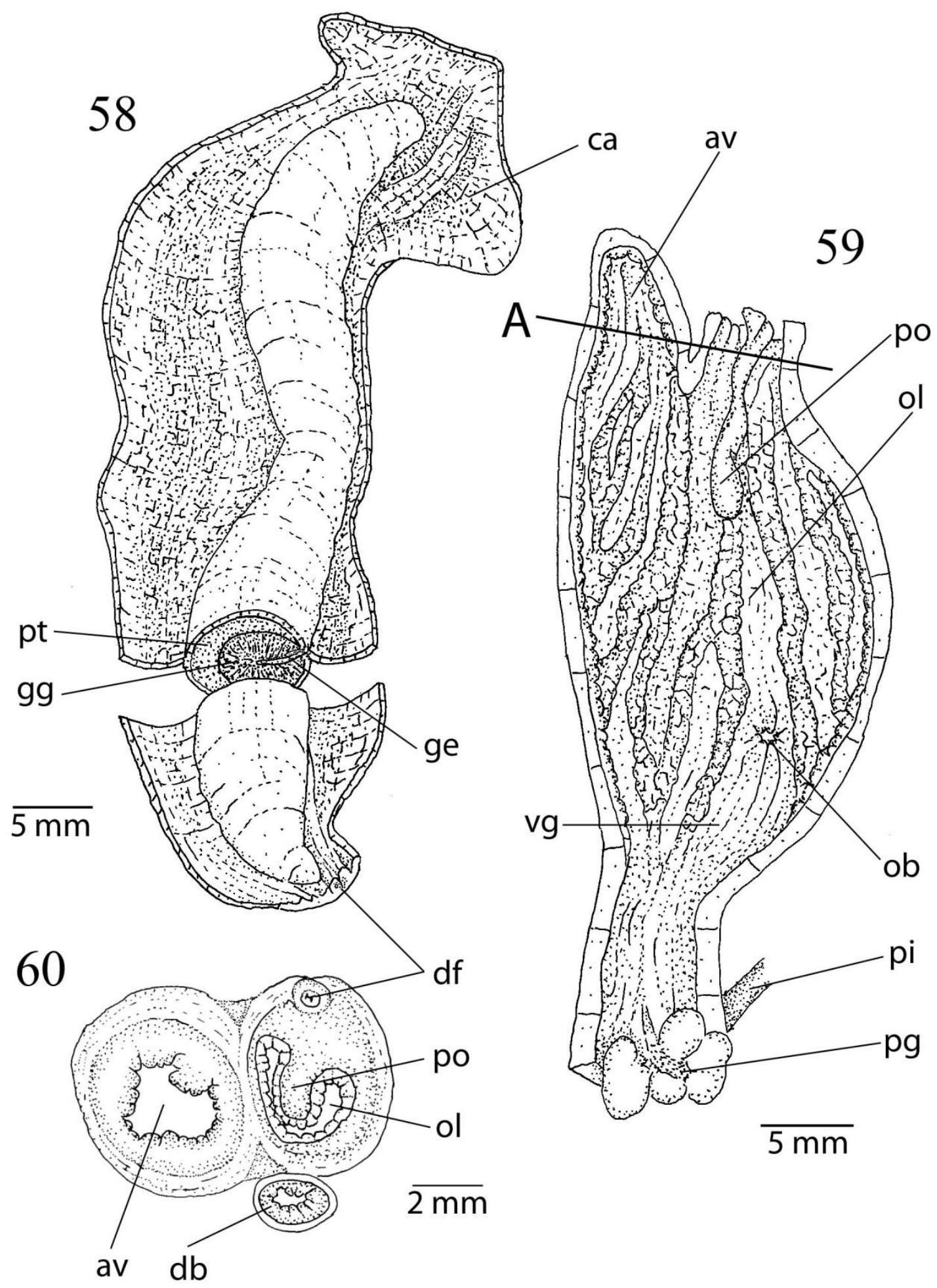

Figuras 58-60. Sistema reprodutivo de Megalobulimus paranaguensis: 58. Espermoviduto com abertura longitudinal do útero; 59. Oviduto livre e vagina abertos longitudinalmente; 60 . Corte pelo plano transversal A do oviduto livre. av: apêndice vaginal; ca: câmara de albume; ge: goteira espermática; gg: glândula genital acessória; ob: óstio do ducto da bursa; ol: oviduto livre; pg: poro genital; pi pênis; po: prega do oviduto; pt: próstata; ut: útero; vg: vagina. 


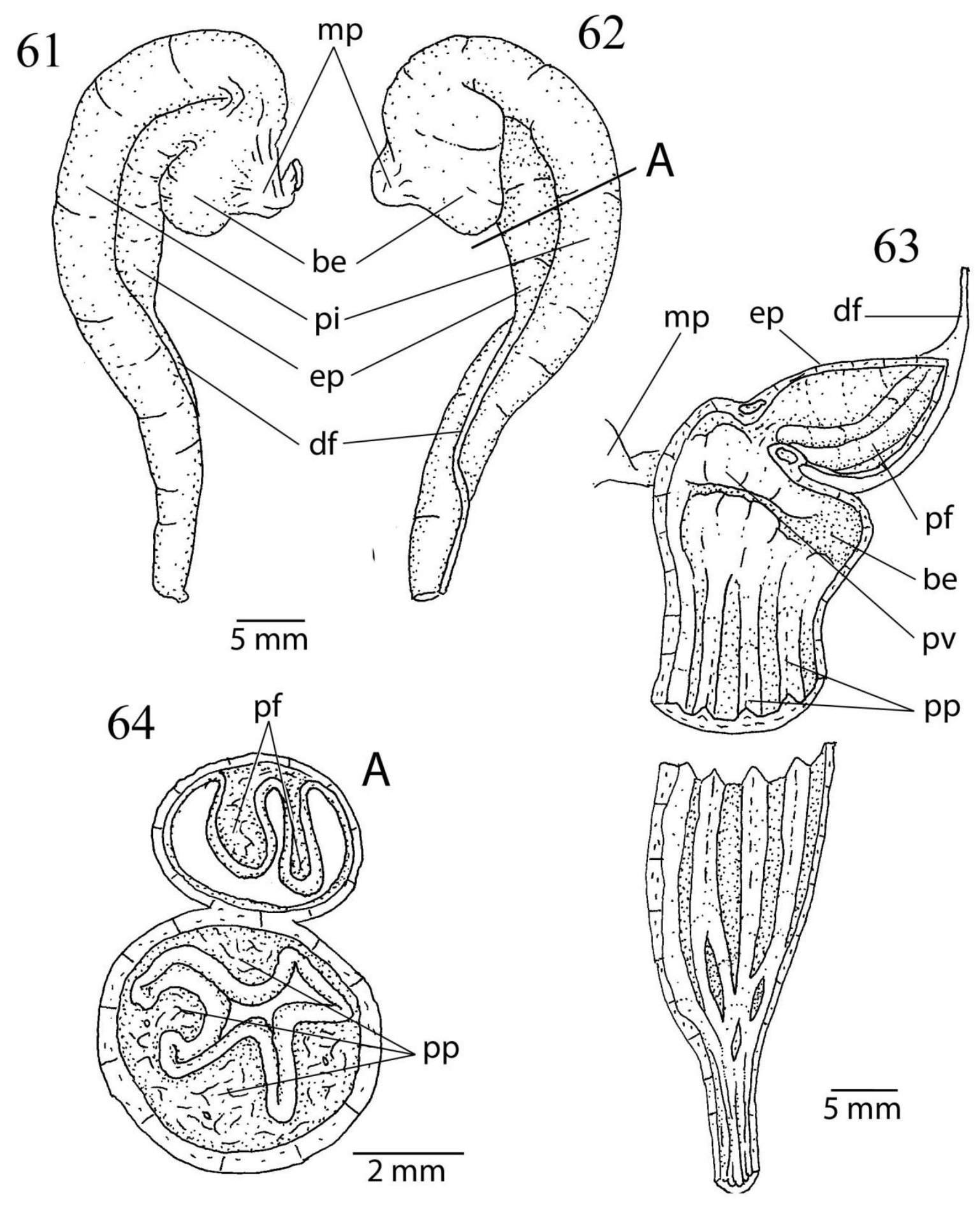

Figuras 61-64. Sistema reprodutivo de Megalobulimus paranaguensis. 61. Complexo peniano, lado esquerdo; 62. Complexo peniano, lado direito; 63. Complexo peniano aberto longitudinalmente; 64. Corte transversal do complexo peniano pelo plano A. be: bolsa do espermatóforo; df: canal deferente; ep: epifalo; mp: músculo peniano; pf: prega do epifalo; pl: musculatura do piloro; pp: pregas penianas; pv: prega transversal do pênis. 


\section{DISTRIBUIÇÃO GEOGRÁFICA}

Na descrição da espécie, Pilsbry \& Ihering (1900), a localidade tipo do $M$. paranaguensis foi atribuída ao município de Paranaguá, na costa do Paraná. Na revisão de Bequaert (1948) foram estudados exemplares desta localidade e de Iguape, município do litoral paulista.

Morretes $(1949,1953,1954)$ descreveu sua ocorrência a partir localidade-tipo de Paranaguá, para oeste até os contrafortes da Serra do Mar nas localidades de Porto de Cima e São João da Graciosa, no município de Morretes sem, no entanto, penetrar na mata densa e nem na vertente serrana. Para o sul ocorreria até Guaratuba, sendo comum nos sambaquis locais. Para o norte ocorre nas ilhas das Peças e do Mel. Em São Paulo, ocorre nos municípios de Peruíbe, Itanhaem e Praia Grande. Mais recentemente, Simone (2006) descreve sua distribuição para o Paraná e São Paulo nos municípios de Peruíbe e Iguape, enquanto que Thomé et al. (2007) restringe sua distribuição na região sul ao Paraná. Colley (2008) registra ocorrências nos municípios paranaenses de Guarequeçaba, Antonina, Morretes e Pontal do Paraná.

Na coleção malacológica do MZSP foram identificados 90 lotes com localidade de coleta (Tab. 2). De forma contígua a espécie se estende pela planície costeira do Paraná e a metade meridional paulista. Ocorre entre Garuva no litoral norte de Santa Catarina, contorna a baia de Paranaguá, ocorrendo nas ilhas do Mel, Superagui e do Cardoso, avança pelo vale do Ribeira e litoral paulista até Juquiá, Itanhaem e Santos. Como pontos extremos e isolados (possivelmente introduzidos) estão ao sul, Itajaí em Santa Catarina, ao oeste, Ribeirão Pires, no planalto paulista, e ao norte, Taubaté no vale do Paraíba do Sul (Fig. 65).

Sua distribuição restringe-se a planícies costeiras do Paraná e da metade meridional de São Paulo onde penetra no vale do Ribeira, e extremo norte da costa catarinense. Esta região é reconhecida geomorficamente como "macrocompartimento litoral das planícies costeiras e estuários" que é caracterizada por largas planícies com longos arcos de praia intercalados por estuários como o de Santos e Cananéia em São Paulo, Paranaguá e Guaratuba no Paraná e São Francisco do Sul em Santa Catarina (Dieter, 1998).

As ocorrências no planalto cristalino paulista, a saber, nos municípios de Taubaté e Ribeirão Pires são consideradas como introduções antrópicas. 


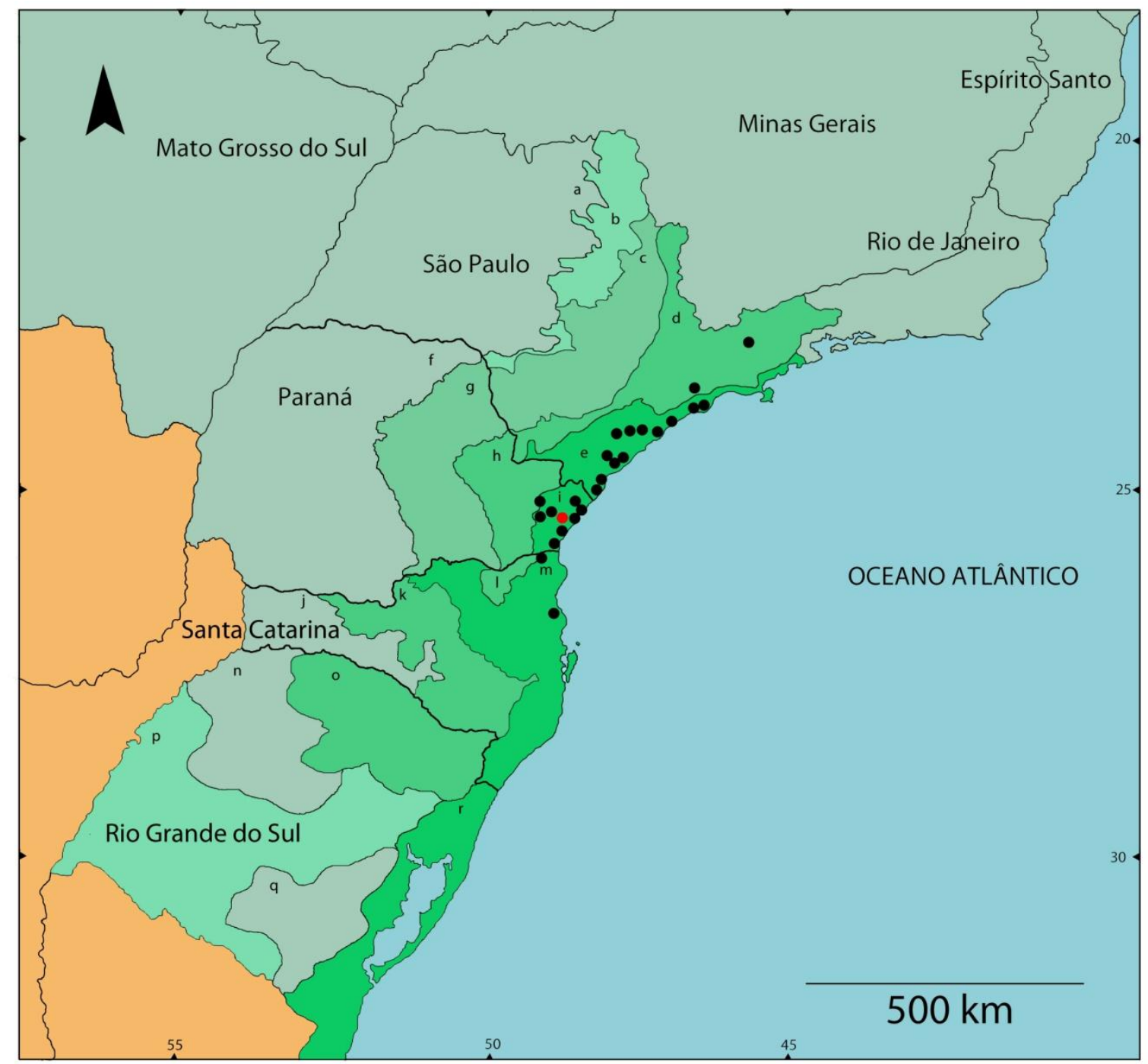

Figura 65. Distribuição geográfica do Megalobulimus paranaguensis. A partir dos lotes depositados no MZUSP. Localidade tipo: Paranaguá/PR (ponto vermelho). d: Planalto cristalino paulista; e: Planície costeira paulista; i: Planície costeira paranaense; m: Planície costeira catarinense.

\begin{tabular}{rr|rr}
\hline \multicolumn{1}{c}{ LOCALIDADE } & \multicolumn{1}{c}{ N. DE } & LOCALIDADE & N. DE \\
LOTES & 12 & Santos, SP & 2 \\
\hline Iguape, SP & 12 & Itanhaem, SP & 1 \\
Morretes, PR & 11 & Miracatu, SP & 1 \\
Guaratuba, PR & 9 & Registro, SP & 1 \\
Cananéia, SP & 8 & Ribeirão Pires, SP & 1 \\
Peruíbe, SP & 6 & Taubaté, SP & 1 \\
Antonina, PR & 5 & Guarequeçaba, PR & 1 \\
Paranaguá, PR & 5 & Ilha do Mel, PR & 1 \\
São João da Graciosa, PR & 3 & Superagui, PR & 1 \\
São Vicente, SP & 2 & Portal do Paraná, PR & 1 \\
Ilha do Cardoso, SP & 2 & Gavura, SC & 1 \\
Juquiá, SP & 2 & Itajaí, SC & 1 \\
\hline Pedro de Toledo, SP & 5
\end{tabular}

Tabela 2. Número de lotes de Megalobulimus paranaguensis por localidade na coleção do MZUSP 


\subsection{Megalobulimus granulosus (Rang, 1831)}

Helix (Cochlogena) granulosa Rang, 1831

Lista sinonímica vide Bequaert, 1948: 160-161. Complemento:

Strophocheilus (Megalobulimus) granulosus granulosus: Bequaert, 1948: 160-162, pl. 12, fig. 5; pl. 14, fig. 1; pl. 29, fig. 4; pl. 32, fig. 3.

Strophocheilus granulosus: Morretes, 1949:143.

Megalobulimus (Phaiopharus) granulosus: Morretes, 1952: 113; 1953: 65; Leme, 1971: 16; Oliveira \& Castro, 1979: [6].

Megalobulimus granulosus: Salgado \& Coelho, 2003: 157; Simone, 2006: 210, fig. 803 (síntipo). Thomé et al. 2007: 22.

Tipos: Síntipo - MNHN.

Localidade tipo: interior do Brasil.

Material examinado. BRASIL: MZSP 48510, 1 espécime (Zulibos \& Hanff leg., 1940), MZSP 98560, 1 concha, MZSP 64431, 1 espécime, MZSP 64425, 1 espécime. Paraná: Pinhão, Reserva Rio dos Touros, MZSP 48501, 2 conchas (A. P. Tramujas col., 27/xi/1991); Rio Branco do Sul, Morro da Tacaniça, MZSP 16560, 1 concha. Santa Catarina: Joinville, MZSP 7998, 2 conchas (1903), Rio Cachoeira (Sambaqui); Corupá (Colônia Hansa), MZSP 3245, 1 concha (W. Ehrhardt col., 1901); Luiz Alves, MZSP 29297, 3 conchas (C. N. Goffergé col., 1961); Piçarras, MZSP 15729, 2 conchas (Luederwaldt col., vii/1919), MZSP 16581, 22 conchas (L. Morretes col., ix/1948), MZSP 29286, 1 concha C. N. Goffergé col., ix/1987); Penha, MZSP 29284, 16 conchas (C. N. Goffergé col., ix/1987), Prainha, MZSP 48224, 3 conchas (17/ix/1948); Blumenau, MZSP 91211, 3 conchas (C. N. Goffergé leg.); Antônio Carlos (Alto Biguaçu), MZSP 29288, 2 conchas (M. Machado col., 25/x/1969); Florianópolis (Ilha de Santa Catarina), Morro das Pedras, MZSP 29293, 1 concha (R. Leal col., x/1967), Praia da Tapera (Sambaqui), MZSP 29289, 5 conchas (Pe. Rohz col.); São Bonifácio, (Rio Bonifácio, entre Tubarão e Santo Amaro), MZSP 16607, 2 conchas (E. Shaden col., 1941); Lauro Müller, MZSP 29283, 6 conchas (G. R. Kloss col., xii/1970). 


\section{CONCHA}

A concha (Figs. 66 e 67) apresenta forma oval-alongada com 5,3 voltas, imperfurada; com contorno convexo e saciforme a esquerda da columela; forte compressão dorsoventral; espira curta com base mais estreita e ápice mais anguloso que no $M$. paranaguensis. Periostraco caduco (Fig. 15) de coloração castanha claro com delicadas faixas radiais um pouco mais escuras. Concha neopiônica (Figs. 68 a 72) com 3,4 voltas discretamente convexas, a primeira volta lisa seguida por costelas regulares prosóclinas curvas apenas na sua origem de sutura a sutura com espaçamentos igual ou maior que sua largura que a partir da 2 1/2 começam a esmaecer na sutura inferior, estando praticamente ausentes no final da protoconcha. Foi observada uma grande variação dentro dos mesmos lotes quanto à espessura e intervalo das costelas neopiônicas. Suturas rasas podendo ocorrer banda subsutural amarelada. Microescultura com intensa granulação em linhas espirais por toda a protoconcha.

A penúltima e a volta-do-corpo são lisas com linhas de crescimento regulares, largas, baixas e espaçadas, com forte microescultura em linhas espirais que atingem o lábio, dando a concha com periostraco conservado um aspecto fosco. O perfil esquerdo da penúltima volta é convexo (vista dorsal).

O lábio interno se apresenta reto e a columela obliqua formando uma dobra na curta parede parietal. Ângulo do lábio externo e parede parietal $<90^{\circ}$. Abertura oval alongada com cerca da $1 / 2$ do comprimento. Perístoma refletido rosa claro e parede parietal arroxeada. 


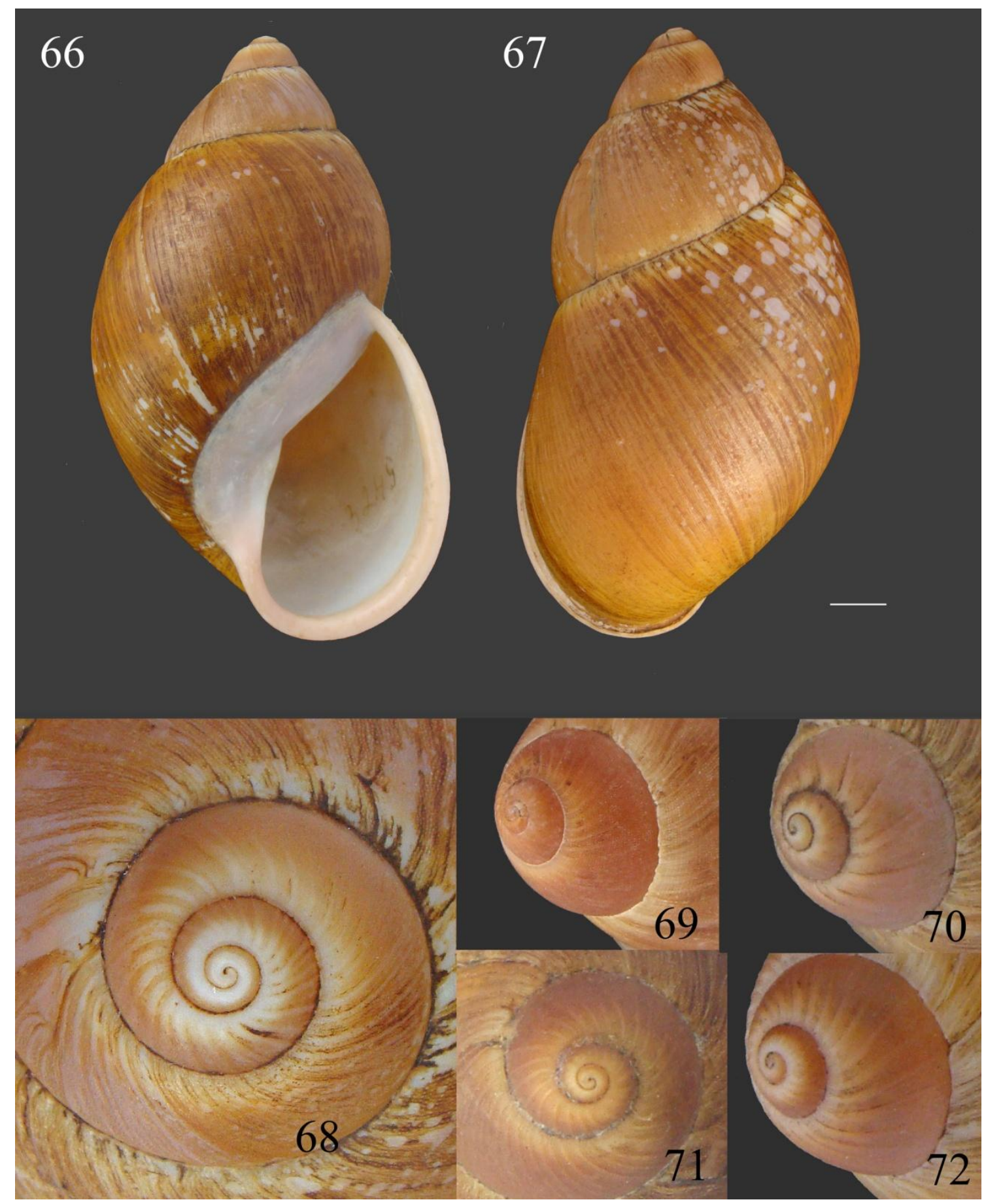

Figuras 66-72. Concha de Megalobulimus granulosus: 66. Vista frontal da concha do exemplar MZSP 3245 (Corucá, SC); 67. Mesmo exemplar em vista dorsal; 68. Mesmo exemplar em vista apical; 69. Protoconcha de um exemplar do lote MZSP 16581 (Piçarras, SC) com as costelas neopiônicas mais adensadas; 70. Protoconcha de um exemplar do lote 29288 (Biguaçu, SC) com costelas neopiônicas afastadas; 71. Vista apical de outro exemplar do lote anterior (MZSP 29288, Biguaçu, SC); 72. Protoconcha do mesmo exemplar. 
Os dados biométricos da concha de $M$. granulosus estão estatisticamente tratados condensados na tabela 3 .

\begin{tabular}{rrrrrr}
\hline & COMP. & LARG. & ALT. & $\begin{array}{c}\text { VOLTAS } \\
\text { PROTOCH. }\end{array}$ & $\begin{array}{c}\text { VOLTAS } \\
\text { TOTAIS }\end{array}$ \\
\hline $\mathbf{n}$ & 105 & 109 & 109 & 78 & 97 \\
$\mathbf{m a x}$ & 116 & 63 & 54 & 3.8 & 5.8 \\
$\mathbf{m i n}$ & 75 & 40 & 36 & 3.0 & 4.6 \\
$\mathbf{a m p l}$ & 41 & 23 & 18 & 0.8 & 1.1 \\
$\boldsymbol{\mu}$ & 93 & 50 & 43 & 3.4 & 5.3 \\
$\mathbf{m}$ & 92 & 50 & 43 & 3.4 & 5.3 \\
$\mathbf{D P}$ & 8 & 5 & 4 & 0.2 & 0.2 \\
$\mathbf{C V}$ & $8.2 \%$ & $9.7 \%$ & $8.9 \%$ & $5.7 \%$ & $3.7 \%$ \\
$\mathbf{p}$ & 0.2172 & 0.3084 & 0.1135 & 0.4195 & 0.3248 \\
\hline
\end{tabular}

Tabela 3. Biometria da concha de Megalobulimus granulosus. Legenda: n: tamanho da amostra; max: valor máximo; min: valor mínimo; ampl: amplitude; $\mu$ : média aritmética; m: mediana; DP: desvio padrão; CV (\%): coeficiente de variação em porcentagem; p: teste de normalidade de D'Agostino-Pearson (distribuição normal nos valores de $\mathrm{p}>0,05$ ).

Não obtivemos material fresco, mas os fixados sugerem que o M. granulosus tenha um tegumento de coloração clara como em M. paranaguensis, ao qual se assemelha em muitos caracteres.

\section{Manto e cavidade palial}

A borda do manto se apresenta semelhante à do $M$. paranaguensis em largura, espessura e do sulco mediano, porém não se observa seu afinamento e prega no lado esquerdo ao lado do músculo columelar. O reto e o ânus estão profundamente aderidos ao angulo posterior da cavidade palial (Fig. 76) fazendo com que o material fixado se rompa. A porção da goteira urinária sobre o intestino posterior limita-se a sua região media com discretas pregas longitudinais (Fig. 77). A goteira prolonga-se até a linha do ânus, continuando pelo sulco urinário externo e o canal lateral (Fig. 76). A região reno-pericárdica tem cerca de um 
terço de sua superfície coberto pelo plexo epirenal. O rim tem a forma alongada com cauda (Fig. 77) em sentido ao fundo da cavidade palial que nesta espécie prolonga-se por atrás do esôfago e intestino proximal (Fig. 81), sendo portanto, mais longa que em M. paranaguensis.

\section{Sistema digestivo}

A rígida mandíbula elasmognata apresenta nas laterais colunas axiais mais estreitas e com sulcos rasos, enquanto que na região central as colunas são proporcionalmente largas e bem marcadas (Fig. 73). Os dentes radulares, distribuídos em cerca de 100 fileiras afatadas entre si são unicúspides, de formato pentagonal e proporção $2: 1$, com uma estreita base e ápice obtuso que ocupa cerca de $1 / 4$ do comprimento (Figs. 74, 75). Apresentam uma bem desenvolvida "raiz" lateral com cerca da metade do comprimento do dente. Os dentes centrais mais estreitos apresentam uma crista média achatada que se prolonga posteriormente encaixando na base do dente posterior (Fig. 75).

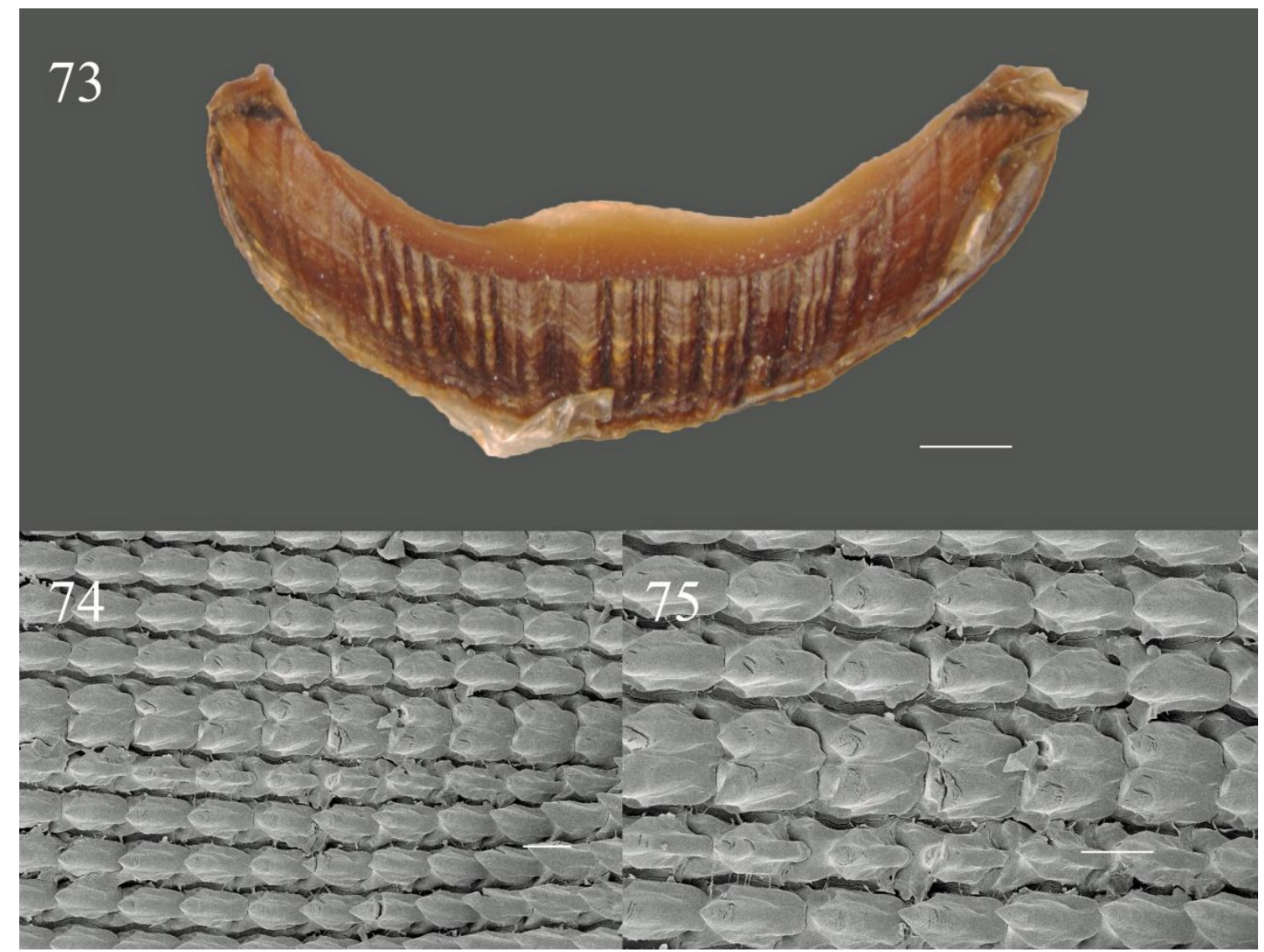

Figuras 73-75. Mandíbula e rádula de Megalobulimus granulosus: 73. mandíbula $($ ESCALA $=1 \mathrm{~mm}) ; 74$. Rádula $($ ESCALA $=0,1 \mathrm{~mm}) ; 75$. Detalhe da linha central de dentes $(\mathrm{ESCALA}=0,1 \mathrm{~mm})$. 
Apresenta uma massa bucal curta com a musculatura extrínseca $(\mathrm{m} 1)$ similar à espécie anterior. Na sua face ventral é distinguível uma faixa muscular extrínseca transversal (m3) e uma bem desenvolvida cinta muscular mandibular (Fig. 78: cd), enquanto que diferentemente da espécie anterior, a artéria radular (ar) origina-se diretamente da artéria cefálica (ac). O m2 tem aspecto fibroso e se insere na massa bucal de forma fasciculada. Internamente o odontóforo apresenta um largo $m 7$ que após se inverter forma uma borda ao redor da borda superior da rádula. Em outros aspectos, o odontóforo assemelha-se plenamente a descrição da espécie anterior.

As aberturas das glândulas salivares e o esôfago apresentam respectivamente a mesma localização e compartimentação que $M$. paranaguensis, tendo o segmento anterior do esôfago uma parede fina, translúcida e distensível, enquanto os outros dois segmentos apresentam pregas longitudinais com a parede mais espessa no segmento médio onde há uma camada de fibras musculares circulares na sua parede (Fig. 80). Dois ductos provenientes da glândula digestiva anterior e de igual calibre desembocam na abertura no lado esquerdo do esôfago posterior próximo a entrada do estômago, onde se origina o tiflossole intestinal (Figs. 80 e $81)$.

O estômago (Figs. 82, 83) de forma de cubo apresenta uma parede muscular espessada com a inserção dorsal do ducto da glândula digestiva posterior. Internamente desta abertura originam-se o tiflossole intestinal e um largo canal intestinal entre o tiflossole e a musculatura pilórica mais volumosa no lado direito do órgão (Figs. 82, 83). Pregas musculares ocupam o restante da superfície interna gástrica.

O intestino proximal apresenta um intervalo liso ampliado entre as pregas p1 e p2 (Fig. 84). Nas pregas pós-valvulares observa-se o mesmo padrão que o $M$. paranaguensis com as pregas p7 espessadas a $45^{\circ}$ com a prega p6 (Fig. 85) formando em suas intersecções uma discreta prega longitudinal.

\section{Sistema Reprodutor}

O sistema reprodutivo (Fig. 86) assemelha-se ao M. paranaguensis, diferenciando-se pelo Carrefour na região proximal do hilo da glândula de albume com um tálom pouco destacável do saco glandular anexo (Fig. 88), em compensação no espermoviduto a próstata 
parece ser facilmente destacável do conjunto (Fig. 86). Assim como no M. paranaguensis as pregas musculares internas do oviduto livre estão paralelas e longitudinais ao órgão e não direcionadas para o óstio do ducto da bursa (Fig. 87).

O ramo masculino apresenta forma fusiforme, com o epifalo tendo um comprimento maior que a metade do pênis e não apresenta flagelos (Figs. 86, 89, 90). Internamente observa-se no ápice peniano uma bem desenvolvida prega transversal (Fig. 89, 90), que assume uma forma peduncular. 


\section{2}

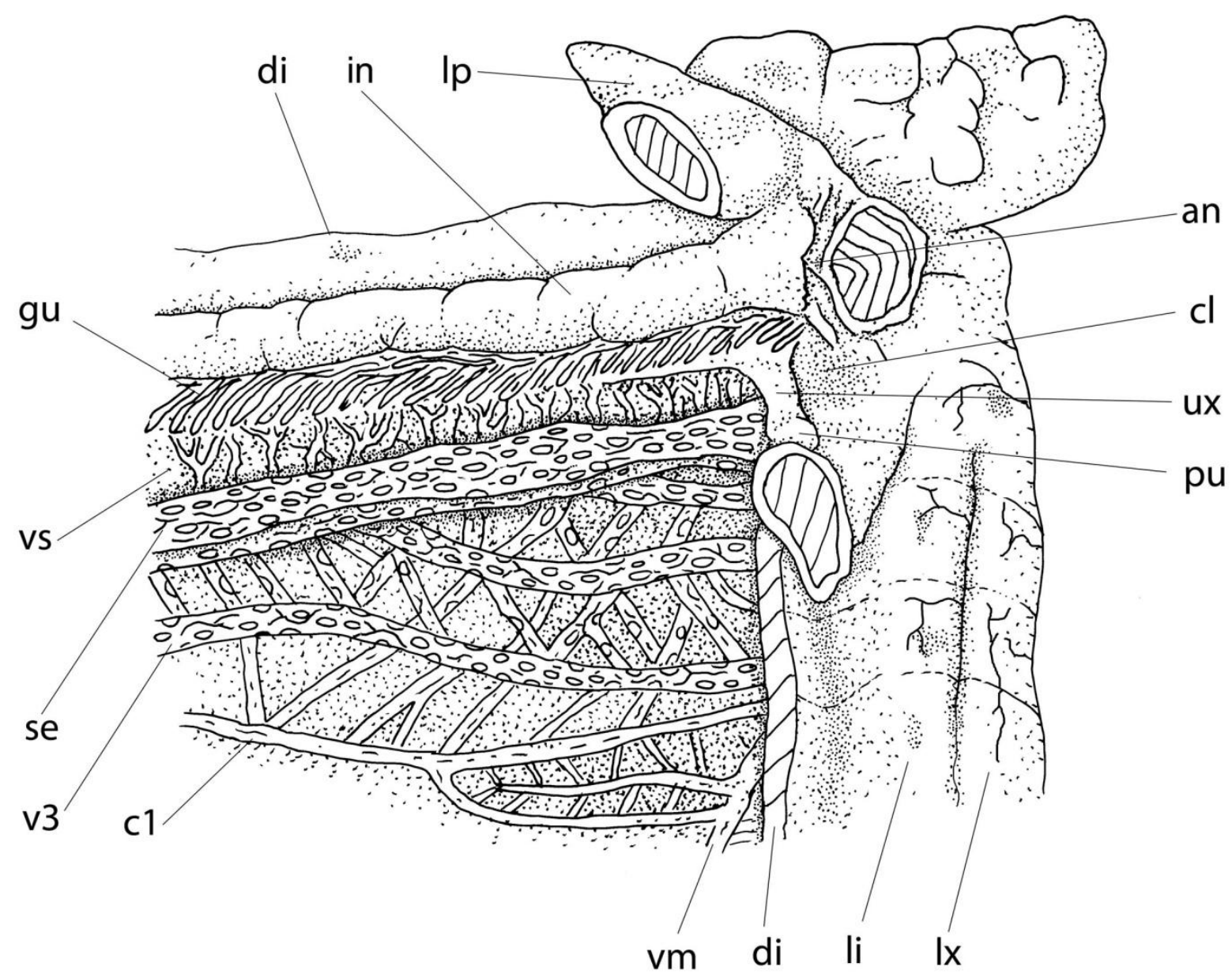

$5 \mathrm{~mm}$

Figura 76. Megalobulimus granulosus: Região distal do septo e pneumóstoma. an: ânus; c1: ramificação do vaso pericárdico; cl: canal lateral; di: diafragma; gu: goteira urinária; in: intestino; li: lábio interno da borda do manto; lp: lábio do pneumóstoma; lx: lábio externo da borda do manto; pu: prega do sulco urinário; se: septo; ux: sulco urinário externo; v3: ramificação da veia pulmonar; vm: veia marginal ou colar; vs: vasos ad-retais. 


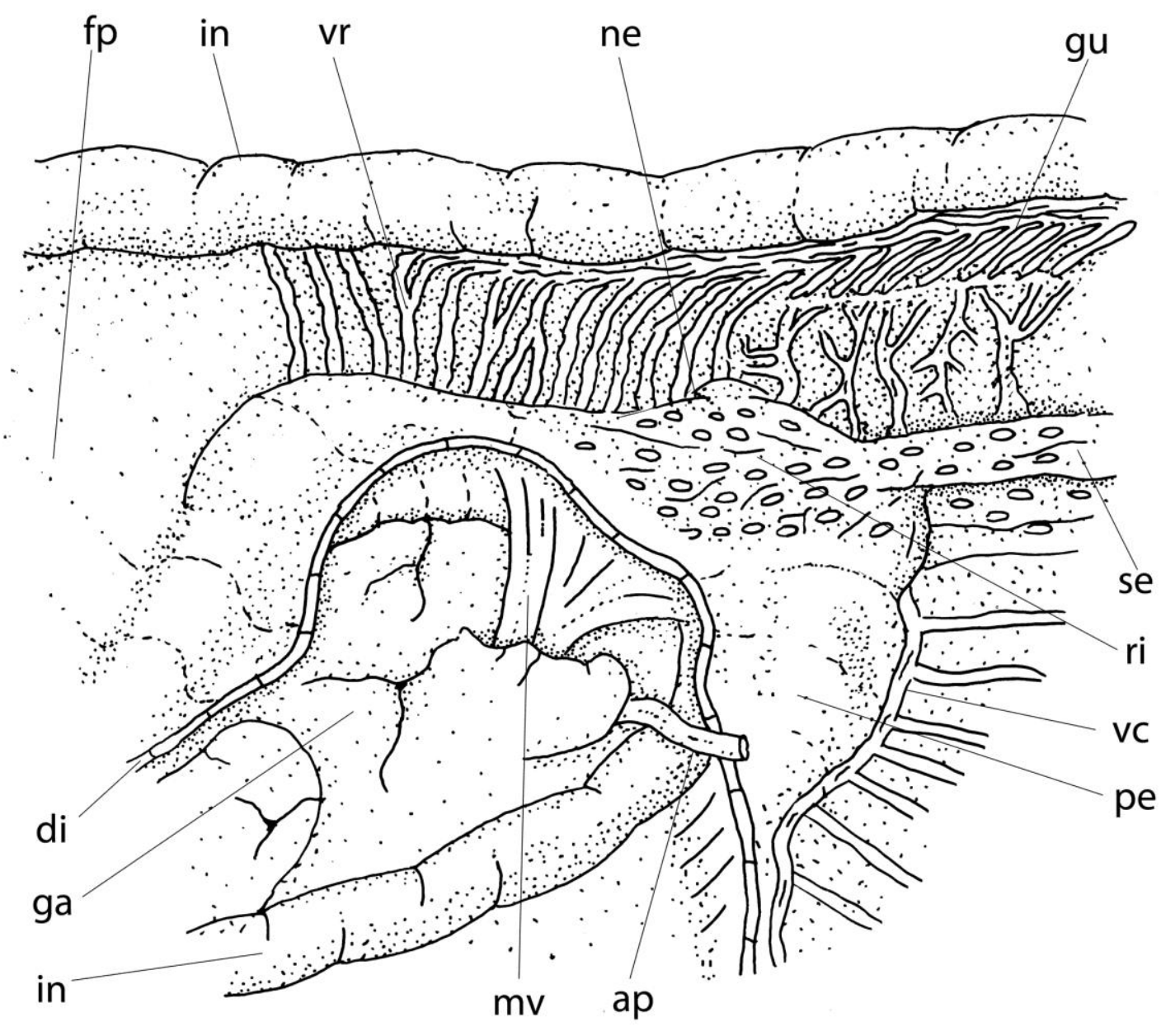

$\overline{5 \mathrm{~mm}}$

Figura 77. Região reno-pericárdica de Megalobulimus granulosus. aa: aorta anterior; ap: aorta posterior; di: diafragma; fp: fundo da cavidade palial; ga: glândula digestiva anterior; gu: goteira urinária; in: intestino; mv: feixe muscular palio-diafragmático; ne: nefróstoma; pe: pericárdio; px: plexo epi-renal; ri: rim; rp: orifício reno-pericárdico; se: septo; vc: vaso pericárdico; ve: ventrículo; vr: vasos ad-renais; vs: vasos ad-retais. 


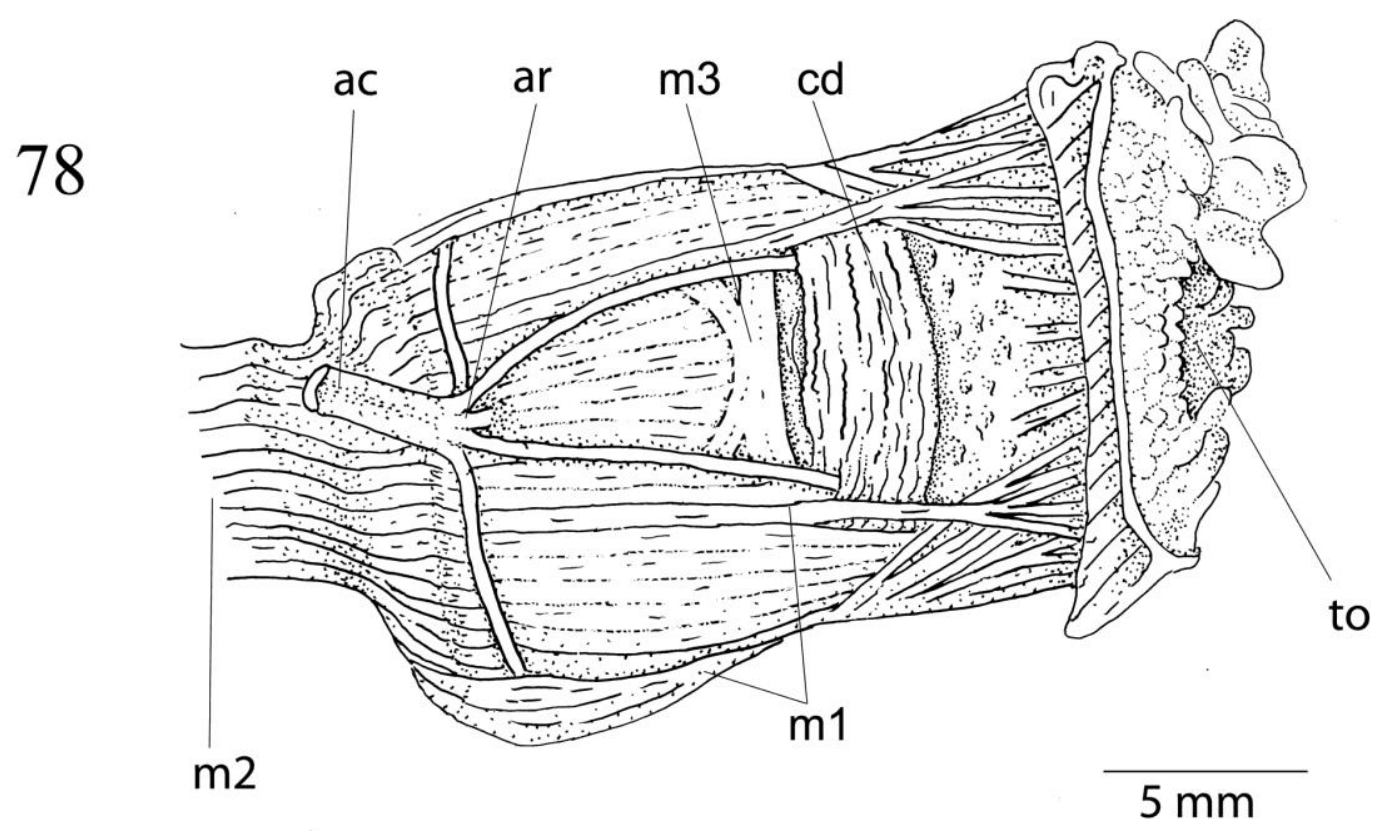

79

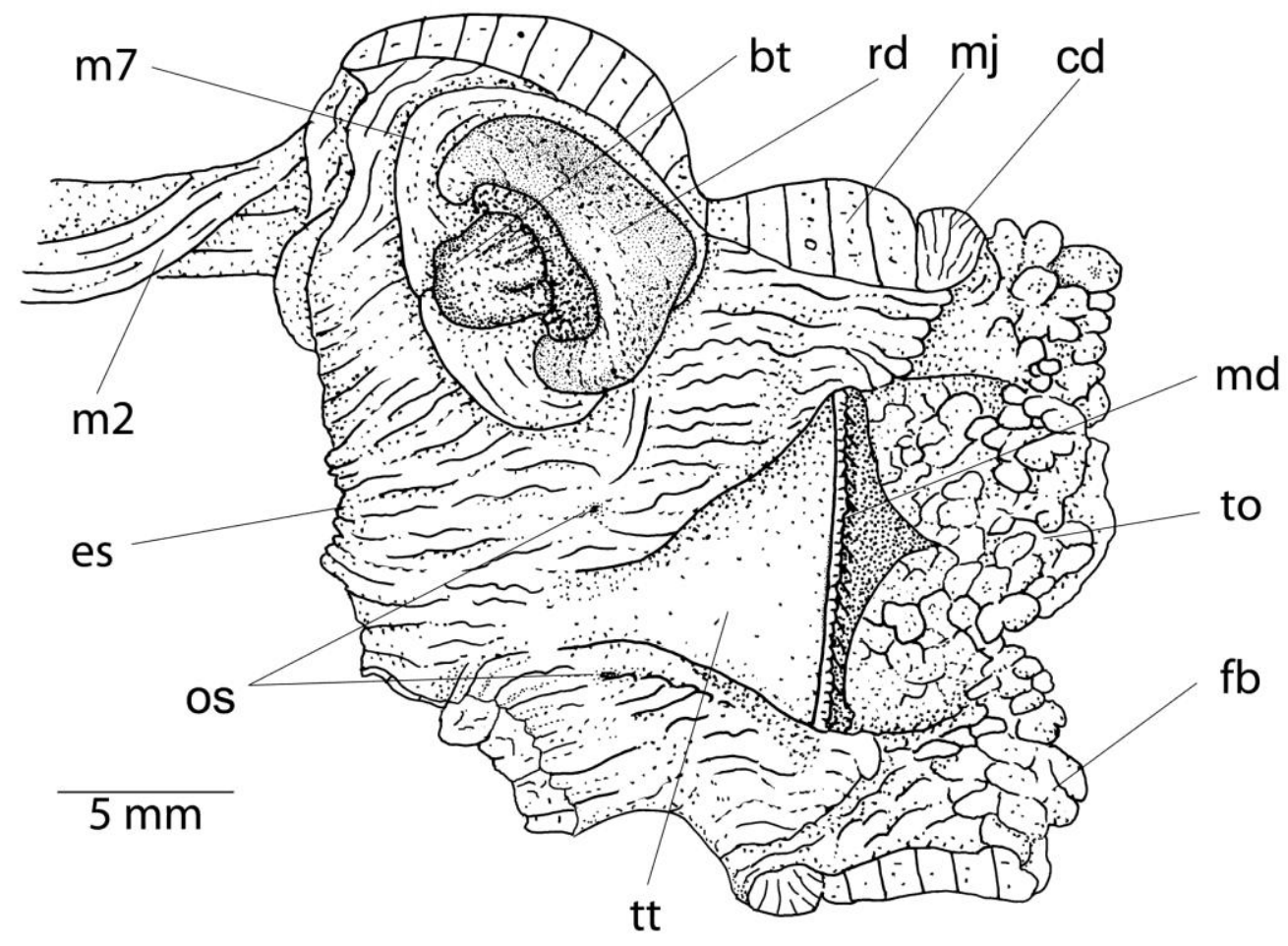

Figuras 78, 79. Massa bucal de Megalobulimus granulosus: 78. Vista ventral da massa bucal; 79. Massa bucal aberta. ac: artéria cefálica; ar: artéria radular; bt: bonete da rádula; cd: cinta muscular da mandíbula; es: esôfago; fb: franja bucal; m2: músculo retrator da massa bucal; m1: músculos extrínsecos longitudinais; m3: músculo extrínseco transverso; m7: músculo núcleo radular; md: mandíbula; mj: músculo mandibular; os: óstios das glândulas salivares; rd: rádula; to: tubo oral; tt: teto da massa bucal. 


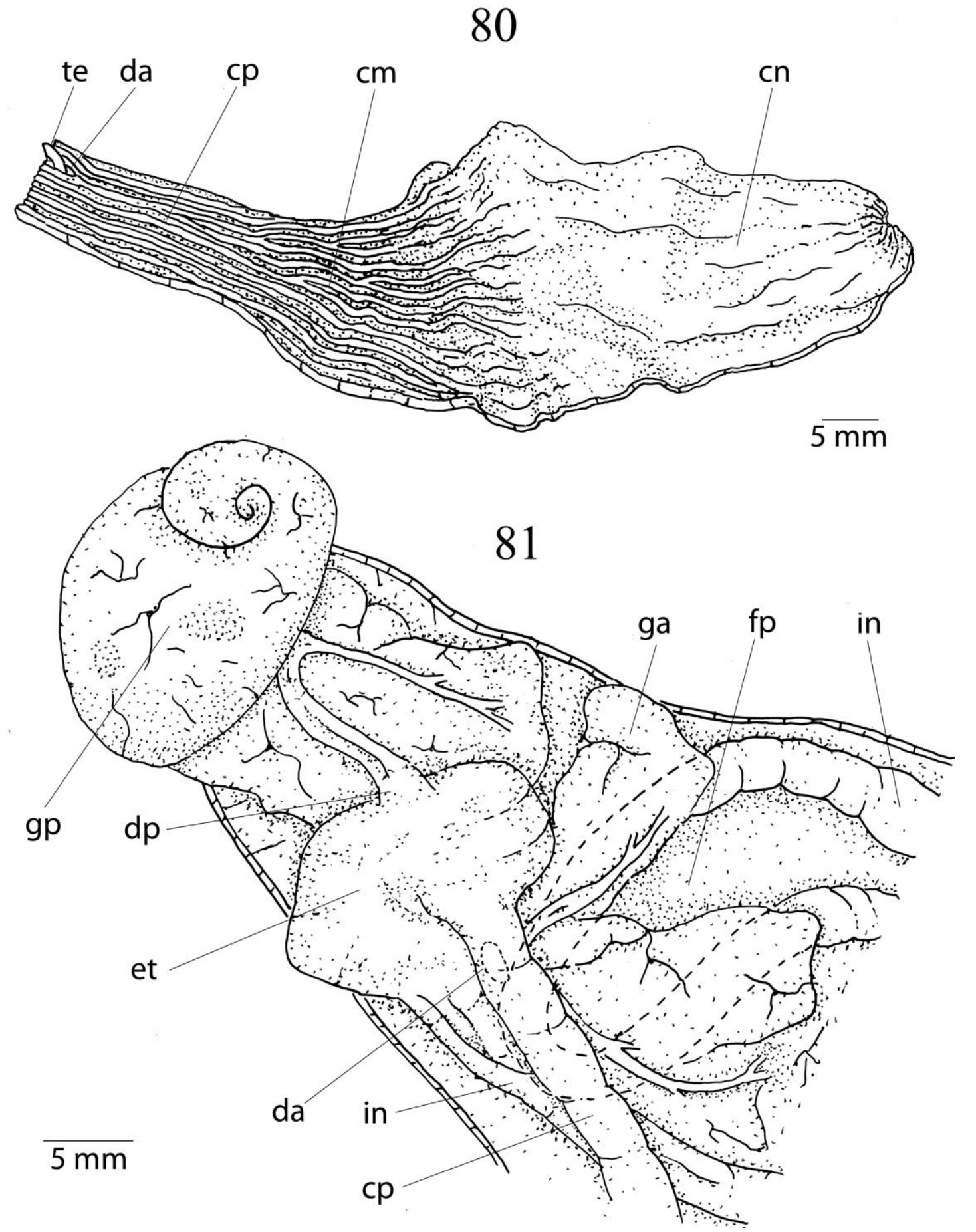

Figuras 80, 81. Sistema digestivo de Megalobulimus granulosus: 80. Esôfago aberto longitudinalmente; 43. Sistema digestivo na hemocele visceral após remoção do sistema reprodutivo, lado direito. cm: câmara média do esôfago; cn: câmara anterior do esôfago; cp: câmara posterior do esôfago; da: ducto para a glândula digestiva anterior; dp: ducto para a glândula digestiva posterior; et: estômago; fp: fundo da cavidade palial; ga: glândula digestiva anterior; gp: glândula digestiva posterior; in: intestino; te: tiflossole esofágico. 


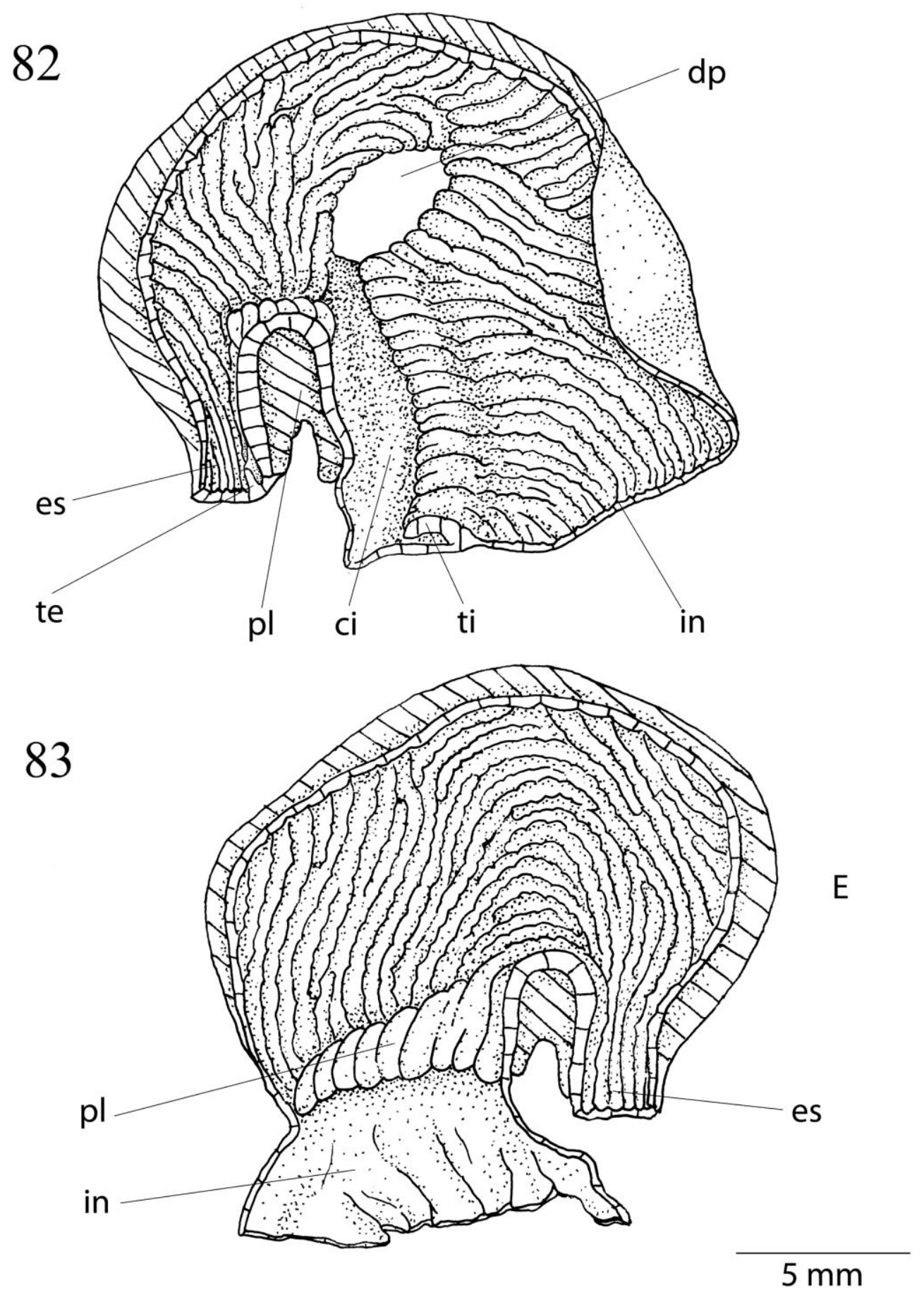

Figuras 82, 83. Estômago de Megalobulimus granulosus: 82: Superfície interna do lado direito; 83: Superfície interna do lado esquerdo. ci: canal intestinal; dp: ducto para a glândula digestiva posterior; es: esôfago; in: intestino; pl: musculatura do piloro; te: tiflossole esofágico; ti: tiflossole intestinal. 


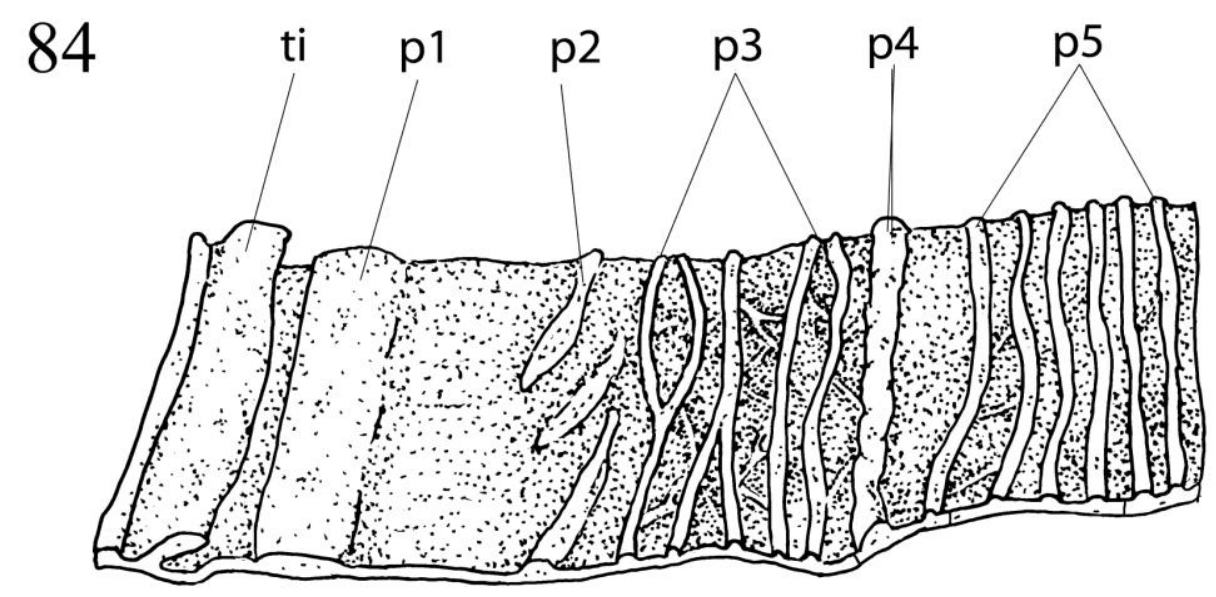

$2 \mathrm{~mm}$

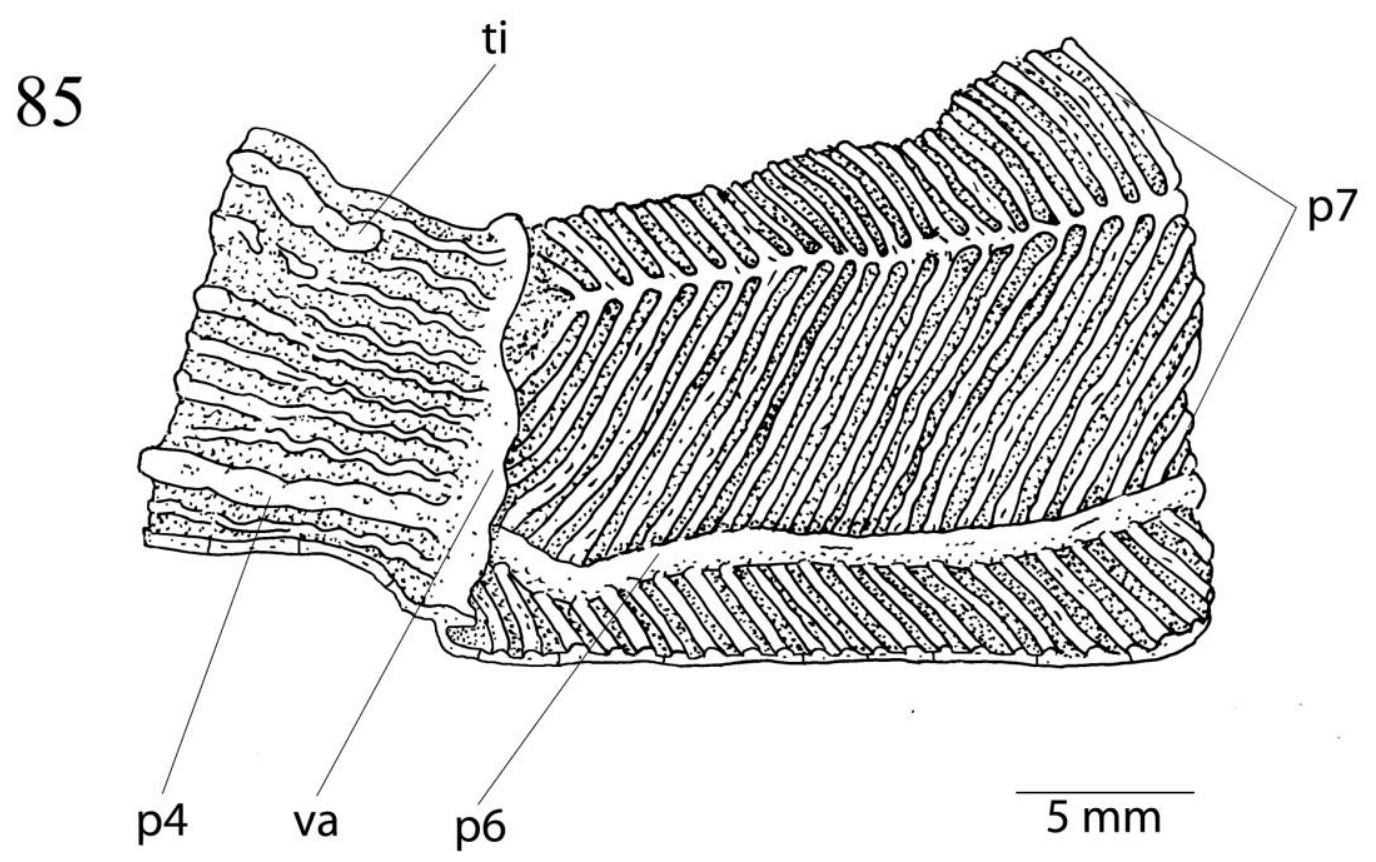

Figuras 84, 85. Sistema digestivo de Megalobulimus granulosus: 84. Superfície interna do intestino proximal; 85. Válvula pré-retal aberta longitudinalmente. p1, p2, p3, p4 e p5: pregas intestinais prévalvulares; $\mathbf{p 6}$ e p7: pregas intestinais pós-valvulares; ti: tiflossole intestinal; va: válvula pré-retal. 

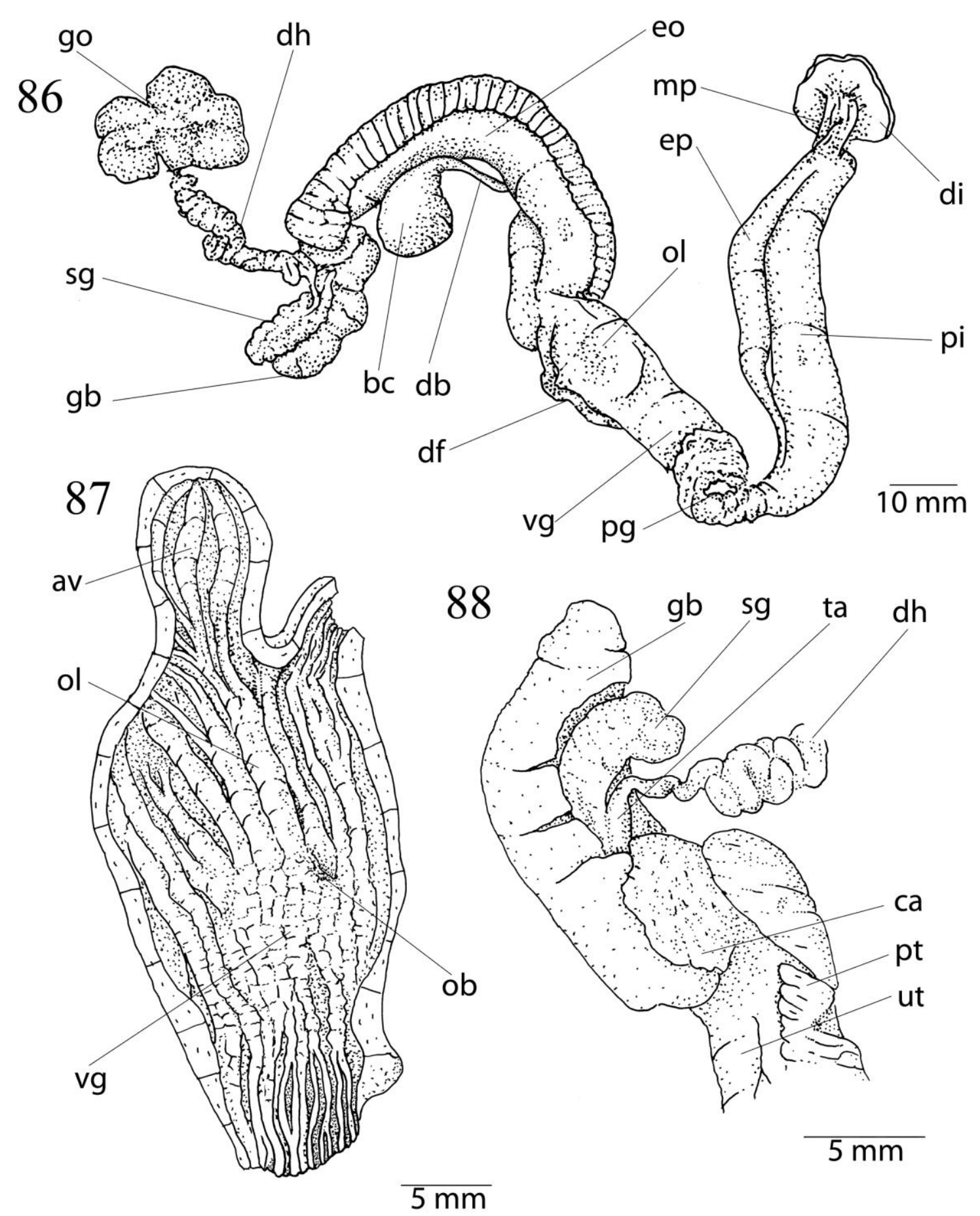

Figuras 86-88. Sistema reprodutivo de Megalobulimus granulosus. 86. Sistema reprodutor em vista direita; 87. Oviduto livre e vagina abertos longitudinalmente; 88. Carrerfour em vista lateral. av: apêndice vaginal; bc: bursa copulatrix (bolsa copulatória); ca: câmara de albume; db: ducto da bursa; df: canal deferente; dh: ducto hermafrodita; ep: epifalo; eo: espermoviduto; gb: glândula de albume; go: gônada; ep: epifalo; gb: glândula de albume; go: gônada; mp: músculo peniano; ob: óstio do ducto da bursa; ol: oviduto livre; pg: poro genital; pi: pênis; pt: próstata; sg: saco glandular anexo; ta: tálamo; ut: útero 


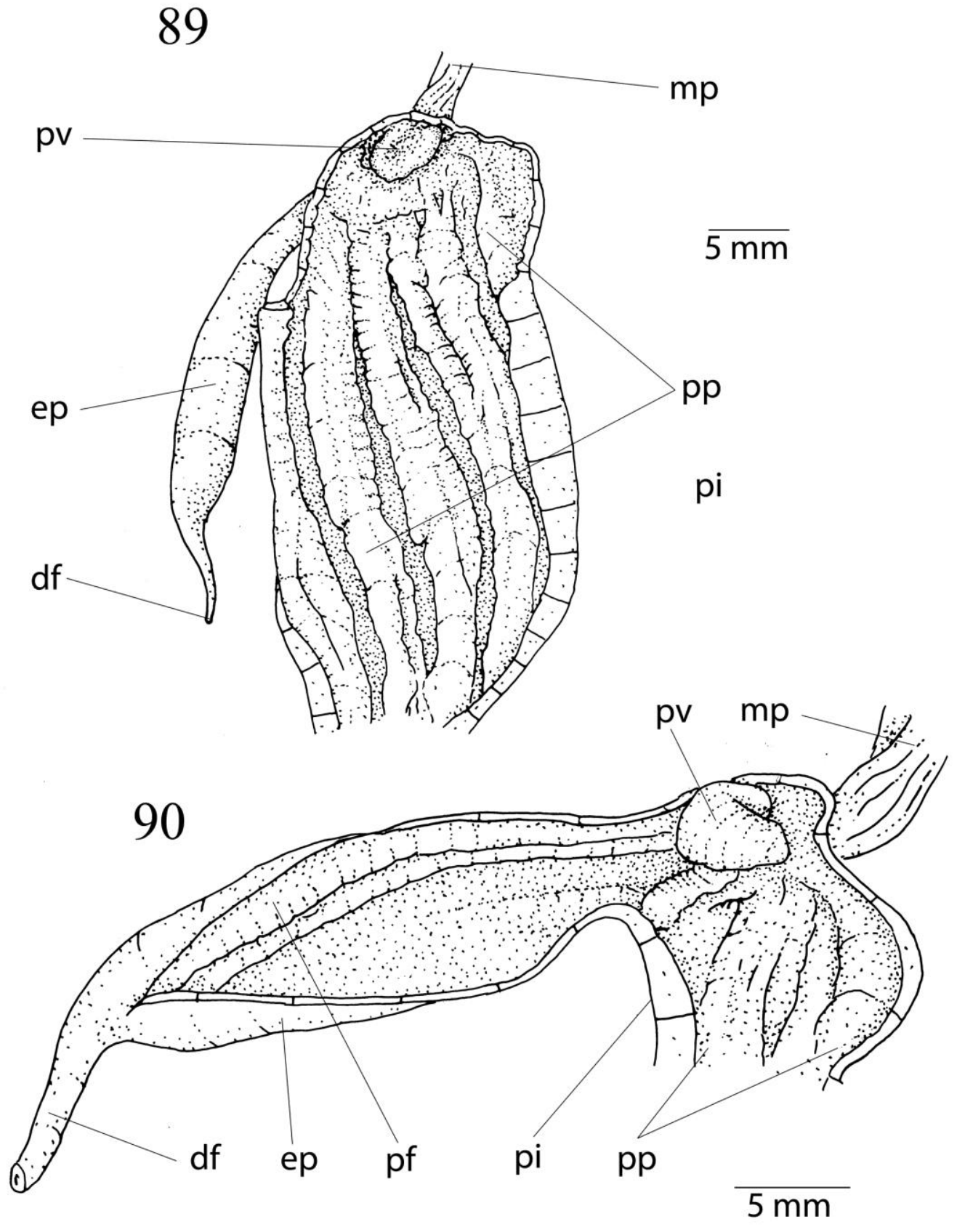

Figuras 89, 90. Sistema reprodutivo de Megalobulimus granulosus: 89. Pênis seccionado longitudinalmente; 90. Ápice peniano e epifalo seccionados longitudinalmente 155. Complexo peniano aberto longitudinalmente. df: canal deferente; ep: epifalo; fl: flagelos; mp: músculo peniano; pi: pênis; pf: prega do epifalo; pp: pregas penianas; pv: prega transversal do pênis. 


\section{DISTRIBUIÇÃO GEOGRÁFICA}

Rang (1831) registrou como localidade tipo as matas no interior do Brasil. Hidalgo (1869) identificou-a na ilha de Ratones Grande, no canal da ilha de Florianópolis, SP onde descreve como abundante entre a vegetação. Esta ilha foi visitada durante a realização desta dissertação em 2011, mas sem sucesso na localização de M. granulosus em contraste com a presença de uma população oportunista de gambás (Didelphis sp.) que, introduzidos, devem ter suprimido os caracóis.

A forte granulação na concha de Megalobulimus bronni, com ocorrência nas serras ao sul do Estado de Minas Gerais, fez com que esta última espécie fosse confundida com o $M$. granulosus sendo erroneamente publicada como tal por Pilsbry (1896) e Oliveira et al. (1984).

Bequaert (1948), baseado apenas em caracteres conquiliológicos, reconhece a sua ocorrência para Cuiabá, MT; Iguape, SP; e em Imbituba e Corupá, SC. Thomé et al. (2007) e Morretes (1953) restringem a ocorrências para o Estado de Santa Catarina, citando o último, São Bonifácio, Piçarras e a ilha de Ratones. Colley (2008) registra sua ocorrência em Antonina, PR.

Dos 28 lotes da coleção do MZSP identificados como M. granulosus (Tab. 4), 24 tinham procedência e delimitaram uma distribuição na planície costeira de Santa Catarina, concentrando-se ao norte entre São Francisco do Sul e Florianópolis (Fig. 91). Esta região é reconhecida geomorfologicamente como o "macrocompartimento litoral das escarpas cristalinas sul" e caracterizado por um litoral recortado com afloramentos de rochas cristalinas pré-cambrianas interrompendo a continuidade da planície costeira (Dieter, 1998).

\begin{tabular}{|c|c|c|c|}
\hline LOCALIDADE & $\begin{array}{c}\text { N. DE } \\
\text { LOTES }\end{array}$ & LOCALIDADE & $\begin{array}{c}\text { N. DE } \\
\text { LOTES }\end{array}$ \\
\hline s/ procedência & 4 & Florianópolis, SC & 2 \\
\hline Piçarras, SC & 3 & Santo Antônio, SC & 2 \\
\hline Luiz Alves, SC & 3 & Pinhão, PR & 1 \\
\hline Blumenal, SC & 3 & Lauro Miller, SC & 1 \\
\hline São Franscico do Sul, SC & 2 & Penha, SC & 1 \\
\hline Joinville, SC & 2 & Alto Biguaçu, SC & 1 \\
\hline Corucá, SC & 2 & Cerro Largo, RS & 1 \\
\hline
\end{tabular}

Tabela 4. Número de lotes de Megalobulimus granulosus por localidade na coleção do MZSP. 


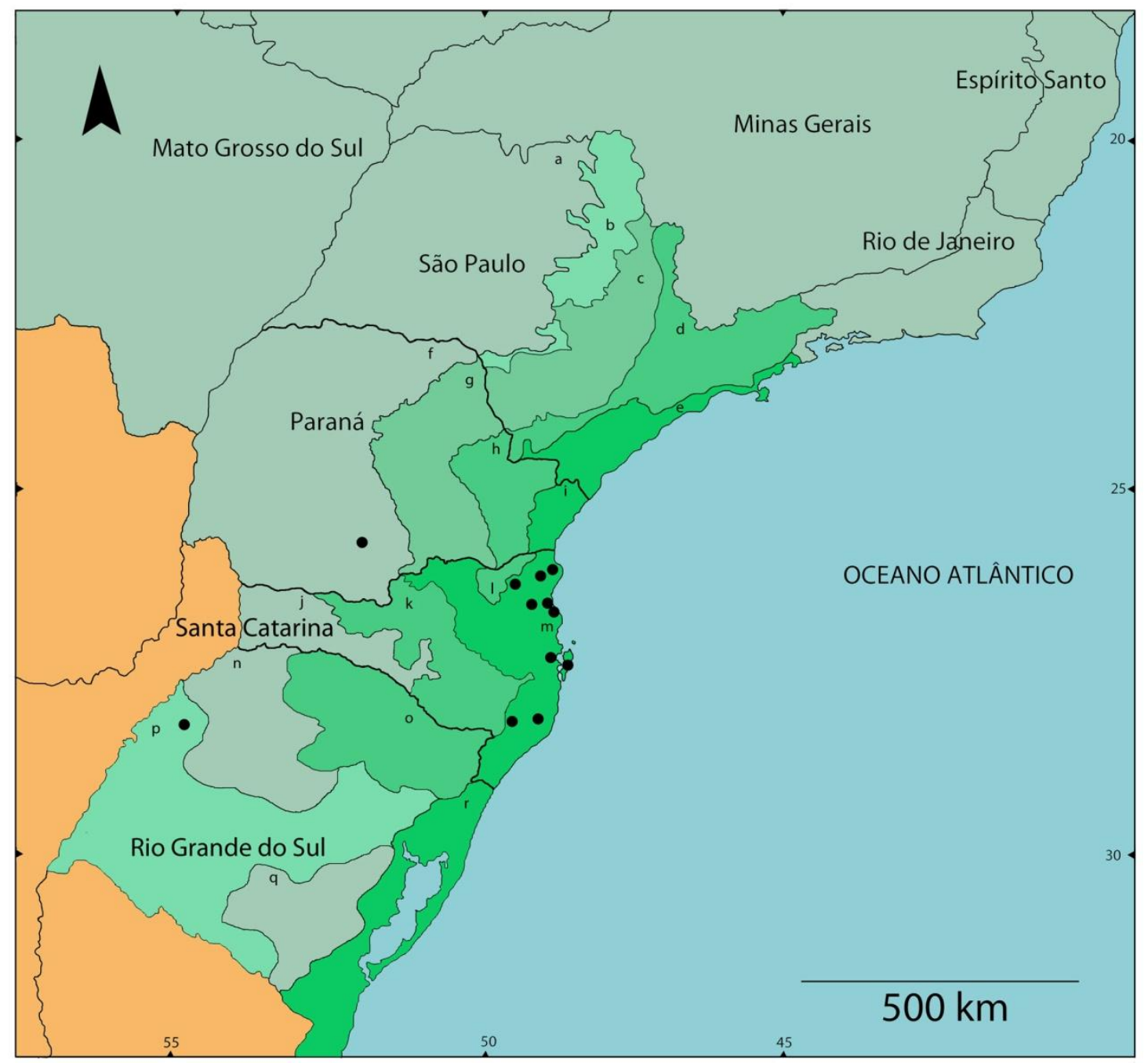

Figura 91. Distribuição geográfica do Megalobulimus granulosus a partir dos lotes depositados no MZSP. Localidade tipo: interior do Brasil. f: Planalto basáltico paranaense; m: Planície costeira catarinense; p: Depressão central rio-grandense. 


\subsection{Megalobulimus abbreviatus (Bequaert, 1948)}

Strophocheilus (Megalobulimus) granulosus abbreviatus Bequaert, 1948: 164, pl. 27, fig. 4 (holótipo).

Megalobulimus (Phaiopharus) abbreviatus: Morretes, 1953: 65; 1954: 112; Leme, 1971: 16

Megalobulimus abbreviatus: Salgado \& Coelho, 2003: 157. Simone, 2006: 206, fig. 779 (parátipo). Thomé et al. 2004: 6; Thomé et al. 2007: 22.

Tipos: Holótipo - MCZ 49537, Parátipos - MCZ 175337, 62291, 179231(2); MZSP 14612

Localidade tipo: BRASIL, RS; Rio Grande, SP.

Material examinado. BRASIL. São Paulo. Rio Grande, MZSP 14612 (Parátipo), 1 concha; Santa Catarina. Laguna, MZSP 105521, 1 espécime (M. Guedes col., xii/2010). Rio Grande do Sul. MZUSP 48235, 1 concha; Caxias do Sul. MZSP 29079, 3 espécimes (A. Machioro col., 19/vii/1993); Taquara. MZSP 16183, 13 conchas (Exp. MZSP col., 24/vii/1965), Gruta da Glória, MZSP 29258, 2 conchas (J. W. Thomé leg.); São Leopoldo. MZSP 29259, 4 conchas (P. H. Heser col.), MZSP 29260, 11 conchas (C. Valle col.); Porto alegre, MZSP 16539, 1 conchas (B. L. de Morretes col., 05/xi/1952), MZSP 29242, 9 conchas (S. Andrade col., x/1967), Viamão (Parque Hilaire), MZSP 29261, 10 conchas (J. W. Thomé leg.), Viamão (Parque Hilaire), MZSP 29262, 22 conchas (J. W. Thomé leg.), Viamão (Parque St. Hilaire), MZSP 29263, 51 conchas (J. W. Thomé leg.), Viamão (Parque St. Hilaire), MZSP 29264, 10 conchas (J. W. Thomé leg.), Viamão (Parque St. Hilaire), MZSP 29265, 4 conchas (J. W. Thomé leg.), Viamão (Parque Hilaire), MZSP 29266, 4 conchas (J. W. Thomé leg.), MZSP 44299, 16 conchas (Museu de Ciências PUCRGS, Andrade col., x/1967), margem do rio Guaíba, MZSP 98233, 2 conchas (Z. R. Ortir col., xi/1970); 


\section{CONCHA}

A concha (Figs. 92-95) apresenta forma oval com 5,4 voltas, imperfurada; com contorno fortemente convexo e saciforme a esquerda da columela; compressão latero-lateral; espira curta, larga, arredondada ; abertura sub-ovalada. Periostraco caduco de coloração castanho amarelada com faixas radiais escuras muito semelhante ao M. paranaguensis.

Concha neopiônica (Figs. 96, 97) com 3,3 voltas discretamente convexas, com aparecimento das costelas neopiônicas prosóclinas a partir da segunda volta, mais largas que M. paranaguensis, bem marcadas e adensadas com espaçamento ampliado entre a 2 e $2 \frac{1}{2} 2$ voltas. Costelas acessórias que não atingem a sutura inferior ou dicotomias das costelas podem ser observadas. A partir da $2 \frac{1}{2}$ voltas no seu terço distal as costelas se alargam e esmaecem. Microescultura (Fig. 97) como nas espécies anteriores com granulação em linhas espirais por toda a protoconcha.

Penúltima volta e a volta-do-corpo com linhas de crescimento regulares, planas e com bordos arredondados com intervalo menor que sua espessura, e que podem se dicotomizar e se fundir. Microescultura em linhas espirais bem mais espaçadas sendo obsoletas na teleoconcha. O perfil esquerdo da penúltima volta é convexo (vista dorsal). Lábio interno curto com a columela reta formando um vinco na parede parietal. Lábio externo formando ângulo $>90^{\circ}$ com a parede parietal Abertura menor que $1 / 2$ do comprimento. Perístoma refletido com coloração variando de rosa a vinho. 


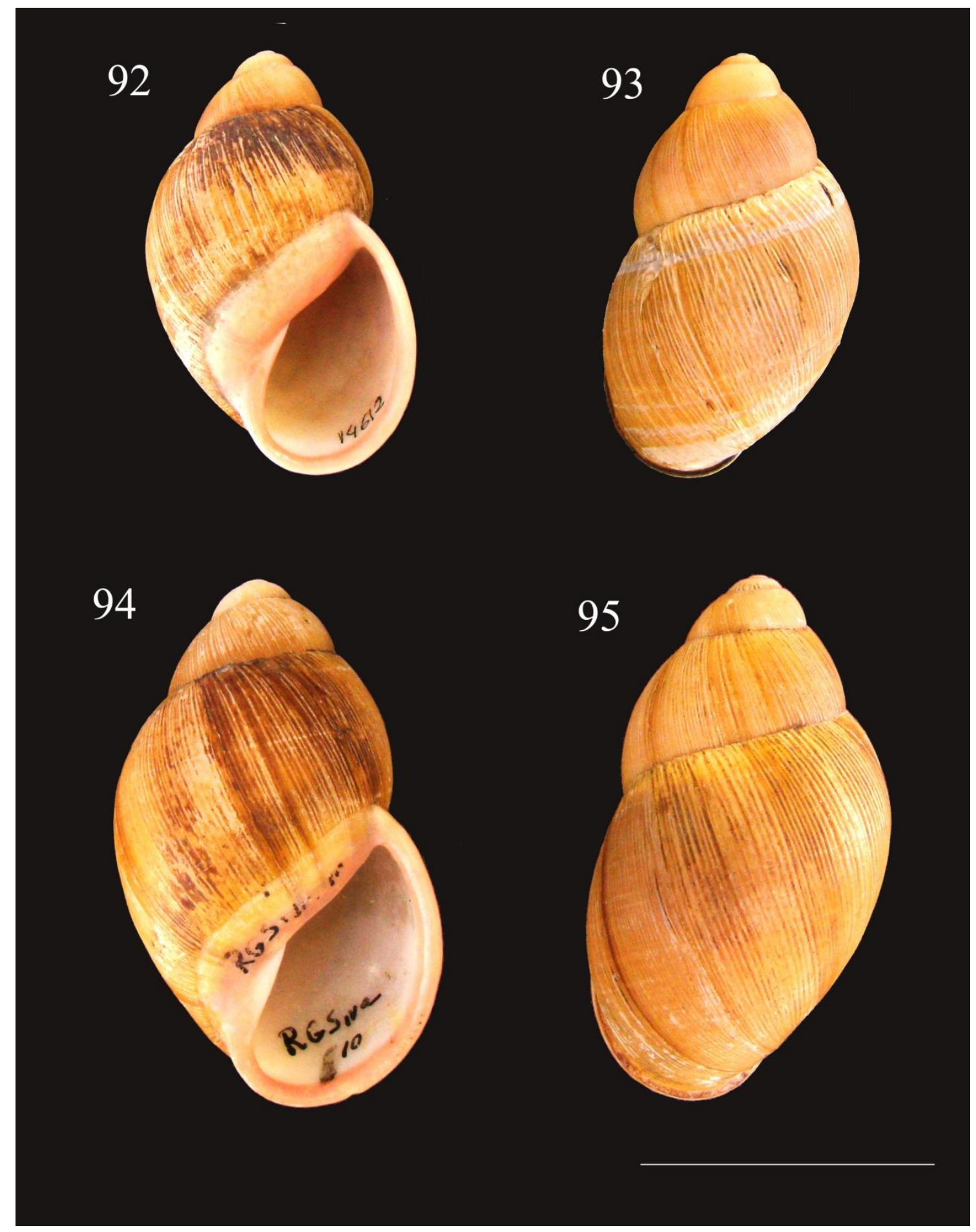

Figuras 92-95. Concha de Megalobulimus abbreviatus: 92 . Vista frontal da concha do parátipo MZSP 14612 (Rio Grande, SP); 93. Mesmo exemplar em vista dorsal; 94. Vista frontal de um exemplar do lote 29262 (Porto Alegre, RS); 94. Mesmo exemplar em vista dorsal. (ESCALA = 50 $\mathrm{mm})$. 


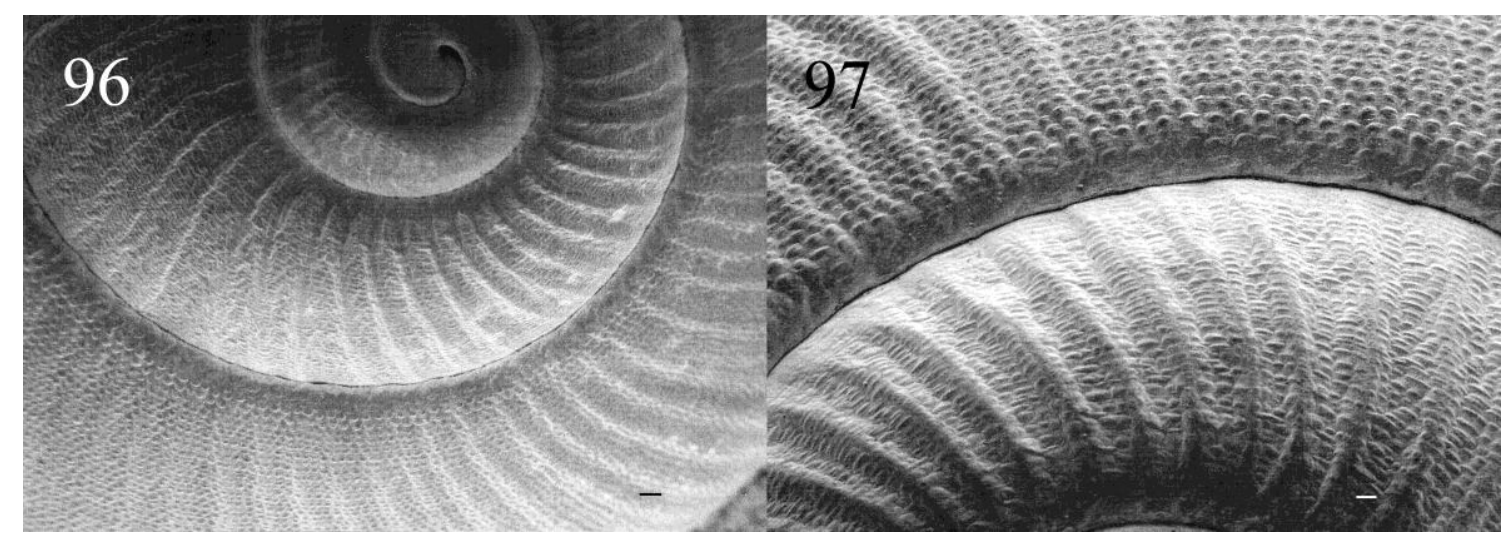

Figuras 96, 97. Protoconcha de Megalobulimus abbreviatus: 96. Vista apical da protoconcha $($ ESCALA $=0,2 \mathrm{~mm}), 97$. Detalhe da escultura $($ ESCALA $=0,1 \mathrm{~mm})$.

Os dados biométricos da concha de Megalobulimus abbreviatus estão estatisticamente tratados condensados na tabela 5 .

\begin{tabular}{rrrrrr}
\hline & COMP. & LARG. & ALT. & $\begin{array}{c}\text { VOLTAS } \\
\text { PROTOCH. }\end{array}$ & $\begin{array}{c}\text { VOLTAS } \\
\text { TOTAIS }\end{array}$ \\
\hline $\mathbf{n}$ & 148 & 148 & 148 & 111 & 142 \\
$\mathbf{m a x}$ & 87 & 52 & 44 & 3.8 & 5.9 \\
$\mathbf{m i n}$ & 64 & 35 & 32 & 3.0 & 4.9 \\
$\mathbf{a m p l}$ & 23 & 17 & 12 & 0.8 & 1.0 \\
$\boldsymbol{\mu}$ & 76 & 43 & 37 & 3.3 & 5.4 \\
$\mathbf{m}$ & 76 & 43 & 37 & 3.3 & 5.4 \\
$\mathbf{D P}$ & 5 & 3 & 2 & 0.2 & 0.2 \\
$\mathbf{C V}(\boldsymbol{\%})$ & $7.0 \%$ & $6.7 \%$ & $6.2 \%$ & $5.3 \%$ & $3.9 \%$ \\
$\mathbf{p}$ & 0.1480 & 0.3522 & 0.5274 & 0.3387 & 0.3803 \\
\hline
\end{tabular}

Tabela 5. Biometria da concha de Megalobulimus abbreviatus. Legenda: n: tamanho da amostra; max: valor máximo; min: valor mínimo; ampl: amplitude; $\mu$ : média aritmética; m: mediana; DP: desvio padrão; CV (\%): coeficiente de variação em porcentagem; p: teste de normalidade de D’Agostino-Pearson (distribuição normal nos valores de $\mathrm{p}>0,05)$.

ANATOMIA

\section{Massa céfalo-pediosa}

Em M. abbreviatus o tegumento apresenta o característico padrão geométrico com uma coloração cinza amarronzada com a borda da sola amarelada (Figs. 98, 99). Apresenta 
como os outros Megalobulimus dois pares de apêndices cefálicos com a franja bucal se projetando lateralmente do par inferior.

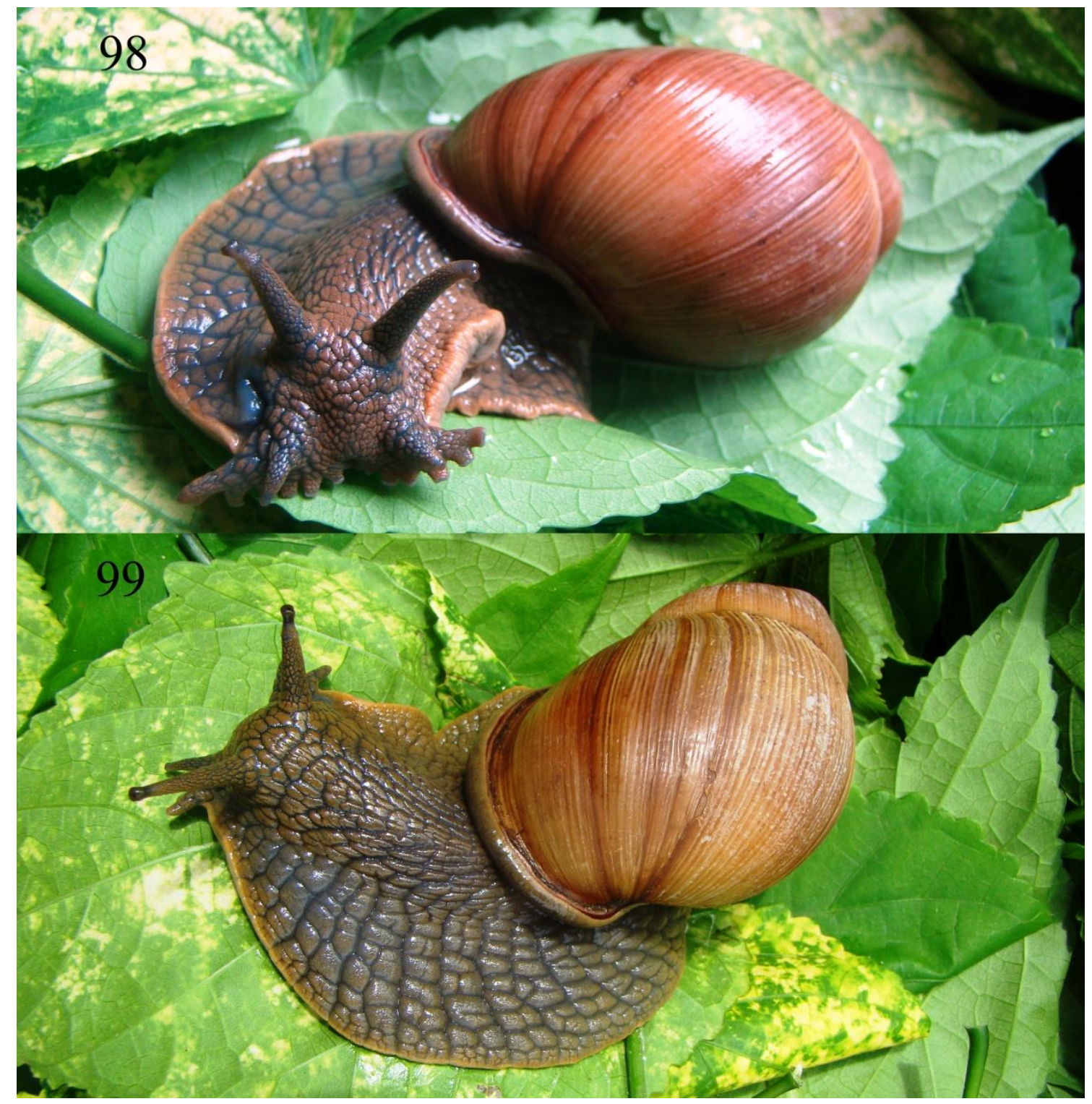

Figuras 98, 99. Megalobulimus abbreviatus. 98. Detalhe dos apêndices cefálicos (MZSP 105521, Laguna, SC); 99. Mesmo exemplar em vista dorsal.

\section{Cavidade palial}

As figuras 100 a 103 representam a topografia do manto e cavidade palial, onde se identifica uma proporcionalmente larga borda do manto; uma grande área essencialmente respiratória (cs) caracterizada pelos vasos paralelos; a região reno-pericárdica (ri/pe) no lado esquerdo; a glândula de albume (gb) ventralmente; e de forma semelhante ao M. granulosus, 
o fundo da cavidade palial (fp) na metade da penúltima volta limitado pela passagem do intestino para a cavidade palial (in).

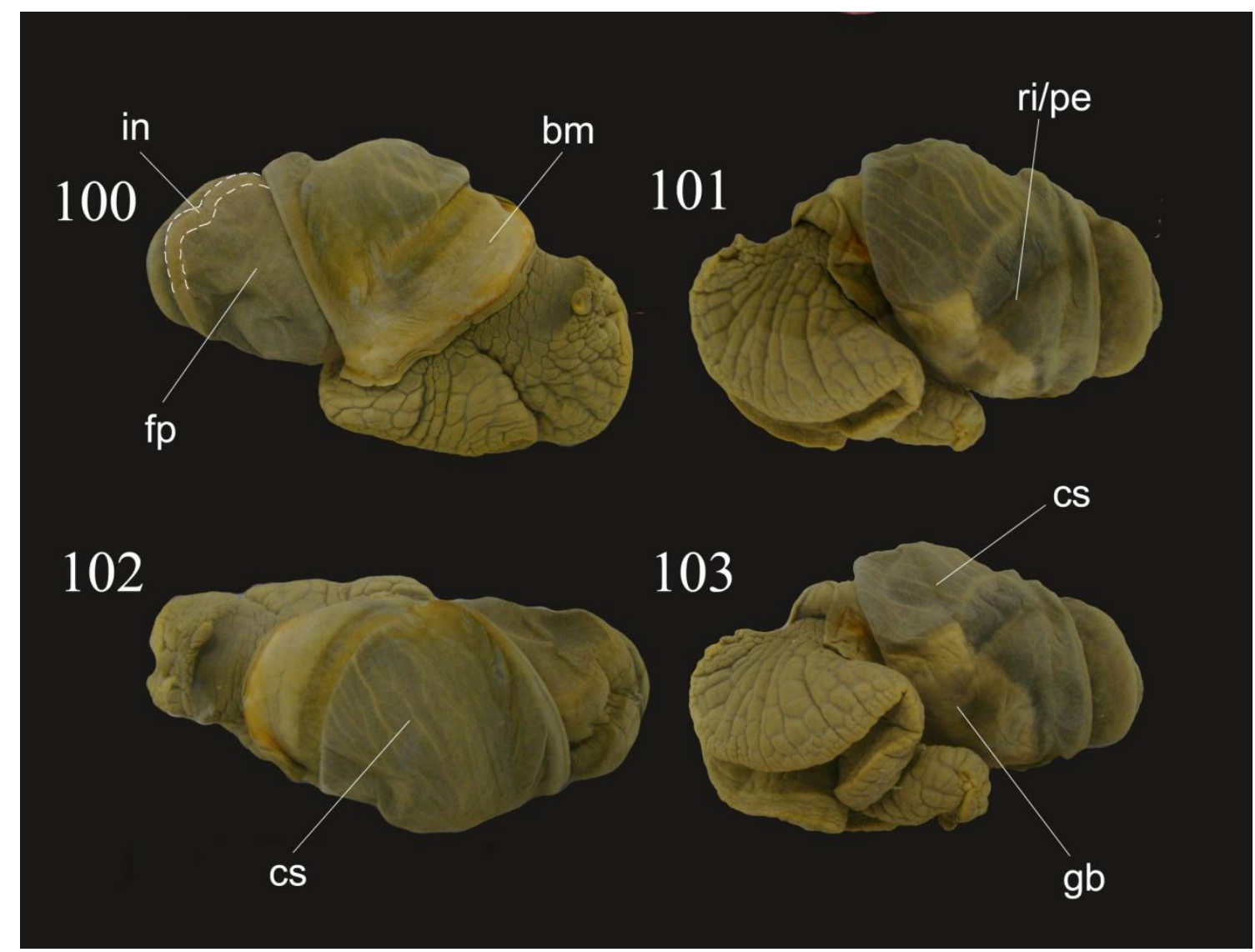

Figuras 98-103. Topografia da massa visceral de Megalobulimus abbreviatus após a remoção da concha (MZSP 105521, Laguna, SC): 100. Topografia na vista direita; 101. Topografia na vista esquerda; 102. Topografia na vista dorsal; 103. Topografia na vista frontal.

A goteira urinária (Figs. 107, 108: gu) diminui sua largura ao se aproximar do pneumóstoma, tornando-se débil antes da linha do ânus, sendo contínua com a concavidade do canal lateral (Fig. 107: cl). Como em M. granulosus o rim tem a forma alongada. Possui um desenvolvido plexo de vasos anastomosados sobre o septo e vasos próximos ao pneumóstoma que se expande sobre aproximadamente metade da superfície reno-pericárdica (Fig. 108: px), e o reto e o ânus estão profundamente fixados na borda posterior da cavidade.

\section{Sistema digestivo}


A peça mandibular (Fig. 104) apresenta colunas axiais largas e regulares em toda sua extensão, formados por feixes de distinguíveis colunas estreitas. Linhas transversais de crescimento são observadas a intervalos constantes. Os dentes radulares estão distribuídos em aproximadamente 80 fileiras compactadas, sendo retangulares e largos, com proporção aproximada de 2:1, unicúspides com ápice com cerca de 1/3 do comprimento aucançando a base do dente seguinte. Dente central um pouco menor com ápice largo em forma de lâmina côncava.

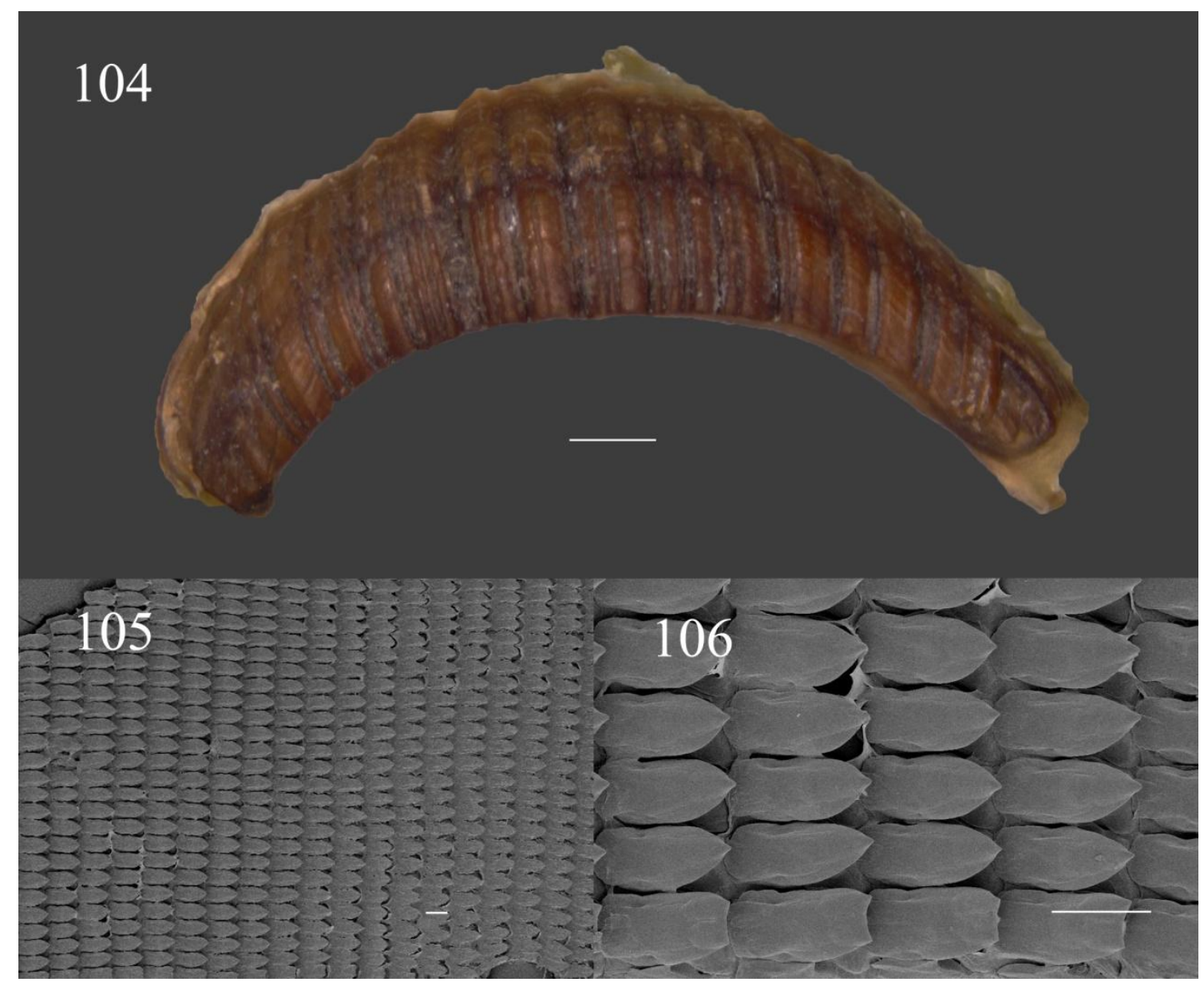

Figuras 104-106. Megalobulimus abbreviatus: 104. Mandíbula (ESCALA = $1 \mathrm{~mm}$ ); 105 e 106. Detalhes dos dentes radulares em SEM (ESCALA $=0,1 \mathrm{~mm})$

Apresenta uma massa bucal longa com a inserção fasciculada do $m 2$. Na sua face ventral a cinta muscular mandibular é pouco distinguível (fig. 109). A artéria cefálica (ac) divide-se em três ramos, dois anteriores e um posterior, que origina a artéria radular e dois ramos laterais (ar). A anatomia da massa bucal aberta longitudinalmente é similar à encontrada em M. paranaguensis (fig. 110). 
No esôfago observamos internamente um padrão também similar ao $M$. paranaguensis com o segmento anterior apresentando pregas plicadas, o médio com grossas pregas musculares e o posterior com discretas pregas serpiginosas (Fig. 111). O ducto da glândula digestiva anterior se insere no lado esquerdo próximo a entrada gástrica.

O estômago (Figs. 113, 114) apresenta paredes espessadas e um padrão de pregas internas longitudinais retas. Como em M. granulosus identifica-se internamente o óstio da glândula digestiva posterior (dp), o canal intestinal (ci) e o tiflossole intestinal (ti). Este ao sair do intestino ocupa grande parte da luz intestinal (Figs. 115, 116). Como nas espécies anteriores apenas a $p 4$ atinge a válvula pré-retal (Fig. 112), e após ela, as pregas p7 paralelizam-se a $p 6$. Na altura do reto as pregas $p 7$ se fundem e aumentam de espessura, restando na altura do ânus cerca de cinco pregas (Fig. 117).

\section{Sistema reprodutor}

As principais características do sistema reprodutivo (Fig. 118) incluem o carrefour na região mediana do hilo da glândula de albume; o tálom não destacável do saco glandular anexo (Fig. 119); e as pregas musculares internas do oviduto livre direcionados para o óstio da bursa copulatrix (Fig. 120).

O ramo masculino (Figs. 121, 122) possui a forma de clava tendo um epifalo com um terço do comprimento peniano e dois flagelos em seu ápice onde se conecta ducto deferente (Fig. 123). Internamente a prega transversal (pv) é desenvolvida mas não pendulosa. 


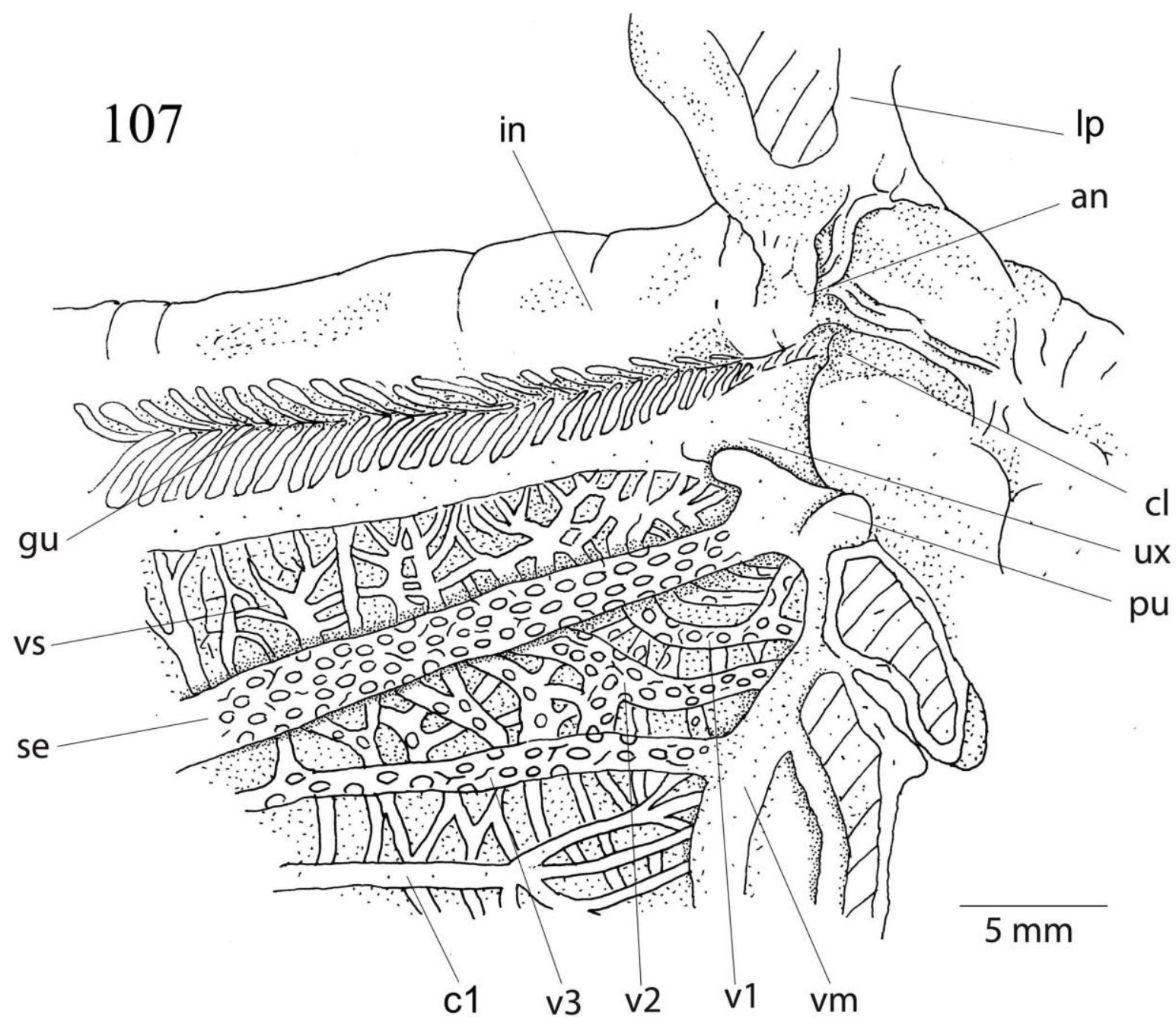

Figura 107. Região distal do septo e pneumóstoma de Megalobulimus abbreviatus. an: ânus; c1: ramificação do vaso pericárdico; cl: canal lateral; gu: goteira urinária; in: intestino; lp: lábio do pneumóstoma; pu: prega do sulco urinário; se: septo; ux: sulco urinário externo; v1, v2 $e$ v3: ramificações da veia pulmonar; vm: veia marginal ou colar; vs: vasos ad-retais. 


\section{8}

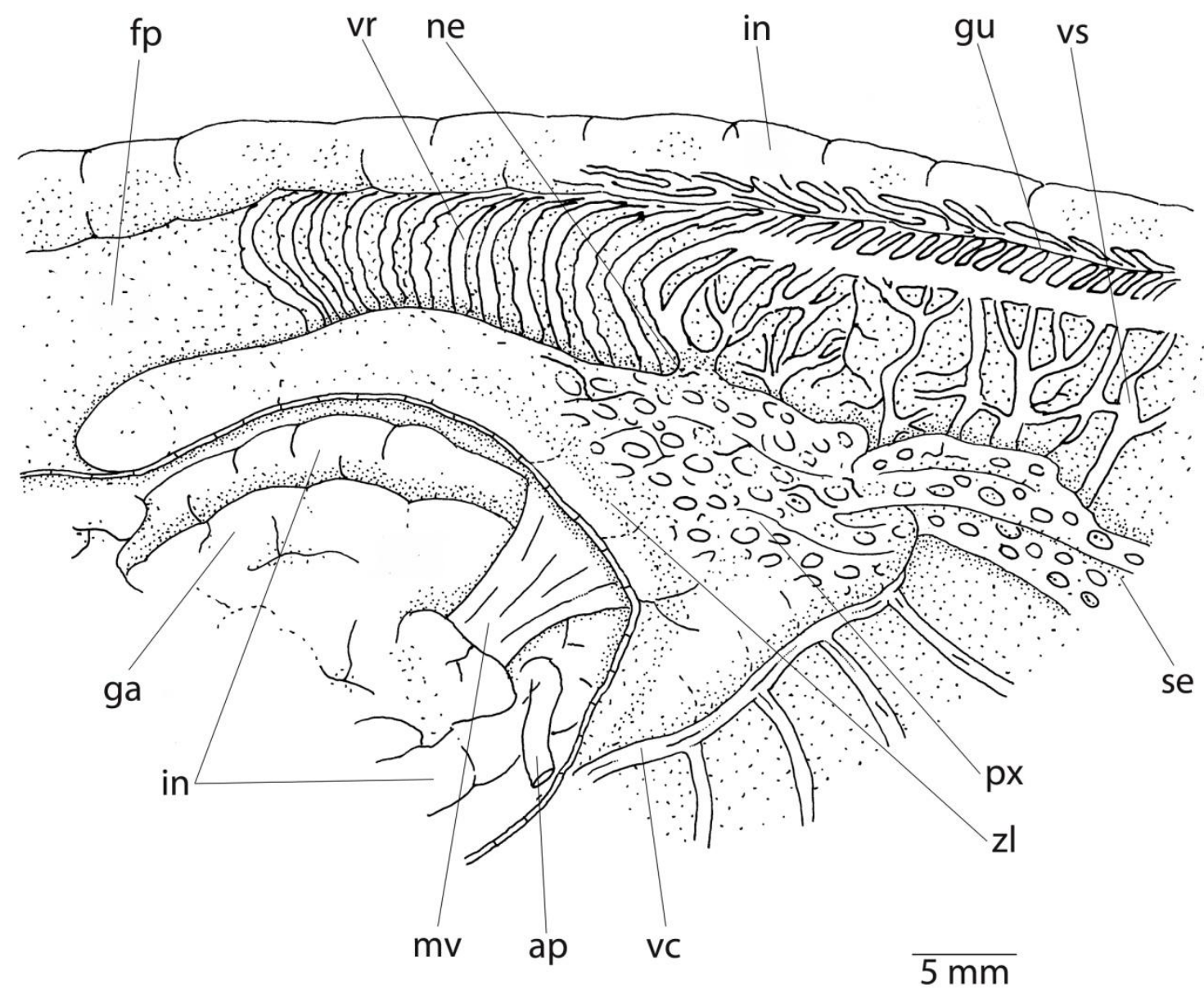

Figura 108. Megalobulimus abbreviatus, detalhe da região reno-pericárdica, vista ventral . ap: aorta posterior; fp: fundo da cavidade palial; ga: glândula digestiva anterior; gu: goteira urinária; in: intestino; mv: feixe muscular palio-diafragmático; ne: nefróstoma; px: plexo epi-renal; se: septo; vc: vaso pericárdico; vr: vasos ad-renais; vs: vasos ad-retais, zl: zona lisa do rim. 

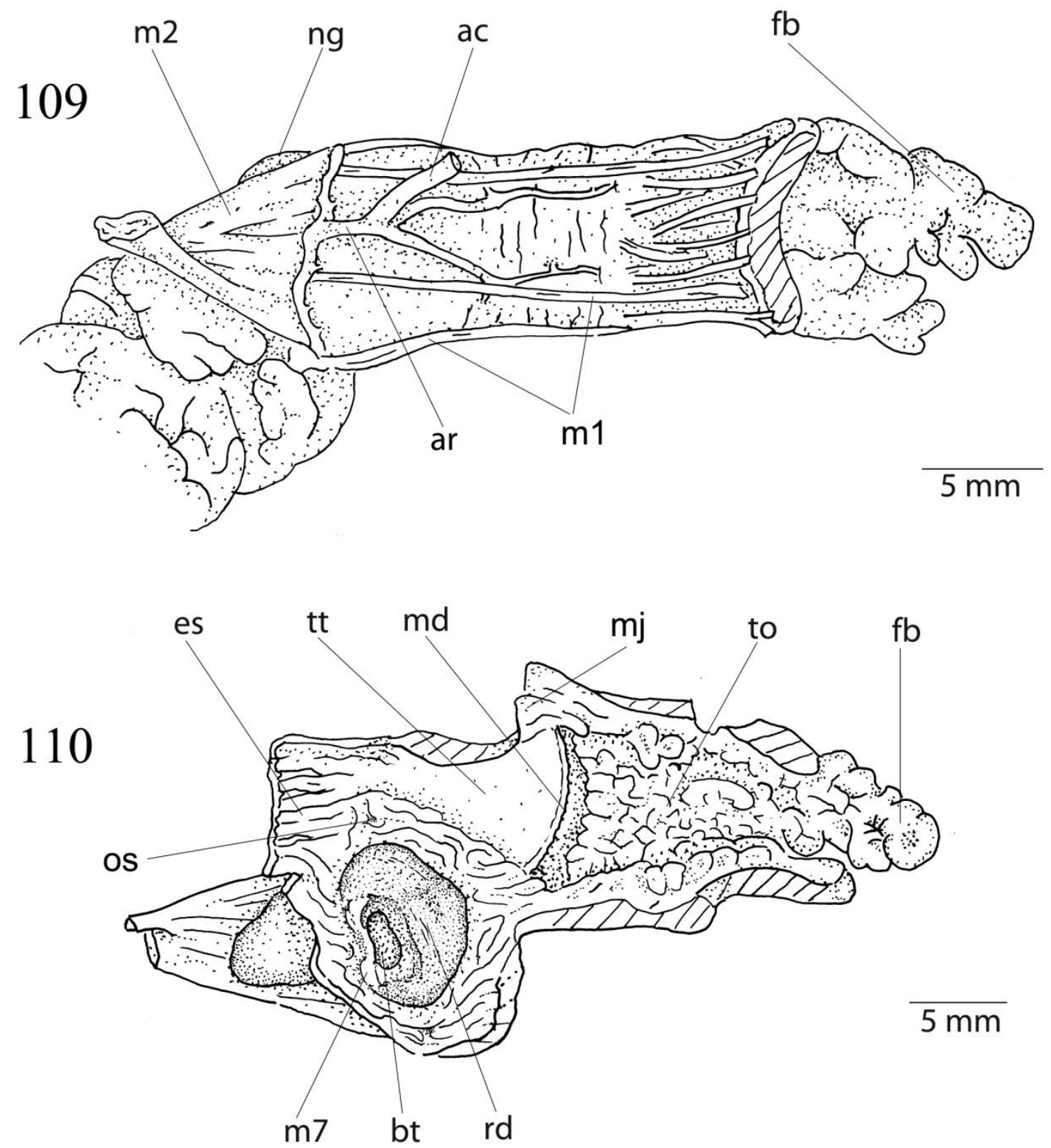

Figuras 109, 110. Massa bucal de Megalobulimus abbreviatus. 109. Vista ventral da massa bucal; 110. Massa bucal aberta longitudinalmente. ac: artéria cefálica; ar: artéria radular; bt: bonete radular; es: esôfago; fb: franja bucal; m1: músculos extrínsecos longitudinais; m2: músculo retrator da massa bucal; m7: músculo núcleo radular md: mandíbula; mj: músculo mandibular ng: núcleo radular; os: óstio do ducto salivar; rd: rádula; to: tubo oral; tt: teto da massa bucal. 


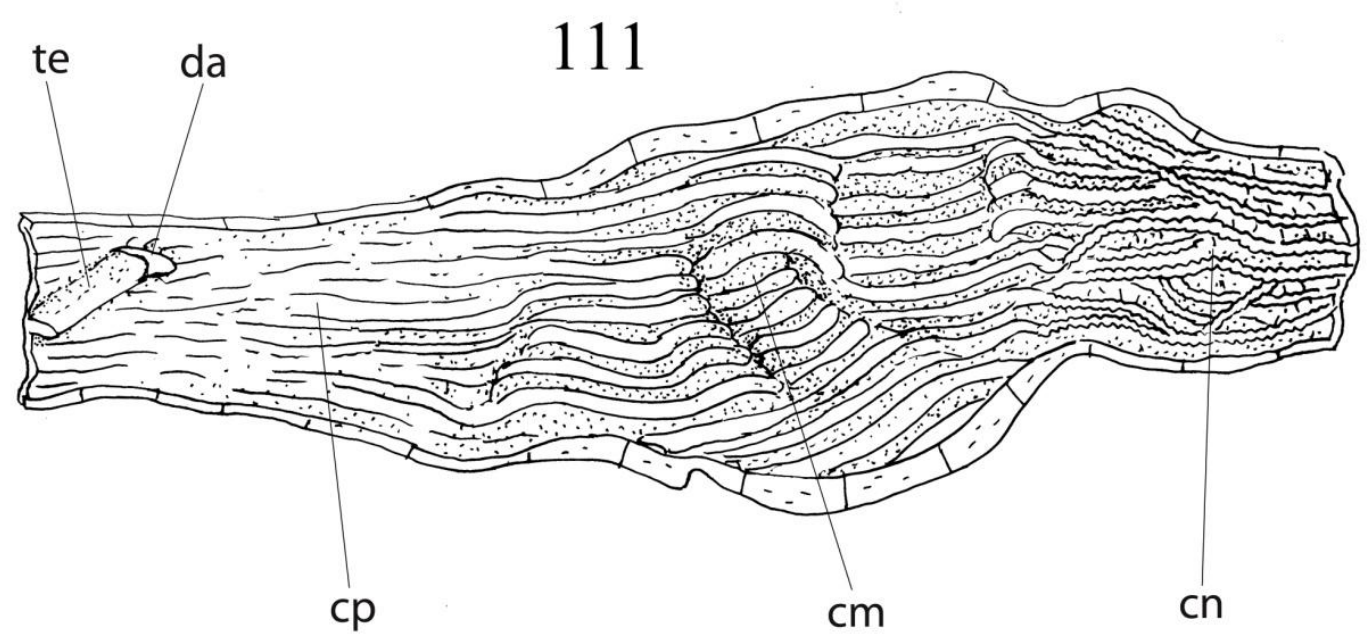

$5 \mathrm{~mm}$

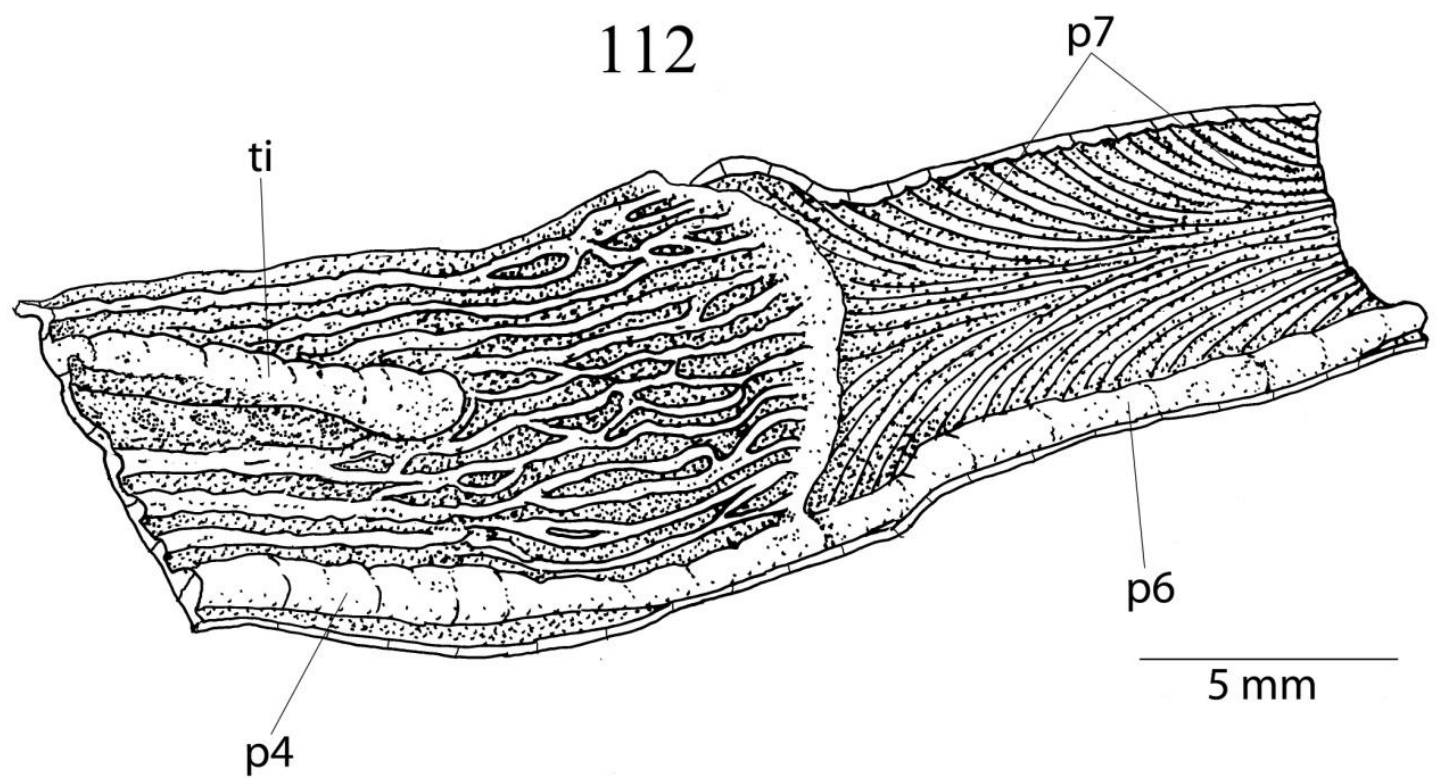

Figuras 111, 112. Sistema digestivo de Megalobulimus abbreviatus. 111. Esôfago aberto longitudinalmente; 112 . Válvula pré-retal no intestino médio aberto longitudinalmente. da: abertura do ducto da glândula digestiva anterior; cm: esôfago médio; cn: esôfago anterior; cp: esôfago posterior; p4: prega intestinal pré-valvular; p6 e p7: pregas intestinais pós-valvulares, te: tiflossole esofágico; ti: tiflossole intestinal. 

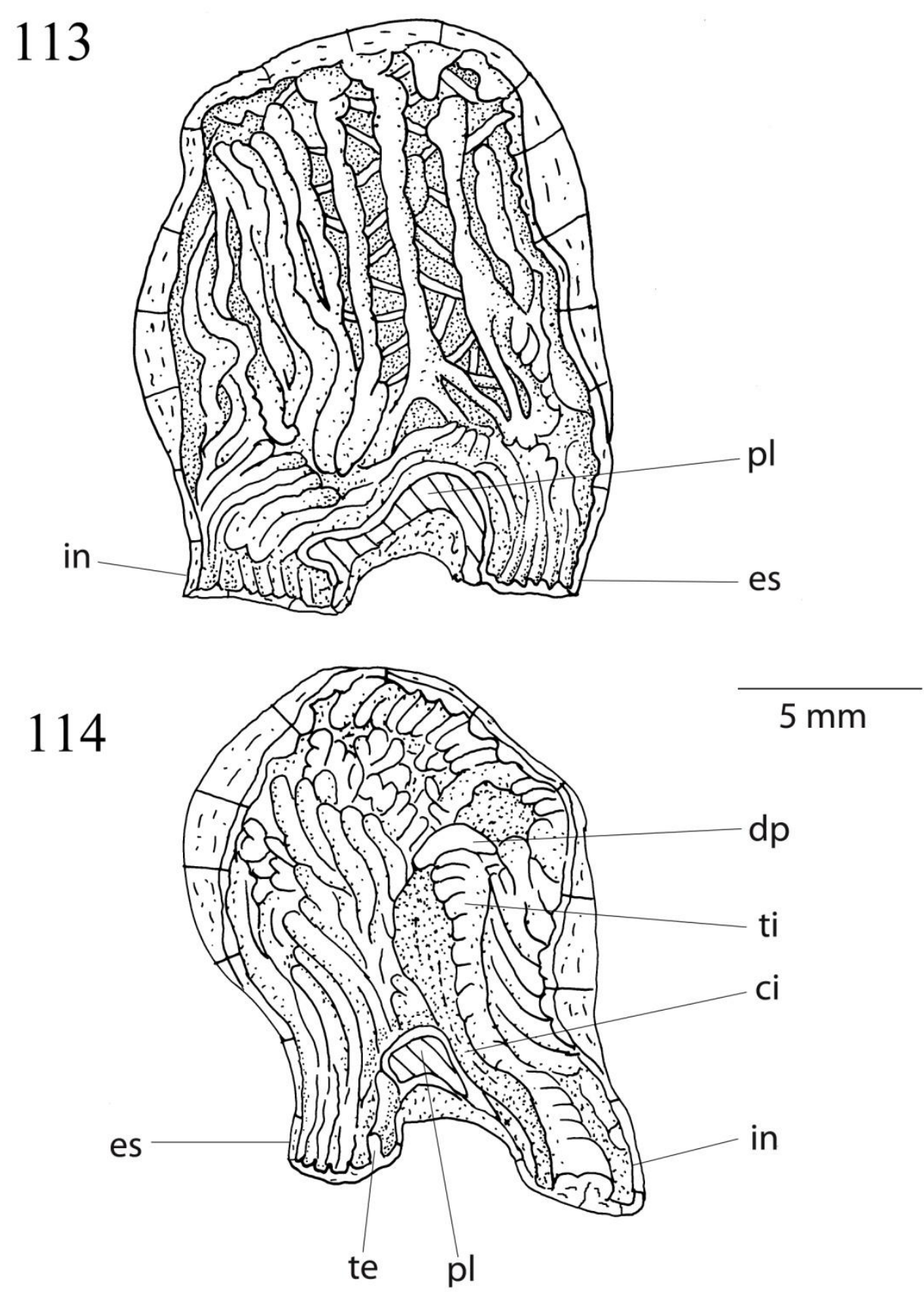

Figuras 113, 114. Estômago de Megalobulimus abbreviatus: 113. Superfície interna do lado esquerdo; 114. Superfície interna do lado direito. ci: canal intestinal; dp: ducto para a glândula digestiva posterior; es: esôfago; in: intestino; pl: musculatura do piloro; te: tiflossole esofágico; ti: tiflossole intestinal. 

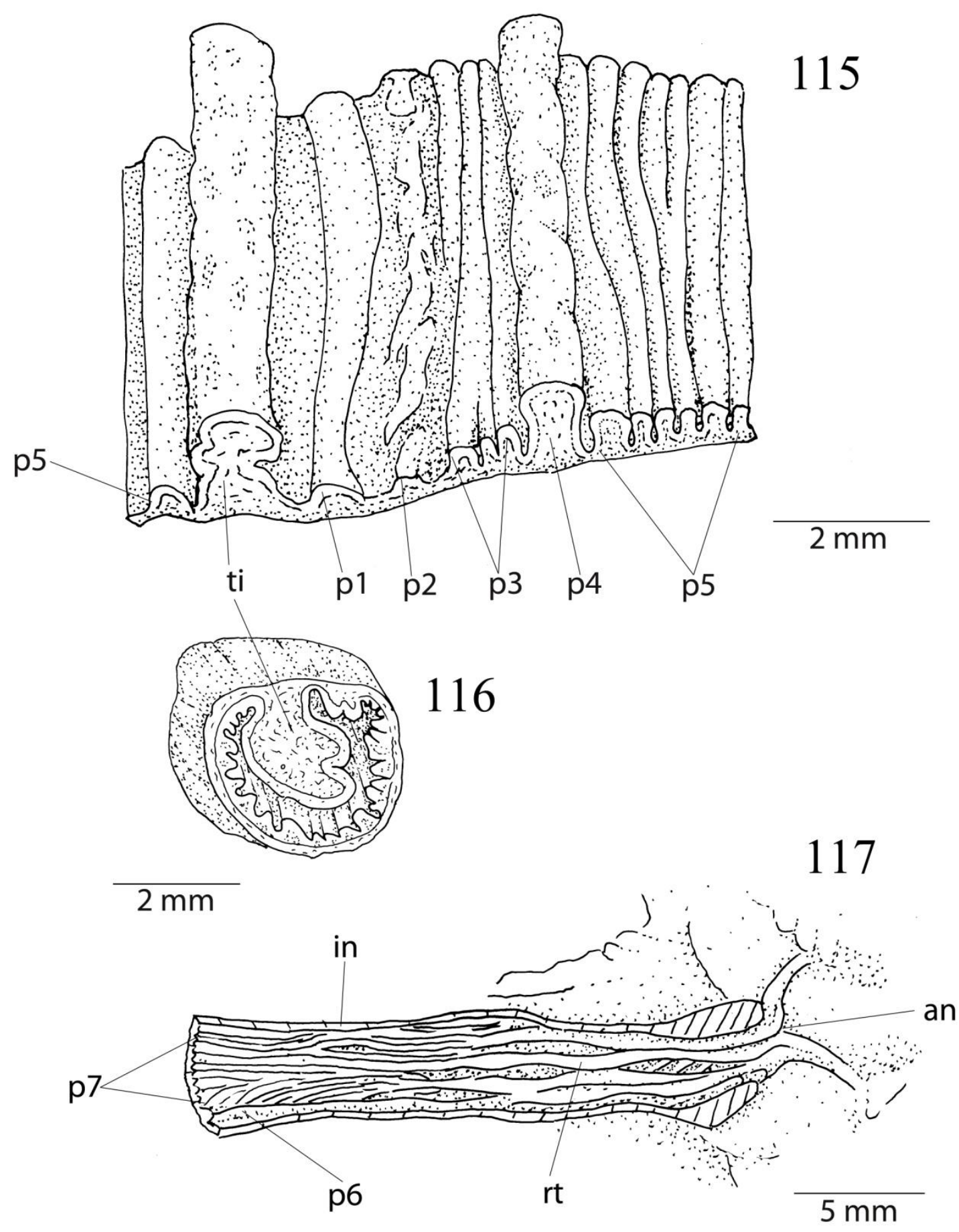

Figuras 115-117. Sistema digestivo de Megalobulimus abbreviatus. 115. Superfície interna do intestino proximal; 116. Corte transversal do intestino proximal à saída do estômago; 117. Abertura longitudinal do intestino posterior e reto. an: ânus; in: intestino; p1, p2, p3, p4 e p5: pregas intestinais pré-valvulares; $\mathbf{p 6}$ e p7: pregas intestinais pós-valvulares; rt: reto; ti: tiflossole intestinal 

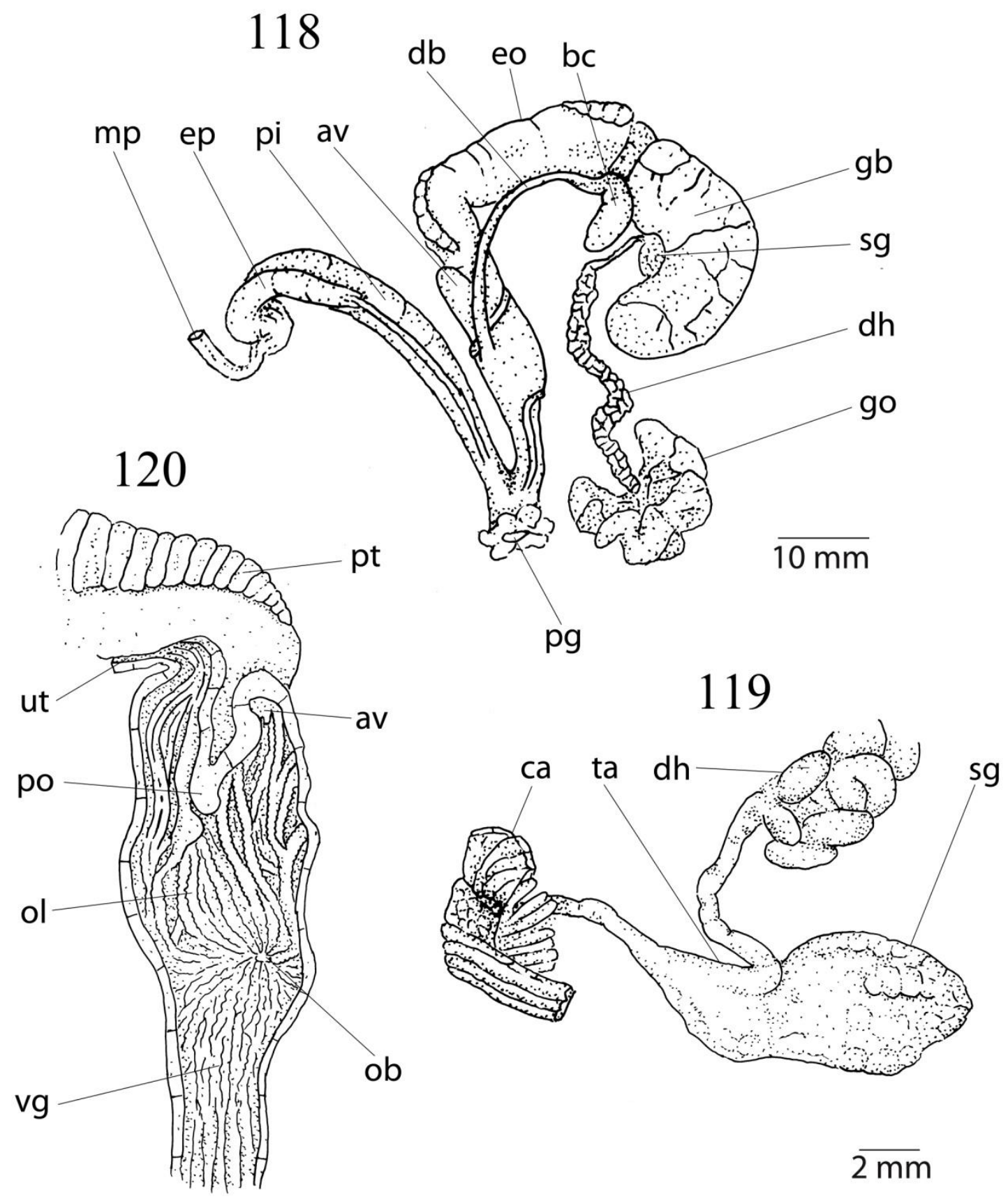

\section{$\overline{\mathrm{mm}}$}

Figuras 118-120. Sistema reprodutor de Megalobulimus abbreviatus. 118. Sistema reprodutivo, lado esquerdo; 119. Detalhe do carrefour; 120 Oviduto livre e vagina abertos longitudinalmente. av: apêndice vaginal; bc: bursa copulatrix (bolsa copulatória); ca: câmara de albume; df: canal deferente; dh: ducto hermafrodita; eo: espermoviduto; ep: epifalo; gb: glândula de albume; go; gônada; mp: músculo peniano; ob: óstio do ducto da bursa; ol: oviduto livre; pg: poro genital; pi: pênis; po: prega do oviduto; pt: próstata; sg: saco glandular anexo; ta: tálamo; ut: útero; vg: vagina. 

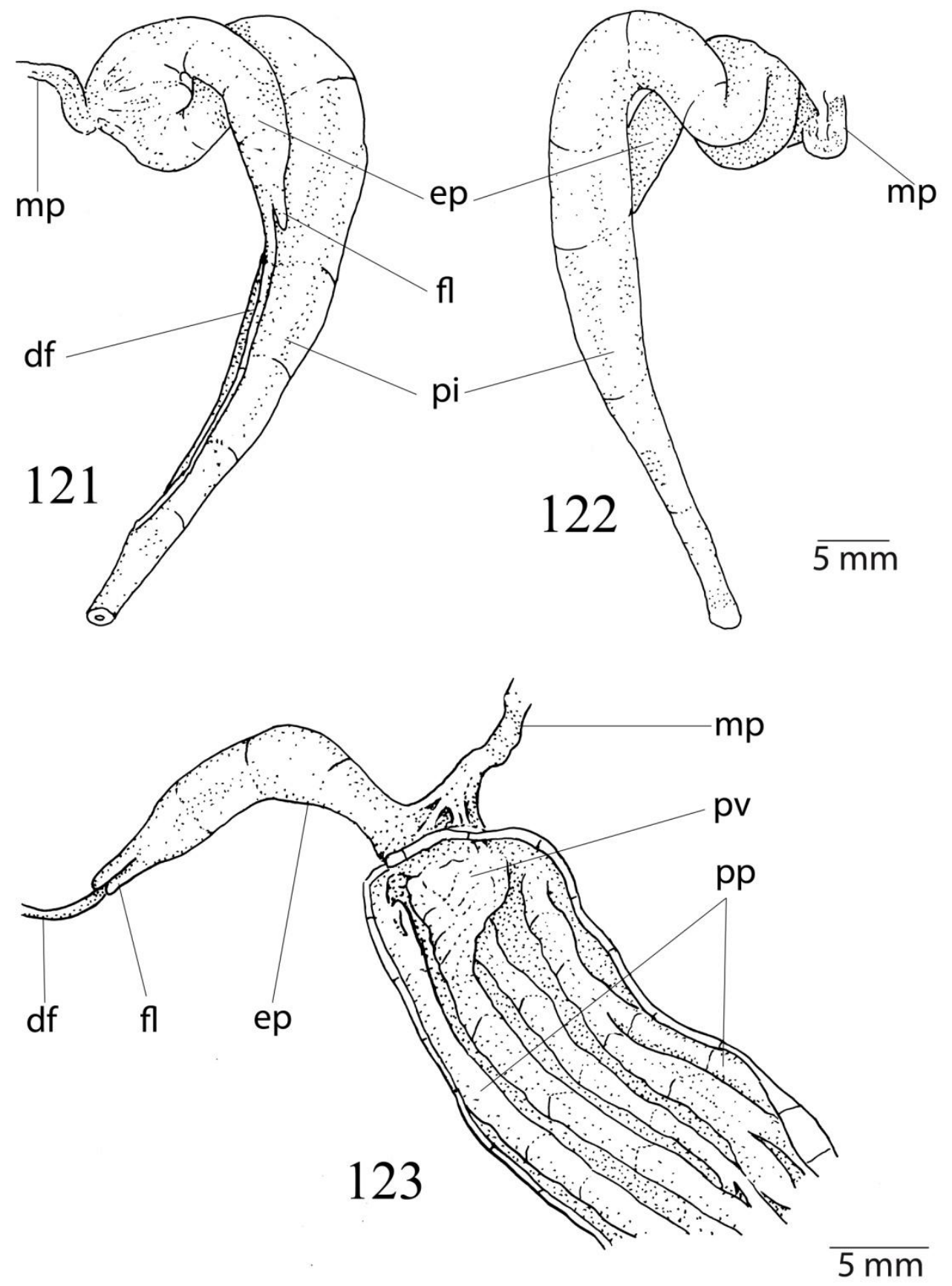

Figuras 121-123. Sistema reprodutor masculino de Megalobulimus abbreviatus. 121. Complexo peniano, lado esquerdo; 122. Complexo peniano, lado direito; 123. Complexo peniano aberto longitudinalmente. df. canal deferente; fl. flagelos; ep. epifalo; mp. músculo peniano; pi. pênis; pp: pregas penianas; pv: prega transversal do pênis. 


\section{DISTRIBUIÇÃO GEOGRÁFICA}

Bequaert (1948) ao descrever o Megalobulimus abbreviatus, não estabeleceu uma localidade tipo ao nomear conchas sem procedência como holótipo e dois parátipos, além de mais três parátipos sendo um do MZSP, proveniente de Rio Grande, SP e dois procedentes do Rio Grande do Sul. O material de São Paulo (MZSP 14612) não possui identificação do coletor e data de coleta, existindo uma incerteza sobre este material.

No MZSP existem vários registros de "Rio Grande, SP" como local de coleta para material coligido no início do século XX. Muitos destes coletados por Ernesto Garbe (18531925), em um período que esta localidade referia-se aos arredores da estação ferroviária homônima. Entretanto Garbe também foi enviado para coletas no Rio Grande do Sul em 1914, e os dois parátipos do MCZ foram coletados por ele naquele Estado (Bequaert, 1948).

Como os demais 17 lotes identificados de M. abbreviatus no MZSP tem procedência na região Sul (Tab. 6), concluímos que pode ter ocorrido falha na manutenção dos registros do lote MZSP 14610. O histórico de que a coleção malacológica ficou sem curador fixo entre o desligamento político de H. v. Ihering em 1914 e o início da década de 1960 (Taddei et al. 1999) corrobora com tal assertiva, e permiti-nos restringir a localidade tipo de Megalobulimus abbreviatus ao Estado do Rio Grande do Sul (Dornellas \& Simone, 2011).

A distribuição geográfica inclui a planície costeira sul catarinense e as planícies e planaltos baixos do nordeste rio-grandense (Fig. 124). Sua presença conspícua na área periurbana de Porto Alegre indica uma característica paradoxal dos Megalobulimus, a adaptação e bom desenvolvimento em áreas antropofizadas como jardins, parques e hortas (Bequaert, 1948; Bruschi-Figueró \& Veitenheimer-Mendes, 2002). 


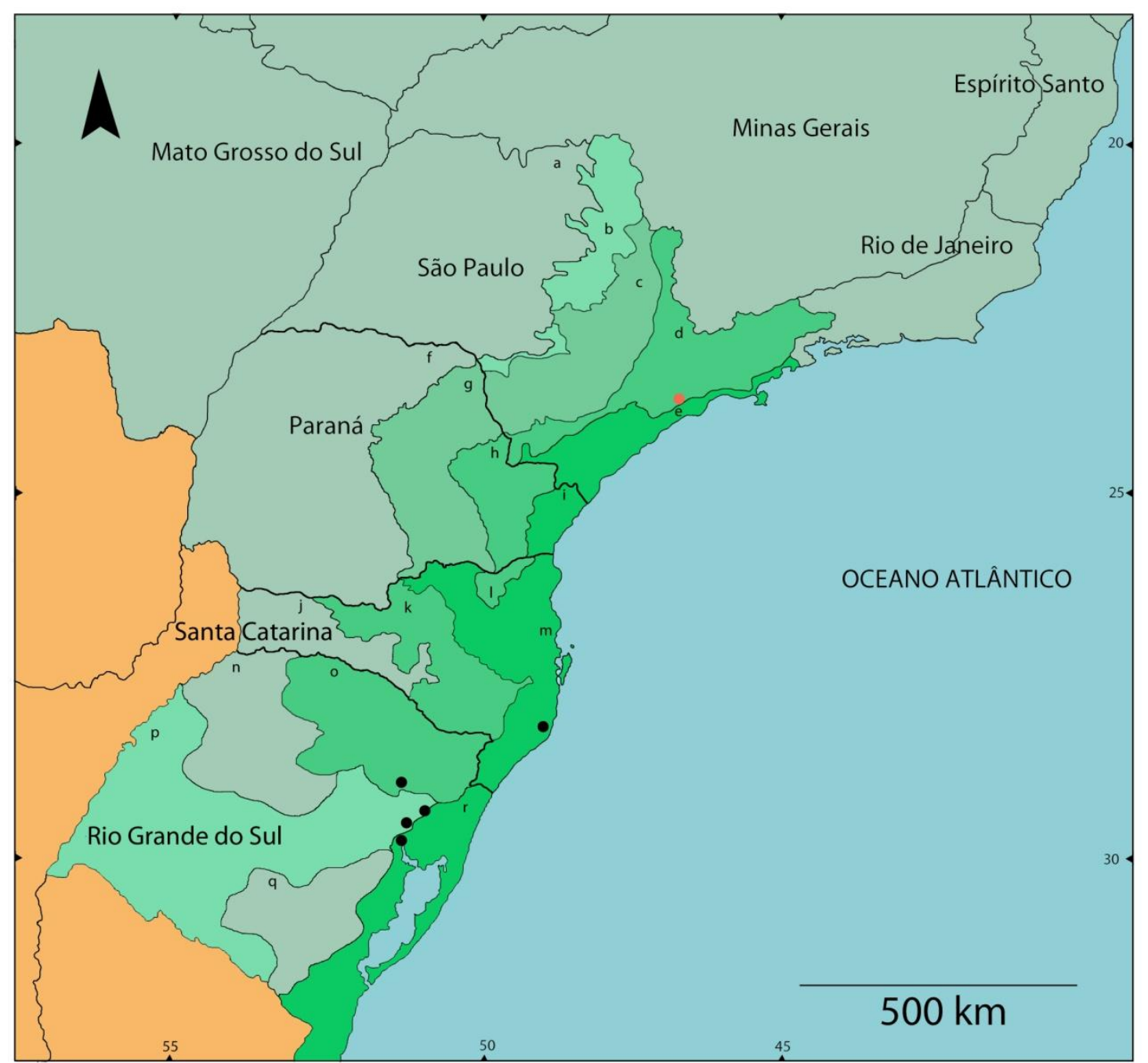

Figura 124. Distribuição geográfica do Megalobulimus paranaguensis. A partir dos lotes depositados no MZUSP. Localidade tipo: Rio Grande, SP (ponto vermelho); RS. d: Planalto cristalino paulista; m: Planície costeira catarinense; p: Depressão central rio-grandense; r: Planície costeira riograndense.

\begin{tabular}{|c|c|c|c|}
\hline LOCALIDADE & $\begin{array}{c}\text { N. DE } \\
\text { LOTES }\end{array}$ & LOCALIDADE & $\begin{array}{c}\text { N. DE } \\
\text { LOTES }\end{array}$ \\
\hline Porto Alegre, RS & 10 & Rio Grande, SP & 1 \\
\hline Taquara, RS & 2 & Laguna, SC & 1 \\
\hline São Leopoldo, RS & 2 & Caxias do Sul, RS & 1 \\
\hline
\end{tabular}

Tabela 6. Número de lotes de Megalobulimus abbreviatus por localidade na coleção do MZSP 


\subsection{Megalobulimus foreli (Bequaert, 1948)}

Strophocheilus (Megalobulimus) granulosus foreli Bequaert, 1948: 165-166, pl. 28, fig. 3. Megalobulimus (Phaiopharus) foreli: Morretes, 1952: 113; 1953: 65.

Megalobulimus foreli: Leme, 1973: 15; Salgado \& Coelho, 2003: 157; Simone, 2006: 216, fig. 796 (holótipo); Thomé et al. 2007: 22.

Tipos: Holótipo - MZSP 1311; Parátipo - MCZ 179290.

Localidade tipo: BRASIL, PR, Ponta Grossa.

Material examinado. BRASIL. Paraná: Sengés, MZSP 29282, 2 conchas (J.B. Cleto col., xii/1967); Jaguariaiva, Arapoti, MZSP 16680, 10 conchas (Phelipe Tod col., iii/1934); Tibagi, MZSP 29273, 3 conchas (C.N. Goffergé col., 1953); Ponta Grossa, MZSP 1311 (Holótipo), 1 concha (Bicego col., 1897), Guaragi, MZSP 29268, 3 conchas (G.R. Kloss col., 15/xii/1965); Guarauna, MZSP 16592, 1 concha (J.P. Machado col., xi/1937).

\section{CONCHA}

Concha fusiforme com comprimento de $89 \mathrm{~mm}$ e 5,9 voltas (Figs. 125, 126), imperfurada, sem expansões laterais e com voltas apenas ligeiramente convexas; espira longa com base estreita, arredondada porém com ápice agudo; abertura sub-ovalada. Periostraco caduco de coloração castanho amarelada como em M. abbreviatus. Concha neopiônica (Figs. $127,128)$ com 3,8 voltas assemelhando-se perfeitamente a descrição de $M$. abbreviatus com a diferença que as costelas nos lotes de Ponta Grossa são ligeiramente mais largas. Microescultura como nas espécies anteriores com granulação em linhas espirais por toda a protoconcha e penúltima volta e esparsa e débil na volta-do-corpo. Linhas de crescimento regulares, planas e com bordos arredondados como em $M$. abbreviatus. Lábio interno e columela arredondados. Lábio externo formando ângulo $>90^{\circ}$ com a parede parietal Abertura com cerca da metade do comprimento. Aparentemente o holótipo seja uma concha rolada e o seu peristoma branco fosco seja a consequência de sua exposição às intempéries. Em outro lote da mesma localidade o peristoma de três indivíduos se mostrou rosa claro. Os dados biométricos da concha estão estatisticamente tratados condensados na tabela 7 . 


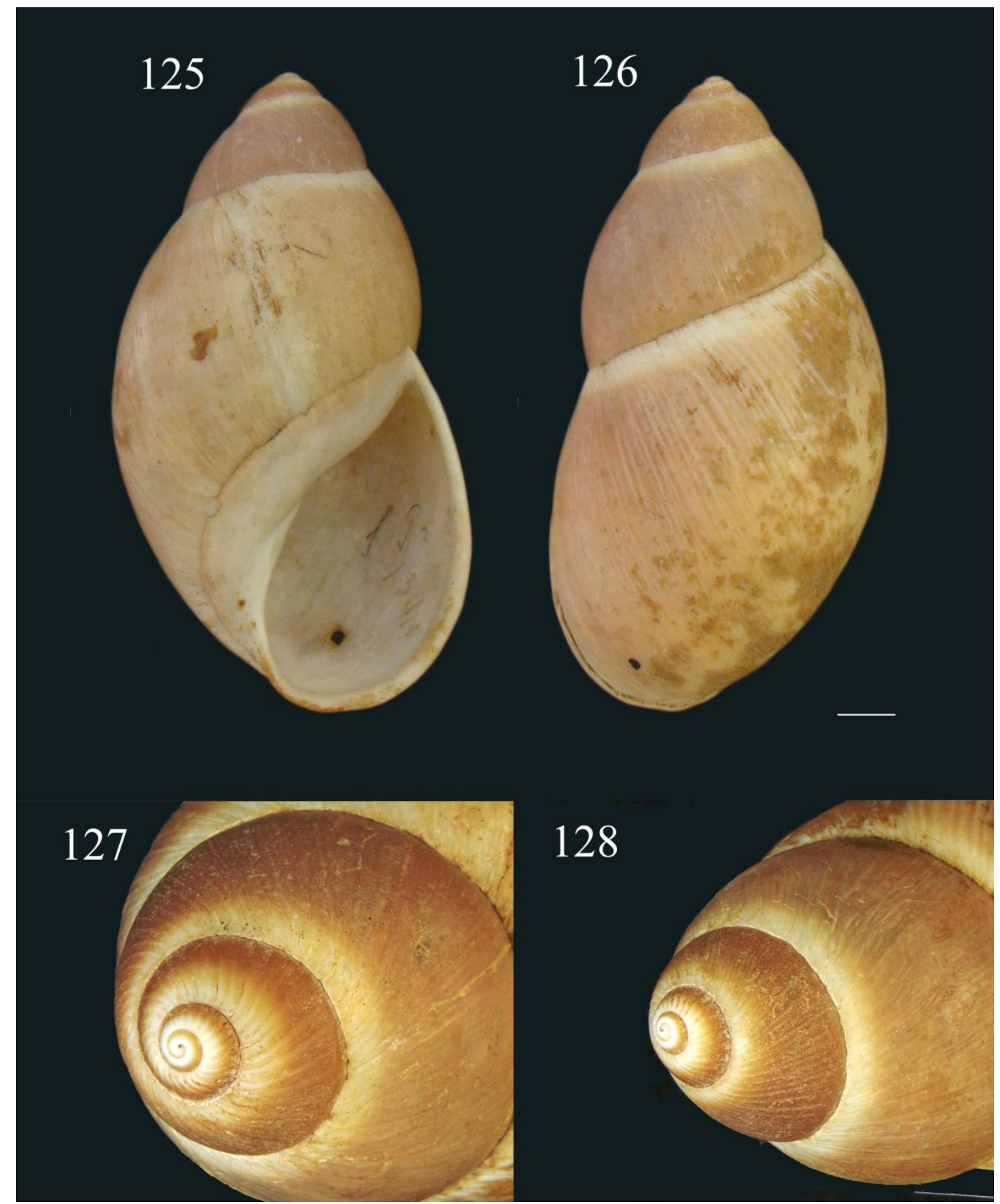

Figuras 125-128. Concha de Megalobulimus foreli. 125: Vista frontal do holótipo MZSP 1311 (Ponta Grossa, PR); 126: Mesmo exemplar em vista dorsal (ESCALA = 10 mm); 127 e 128: mesmo exemplar detalhando a concha neopiônica. 


\section{COMP. LARG. ALT. VOLTAS VOLTAS PROTOCH. TOTAIS}

\begin{tabular}{rrrrrr}
\hline $\mathbf{n}$ & 18 & 18 & 18 & 14 & 15 \\
$\mathbf{m a x}$ & 94 & 49 & 43 & 4.0 & 6.0 \\
$\mathbf{m i n}$ & 76 & 41 & 38 & 3.5 & 5.5 \\
$\mathbf{a m p l}$ & 18 & 8 & 5 & 0.5 & 0.5 \\
$\boldsymbol{\mu}$ & 88 & 45 & 41 & 3.8 & 5.8 \\
$\mathbf{m}$ & 89 & 46 & 41 & 3.8 & 5.9 \\
$\mathbf{D P}$ & 5 & 3 & 1 & 0.2 & 0.1 \\
$\mathbf{C V}(\boldsymbol{\%})$ & $6.2 \%$ & $6.0 \%$ & $3.5 \%$ & $4.1 \%$ & $2.5 \%$ \\
$\mathbf{p}$ & $\mathrm{NS}$ & $\mathrm{NS}$ & $\mathrm{NS}$ & $\mathrm{NS}$ & $\mathrm{NS}$ \\
\hline
\end{tabular}

Tabela 7. Biometria da concha de Megalobulimus abbreviatus. Legenda: $\mathrm{n}$ : tamanho da amostra; max: valor máximo; min: valor mínimo; ampl: amplitude; $\mu$ : média aritmética; m: mediana; DP: desvio padrão; CV (\%): coeficiente de variação em porcentagem; p: teste de normalidade de D'Agostino-Pearson (NS: número de indivíduos insuficientes)

\section{DISTRIBUIÇÃO GEOGRÁFICA}

Esta espécie foi descrita a partir de duas conchas enviadas por Oliveiro M. de Oliveira Pinto (1896-1981), então diretor do Departamento de Zoologia da Secretaria da Agricultura para Joseph C. Bequaert (1886-1982), enquanto este coligia material junto aos museus para sua revisão da família Strophocheilidae em meados da década de 1940. As duas conchas foram coletadas em 1897 no município de Ponta Grossa, PR por Beniamino Bicego e, embora registrados na coleção como uma nova espécie (Strophocheilus foreli), não foram descritas na época por Hermann von Ihering (1850-1930).

A localidade tipo é o município paranaense de Ponto Grossa que assim como os outros cinco lotes triados do MZSP (Tab. 8) procedem da metade oriental do denominado segundo planalto onde os "campos gerais", uma zona fitogeográfica com campos limpos e matas de galerias ou capões isolados de floresta ombrófila mista e a araucária eram a paisagem dominante (Fig. 129). 


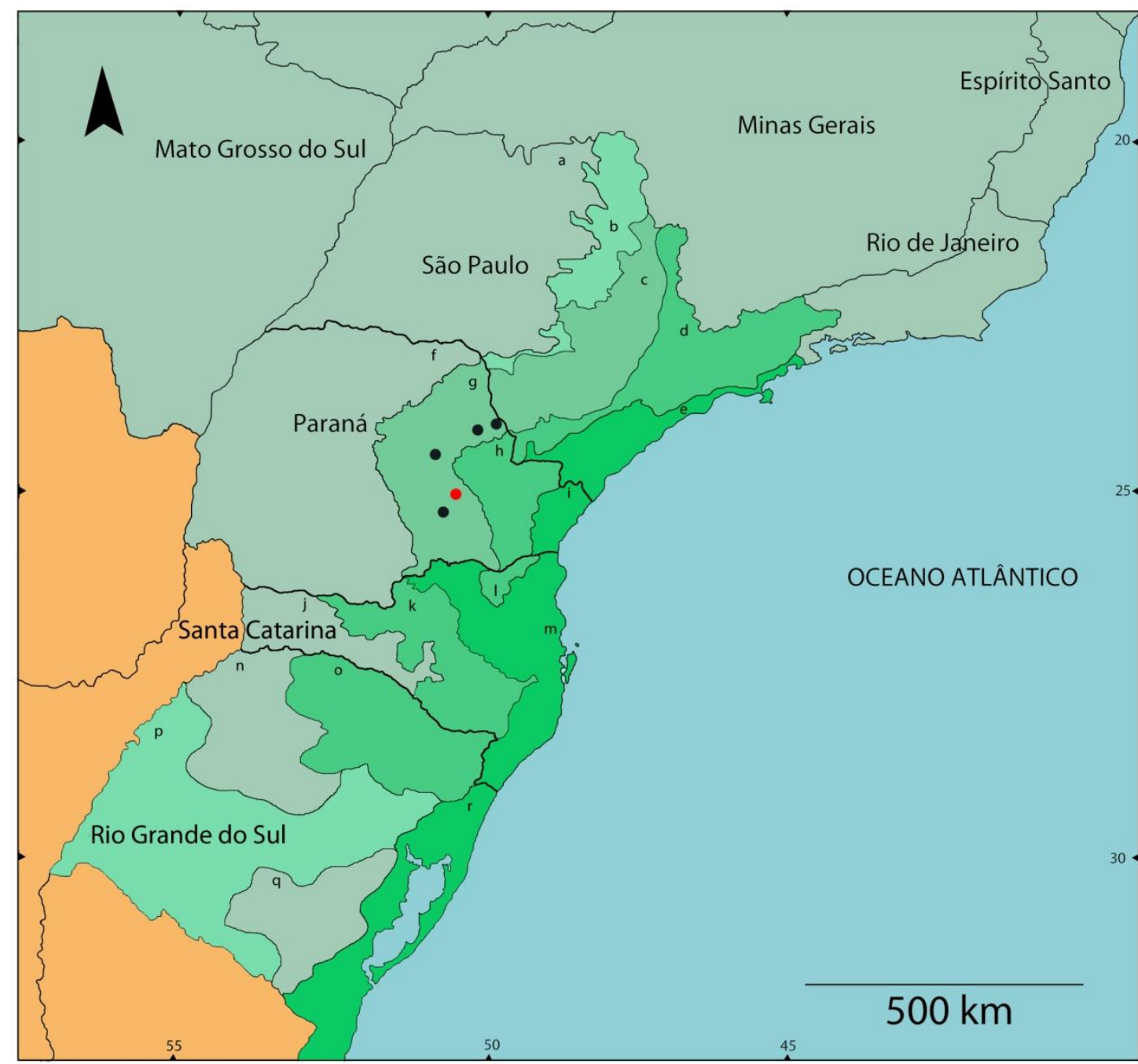

Figura 129. Distribuição geográfica do Megalobulimus foreli. A partir dos lotes depositados no MZSP. Localidade tipo: Ponta Grossa/PR (ponto vermelho). g: Segundo planalto paranaense.

\begin{tabular}{rr|cr}
\hline \multicolumn{1}{|c|}{ LOCALIDADE } & \multicolumn{1}{c}{ N. DE } & \multirow{2}{*}{ LOCALIDADE } & \multicolumn{2}{c}{ N. DE } \\
LOTES & 2 & Tibagi, PR & 1 \\
\hline Ponta Grossa, PR & 1 & Guarauna, PR & 1 \\
Sengés, PR & 1 & & \\
Jaguariaiva, PR & 1 & & \\
\hline
\end{tabular}

Tabela 8. Número de lotes de Megalobulimus foreli por localidade na coleção do MZSP 


\subsection{Megalobulimus aff. gummatus}

Strophocheilus gummatus: Morretes, 1949: 143 (parte) (non Hidalgo, 1870).

Megalobulimus (Phaiopharus) gummatus: Morretes, 1952: 113; 1953: 65 (parte).

Megalobulimus gummatus: Leme, 1971: 15 (parte); Salgado \& Coelho, 2003: 158 (parte); Simone, 2006: 211, fig. 804 (parte); Thomé et al. 2007: 22 (parte) (non Hidalgo, 1870).

Material examinado. BRASIL. São Paulo. Sorocaba, MZSP 62129, 1 concha (L. Simone col., ii/1988); Mogi das Cruzes, Serra do Itapeti, MZSP 28962 (D. Barcelo col., vii/1991); Itapecerica da Serra, MZSP 15724, 1 concha (E. X. Rabello col.); São Sebastião (possível compra), MZSP 96475, 2 conchas (G. D. Oliveira leg., 13/xi/1968); Cubatão, MZSP 64563, 1 concha (Mayer col.); Juquetiba, MZSP 92832, 2 conchas (M. Moraes col., vii/1973); Tapiraí, Cabeça de Anta, MZSP 16039, 5 conchas (J. S. Borges col., iv/1964); São Vicente, MZSP 16615, 1 concha (Dr. Krüger col., 1941); Itapeva, Bairro das Pedras, MZSP 29320, 1 concha (G. M. S. Ribeiro col., 30/v/1967), MZSP 96474, 2 conchas (G. J. Ribeiro col., xi/1968); Itanhaém, MZSP 42350, 1 concha (J. E. A. Ranali col.), MZSP 92833, 1 concha (M. Ferreira col., xi/1978); Guapiará, Fazenda Intervales, MZSP 28925, 2 conchas (Exp. MZSP col. 22/iii/1983), Gruta do Término, MZSP 29316, 1 concha, Fazenda Intervales, MZSP 30460, 1 espécime (Exp. MZSP col., 22/iii/1983); Miracatu, Serra dos Moraes, MZSP 49935, 1 espécime (F. de Castro \& F. R. Rios col., 08/ix/2004), Serra dos Moraes, MZSP 49936, 1 espécime (F. de Castro \& F. R. Rios col., 08/ix/2004), FPZSP (nascido cativeiro), MZSP 49937, 1 espécime (F. de Castro \& F. R. Rios col., 06/viii/2003), FPZSP (nascido cativeiro), MZSP 49940, 1 espécime (F. de Castro \& F. R. Rios col., 10/v/2005), FPZSP (nascido cativeiro), MZSP 49941, 1 espécime (F. de Castro \& F. R. Rios cols., 19/i/2005), FPZSP (nascido cativeiro), MZSP 49942, 1 espécime (F. de Castro \& F. R. Rios cols., 09/iii/2005), FPZSP (nascido cativeiro), MZSP 49944, 1 espécime (F. de Castro \& F. R. Rios cols., 04/iv/2004), FPZSP (nascido cativeiro), MZSP 49945, 1 espécime (F. de Castro \& F. R. Rios cols., 27/iv/2004); Pedro de Toledo, Bairro das Amoreiras, MZSP 92837, 1 concha (SUCEN col., viii.1980); Itariri, MZSP 48256, 1 espécime (ii/1983), MZSP 96477, 2 conchas (G. Ishiumi col., ii/1983); Peruíbe, MZSP 29309, 1 concha ( J. Leopoldo \& A.M. Olalla col., 05/vi/1963); Biguá, MZSP 92836, 1 concha (SUCEN col., ix/1983); Juquiá, Poço Grande-Rio Juquiá, MZSP 269, 3 conchas (A. Hempel col., 1898), MZSP 90913, 1 concha (A. M. Abrão col., ix/1976), MZSP 90914, 1 concha (L. L. Corrêa col., iii/1980), MZSP 96478, 1 concha (L. Lacerda col., ix/1980), MZSP 96479, 1 concha (L. Alonso col., xii/1975); Registro, MZSP 48523, 1 concha; Eldorado Paulista, MZSP 29315, 2 conchas (G. A. S. Melo col., vii/1968); Iporanga, MZSP 7996, 1 concha (R. Krone col.), MZSP 15594, 13 espécimes (Leme col., 01/vii/1961), MZSP 15603, 2 conchas (Leme \& Papavero col., 13/xi/1963), MZSP 15617, 4 conchas (Leme \& Papavero col., xi/1963), MZSP 33031, 8 conchas (Coltro col.), Abismo da Flecha, MZSP 43529, 1 concha (C. Lino col., 10/vii/1981), Abismo da Flecha, MZSP 43533, 1 concha (C. Lino col., 10/vii/1981), Abismo da Flecha, MZSP 43689, 1 concha (C. Lino col., 10/vii/1981), Abismo da Flecha, MZSP 43697, 1 concha (C. Lino col., 10/vii/1981), MZSP 92835, 1 concha (D. H. Guilherme col., v/1970), MZSP 15594, 3 conchas (Leme col., 
xi/1961); Jacupiranga, MZSP 32541, 1 concha (vi/2000); Iguape, Núcleo Despraiado, MZSP 28773, 2 conchas (P. da Rocha \& B. Mestre cols., 29/ix/1997), MZSP 28893, 2 espécimes (N. Maraccioli col.), MZSP 29311, 1 concha (Massuda col., 02/vii/1966), MZSP 29312, 4 conchas (L. Elloi col., 1993), MZSP 29317, 2 conchas (R. Krone col.), MZSP 71070, 1 concha (A. Galdino col., 2004); Pariquera-açú, MZSP 29313, 1 concha (E. X. Rabello col., 9/vii/1974), Fazenda Experimental de Pariquera-açú, MZSP 29318, 1 concha (E. X. Rabello col., 29/vi/1974). Paraná. Sergés, (Morungava), MZSP 16603, 10 conchas (P. Jaussaid col., 20/vii/1934); Morretes, MZSP 16610, 2 conchas (L. de Morretes col.).

\section{CONCHA}

A descrição da concha de $M$. aff. gummatus (Figs. 130-133) é muito similar ao $M$. paranaguensis: forma oval com 5,3 voltas, imperfurada a semiperfurada; com contorno fortemente convexo e saciforme a esquerda da columela; compressão dorso-ventral; espira larga, arredondada e mamilar; abertura hemi-oval. Periostraco de caduco a persistente de coloração castanho amarelada com faixas radiais escuras. Concha neopiônica (Figs. 134, 135) com 3,3 voltas discretamente convexas, sendo a 1 e 1/4 lisas seguida pelo aparecimento de costelas a partir da sutura inferior que atingem a superior na $1 \frac{1 / 2}{2}$ voltas. Costelas com inserção superior dendrítica prosóclinas largas e regulares com intervalos maiores que a largura da costela com microescultura de linhas radiais pontuadas (Fig. 135) que a partir da terceira volta não atingem a sutura inferior. Penúltima volta e volta-do-corpo com linhas de crescimento de estreitas a médias variando nas faixas mais pigmentadas na teleoconcha, arredondadas, com intervalos regulares. A penúltima apresenta marcada microescultura granulosa em linhas espirais que esmaecem na volta-do-corpo. $\mathrm{Na}$ última volta pequenas estrias em feixes podem ocorrer sobre as costelas e transversalmente curtas estrias bem marcadas (striolae) e aparentes "marteladas" (malleata) dão a concha um aspecto rugoso. $\mathrm{O}$ perfil esquerdo da penúltima volta é convexo (vista dorsal). Geralmente o peristoma de coloração branca e esta espessado mas pouco ou nada refletido nos espécimes adultos. Lábio interno reto e columela oblíqua. Ângulo do lábio externo e parede parietal $<90^{\circ}$. Abertura maior que $1 / 2$ do comprimento. 


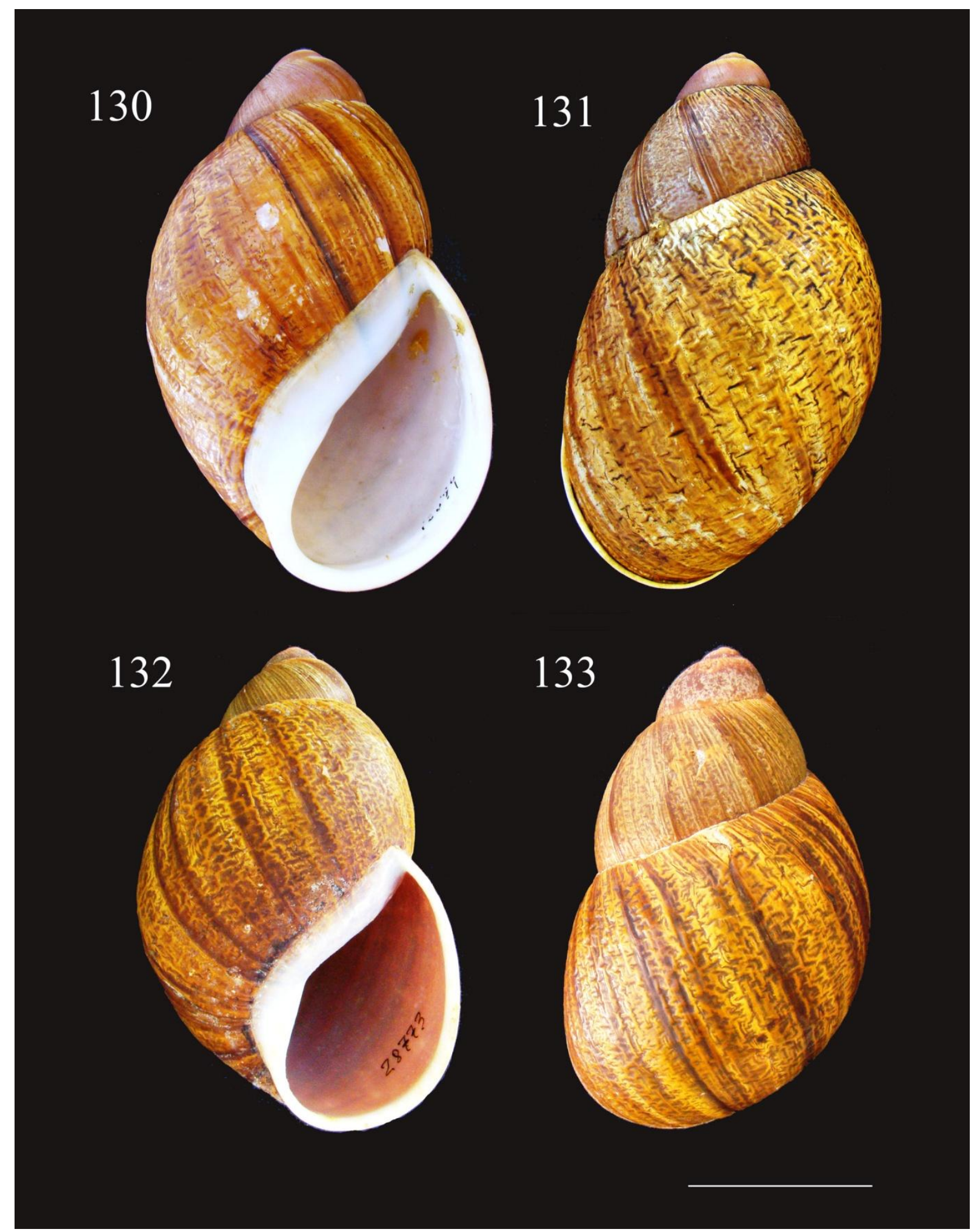

Figuras 130-133. Concha de Megalobulimus aff. gummatus. 130. Vista frontal de um exemplar do lote MZSP 15594 (Iporanga, SP); 131. Mesmo exemplar em vista dorsal; 132. Vista frontal de um exemplar do lote 28773 (Iguape, SP); 133. Mesmo exemplar em vista dorsal. $(\mathrm{ESCALA}=50 \mathrm{~mm})$. 


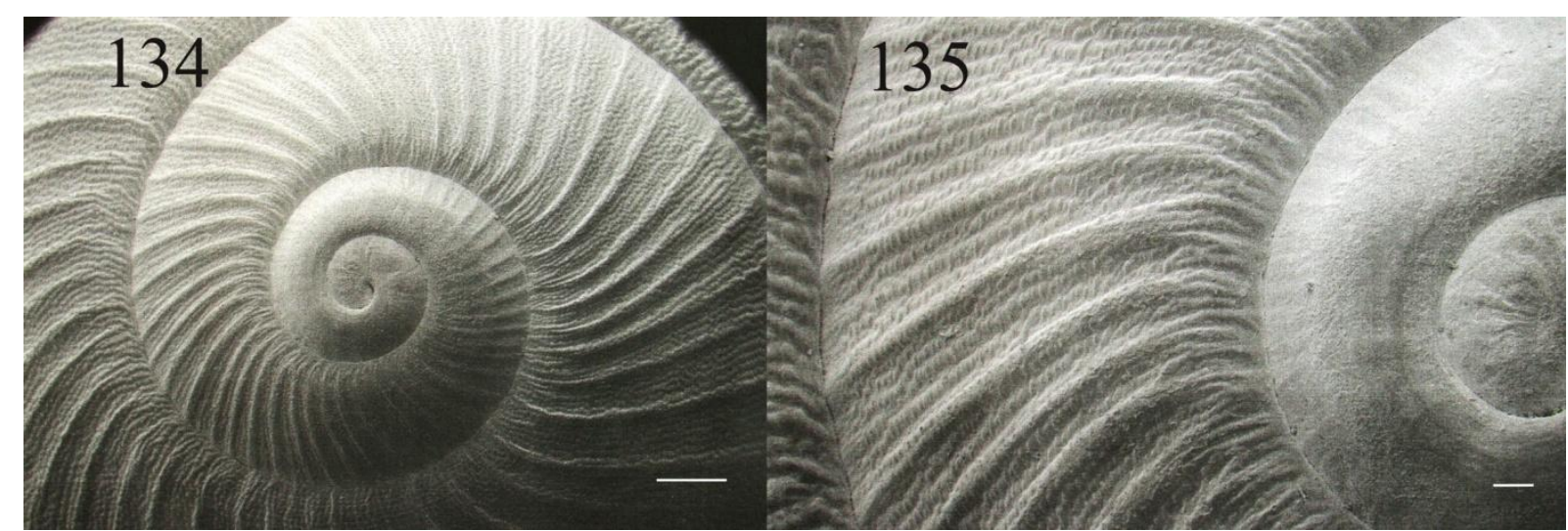

Figuras 134, 135. Protoconcha de Megalobulimus aff. gummatus. 134. Vista apical $($ ESCALA $=1 \mathrm{~mm}) ; 135$. Detalhe das costelas neopiônicas $($ ESCALA $=0,2 \mathrm{~mm})$.

Os dados biométricos da concha de $M$. aff. gummatus estão estatisticamente tratados e condensados na tabela 9 .

\begin{tabular}{rrrrrr}
\hline & COMP. & LARG. & ALT. & $\begin{array}{c}\text { VOLTAS } \\
\text { PROTOCH. }\end{array}$ & $\begin{array}{l}\text { VOLTAS } \\
\text { TOTAIS }\end{array}$ \\
\hline $\mathbf{n}$ & 98 & 96 & 95 & 64 & 69 \\
$\mathbf{m a x}$ & 135 & 75 & 62 & 3.8 & 5.8 \\
$\mathbf{m i n}$ & 93 & 54 & 48 & 3.0 & 4.9 \\
$\mathbf{a m p l}$ & 42 & 21 & 14 & 0.8 & 0.9 \\
$\boldsymbol{\mu}$ & 113 & 65 & 55 & 3.4 & 5.3 \\
$\mathbf{m}$ & 114 & 65 & 55 & 3.4 & 5.3 \\
$\mathbf{D P}$ & 9 & 4 & 3 & 0.2 & 0.2 \\
$\mathbf{C V}$ & $7.8 \%$ & $6.9 \%$ & $6.2 \%$ & $4.6 \%$ & $3.7 \%$ \\
$\mathbf{p}$ & 0.4880 & 0.8116 & 0.3437 & 0.7424 & 0.6465 \\
\hline
\end{tabular}

Tabela 9. Biometria da concha de Megalobulimus cf. gummatus. Legenda: n: tamanho da amostra; max: valor máximo; min: valor mínimo; ampl: amplitude; $\mu$ : média aritmética; m: mediana; DP: desvio padrão; CV (\%): coeficiente de variação em porcentagem; p: teste de normalidade de D'Agostino-Pearson (distribuição normal nos valores de $\mathrm{p}>0,05)$.

DISCUSSÃO TAXONÔMICA (M. aff. gummatus / M. gummatus)

$\mathrm{Na}$ fase de triagem dos lotes na coleção malacológica do MZSP, constatou-se que existiam duas populações distintas geograficamente e com significativas diferenças conquiliológicas designadas igualmente como $M$. gummatus. Uma com localidade e ocorrências no Rio de Janeiro (Hidalgo, 1870) e outra na região do Vale do Ribeira e litoral 
sul de São Paulo, sendo esta última selecionada para o estudo anatômico comparativo com as espécies do "complexo M. granulosus" por ser simpátrica ao M. paranaguensis. Assim no restante desta dissertação, serão estudados os exemplares procedentes de São Paulo, designados doravante provisóriamente como $M$. aff. gummatus.

Comparativamente, a concha de M. gummatus (Figs. 136, 137) apresenta as mesmas características de protoconcha e dimensões externas (Tab. 10), mas diferencia-se pela espira mais alta, peristoma mais refletido e espesso, com os lábios externo e interno paralelos dando a abertura da concha uma forma reta. A volta-do-corpo é levemente martelada e apresenta discretas linhas espiras regulares que ao se sobreporem às linhas de crescimento, resultam num padrão quadriculado.

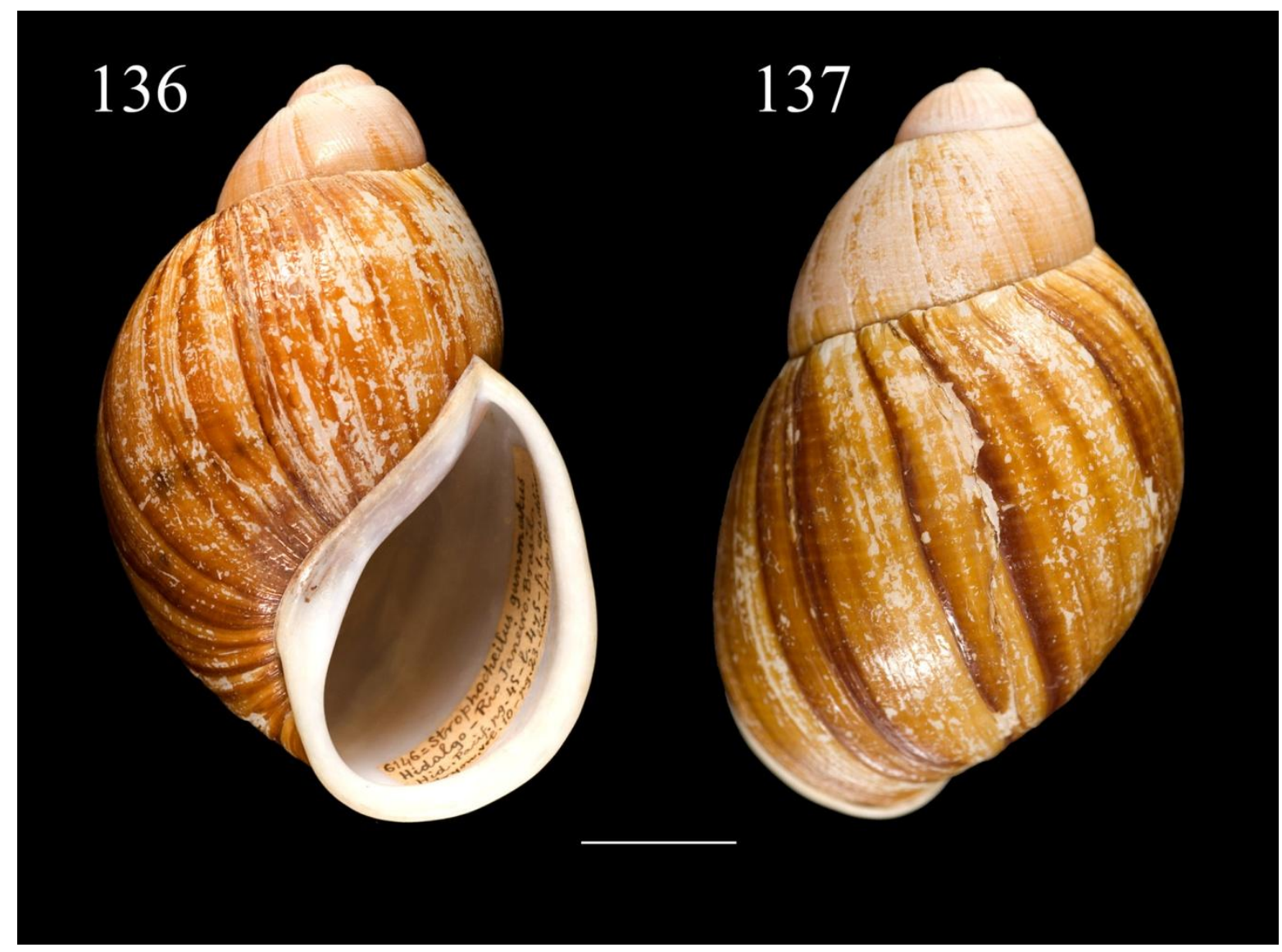

Figuras 136, 137. Concha holótipo de Megalobulimus gummatus MNCN 15.05/3199: 136. Vista frontal; 137. Vista dorsal $($ ESCALA $=20 \mathrm{~mm}$ ). Cortezia de Rafael Araujo. 


\begin{tabular}{rrrrrr}
\hline & COMP. & LARG. & ALT. & $\begin{array}{c}\text { VOLTAS } \\
\text { PROTOCH. }\end{array}$ & $\begin{array}{l}\text { VOLTAS } \\
\text { TOTAIS }\end{array}$ \\
\hline $\mathbf{n}$ & 15 & 15 & 15 & 11 & 13 \\
$\mathbf{m a x}$ & 120 & 69 & 57 & 3.6 & 5.4 \\
$\mathbf{m i n}$ & 108 & 60 & 51 & 3.3 & 5.1 \\
$\mathbf{a m p l}$ & 12 & 9 & 6 & 0.4 & 0.3 \\
$\boldsymbol{\mu}$ & 113 & 64 & 53 & 3.4 & 5.2 \\
$\mathbf{m}$ & 112 & 63 & 53 & 3.5 & 5.3 \\
$\mathbf{D P}$ & 3 & 3 & 2 & 0.1 & 0.1 \\
\hline $\mathbf{C V}(\boldsymbol{\%})$ & $2.8 \%$ & $4.8 \%$ & $3.7 \%$ & $3.4 \%$ & $1.7 \%$ \\
$\mathbf{p}$ & $\mathrm{ns}$ & $\mathrm{ns}$ & $\mathrm{ns}$ & $\mathrm{ns}$ & $\mathrm{ns}$ \\
\hline
\end{tabular}

Tabela 10. Biometria da concha de Megalobulimus gummatus. Legenda: n: tamanho da amostra; max: valor máximo; min: valor mínimo; ampl: amplitude; $\mu$ : média aritmética; m: mediana; DP: desvio padrão; CV (\%): coeficiente de variação em porcentagem; p: teste de normalidade de D'Agostino-Pearson (distribuição normal nos valores de $\mathrm{p}>0,05$ ).

ANATOMIA (M. aff. gummatus)

\section{Manto e cavidade palial}

Apresenta um tegumento de coloração cinza clara nos espécimes fixados. Borda do manto semelhante às espécies precedentes. Na cavidade palial (Figs. 141, 142) a goteira urinária avança até as proximidades do ânus, tendo continuidade pelo anal lateral e sulco urinário. O plexo de vaso sobre o septo é bem desenvolvido cobrindo cerca da $1 / 2$ da superfície reno-pericárdica (px), e apresentando muitas dicotomias os tributários da veia marginal (v1 a v3). Rim com forma triangular com cauda posterior e fundo da cavidade palial na última volta similares ao M. paranaguensis.

\section{Sistema digestivo}

A hemocele cefalopedal apresenta uma musculatura julgal mais robusta que nas espécies anteriores. A mandíbula (Fig. 138) com colunas axiais regulares proporcionalmente mais estreitas que das espécies anteriores, com linhas transversais de crescimento. Dentes 
radulares similares aos observados em $M$. granulosus. Estão distribuídos em aproximadamente 130 fileiras espaçadas (Figs. 139, 140) com formato retangular de proporções 3:1, ápice curto e obtuso, com uma discreta "raiz" lateral, enquanto que a coluna central apresenta-se estreita com pequenos dentes triangulares com o ápice direcionado para sua base não atingindo o dente posterior.

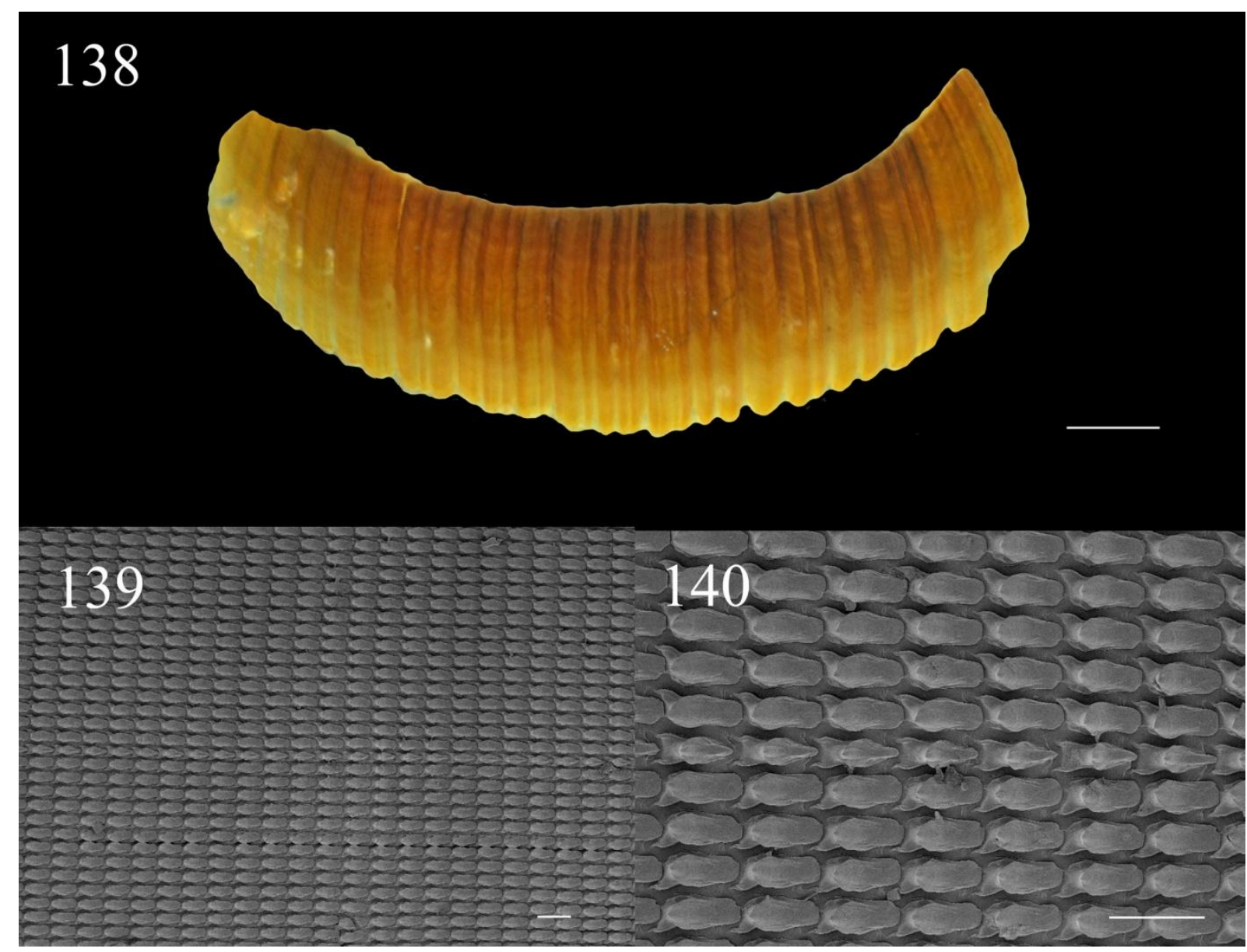

Figuras 138-140. Megalobulimus aff. gummatus: 138. Mandíbula (ESCALA = $10 \mathrm{~mm}) ; 139$. Rádula em SEM (ESCALA = 0,2 mm); 140. Detalhe do dente radular central (ESCALA = 0,2 mm).

A massa bucal (Fig. 143) se assemelha a M. paranaguensis com exceção da desembocadura dos ductos salivares que se encontram mais mediais e posteriores no teto da massa bucal (os). O esôfago (Fig. 144) apresenta uma configuração similar a descrita em $M$. granulosus com a parede do seguimento anterior delgada e translúcida, com uma superfície interna lisa e sem pregas (cn). O esôfago médio com fortes pregas musculares e o posterior com pregas discretas e serpiginosas que se avolumam na altura da inserção do ducto da glândula digestiva anterior no seu lado esquerdo. 
O estômago (Figs. 144, 145) com paredes fortemente musculosas recebe o ducto da glândula digestiva posterior no seu lado posterior direito. Internamente a parede é recoberta por pregas musculares, sendo reconhecido o canal intestinal (ci), o tiflossole intestinal (ti) e a musculatura pilórica (pl). Apresenta um canal esofágico (cf) que diferentemente de $M$. paranaguensis não se conecta ao canal intestinal, sendo limitado por uma prega entre a parede gástrica e a musculatura pilórica.

Embora o corte transversal do intestino proximal (Fig. 148) sugira uma distribuição uniforme das pregas intestinais, quando o órgão é secionado longitudinalmente (Fig. 149) observa-se uma maior distância entre as pregas $p 1$ e $p 2$ de forma semelhante a observada em M. granulosus. Como nas espécies anteriores, apenas a p4 (Fig. 149) atinge a válvula préretal, e após esta se observa pregas $p 7$ adensadas e encostadas umas as outras, que no intestino posterior (Fig. 150) se anastomosam em quatro pregas anais.

\section{Sistema reprodutivo}

O sistema reprodutivo (Figs. 151-160) apresenta um relativamente longo ducto hermafrodita (dh) que se insere apicalmente em um tálom destacável do corpo do saco glandular anexo de aspecto granuloso (Fig. 156). O carrerfour esta localizado medialmente no hilo da glândula de albume (gb) e a abertura distal da câmara de albume (Fig. 157) revela duas pregas na entrada do útero também observadas no M. paranaguensis. A próstata (pt) não é destacável do espermoviduto que apresenta em corte transversal (Fig. 158) a mesma configuração observada nas demais espécies do gênero Megalobulimus com a existência da glândula genital anexa (gg). As pregas internas do oviduto livre não estão direcionadas para a abertura do ducto da bursa copulatrix (Fig. 160), cujo ducto alargado e achatado conduz a uma bolsa de forma elíptica (Fig. 151) com a disposição de pregas na superfície interna semelhante as espécies anteriores.

Uma espessa bainha com conjuntivo com fibras musculares, vasos e nervos recobre o ramo masculino. Apresenta um pênis longo e cilíndrico que tracionado pelo ducto deferente como em M. paranaguensis assume uma postura convoluta com dobras e espirais (Figs. 152, 153). O epifalo é largo e curto com comprimento menor que $1 / 4$ do pênis, possuindo dois flagelos firmemente envolvidos escondidos pela bainha (Fig. 154). O epifalo também não recebe externamente feixes musculares do músculo retrator peniano. Internamente as pregas 
penianas apresentam a mesma configuração do $M$. paranaguensis, com uma discreta prega transversal não volumosa nem pedunculosa (Fig. 155). Não é evidente uma distensão do ápice peniano como em M. paranaguensis.

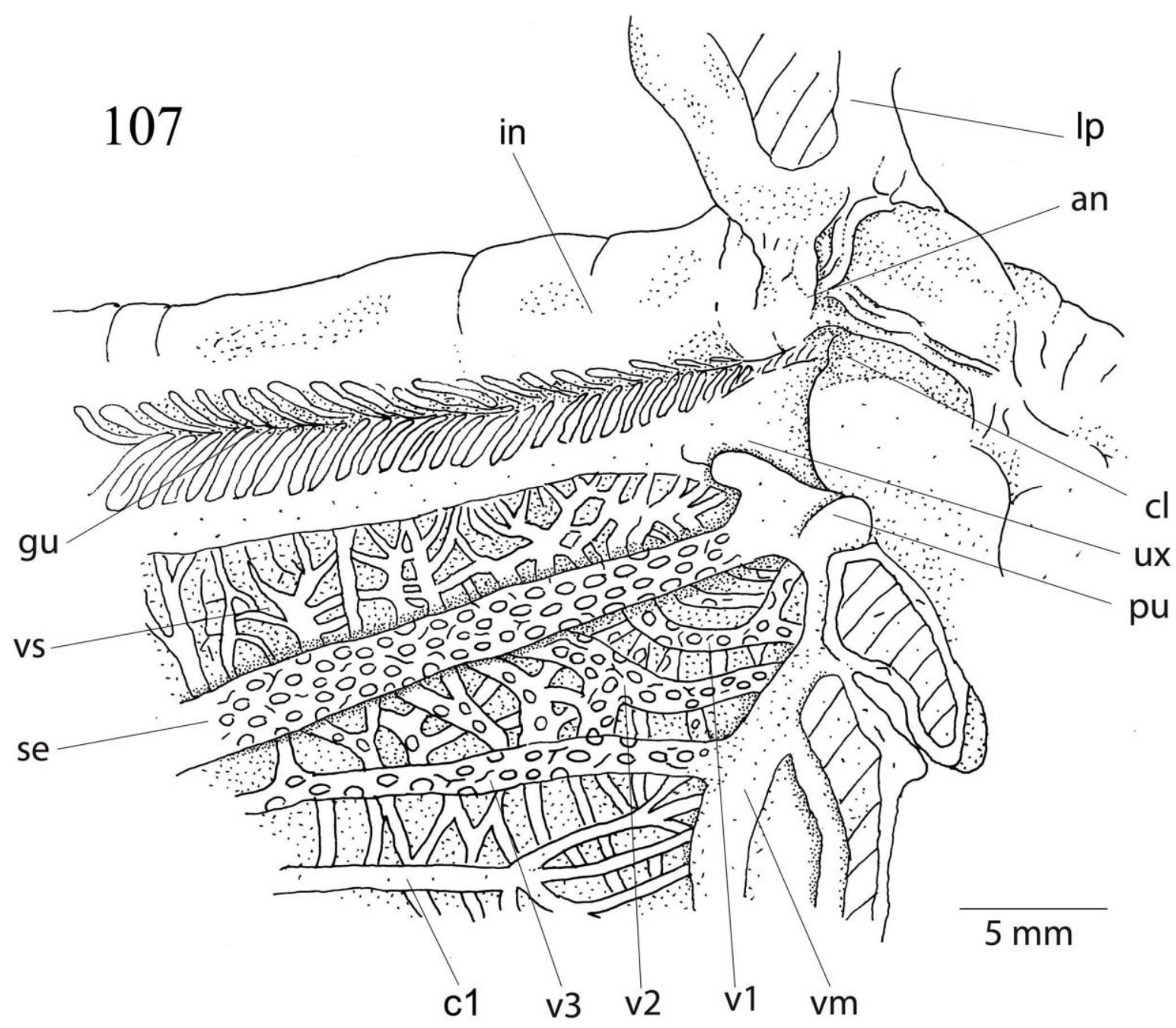

Figura 141. Região distal do septo e pneumóstoma em Megalobulimus aff. gummatus. an: ânus; cl: canal lateral; gu: goteira urinária; pu: prega do sulco urinário; rt: reto; se: septo; ux: sulco urinário externo; v1, v2 $e$ v3: ramificações da veia pulmonar; vm: veia marginal ou colar; vs: vasos ad-retais. 


\section{2}

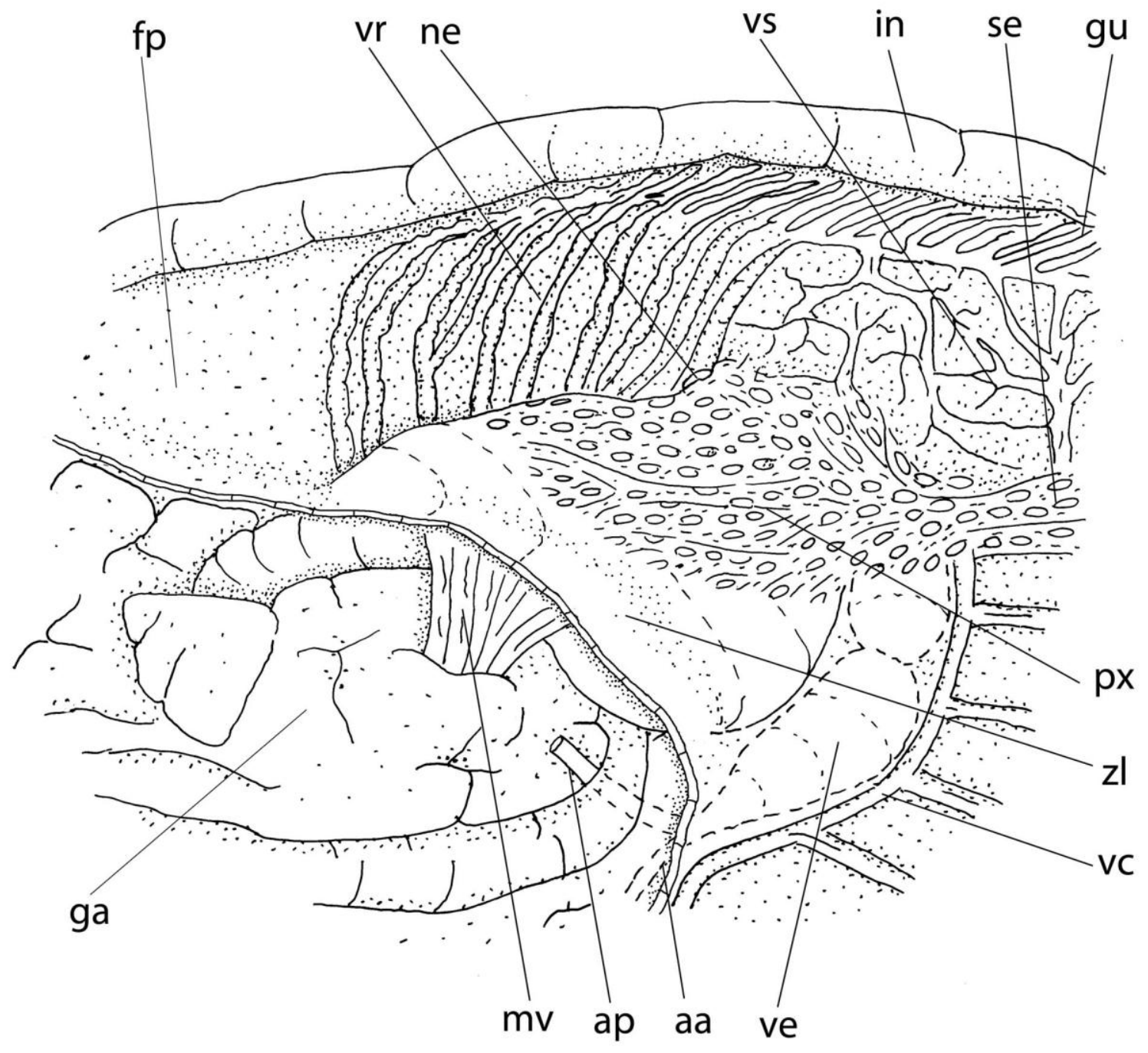

$\overline{5 \mathrm{~mm}}$

Figura 142. Região reno-pericárdica da câmara palial de Megalobulimus aff. gummatus. aa: aorta anterior; ap: aorta posterior; fp: fundo da cavidade palial; ga: glândula digestiva anterior; gu: goteira urinária; in: intestino; mv: feixe muscular palio-diafragmático; ne: nefróstoma; px: plexo epi-renal; se: septo; vc: vaso pericárdico; ve: ventrículo; vr: vasos ad-renais; vs: vasos ad-retais, zl: zona lisa do rim. 


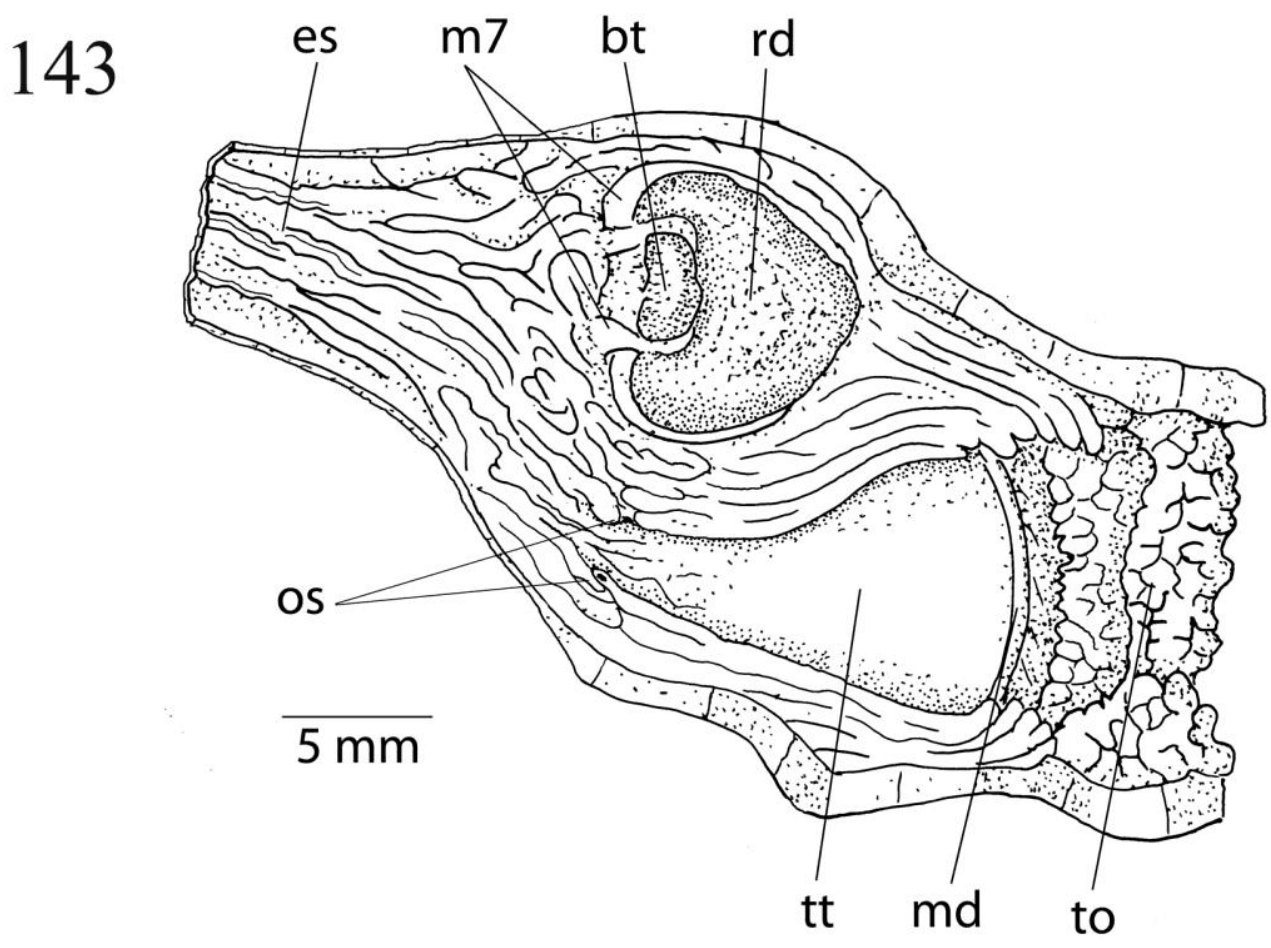

\section{4}

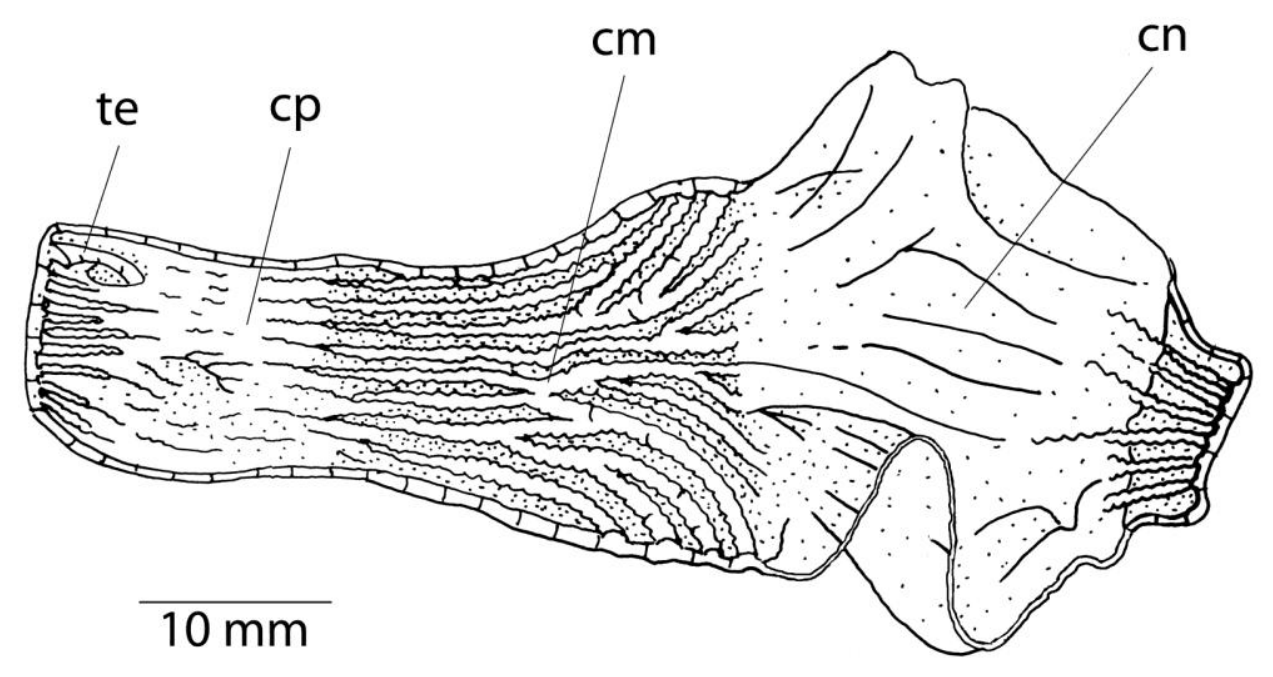

Figuras 143, 144. Sistema digestivo em Megalobulimus aff. gummatus: 143. Abertura longitudinal da massa bucal; 144. Abertura longitudinal do esôfago. bt: bonete da rádula; cn: esôfago anterior; cm: esôfago médio; cp: esôfago posterior; cr: cartilagem radular; fb: franja bucal; m7: músculo núcleo radular; md: mandíbula; os: óstios dos ductos salivares; rd: rádula; te: tiflossole esofágico; to: tubo oral; tt: teto da massa bucal. 

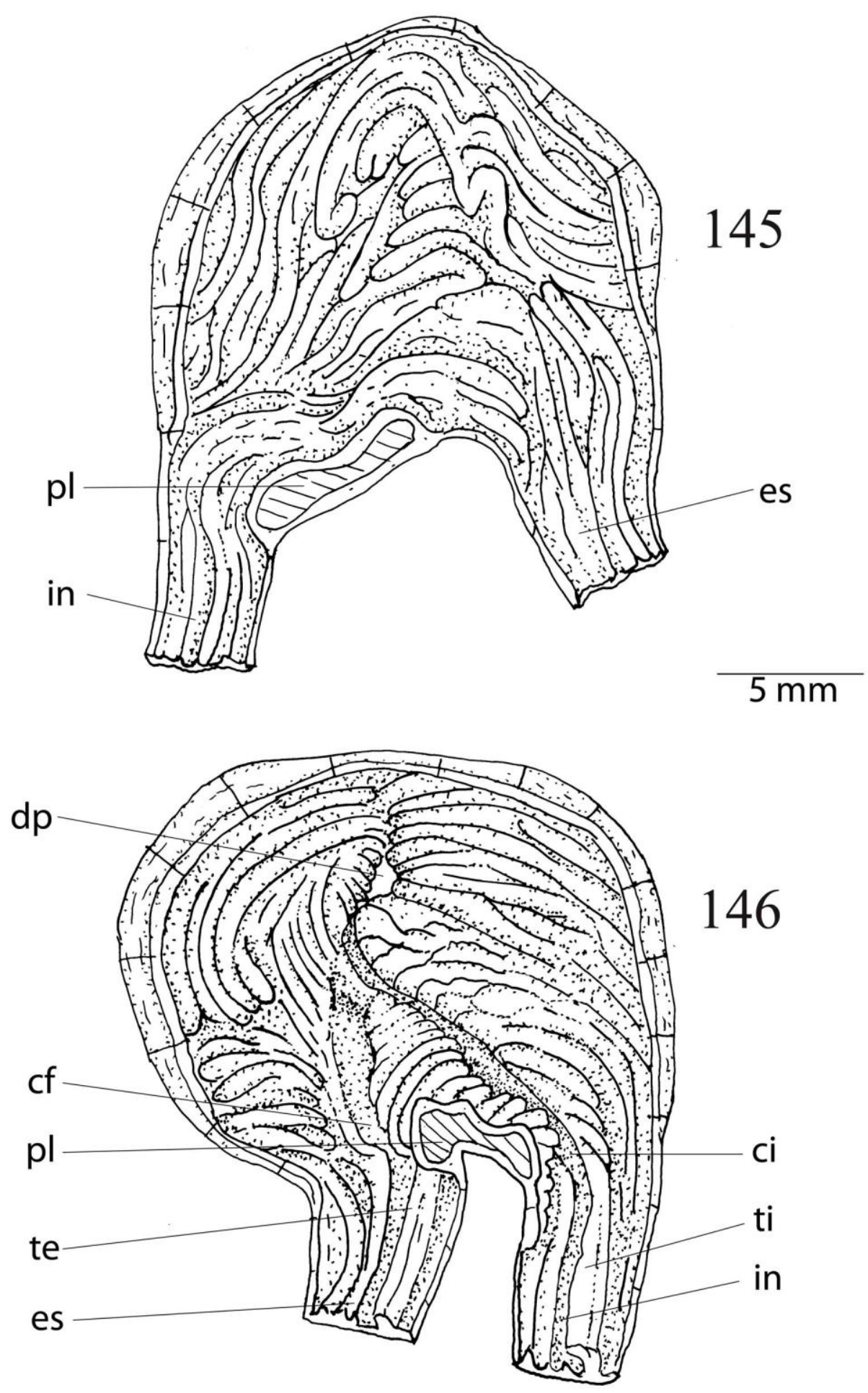

Figuras 145, 146. Estômago de Megalobulimus aff. gummatus: 145: Superfície interna do lado esquerdo; 146: Superfície interna do lado direito. cf. canal esofágico; ci. canal intestinal; dp. ducto para a glândula digestiva posterior; es. esôfago; in. intestino; pl. musculatura do piloro; te. tiflossole esofágico; ti. tiflossole intestinal. 


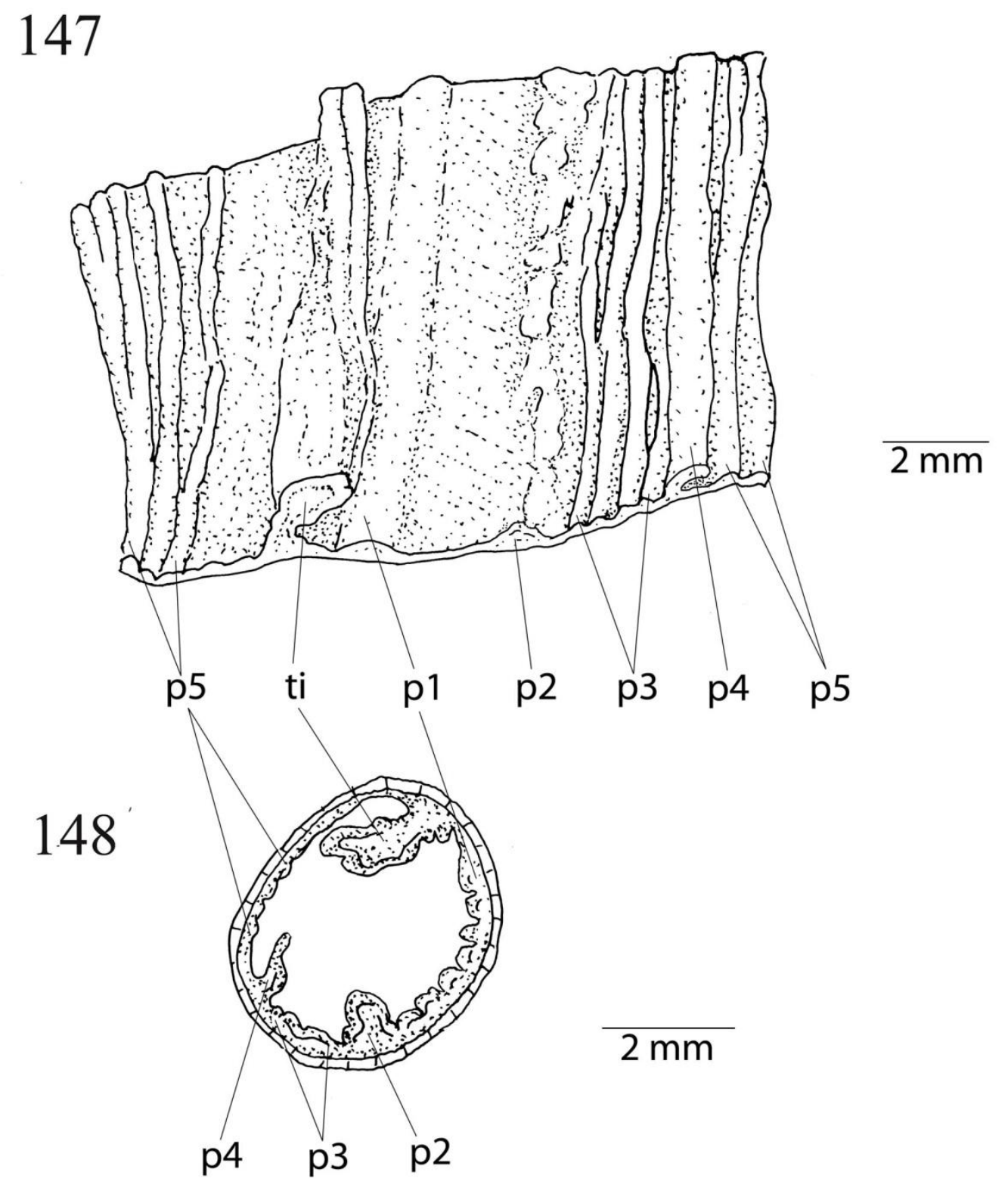

Figuras 147, 148. Intestino proximal de Megalobulimus aff. gummatus: 147. Superfície interna do intestino proximal; 148. Corte transversal do intestino proximal. p1, p2, p3, p4 e p5: pregas intestinais pré-valvulares; ti: tiflossole intestinal. 

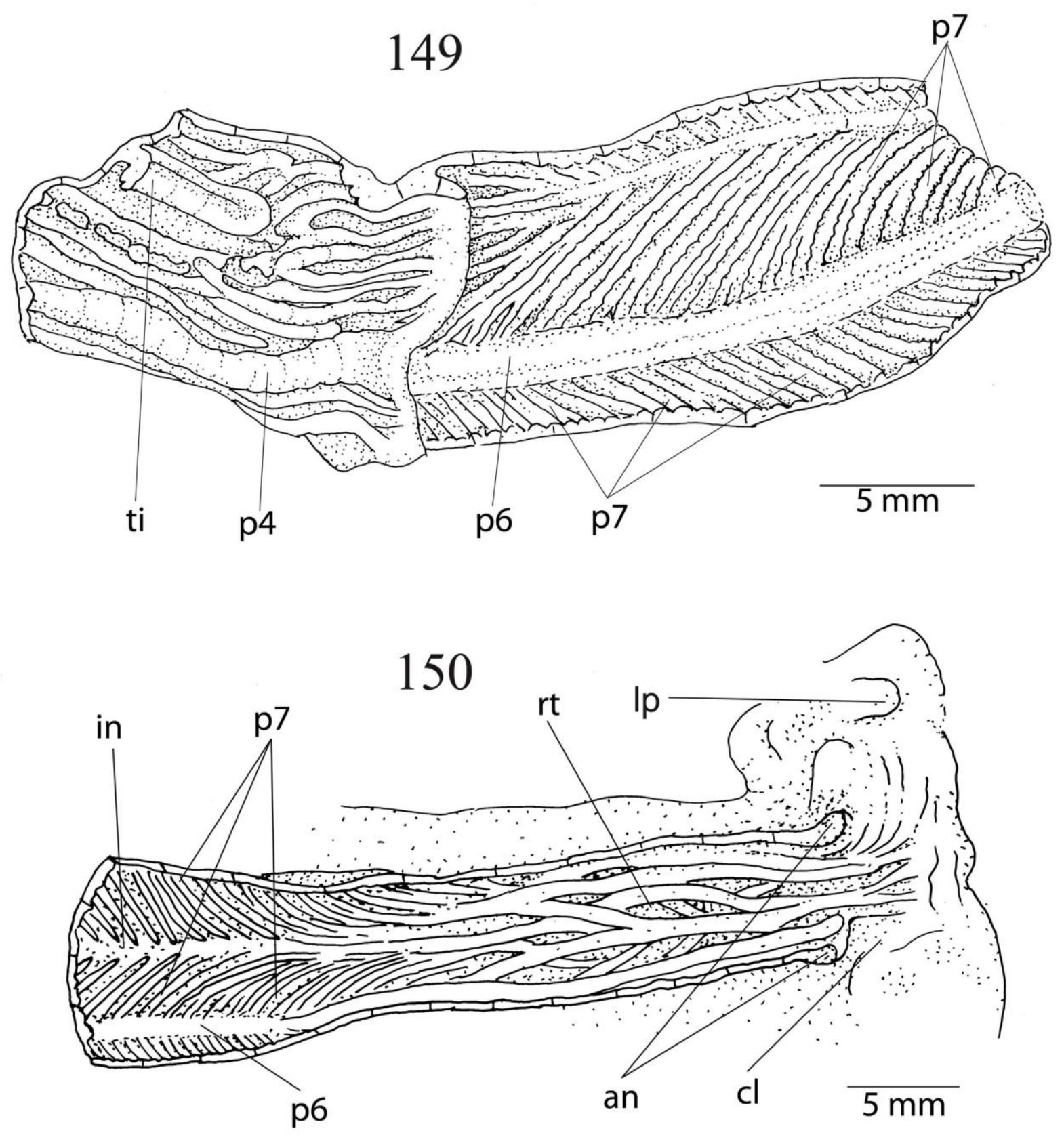

Figuras 149, 150. Intestino médio e posterior de Megalobulimus aff. gummatus. 149. Válvula préretal aberta longitudinalmente; 150. Intestino posterior aberto longitudinalmente. an: ânus; cl: canal lateral; in: intestino posterior; lp: lábio do pneumóstoma; p4: prega intestinal pré-valvular; p6 e p7: pregas intestinais pós-valvulares; rt: pregas retais; ti: tiflossole intestinal. 


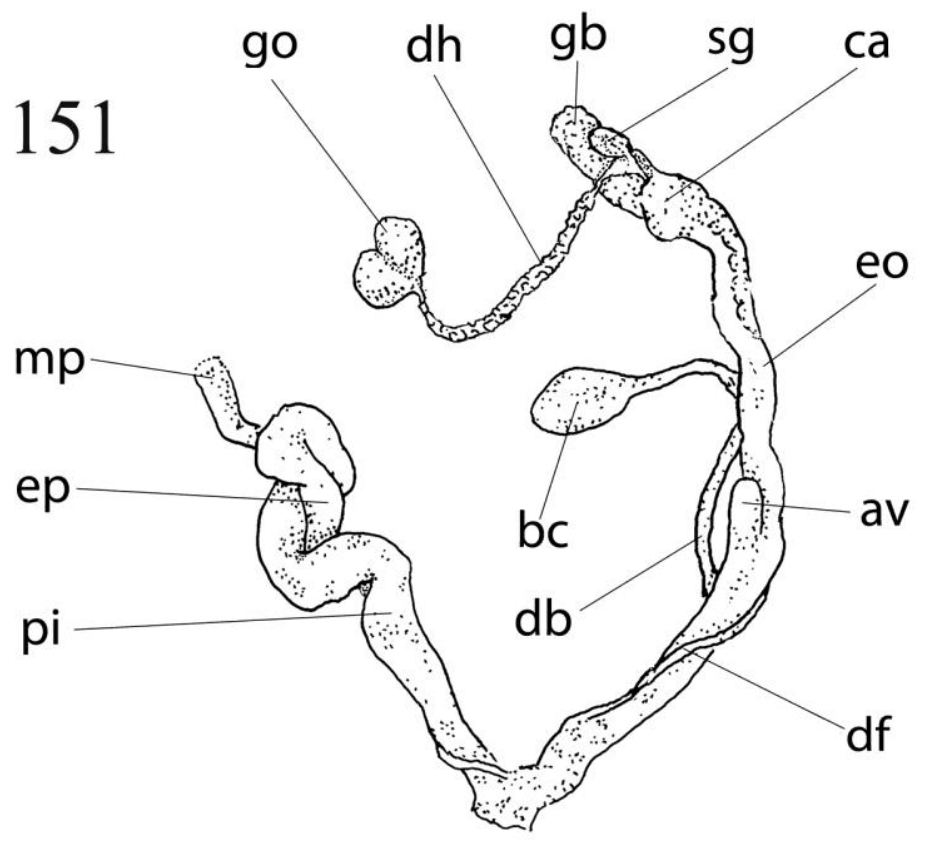

$\overline{10 \mathrm{~mm}}$

152

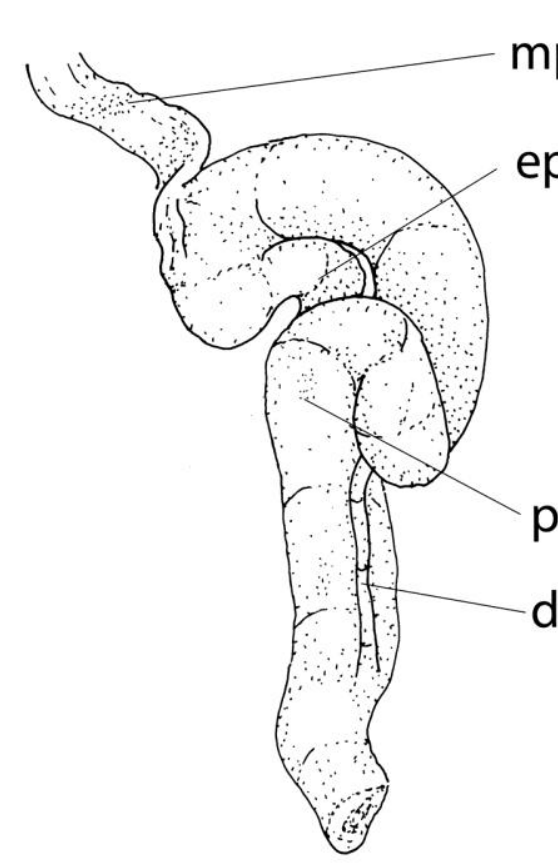

$\mathrm{mp}$

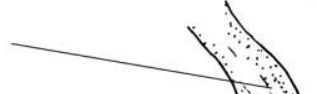

ep
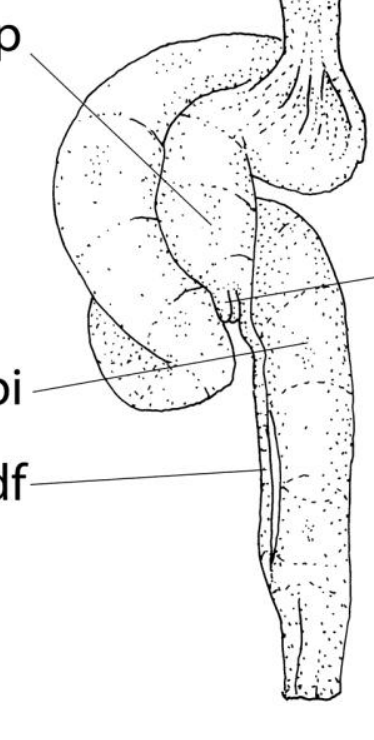

\section{$\overline{5 \mathrm{~mm}}$}

Figuras 151-153. Sistema reprodutor de Megalobulimus aff. gummatus. 151. Sistema reprodutor em vista esquerda; 152. Complexo peniano em vista esquerda; 153. Complexo peniano em vista direita. an: ânus; av: apêndice vaginal; bc: bursa copulatrix (bolsa copulatória); ca: câmara de albume; df: canal deferente; dh: ducto hermafrodita; eo: espermoviduto; fl: flagelos; ep: epifalo; gb: glândula de albume; go: gônada; mp: músculo peniano; pi: pênis; sg: saco glandular anexo. 


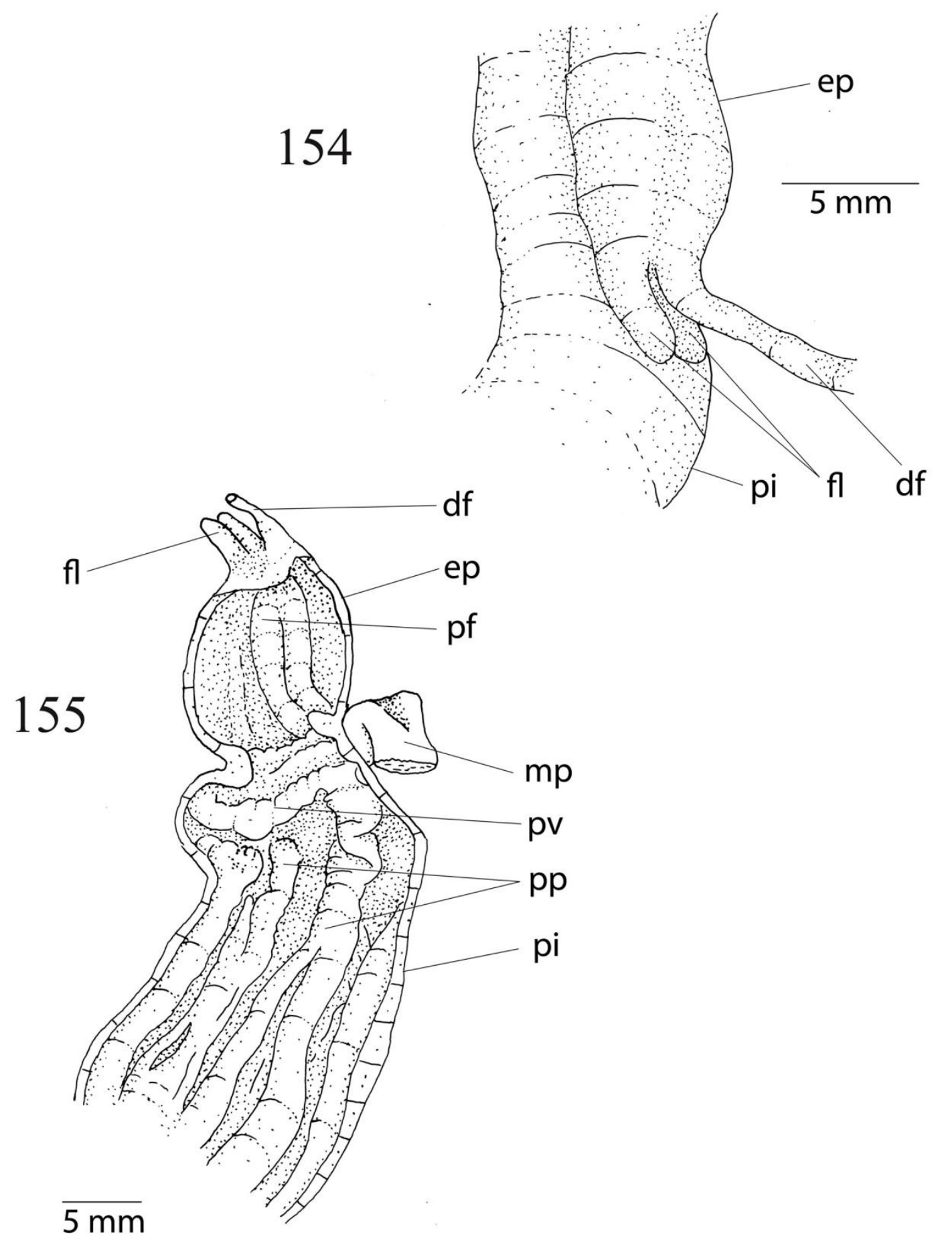

Figuras 154, 155. Sistema reprodutivo de Megalobulimus aff. gummatus: 154. Epifalo e flagelos; 155. Complexo peniano aberto longitudinalmente. df: canal deferente; ep: epifalo; fl: flagelos; mp: músculo peniano; pi: pênis; pf: prega do epifalo; pp: pregas penianas; pv: prega transversal do pênis. 

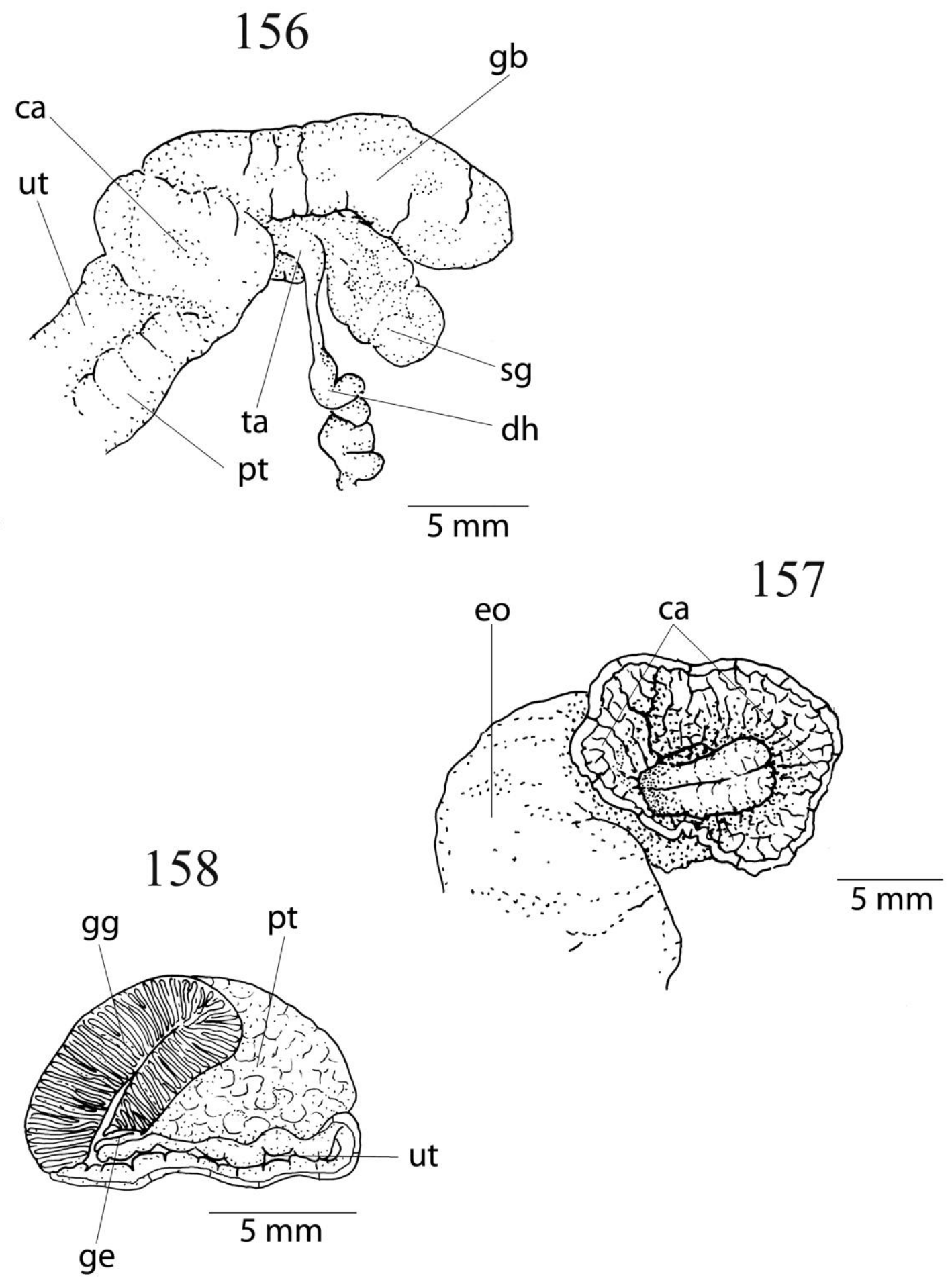

Figuras 156-158. Sistema reprodutor de Megalobulimus aff. gummatus: 156: Carrerfour em vista lateral; 157. Câmera da albume e entrada para o espermoviduto; 158. Corte transversal do espermoviduto. ca: câmara de albume; db: ducto da bursa; dh: ducto hermafrodita; eo: espermoviduto; gb: glândula de albume; ge: goteira espermática; gg: glândula genital acessória; pt: próstata; sg: saco glandular anexo; ta: tálom; ut: útero. 


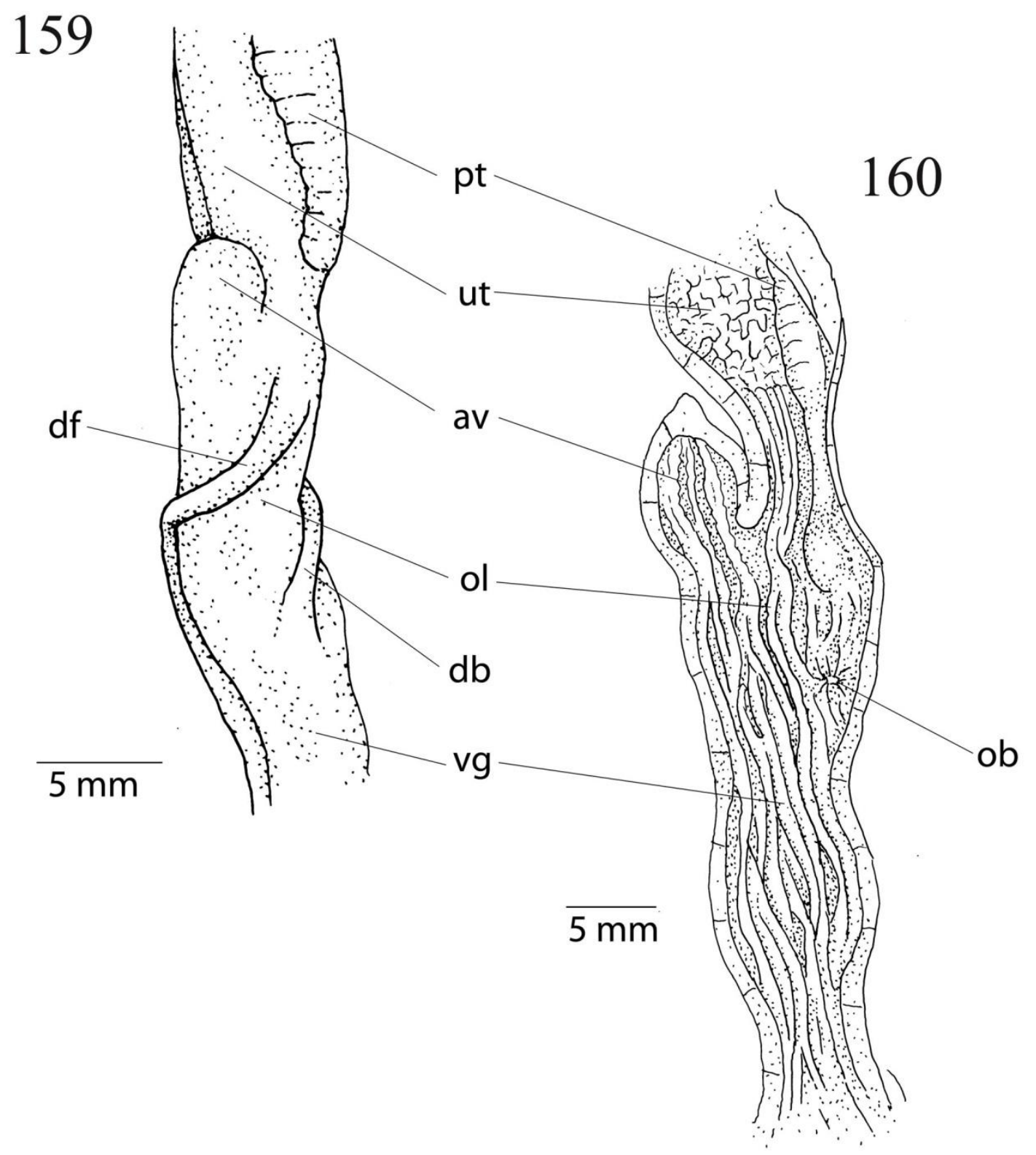

Figuras 159, 160. Sistema reprodutor de Megalobulimus aff. gummatus: 159. Espermoviduto e segmento feminino em vista lateral; 160 . Oviduto livre e vagina abertos longitudinalmente. av: apêndice vaginal; db: ducto da bursa; ob: óstio do ducto da bursa; ol: oviduto livre; po: prega do oviduto; pt: próstata; ut: útero; vg: vagina. 


\section{DISTRIBUIÇÃO GEOGRÁFICA}

Hidalgo (1869) localiza o M. gummatus no Rio de Janeiro "Entre las plantas, en puntos donde la vegetación es muy abundante. Poco común". Bequaert (1948), baseado exclusivamente nos caracteres da concha, identificou M. gummatus nas localidades de Cabo Frio, Corcovado e Serra da Mantiqueira, RJ, e no rio 'Gregugi' (possivelmente grafia errada de 'Gongogi'), na Bahia. A partir de meados do século XX, as referências de ocorrências de M. aff. gummatus para a região do Vale do Ribeira, no litoral sul de São Paulo, são descritas como M. gummatus. Assim, Morretes (1953), registra a ocorrência de M. gummatus no Estado do Rio de Janeiro, e nos municípios de São Vicente, Juquiá e Iporanga, em São Paulo, enquanto que Thomé et al. (2007) registra para a Região Sul a ocorrência apenas no Paraná, e Agudo-Padrón (2008) estudando os moluscos de Santa Catarina, registra M. gummatus no extremo oeste do Estado no município de São João do Oeste e Piratuba.

Os 55 lotes estudados do MZSP de $M$. aff. gummatus com registro de localidade (Tab. 11), estão distribuídos por uma ampla área que inclui a região do Vale do Ribeira, litoral paulista meridional, e nos planaltos próximos com cerca de 600 metros de altitude (Fig. 161), enquanto que os 12 lotes de M. gummatus estão restritos as localidades Cabo Frio e Arraial do Cabo, RJ (Tab. 12).

O M. aff. gummatus aparenta ter uma maior tolerância ambiental em relação as demais espécies e as localidades fora do Vale do Ribeira são consideradas como introduções.

\begin{tabular}{rr|lr}
\hline \multicolumn{1}{c}{ LOCALIDADE } & $\begin{array}{c}\text { N. DE } \\
\text { LOTES }\end{array}$ & \multicolumn{1}{c}{ LOCALIDADE } & $\begin{array}{c}\text { N. DE } \\
\text { LOTES }\end{array}$ \\
\hline Iporanga, SP & 8 & Itapecerica da Serra, SP & 1 \\
Miracatu, SP & 8 & Jacupiranga, SP & 1 \\
Iguape, SP & 7 & Juquetiba, SP & 1 \\
Juquiá, SP & 5 & Mogi das Cruzes, SP & 1 \\
Itariri, SP & 3 & Pedro de Toledo, SP & 1 \\
Guapiará, SP & 3 & Peruíbe, SP & 1 \\
Itanhaem, SP & 2 & Registro, SP & 1 \\
Itapeva, SP & 2 & São Sebastião, SP & 1 \\
Pariguera-açú, SP & 2 & São Vicente, SP & 1 \\
Biguá, SP & 1 & Tapiraí, SP & 1 \\
Cubatão, SP & 1 & Morretes, PR & 1 \\
Eldorado Paulista, SP & 1 & Sengés, PR & 1 \\
\hline
\end{tabular}

Tabela 11. Número de lotes de Megalobulimus aff. gummatus por localidade na coleção do MZSP 


\begin{tabular}{cc|cr}
\hline LOCALIDADE & $\begin{array}{c}\text { N. DE } \\
\text { LOTES }\end{array}$ & LOCALIDADE & \multicolumn{2}{c}{ N. DE } \\
LOTES
\end{tabular}

Tabela 12. Número de lotes de Megalobulimus gummatus por localidade na coleção do MZSP

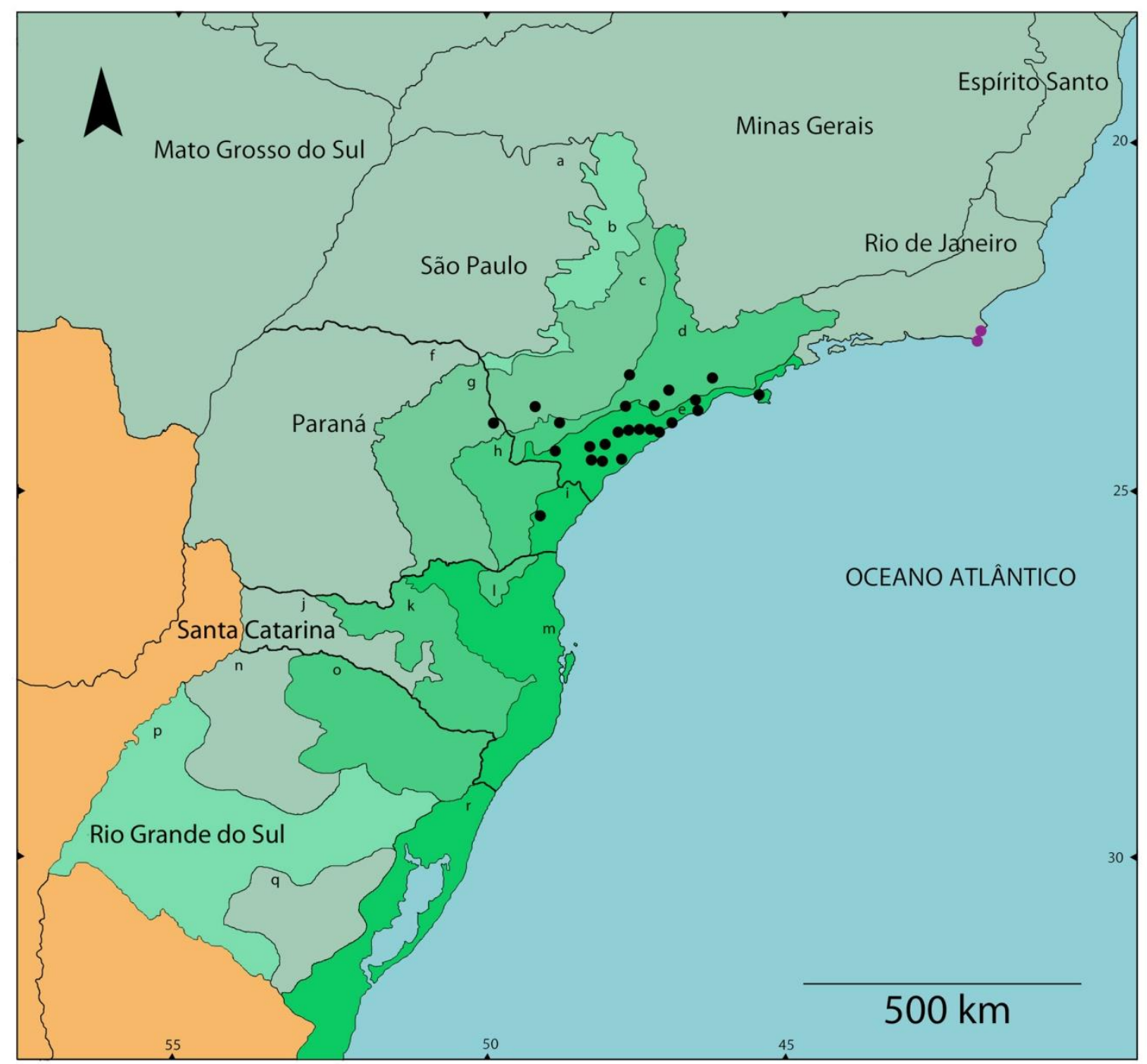

Figura 161. Distribuição geográfica do Megalobulimus aff. gummatus (pontos pretos) e Megalobulimus gummatus (pontos roxos) baseada nas localidades dos lotes depositados no MUSP. d: Planalto cristalino paulista; c: Depressão periférica paulista; d: Planalto cristalino paulista; e: Planície costeira paulista; $\mathbf{g}$ : Segundo planalto paranaense; i: Planície costeira paranaense. 


\subsection{Megalobulimus haemastomus (Scopoli, 1786)}

Bulimus haemastomus Scopoli, 1786

Lista sinonímica vide Bequaert, 1948: 74-75. Complemento:

Strophocheilus (Megalobulimus) oblongus haemastomus: Bequaert, 1948: 75-78, pl. 6, fig. 2; pl. 21, fig. 4; pl. 24, fig. 5 .

Strophocheilus crassus: Morretes, 1949: 143.

Psiloicus haemastomus: Morretes, 1952, p.113; Leme, 1971: 17.

Megalobulimus oblongus haemastomus: Scarabino, 2003: 211.

Megalobulimus haemastomus: Salgado \& Coelho, 2003: 158; Simone, 2006: 211, fig. 805;

Thomé et al. 2007: 22.

Tipo: perdido

Localidade tipo: não informada.

Material examinado. BRASIL. MZSP 64426, 14 espécimes, MZSP 98932, 1 espécime, MZSP 98933, 1 espécime. Rio Grande do Sul. Monte Alegre, MZSP 3268, 12 conchas (H. Von Ihering col.); Cerro Largo, MZSP 29239, 1 concha (C.N. Goffergé col., ii/1951); São Borja, Reserva Biológica São Donato, MZSP 48238, 1 concha (A. Assunção col., 23/vii/1980); Faxinal do Soturno, São João do Poleseme, MZSP 28949, 2 conchas (H.R. Schumacher col., 18/v/1982); Santa Maria, MZSP 48244, 4 conchas (L. Indrusiak col., xii/1976); Porto Alegre, MZSP 29263, 48 exemplares; Tapes, Lagoa do Cerro, MZSP 16184, 27 conchas (Meirelles col.); Bagé, MZSP 29109, 3 espécimes (A. Berge col., 1990). URUGUAI. MZSP 64528, 3 espécimes (MNHNM leg.).

\section{CONCHA}

As proporções externas da concha oval alongada (Figs. 162-171) são muito semelhantes ao M. abbreviatus com comprimento em torno de $68 \mathrm{~mm}$ em 5,5 voltas. Difere por ser geralmente perfurata, não ser saciforme a esquerda da columela, e pelo deslocamento para a direita (vista frontal) da abertura. Espira curta, larga e com ápice de arredondado à ligeiramente agudo. Periostraco caduco de coloração castanho amarelada. Concha neopiônica (Figs. 172, 173) com 3,3 voltas discretamente convexas, com aparecimento das costelas neopiônicas prosóclinas a partir da segunda volta, largas de sutura a sutura como em $M$. 
abbreviatus, mas regulares e constantes na largura e intervalos, e sem costelas acessórias. Microescultura granulosa discreta facilmente perdida

Penúltima volta e a volta-do-corpo com linhas de crescimento e intervalos irregulares, planas e com bordos retos no denominado padrão "oblongus" com microescultura granulosa na penúltima volta. Lábio externo formando ângulo $>90^{\circ}$ com a parede parietal Abertura estreita e menor que $1 / 2$ do comprimento, deslocada para a direita por um lábio interno e columela retos. Perístoma refletido e geralmente espessado (Fig. 2), sendo esta a principal característica conquiliológica atribuída a esta espécie (Scopoli, 1786; Bequaert, 1948). 


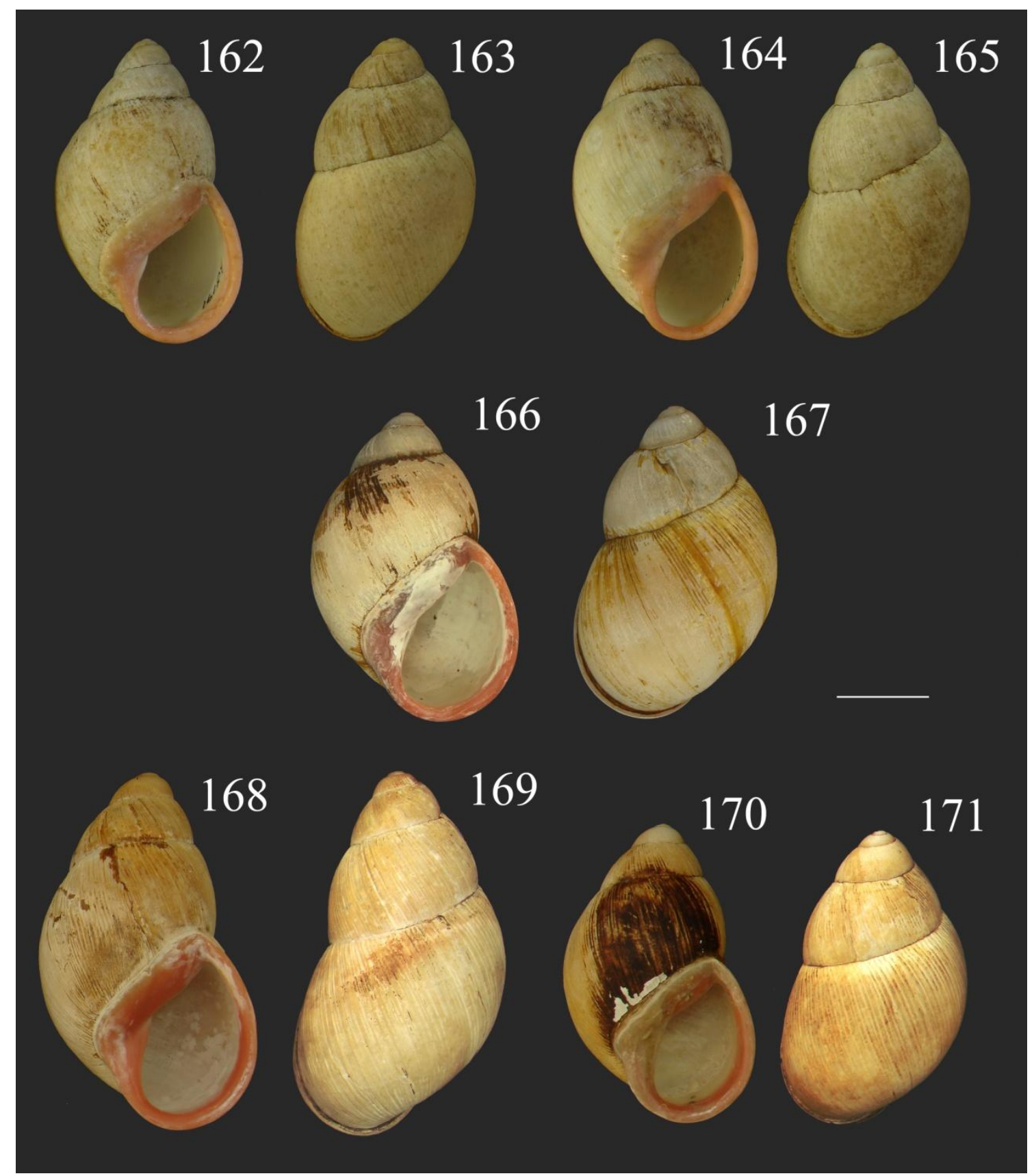

Figuras 162-171. Concha de Megalobulimus aff. haemastomus: 162 a 165. Duas conchas do lote MZSP 16184 (Tapes, RS) em vistas frontal e dorsal; 166 e 167. Concha do lote MZSP 29263 (Porto Alegre, RS) em vista frontal e dorsal; 168 a 171. Duas conchas do lote 64528 (Uruguai) em vistas frontais e dorsais $(\mathrm{ESCALA}=20 \mathrm{~mm})$ 


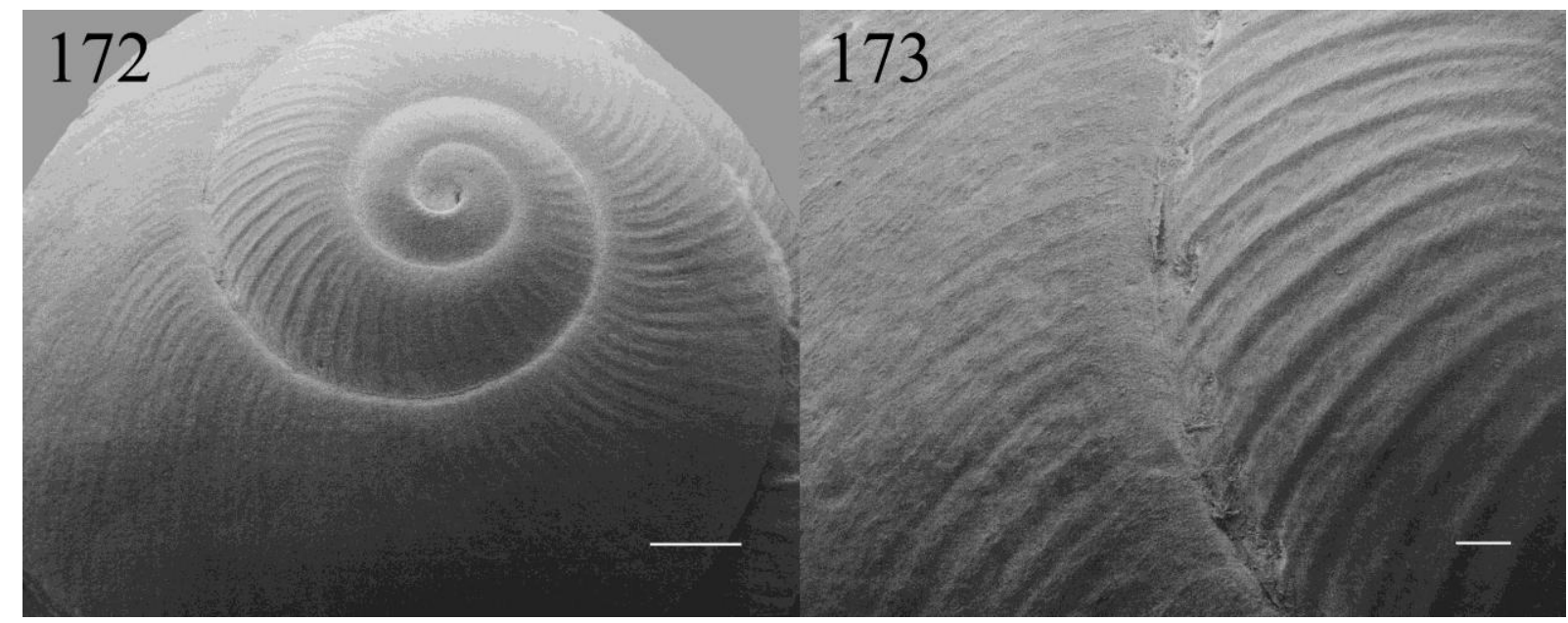

Figuras 172, 173. Protoconcha de Megalobulimus cf. haemastomus. 172. Vista apical $(\mathrm{ESCALA}=1 \mathrm{~mm}) ; 173$. Detalhe das costelas neopiônicas $($ ESCALA $=2 \mathrm{~mm})$.

Os dados biométricos da concha de $M$. cf. haemastomus estão estatisticamente tratados e condensados na tabela 13 .

\begin{tabular}{rrrrrr}
\hline & COMP. & LARG. & ALT. & $\begin{array}{c}\text { VOLTAS } \\
\text { PROTOCH. }\end{array}$ & $\begin{array}{l}\text { VOLTAS } \\
\text { TOTAIS }\end{array}$ \\
\hline $\mathbf{n}$ & 62 & 63 & 63 & 41 & 58 \\
$\mathbf{m a x}$ & 86 & 47 & 41 & 3.6 & 5.8 \\
$\mathbf{m i n}$ & 60 & 34 & 30 & 3.0 & 5.0 \\
$\mathbf{a m p l}$ & 26 & 13 & 11 & 0.6 & 0.8 \\
$\boldsymbol{\mu}$ & 68 & 39 & 34 & 3.3 & 5.4 \\
$\mathbf{m}$ & 68 & 39 & 34 & 3.3 & 5.5 \\
$\mathbf{D P}$ & 4 & 3 & 2 & 0.2 & 0.2 \\
$\mathbf{C V}$ & $6.4 \%$ & $6.6 \%$ & $6.2 \%$ & $5.5 \%$ & $4.0 \%$ \\
$\mathbf{p}$ & $<0.0001$ & 0.0053 & 0.0103 & 0.2622 & 0.1822 \\
\hline
\end{tabular}

Tabela 13. Biometria da concha de Megalobulimus cf. haemastomus. Legenda: n: tamanho da amostra; max: valor máximo; min: valor mínimo; ampl: amplitude; $\mu$ : média aritmética; m: mediana; DP: desvio padrão; CV (\%): coeficiente de variação em porcentagem; p: teste de normalidade de D'Agostino-Pearson (distribuição normal nos valores de $\mathrm{p}>0,05)$.

\section{ANATOMIA DOS TECIDOS MOLES}

\section{Cavidade palial}


A borda do manto observada após a remoção da concha apresenta-se larga e pouco volumosa similar ao M. abbreviatus. Um sulco percorre sua superfície dividindo-a em um estreito lábio externo e um largo lábio interno (Fig. 180). No exame da região do pneumóstoma (Fig. 179) observa-se um discreto plexo de vasos anastomosados sobre o septo e os primeiros tributários do vaso colar (c3). A goteira urinária com pregas oblíquas bilaterais recobre parte da circunferência do intestino posterior, prolongando-se até o ânus; não há uma concavidade lateral ao ânus (o denominado canal lateral observado nas espécies precedentes), entretanto o sulco urinário externo (ux) apresenta uma continuidade em forma de calha no lábio interno da borda do manto (Figs. 179, 180).

Na região reno-pericárdica o rim tem forma triangular com uma cauda curta e o fundo da cavidade palial esta localizado no meio da penúltima volta como em M. granulosus e $M$. abbreviatus.

\section{Sistema digestivo}

A mandíbula elasmognata e pigmentada apresenta largas colunas axiais estreitas e rasas na região central que se esmaecem em sentido as laterais.

Nos dentes radulares foram observados dois diferentes, embora similares, padrões no formato e distribuição dos dentes, significando que as amostras de M. cf. haemastomus utilizadas podem pertencer a espécies próximas distintas que na presente dissertação foram agrupadas pelas características em comum com o objetivo de serem confrontadas com as espécies do "complexo M. granulosus".

Os dentes radulares (Figs. 175-178) estão alinhados em cerca de 80 fileiras, são espaçados tanto nas colunas como nas linhas, tem a forma retangular com a largura maior que a metade do comprimento, e apresentam um ápice curto e obtuso. $\mathrm{O}$ dente central é mais curto e estreito e não apresenta crista. Em indivíduos procedentes do Uruguai (Fig. 177), há maior espaçamento entre os dentes que apresentam um ápice mais raso e obtuso; enquanto que o dente central assume um forma ovalada (Fig. 178). 


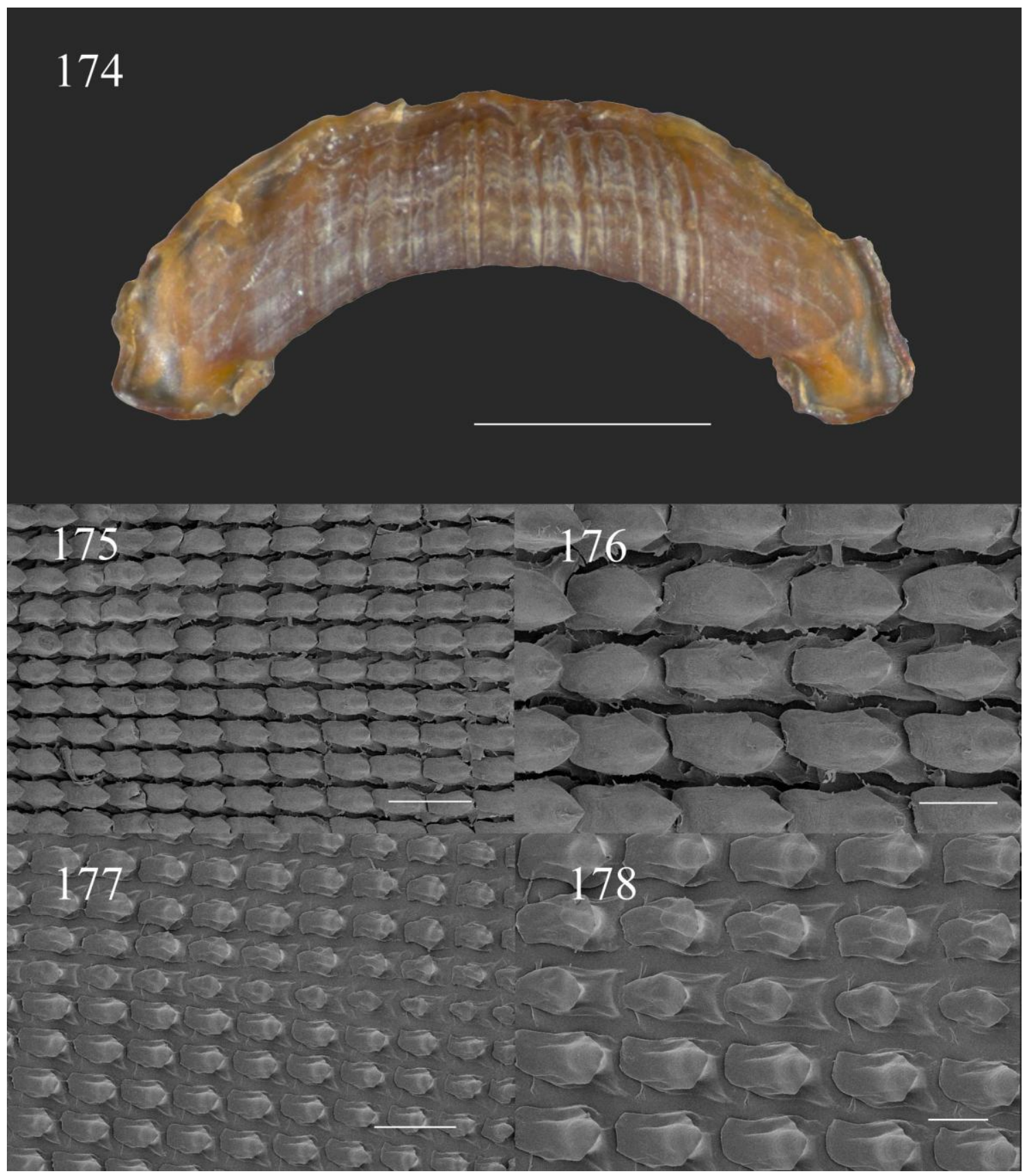

Figuras 174-178. Megalobulimus aff. haemastomus. 174. Mandíbula (ESCALA = 2 mm); 175, 176. Rádula de um espécime de Bagé, MZSP 29109; 177, 178. Rádula de um espécime do Uruguai, 64528) (ESCALA 175, $177=0,2 \mathrm{~mm}$; ESCALA 176, $178=0,1 \mathrm{~mm}$ ).

Massa bucal curta as aberturas dos ductos das glândulas salivares próximas ao teto da cavidade (Fig. 181: os). Odontóforo com um proeminente bonete radular, com musculatura radular apresentando o mesmo padrão das espécies anteriores, embora com feixes proporcionalmente menos volumosos. Inserção do $m 2$ por fáscias musculares. A artéria radular origina-se da ramo posterior esquerdo da cefálica como nos $M$. paranaguensis e $M$. aff. gummatus. 
Similarmente as espécies anteriores o esôfago apresenta as glândulas salivares parcialmente fundidas e aderidas à uma membrana tubular sobre seu segmento anterior. Entretanto este órgão apresenta as paredes delgadas e translúcidas por toda sua extensão (Fig. 182). No segmento anterior (cn) uma única e larga prega plicada pode ser distinguida ventralmente, enquanto que no segmento médio $(\mathrm{cm})$ identificam-se discretas pregas com anastomoses transversais, e no posterior (cp) pregas igualmente discretas e serpiginosas, que se alinham na altura da abertura do ducto da glândula digestiva posterior (da).

O estômago (Figs. 183, 184) apresenta uma forma arredondada e suas paredes finas estão geralmente distendidas por alimento, e com aspecto nacarado nas áreas centrais nos lados direito e esquerdo onde a musculatura parece ser substituída por uma fáscia fibrosa. Internamente distingue-se a inserção do ducto da glândula digestiva posterior (dp) dorso lateralmente a direita, o tiflossole intestinal (ti), e o canal intestinal (ci). Uma também delgada musculatura pilórica ( $\mathrm{pl}$ ) pode ser observada na curvatura menor e circundando a saída gástrica.

O intestino proximal e médio são igualmente distendidos e delgados. Internamente (Figs. 185, 186) o segmento médio exibe pregas baixas e discretas com exceção do tiflossole intestinal (ti) e da p4. Diferentemente de todas as espécies anteriores, na altura da válvula préretal, apenas o tiflossole intestinal e precocemente interrompido e não tem contato com a válvula (Fig. 186). A distribuição das pregas pós-valvulares são similares às observadas em M. paranaguensis e M. granulosus.

\section{Sistema reprodutor}

O sistema reprodutor de M. cf. haemastomus (Fig. 187) apresenta o mesmo padrão das espécies anteriores com a gônada (go) envolvida pela glândula digestiva posterior, um relativamente longo espermoviduto e a presença de um apêndice vaginal (Fig. 189).

As características observadas $M$. cf. haemastomus incluem uma glândula de albume e espermoviduto com vincos retos em sua superfície causados pela compressão do músculo columelar; carrefour deslocado proximalmente no hilo da glândula de albume; tálom destacável do saco glandular anexo que se apresenta liso sem aspecto granuloso (Fig. 187, 188: sg). De forma semelhante aos M. granulosus e $M$. abbreviatus apresenta as pregas musculares do oviduto livre direcionadas para o óstio do ducto da bursa copulatrix (Fig. 189), 
que é curto com aproximadamente a metade do comprimento do espermoviduto (Fig. 187: $\mathrm{db}$ ), e conduz para uma bursa arredondada com paredes finas e desprovida de pregas internas que estava muito aumentada de volume em alguns exemplares, mas não necessariamente distendida (bc). O conteúdo da bursa variou de um material pastoso aquoso a um núcleo sólido acrescido de camadas concêntricas imersos em um meio líquido.

Nesta espécie observamos nos indivíduos estudados um poro genital raso onde em um exame externo pode se identificar uma abertura dorso anterior para o ramo masculino e outra posterior e ventral pata o feminino.

O ramo masculino (Figs. 187, 190) apresenta a forma de clava, tendo o epífalo cerca de $1 / 2$ do comprimento peniano. Uma inserção alta do músculo peniano não evidencia feixes para o epífalo, que apresenta dois longos e desiguais flagelos laterais à desembocadura do ducto deferente. Internamente no ápice peniano observamos pregas penianas e uma bem desenvolvida prega transversal (Fig. 190: pv). 


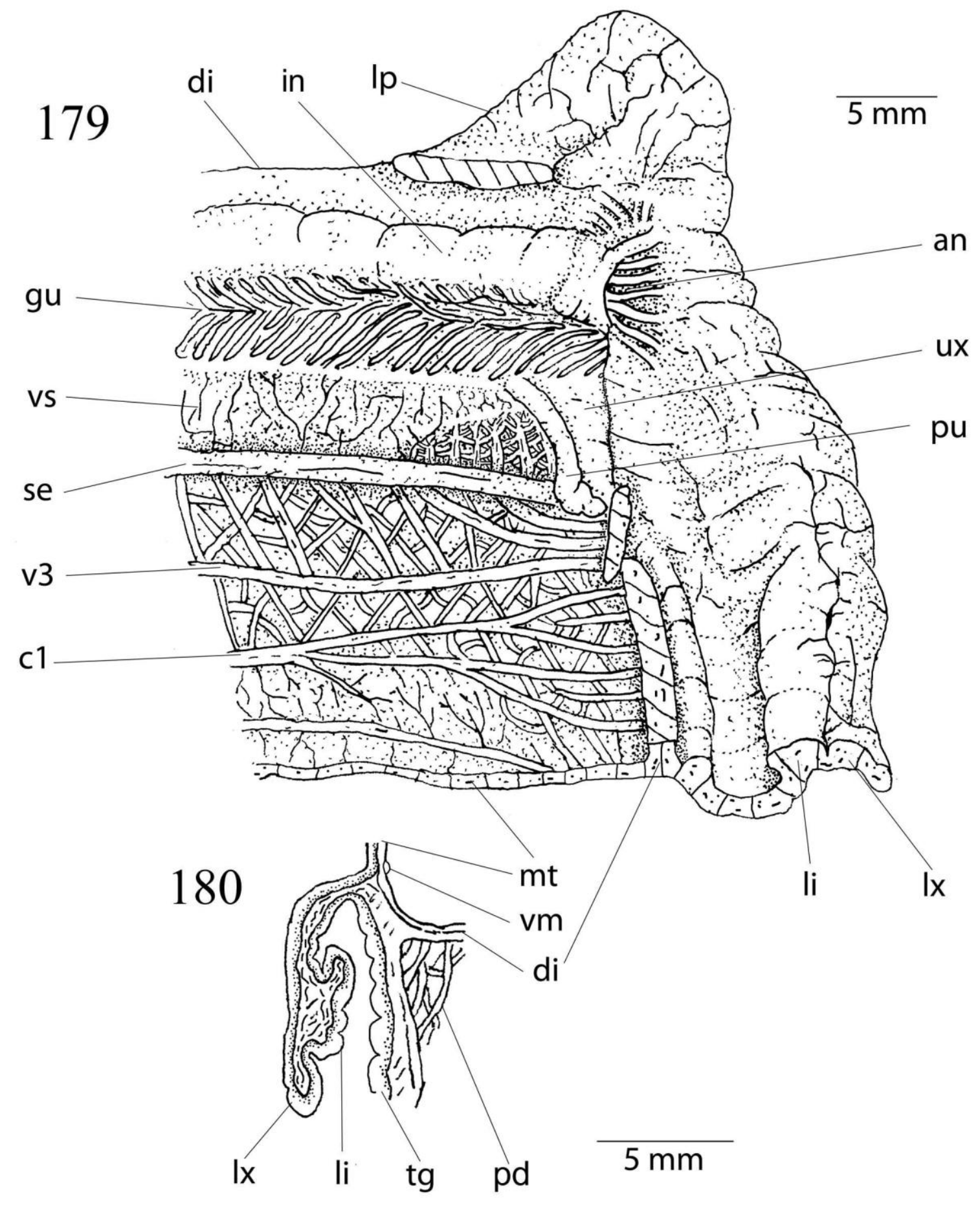

Figura 179, 180. Região distal do septo e pneumóstoma, e secção transversal da borda do manto de Megalobulimus abbreviatus. an: ânus; c1: ramificação do vaso pericárdico; di: diafragma; gu: goteira urinária; in: intestino; li: lábio interno da borda do manto; lp: lábio do pneumóstoma; lx: lábio externo da borda do manto; mt: manto; pd: pé; pu: prega do sulco urinário; se: septo; tg: tegumento; ux: sulco urinário externo; v3: ramificação da veia pulmonar; vm: veia marginal ou colar; vs: vasos ad-retais. 


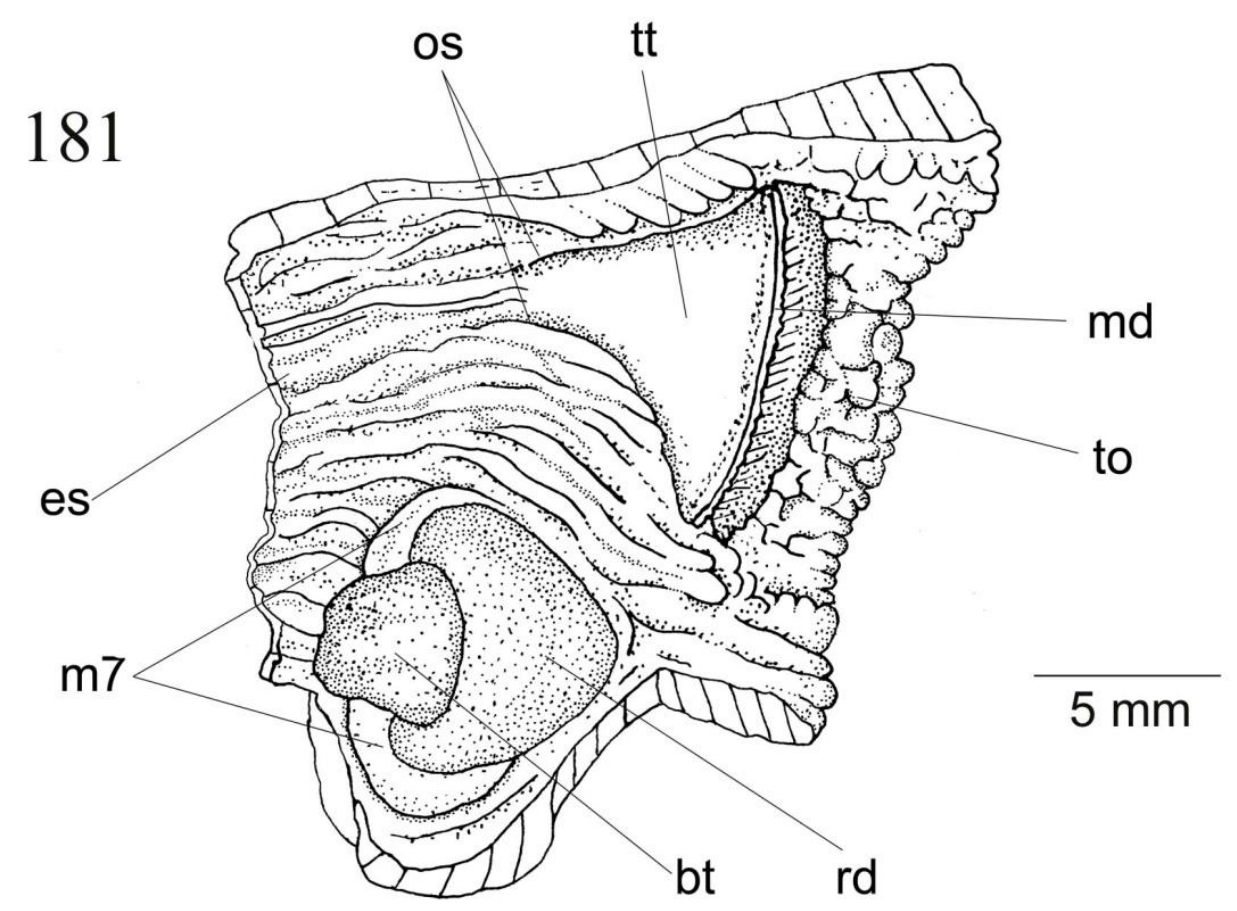

182

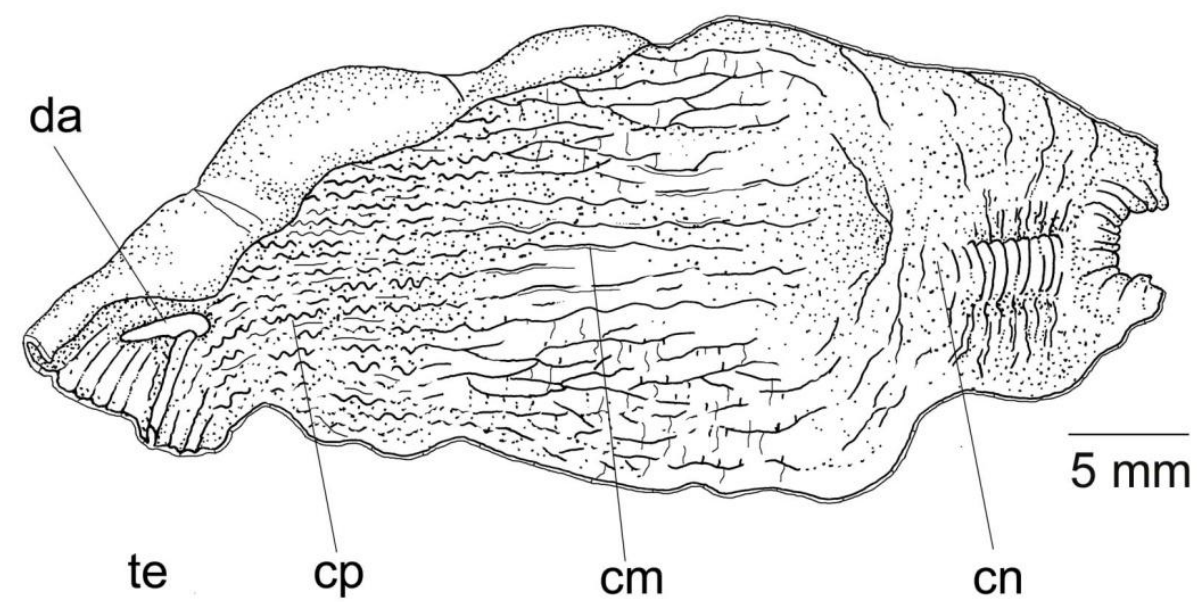

Figuras 181, 182. Sistema digestivo em Megalobulimus cf. haemastomus: 181. Abertura longitudinal da massa bucal; 182. Abertura longitudinal do esôfago. bt: bonete da rádula; cn: esôfago anterior; cm: esôfago médio; cp: esôfago posterior; cr: cartilagem radular; m7: músculo núcleo radular; md: mandíbula; os: óstios dos ductos salivares; rd: rádula; te: tiflossole esofágico; to: tubo oral; tt: teto da massa bucal. 


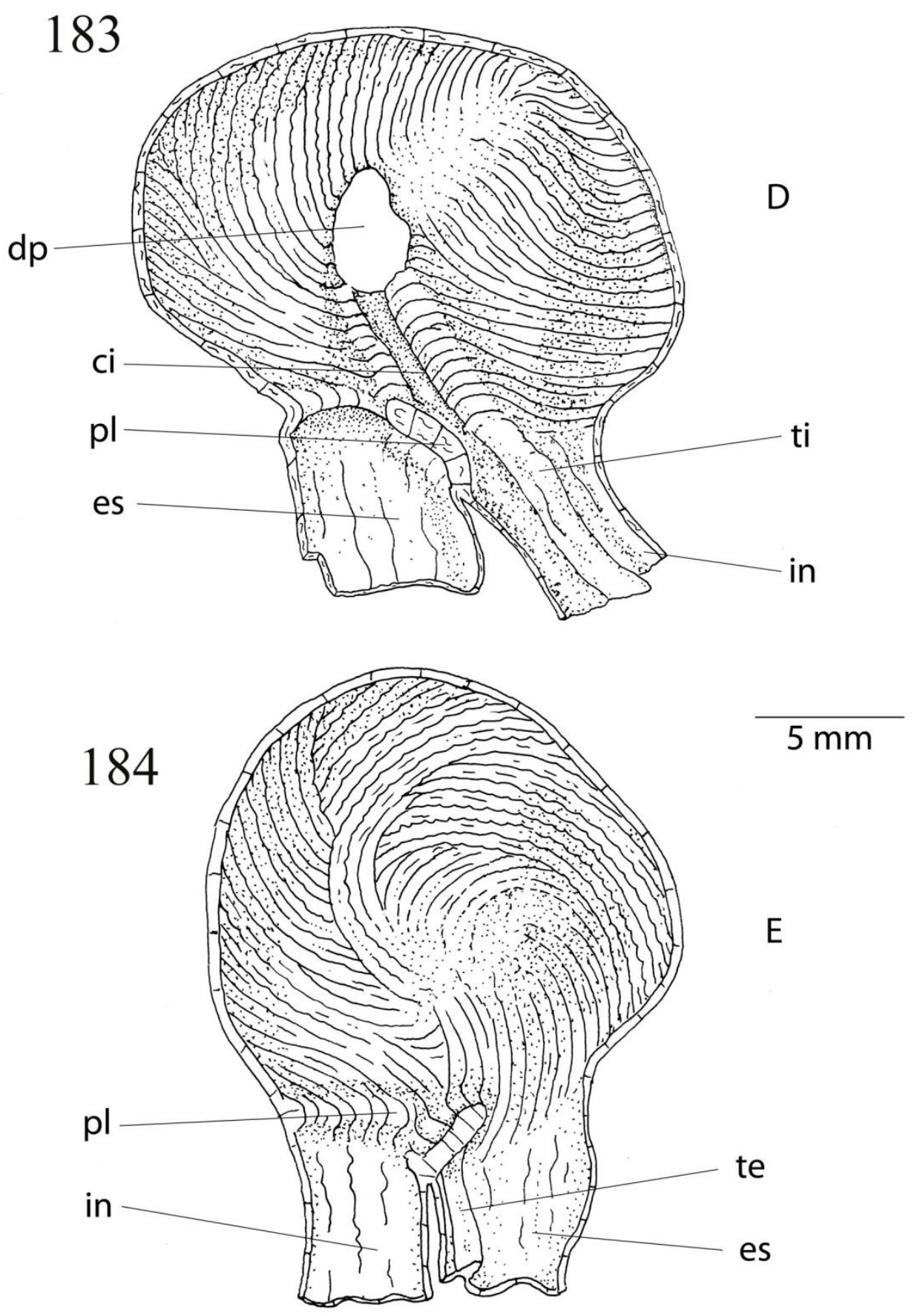

Figuras 183, 184. Estômago de Megalobulimus cf. haemastomus: 183: Superfície interna do lado direito; 184: Superfície interna do lado esquerdo. ci. canal intestinal; dp. ducto para a glândula digestiva posterior; es. esôfago; in. intestino; pl. musculatura do piloro; te. tiflossole esofágico; ti. tiflossole intestinal. 

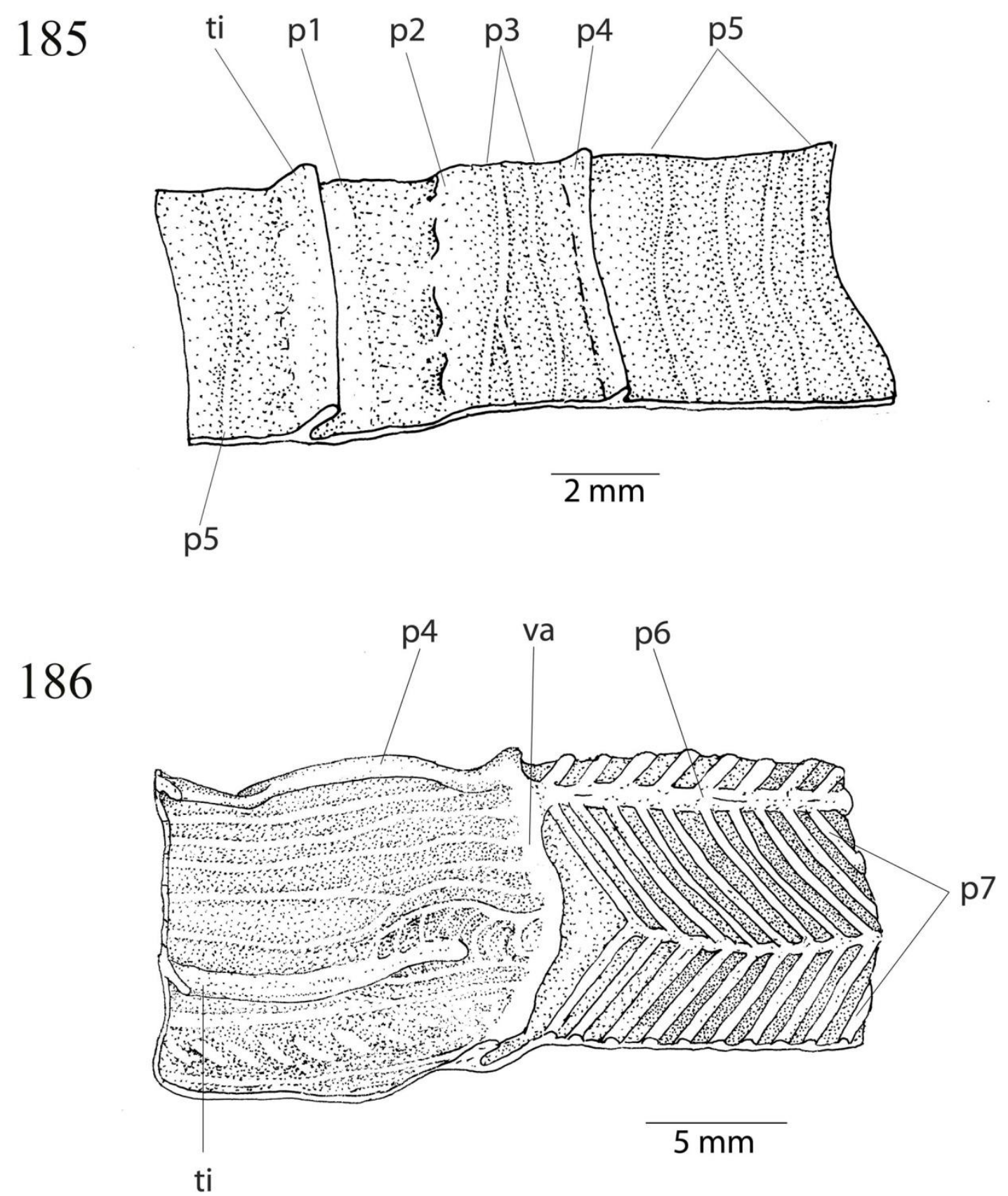

Figuras 185, 186. Sistema digestivo de Megalobulimus granulosus: 185. Superfície interna do intestino proximal; 186. Válvula pré-retal aberta longitudinalmente. p1, p2, p3, p4 e p5: pregas intestinais pré-valvulares; p6 e p7: pregas intestinais pós-valvulares; ti: tiflossole intestinal; va: válvula pré-retal. 


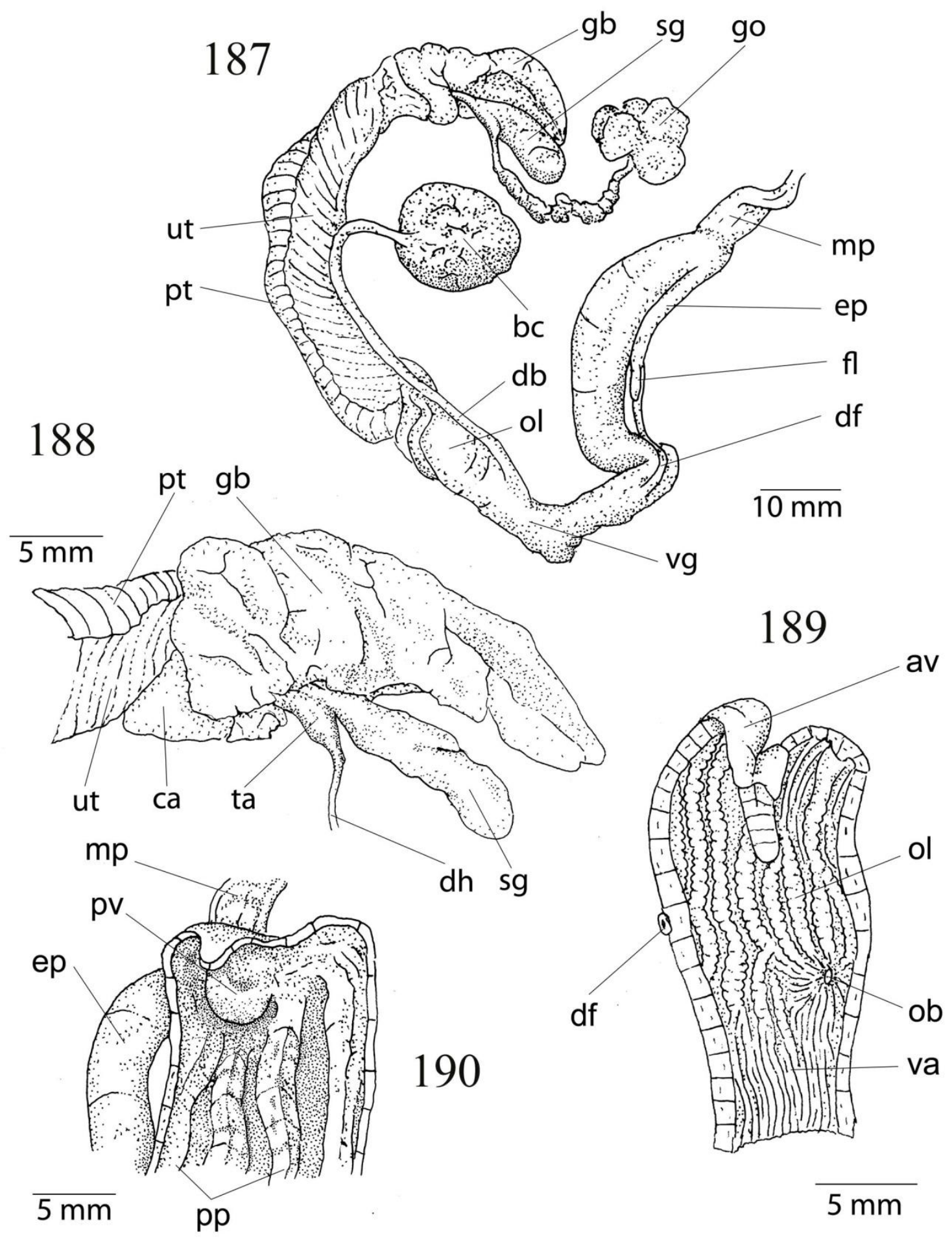

Figuras 187-190 Sistema reprodutor de Megalobulimus cf. haemastomus. 187. Sistema reprodutor em vista direita; 188. Carrefour em vista lateral; 189. Oviduto livre e vagina abertos longitudinalmente; 190. Ápice peniano seccionado longitudinalmente. av: apêndice vaginal; bc: bursa copulatrix (bolsa copulatória); ca: câmara de albume; db: ducto da bursa; df: canal deferente; dh: ducto hermafrodita; ep: epifalo; eo: espermoviduto; gb: glândula de albume; go: gônada; ep: epifalo; gb: glândula de albume; go: gônada; mp: músculo peniano; ob: óstio do ducto da bursa; ol: oviduto livre; pg: poro genital; pi: pênis; pp: pregas penianas; pt: próstata; pv: prega transversal; sg: saco glandular anexo; ta: tálamo; ut: útero 


\section{DISTRIBUIÇÃO GEOGRÁFICA}

A descrição do Megalobulimus haemastomus foi baseada em material, atualmente perdido, da coleção do Marshal Augereau, o Duque de Castiglione (1757-1816), não sendo informada sua procedência (Scopoli, 1786). Foi considerada sinonímia para M. oblongus (Müller, 1774) e para sua "variedade crassus" até a revisão de Bequaert (1948) que embora tenha considerado exemplares de grandes dimensões procedentes de Corumbá e Três Lagoas, como M. haemastomus, restringiu o taxon aos "espécimes pequenos, de conchas pesadas e com lábios espessados de ocorrência geográfica ao sul".

Morretes (1949) registra sua ocorrência na região do Paraná, em Concepción, Argentina e no Uruguai; Thomé et al. (2007) considera no cone sul sua ocorrência na Argentina e nos Departamentos de Paysandú e Soriano, Uruguai, excluindo sua presença para o Brasil enquanto que Simone (2006) sintetiza a distribuição como sendo nas regiões Centro e Sul do Brasil, Uruguai e Argentina. No território do Uruguai sua presença foi registrada por Felippone \& Barattini (1938) como "frecuente en la mayor parte de nuestros departamentos", e por Scarabino (2003) no oeste do país nos Departamentos de Paisandú e Soriano.

Os nove lotes no MZSP com procedência limitam a distribuição do $M$. cf. haemastomus principalmente a região da depressão central rio-grandense, incluindo também registros para planície costeira e região de Porto Alegre, onde é simpátrica ao M. abbreviatus (Parque Natural Municipal Saint-Hilaire) e Uruguai (Fig. 191 e Tab. 14). 


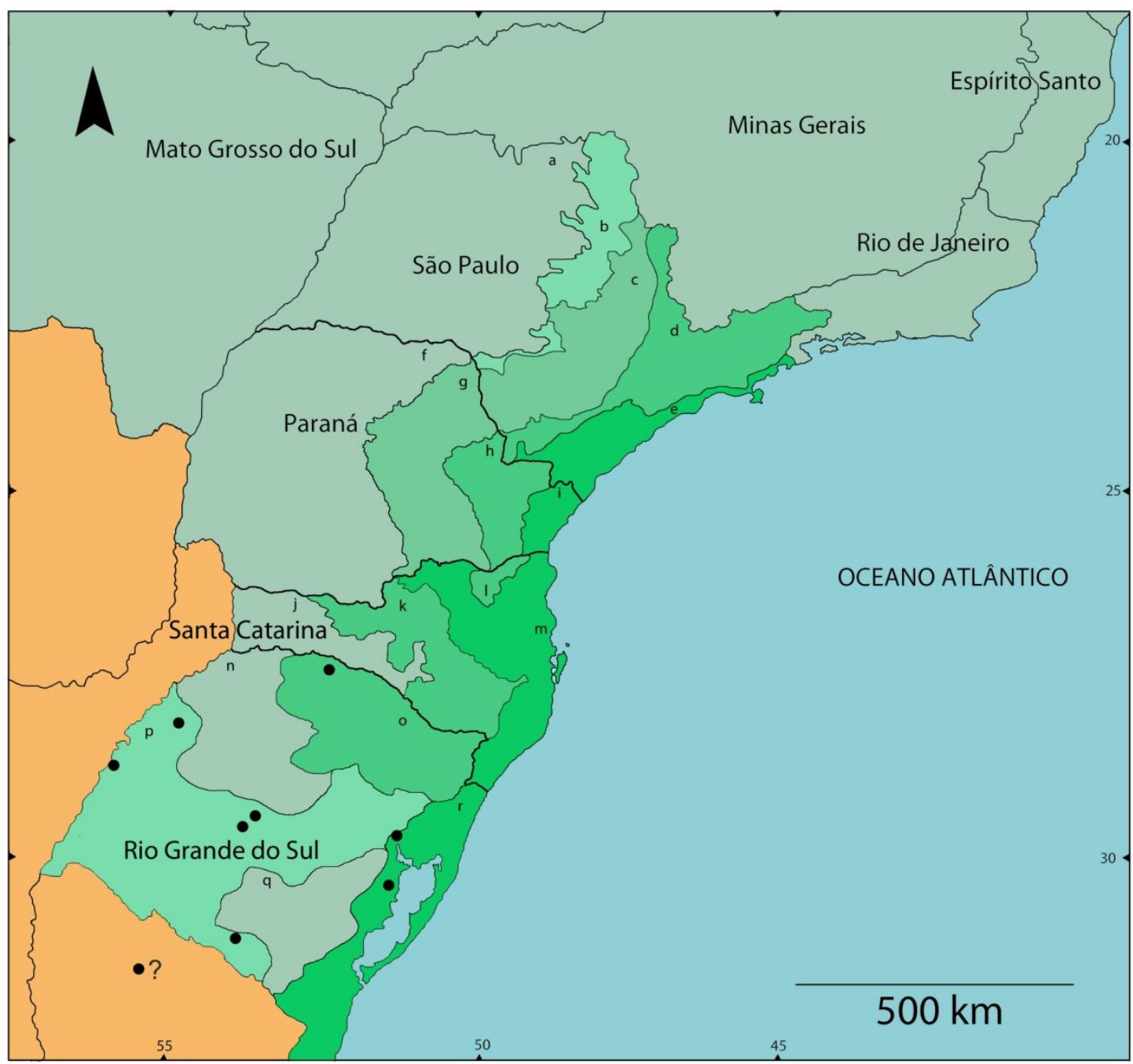

Figura 191. Distribuição geográfica do Megalobulimus cf. haemastomus a partir dos lotes depositados no MUSP. Localidade tipo: interior do Brasil. o: Planalto basáltico rio-grandense; p: Depressão central rio-grandense; $\mathbf{r}$ : Planície costeira rio-grandense.

\begin{tabular}{rr|cc}
\hline \multicolumn{1}{|c}{ LOCALIDADE } & N. DE & \multirow{2}{*}{ LOCALIDADE } & N. DE \\
& LOTES & LOTES \\
\hline s/ procedência & 3 & Porto Alegre, RS & 1 \\
Faxinal do Soturno, RS & 2 & Santa Maria, RS & 1 \\
Bagé, RS & 1 & São Borja, RS & 1 \\
Cerro Largo, RS & 1 & Tapes, RS & 1 \\
Monte Alegre, RS & 1 & & \\
\hline
\end{tabular}

Tabela 14. Número de lotes de Megalobulimus cf. haemastomus por localidade na coleção do MUSP 
Visando um melhor entendimento comparativo, não misturando dados de naturezas distintas, na discussão os caracteres mensuráveis das conchas, ou seja, sua biometria; os caracteres qualitativos de escultura e ornamentações das conchas; e os caracteres determinados no estudo da anatomia dos tecidos moles, foram analisados separadamente.

\section{BIOMETRIA DA CONCHA}

Para contextualizar os dados quantitativos, os resultados das análises estatísticas da biometria das conchas do "complexo M. granulosus", de M. aff. gummatus (e M. gummatus) e $M$. cf. haemastomus foram confrontados entre si e com outras três espécies de Megalobulimus (Figs. 192-197) que incluem M. ovatus, M. sanctipauli e M. yporanganus que apresentam uma distribuição simpátrica com o complexo estudado (Fig. 198). Os resultados parciais para cada medida ou relação estão nos anexos (Anexos 5.1, 5.2) e apresentados graficamente (Figs. 199-206), enquanto que a tabela 15 representa as medidas e relações que não apresentaram diferenças (significativamente iguais, $p>0,05$ ) entre as espécies. 


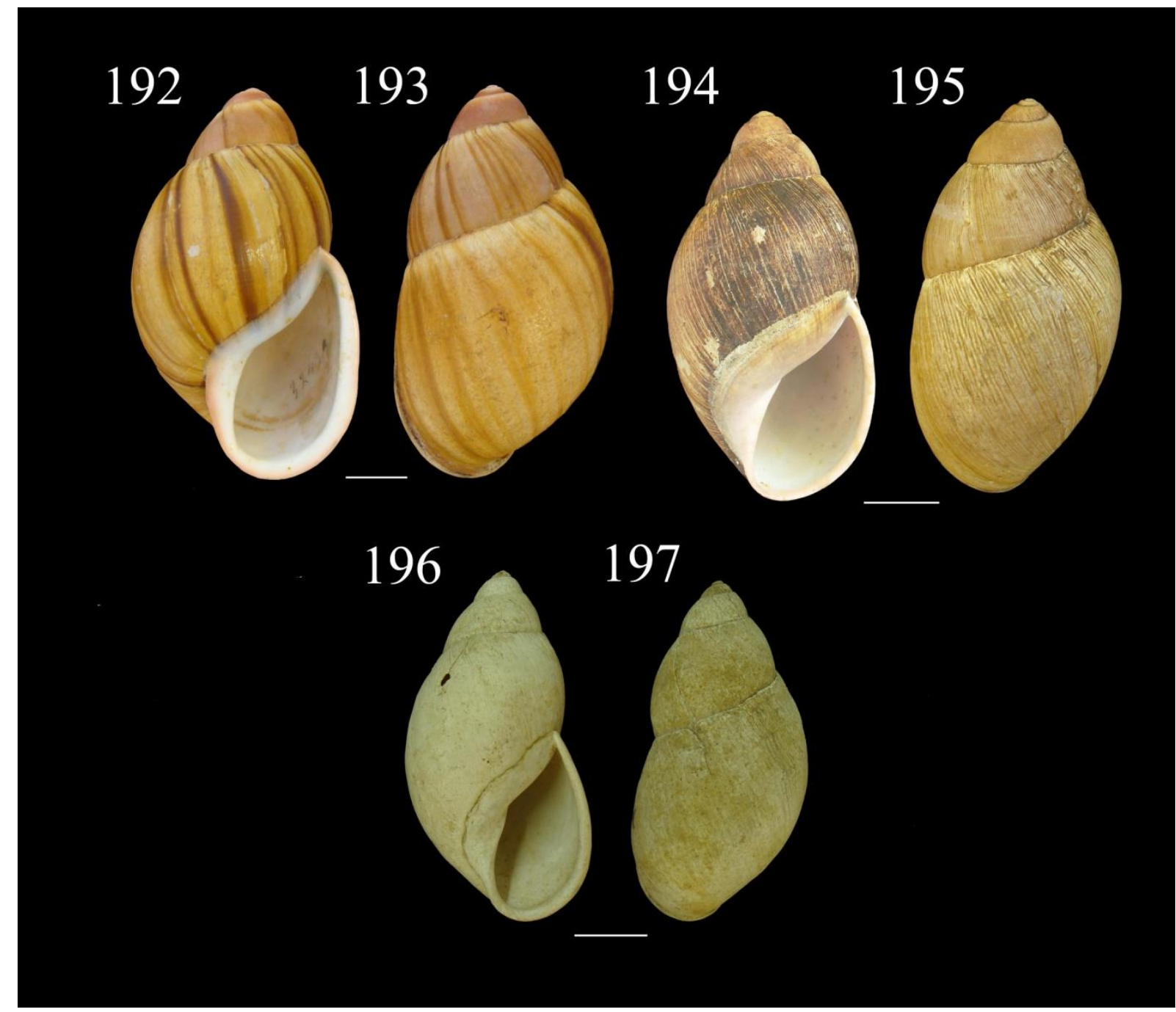

Figuras 192-197. Conchas de espécies utilizadas na comparação conquiliológica com o "complexo Megalobulimus granulosus": 192, 193. M. ovatus (MZSP 3243, Itanhaem, SP) vista frontal e dorsal; 194, 195. M sanctipauli (MZSP 1310, Ubatuba, SP) vista frontal e dorsal; 196, 197. M. yporanganus (MZSP 15593, Iporanga, SP) vista frontal e dorsal. (ESCALA $=20 \mathrm{~mm}$ ). 


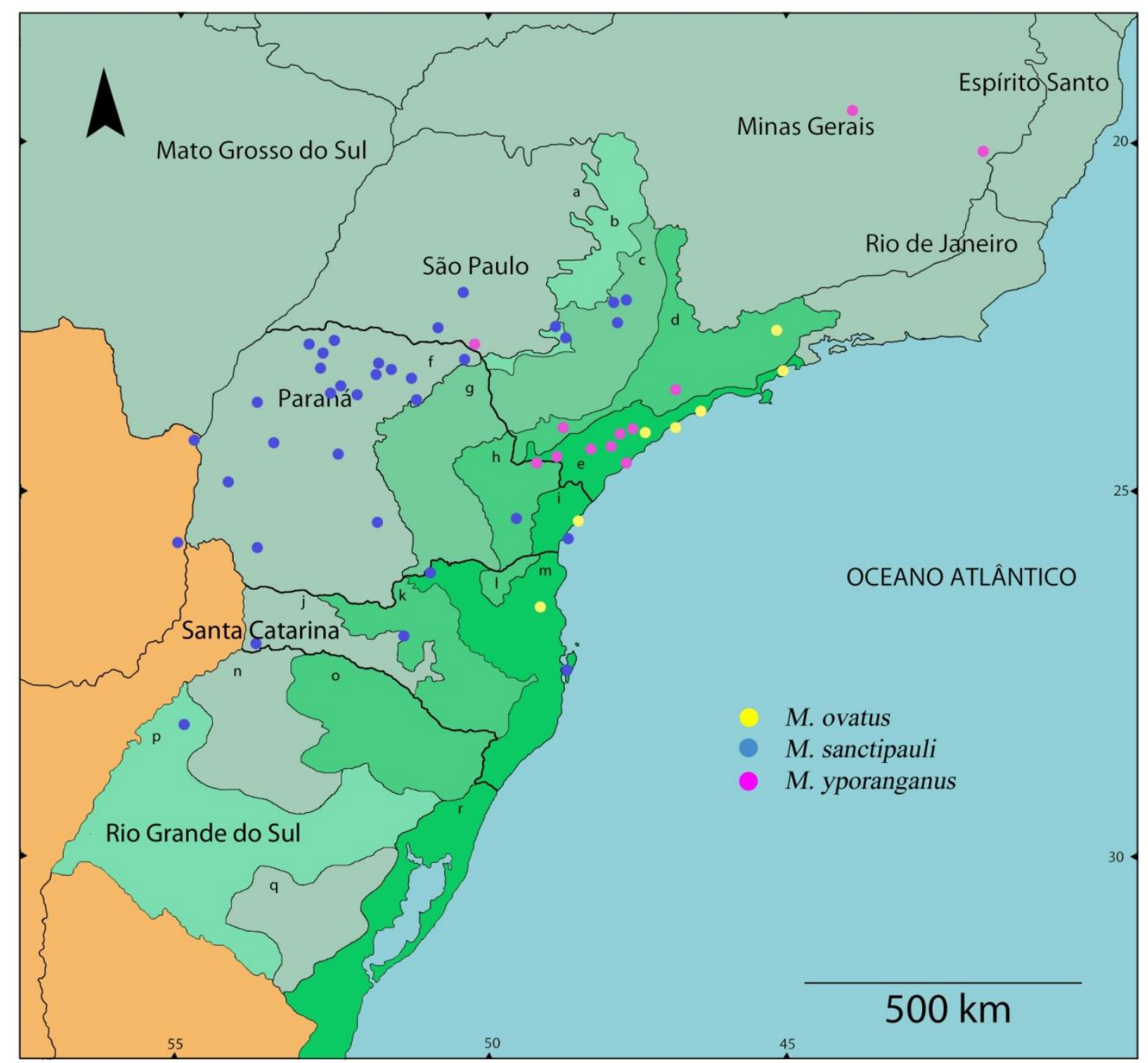

Figura 198. Ocorrência das espécies externas ao "complexo $M$. granulosus" utilizadas neste estudo: $M$. ovatus (apenas populações de São Paulo e região Sul): Planície costeira paulista; $M$. sanctipauli: Na depressão periférica paulista, e planalto basáltico paranaense e catarinense; $M$. yporanganus: Planície costeira paulista e Vale do Ribeira.

$\mathrm{Na}$ analise conjunta das figuras 204 e 205 permite dividir as espécies estudadas em dois grupos, as proporcionalmente mais largas e mais altas de aspecto ovalado: $M$. paranguensis e $M$. abbreviatus do complexo $M$. granulosus, e também $M$. aff. gummatus, $M$. cf. haemastomus, M. ovatus, e M. gummatus, das espécies de menor largura e altura com aspecto fusiforme que incluem o M. granulosus e $M$. foreli do complexo granulosus, e as externas M. sanctipauli e M. yporanganus. 

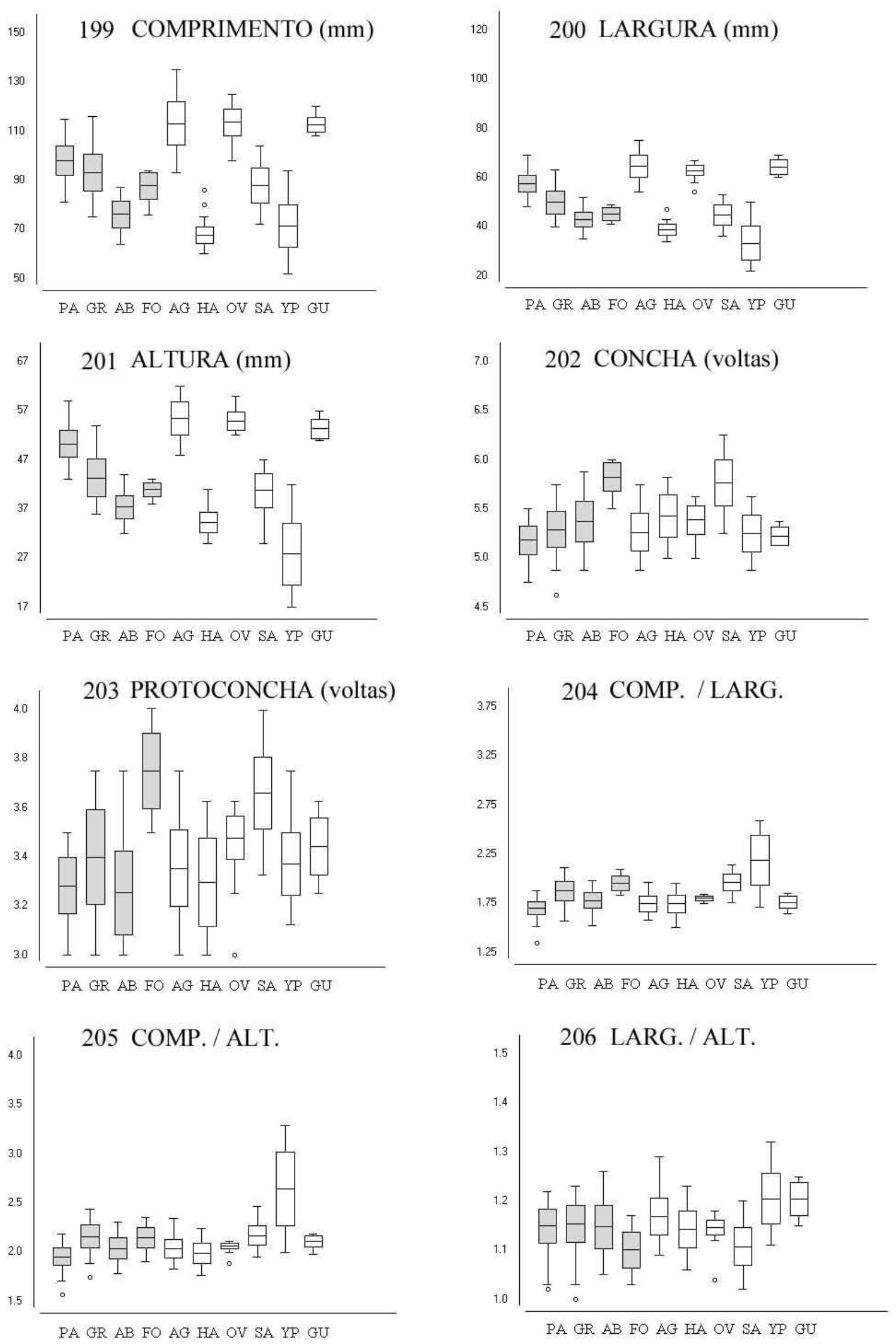
Figuras 199-206. Gráficos Box-Plot com média e box de 1 desvio-padrão e Whisker em valores máx. e mín. comparando a biometria das conchas das espécies do "complexo Megalobulimus granulosus" (com as caixas cinzas) e espécies externas (com as caixas brancas): 199. Comprimento da concha em milímetros; 200. Largura da concha em milímetros; 201. Altura em milímetros; 202. Número de voltas totais da concha; 203. Número de voltas da protoconcha; 204. Relação entre o comprimento da concha e sua largura; 205. Relação entre o comprimento da concha e sua altura; 206. Relação da largura da concha com sua altura. PA: M. paranaguensis; GR: $M$. granulosus; AB: M. abbreviatus; FO: M. foreli; AG: M. aff. gummatus; HA: M. cf. haemastomus; OV: M. ovatus; SA: M. sanctipauli; YP: M. yporanganus; GU: M. gummatus.

Todas as espécies estudadas apresentam compressão dorso-ventral (Fig. 206) sendo esta mais suave nas espécies $M$. foreli e $M$. sanctipauli, e mais brusca nas externas $M$. yporanganus e $M$. gummatus, não sendo, portanto uma característica válida para a diagnose do "complexo M. granulosus".

$\mathrm{Na}$ analise visual conjunta das figuras 202, 203 e 206 constata-se que dentro do "complexo M. granulosus" o número de voltas totais, da protoconcha, e a relação largura/altura das conchas do $M$. foreli se diferenciam da média ocupada pelas demais espécies do grupo, estando em um patamar similar à espécie externa $M$. sanctipauli. Estatisticamente a interpretação é ligeiramente diferente, sendo as duas espécies consideradas iguais em todas as medidas, com exceção do número de voltas da protoconcha (Tab. 15).

Na comparação entre $M$. abbreviatus e $M$. cf. haemastomus, o número de voltas da concha e da protoconcha, e a intensidade do achatamento dorso-ventral são iguais estatisticamente (Tab. 15).

Externamente ao complexo estudado, $M$. aff. gummatus e $M$. gummatus são estatisticamente iguais quanto ao comprimento, largura, número de voltas totais e da protoconcha, e na relação comprimento / largura, entretanto o M. gummatus apresenta uma compressão dorso-ventralmente significativamente maior.

\section{ESCULTURAÇÃO DA CONCHA}

As características da concha neopiônica foram as de maior peso na revisão de Bequaert (1948) e, embora, possam variar como os demais caracteres conquiliológicos, se mostraram úteis na diferenciação das espécies estudadas. Comparativamente as costelas mais 
largas foram observadas em M. granulosus (que apresentou maior variação neste caractere) e M. aff. gummatus, e a mais estreita foi observada em M. paranaguensis.

Protoconcha com costelas acessórias e incompletas que podem se dicotomizar ou se fundir, e que podem variar na espessura, e um padrão de linhas de crescimento na penúltima e última volta uniformes e discretos foram observadas em M. foreli (Figs. 127, 128) e M. abbreviatus. Este padrão é também observado em M. sanctipauli (Fig. 208, 209) e parece ser constantes nas espécies distribuídas no planalto meridional brasileiro. A similaridade biométrica (Tab. 15), da escultura e a proximidade geográfica entre as ocorrências entre $M$. foreli (Fig. 129), no segundo planalto paranaense e M. sanctipauli (Fig. 198), no terceiro planalto paranaense, pode indicar uma proximidade taxonômica, cuja comprovação pela analise anatômica não foi possível.

Costelas regulares e com intervalo igual ou maior à sua espessura, seguindo o padrão do "complexo M. terrestris" (Bequaert, 1948), foram observado em M. granulosus e no $M$. aff. gummatus, enquanto que costelas neopiônicas bem marcadas, constantes de sutura a sutura com intervalos regulares iguais ou menores que sua espessura foram observadas em $M$. cf. haemastomus, sendo esta típica das espécies do "complexo M.oblongus" (Bequaert, 1948) como M. proclives (Leme \& Indrusiak, 1995), M. riopretensis e M. mogianensis (Simone \& Leme, 1998)

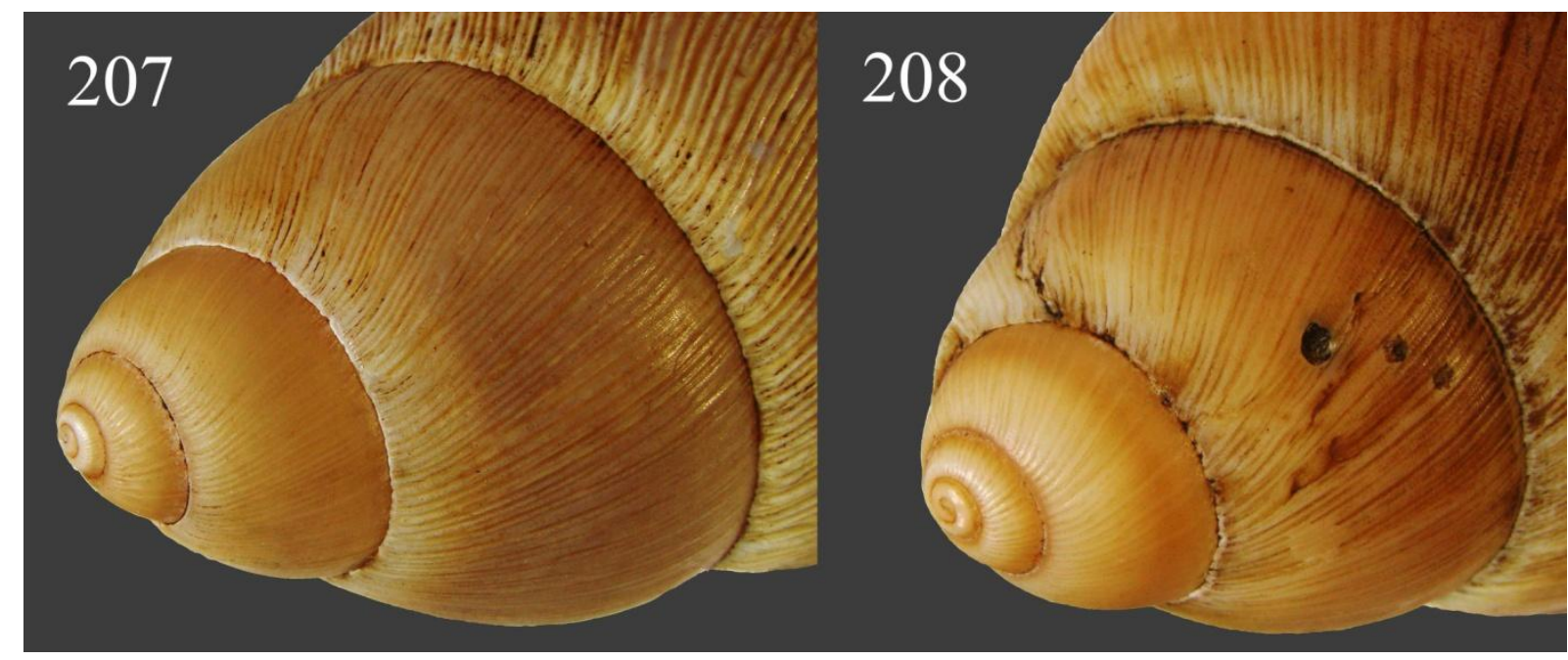

Figuras 207, 208. Espiras de Megalobulimus sanctipauli. 208. Espécime MZSP 7980, PR; 209. Espécime MZSP 1310, PR. 


\begin{tabular}{|c|c|c|c|c|c|c|c|c|c|c|}
\hline & 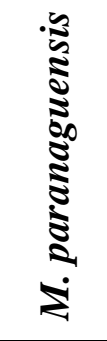 & 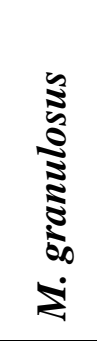 & 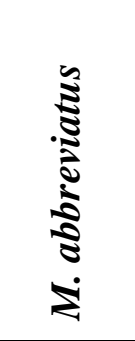 & 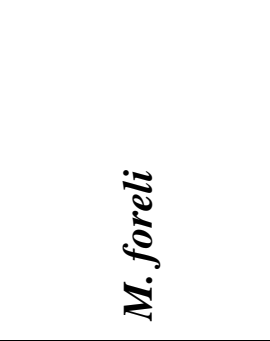 & 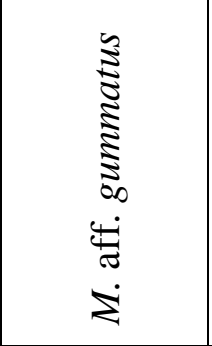 & 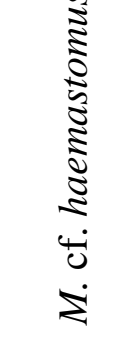 & 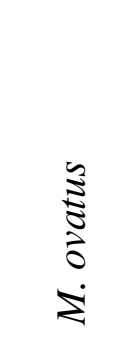 & 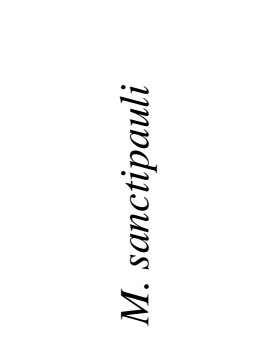 & 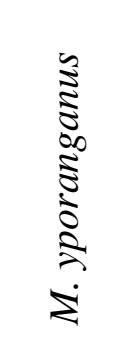 & 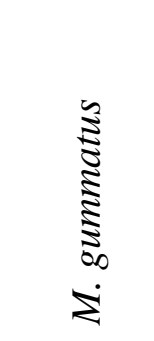 \\
\hline M. paranaguensis & & 8 & 5,8 & & & 5,8 & 8 & & & 4 \\
\hline M. granulosus & 8 & & 8 & 7 & 4,5 & 8 & 8 & 7 & 4,5 & 4,5 \\
\hline M. abbreviatus & 5,8 & 8 & & & 7 & $4,5,8$ & $4,7,8$ & & & 6 \\
\hline M. foreli & & 7 & & & & & & $1,2,3,4,6,7,8$ & & 7 \\
\hline M. aff. gummatus & & 4,5 & & & & 5,6 & $1,3,7$ & & & $1,2,5,6$ \\
\hline M. cf. haemastomus & 5,8 & 8 & $4,5,8$ & & 5,6 & & 4,8 & & & \\
\hline M. ovatus & 8 & 8 & $4,7,8$ & & 1,3 & 4 & & & & $1,2,5$ \\
\hline M. sanctipauli & & 7 & & $1,2,3,4,6,7,8$ & & & & & & \\
\hline M. yporanganus & & 4,5 & & & 5 & & & & & $4,5,8$ \\
\hline M. gummatus & 4 & 4,5 & 6 & 7 & $1,2,4,5,6$ & & $1,2,5$ & & $4,5,8$ & \\
\hline
\end{tabular}

Tabela 15. Similaridade pelo Teste $T$ de Student $(p>0,05)$ dos dados biométricos entre as espécies pertencentes ao "complexo Megalobulimus granulosus" e espécies externas ao complexo: 1. Comprimento da concha similar; 2. Largura de concha similar; 3. Altura de concha similar; 4. Número de voltas totais da concha similar; 5. Número de voltas na protoconcha similar; 6. Relação comprimento da concha / largura da concha similar; 7. Relação comprimento da concha / altura da concha similar; 8. Relação Largura da concha / altura da concha similar. 
M. granulosus apresenta tanto a penúltima quanto última voltas praticamente lisas devido ao grande espaçamento entre as linhas de crescimento, enquanto que $M$. paranaguensis, $M$. aff. gummatus e $M$. cf. haemastomus possuem linhas de crescimento bem marcadas e irregulares.

A microescultura granulosa não é exclusividade do "complexo M. granulosus" e foi encontrada na protoconcha e penúltima volta de todas as espécies estudadas. $\mathrm{Na}$ volta do corpo, ocorre de forma conspícua apenas em M. granulosus, de forma débil em M. paranaguensis, M. foreli, M. abbreviatus e M. cf. haemastomus. Embora intensa na penúltima volta no $M$. aff. gummatus, esta ausente na sua volta-do-corpo.

As escultura de "marteladas" (malleata) e estrias curtas espirais (striolae) ocorrem nas espécies estudadas em $M$. paranaguensis e $M$. aff. gummatus e ocasionalmente em M. ovatus.

Um perióstraco brilhante e lustroso, indicando a persistência, geralmente temporária, do perióstraco com uma escassa presença de microesculturas na teleconcha ocorre no $M$. paranaguensis e no $M$. aff. gummatus, sendo relatada no M. gummatus (Hidalgo, 1869), e no “complexo M. ovatus" (Leme, 1989). Em todas as espécies estudadas, a concha são imperfuradas com ocasionais semi-perfuradas, sendo a exceção a $M$. cf. haemastomus que são majoritariamente perfuradas.

Como característica da família Strophocheilidae, todas as espécies apresentam o lábio invertido e espessado (Bequaert, 1948), entretanto cerca da metade das conchas de indivíduos adultos de $M$. aff. gummatus e, ocasionalmente, $M$. granulosus e $M$. yporanganus podem apresenta um lábio pouco invertido mas consideravelmente espessados, mais perceptíveis pela borda volumosa no lado interno do peristoma. A parede parietal é proporcionalmente mais larga nas espécies menores como $M$. abbreviatus e $M$. cf. haemastomus sendo evidentes nos espécimes com peristoma rubro recém-depositado.

Diferentemente das demais espécies, M. cf. haemastomus apresenta uma columela reta em continuação a um lábio interno também reto (Figs. 168, 170).

A coloração do peristoma pode variar muito em função do ciclo de deposição de uma nova camada e do tempo que a concha ficou exposta a intempéries. Um peristoma variando de rosa esbranquiçado a vinho foi observado em $M$. paranaguensis, $M$. 
granulosus, M. abbreviatus e $M$. cf. haemastomus, similares à maioria das espécies de Megalobulimus. Um peristoma branco foi descrito para M. foreli (Bequaert, 1948) em um holótipo aparentemente "rolado" enquanto que os outros lotes daquela espécie no MZSP apresentam um peristoma rosado claro. Um peristoma exclusivamente branco sempre foi observado nos $M$. aff. gummatus e $M$. gummatus estudados. Também ocorre em M. auritus (Leme, 1993) e em M. albus (Bland \& Binney) (MZSP 3261, Tobago).

\section{ANATOMIA}

Embora a coloração da massa céfalo-pediosa apresente variação entre as espécies e, portanto, importante em uma análise comparativa, existe a necessidade de espécimes vivos, o que infelizmente não foi possível para todas as espécies. Uma cor uniforme cinza claro foi verificada em $M$. paranaguensis e um bege claro para $M$. aff. gummatus. O M. abbreviatus possui tegumento cinza amarronzado com as bordas da sola amareladas. A literatura registra para Megalobulimus lopesi (Leme, 1989) um tegumento homogeneamente cinza com exceção da sola que apresenta a região central amarelada com as bordas ligeiramente acinzentadas, para $M$. riopretensis uma coloração homogênea cinza clara azulada (Simone, 1995), para M. parafragilior que é cinza escuro com exceção da região mediana da sola que é clara (Leme \& Indrusiak, 1990). Indivíduos de procedências distintas relacionados ao "complexo M. oblongus" apresentam um padrão de cinza com a sola uniformemente mais clara (Fig. 1).

\section{Cavidade palial}

As características da borda do manto se mostraram constantes nas espécies estudadas, com exceção de $M$. cf. haemastomus que apresenta um sulco em forma de canal em seu lábio interno em continuação ao sulco urinário externo (Fig.179, 180). Na literatura $M$. riopretensis apresenta duas protuberâncias de forma elíptica em seu lábio externo (Simone, 1995).

Internamente na cavidade palial, os vasos da região estritamente respiratória apresentam pouca variação nas espécies estudadas, com exceção da inserção comum entre o $c 1$ e $c 2$ no vaso pericárdico em M. paranaguensis (Fig. 32) e um $v 3$ com muitas dicotomias em M. aff. gummatus (Fig. 141). O plexo de vasos anastomosados foi mais evidente em $M$. paranaguensis e $M$. aff. gummatus, e muito discreto em $M$. cf. 
haemastomus (Fig. 179). A profundidade da cavidade palial encontrada em $M$. paranaguensis e $M$. aff. gummatus estava limitada ao início da volta-do-corpo (Figs. 18 e 43), enquanto que para as outras espécies ela se estendia à cerca da metade da penúltima volta (Fig. 100).

A goteira urinária forneceu caracteres para a diferenciação entre as espécies. Espraia-se sobre o intestino posterior em todas as espécies com exceção de $M$. granulosus; e não atinge a linha do ânus em M. paranaguensis e M. abbreviatus. Todas as espécies, com exceção de $M$. cf. haemastomus, apresentam uma concavidade lateral ao ânus, contínua a goteira urinária, e aqui denominada "canal lateral". Um reto profundamente inserido na dobra entre o manto e o diafragma, causando até a ruptura de tecidos ao expor as pregas anais pela abertura do lábio do pneumóstomo foi apenas observada em M. granulosus e M. abbreviatus (Figs. 76, 107).

Na região reno-pericárdica, o rim apresentou a forma triangular com uma cauda posterior em $M$. paranaguensis e $M$. aff. gummatus, ou um rim estreito com cauda alongada com $M$. granulosus, $M$. abbreviatus e $M$. cf. haemastomus. A proporção da cobertura pelo plexo anastomosado que acompanha o septo e se espraia sobre a área reno-pericárdica, variou entre as espécies, ocupando cerca de $3 / 4$ em M. paranaguensis, 1/2 em $M$. aff. gummatus, 1/3 em M. granulosus, 1/5 em M. abbreviatus, e imperceptível em M. cf. haemastomus. Na literatura, o rim de M. auritus é descrito como curto e triangular (Leme, 1993); alongado, de contorno irregular e extremidade distal volumosa e arredondada em $M$. proclivis (Leme \& Indrusiak, 1995); curto e cordiforme em $M$. parafragilior (Leme \& Indrusiak, 1990); e triangular em $M$. riopretensis e $M$. mogianensis (Simone, 1995).

\section{Sistema digestivo}

O sistema digestivo inicia-se com a massa bucal. Na sua superfície externa são observados inúmeros feixes de músculos denominados, em conjunto por Scott (1939), como músculos extrínsecos da massa bucal, Aqui eles são denominados como $m 1$, que se mantiveram constantes nas espécies estudadas. Uma massa muscular transversal ocorre na face ventral unindo as laterais da peça mandibular em todas as espécies, sendo mais visível em M. paranaguensis (Fig. 38) e M. granulosus (Fig.78). Também na face ventral a origem da artéria radular ocorre diretamente da artéria cefálica em $M$. 
granulosus e M. abbreviatus (Fig. 109) ou do ramo posterior esquerdo como $M$. paranaguensis (Fig. 38), M. aff. gummatus e M. cf. haemastomus.

Com a massa bucal aberta longitudinalmente podemos diferenciar pela altura do triângulo formado pelo teto (tt) rebatido, uma massa bucal curta como a observada em M. granulosus (Fig. 79) e M. cf. haemastomus (Fig. 181), ou uma massa bucal longa como em M. paranaguensis (Fig. 39), M. abbreviatus (Fig. 110) e M. aff. gummatus (Fig. 143). A dimensão do bonete radular apresentou uma relação direta com este caractere, sendo proporcionalmente maior nas massas bucais curtas. O odontóforo não teve alterações significativas entre as espécies estudadas.

O esôfago corresponde a toda porção do sistema digestivo entre a massa bucal e o estômago (Simone, 1995), e sua dilatação posterior em um inglúvio desenvolvido para armazenar o alimento ingerido (Dimitriadis, 2001), está sempre presente nos Stylommatophora muito grandes (Tillier, 1989). Este inglúvio pode ser subdividido em câmara anterior e posterior por uma constrição que corresponde à passagem do órgão da cavidade pedal para a visceral (Dimitriadis, 2001).

Nas espécies de Megalobulimus estudadas podemos diferenciar claramente estes três segmentos designados como esôfago anterior, médio (a transição entre as hemoceles) e posterior, ocorrendo diferentes padrões com exceção do segmento médio geralmente composto internamente de fortes pregas musculares longitudinais e externamente envolto por feixes de músculos circulares. M. granulosus (Fig. 80) e $M$. aff. gummatus (Fig. 144) apresentam o primeiro segmento com paredes finas, translúcidas, sem pregas e ocasionalmente distendidas por alimento, mas diferenciam no segmento posterior onde o $M$. granulosus mantém um padrão de pregas musculares similares ao segmento médio, enquanto que em M. gummatus o segmento posterior apresenta pregas discretas. M. paranaguensis (Fig. 42) e M. abbreviatus (Fig. 111) apresentam o mesmo padrão, com o segmento anterior com pregas plicadas e com grande capacidade de distensão, e o posterior com pregas discretas. Diferentemente destes, M. cf. haemastomus (Fig. 182) apresenta um esôfago totalmente distensível de paredes finas e pouco musculares, inclusive no segmento médio, com pregas discretas no seu segmento médio e posterior. Todas as espécies estudadas recebem o ducto da glândula digestiva anterior no terço distal do esôfago posterior, sendo que em $M$. granulosus o ducto é bifurcado (Fig. 81). 
Para as espécies do "complexo $M$. oblongus" anteriormente estudadas $M$. lorentzianus (Scott, 1939), M. riopretensis e M. mogianensis (Simone, 1995), a câmara posterior apresenta uma parede fina, distendida e sem pregas internas, que recebe o ducto da glândula digestiva anterior em seu terço final. Megalobulimus auritus (Leme, 1993) também apresenta a câmara posterior do esofágico com pregas internas, diferenciando-se na inserção do ducto bifurcado da glândula digestiva anterior no seu terço médio.

A inserção do ducto da glândula digestiva posterior é na face posterior esquerda em $M$. paranaguensis (Fig. 43) e $M$. aff. gummatus e na face superior direita em $M$. granulosus (Fig. 80), M. abbreviatus e M. cf. haemastomus, mostrando a posição do estômago tem uma relação direta com a profundidade da cavidade palial. Os estômagos de . granulosus (Figs. 82, 83) e M. abbreviatus (Figs. 113, 114) apresentam internamente pregas musculares paralelas, um tiflossole intestinal (ti) a partir do canto inferior da abertura do ducto da glândula digestivo posterior, um canal liso ao seu lado aqui denominado de canal intestinal (ci), e um espessamento muscular na curvatura menor que avança pelo lado direito da passagem para o intestino, denominada de musculatura pilórica ( $\mathrm{pl}$ ) onde se conecta tiflossole esofágico (te). Em $M$. paranaguensis (Figs. 44, 45) e M. aff. gummatus (Figs. 145, 146) à esta descrição é acrescentado outro canal liso, denominado canal esofágico (cf), que acompanha o tiflossole homônimo e circunda a musculatura pilórica e que se encontra com o canal intestinal, diferindo de $M$. aff. gummatus que tem a conexão dos canais impedida por uma delgada prega. O M. cf. haemastomus apresenta a configuração do M. granulosus, mas com uma parede gástrica fina com as faces laterais nacaradas e com as pregas e musculatura pilórica discretas, contratando com a regra de um estômago musculoso com superfície interna intensamente dobrada e limites externos nítidos tido como característico dos Megalobuliminae (Leme, 1971).

O padrão e o número das pregas intestinais foram constantes nas espécies estudadas, cabendo registrar a grande dimensão do tiflossole intestinal à saída do estômago em M. abbreviatus (Fig. 116) em contraste com o discreto tiflossole e pregas de $M$. cf. haemastomus (Fig. 185), e a maior distância entre a $p 1$ e a primeira $p 2$ observada em M. granulosus (Fig. 84) e M. aff. gummatus (Fig. 147) em comparação com as outras espécies. Na região da válvula pré-retal, apenas a prega $p 4$ atinge a 
válvula em todas as espécies estudadas (Figs. 47, 85, 112, 149) com exceção de $M$. cf. haemastomus, onde apenas o tiflossole intestinal não atinge a válvula (Fig. 186). Pregas pós-valvulares $p 7$ espaçadas e formando um ângulo de $45^{\circ}$ com a $p 6$ foram observadas em M. paranaguensis, M. granulosus e M. cf. haemastomus, enquanto que $M$. aff. gummatus apresenta as $p 7$ adensadas a $45^{\circ}$, todas convergindo para um cordão longitudinal. No M. abbreviatus as pregas $p 7$ se tornam paralelas a $p 6$, sem haver um cordão. Em todas as espécies estudadas a $p 6$ atinge a borda do ânus e as pregas $p 7$ se anastomosam no terço distal do intestino posterior formando as pregas retais que avançam pelo ânus sobre a borda do manto. Estas são estreitas em $M$. paranaguensis (Fig. 48) e em M. cf. haemastomus, e largas em M. granulosus, M. abbreviatus (Fig. 117) e $M$. aff. gummatus (Fig. 150). Em estudos anteriores, as pregas $p 7$ de $M$. parafragilior e $M$. auritus também não formam um cordão longitudinal pós-valvular (Leme, 1993).

\section{Sistema reprodutivo}

No sistema reprodutivo a região do carrefour está localizada no hilo da glândula de albume, podendo ser medial como em M. paranaguensis (Fig. 53) e M. abbreviatus (Fig. 118) ou ter uma posição proximal junto a câmara de albume (ca) como em $M$. granulosus (Fig. 88), M. aff. gummatus (Fig. 156) e M.cf. haemastomus (Fig. 188). O tálom, que recebe apicalmente o ducto hermafrodita nas espécies estudadas, pode estar individualizado (destacável) do saco glandular anexo (sa) como em M. paranaguensis, M. aff. gummatus e M.cf. haemastomus, ou não, como observado em M. granulosus e M. abbreviatus. De modo similar ao talom, a próstata pode parecer 'destacável' do espermoviduto em M. granulosus, M. abbreviatus e M.cf. haemastomus, e de forma contrária em $M$. paranaguensis e $M$. aff. gummatus. Em todas as espécies estudadas a próstata corresponde a uma faixa que ocupa cerca de 1/3 do diâmetro do espermoviduto. Nas espécies previamente estudadas M. lopesi (Leme, 1989) apresentou um tálom não destacável do saco glandular anexo, um segmento indiferenciado externamente proximal e a uma próstata em uma faixa estreita no espermoviduto. Este último caractere se repete em M. parafragilior (Leme \& Indrusiak, 1990) e nas espécies do “complexo M. ovatus". Um tálom bem desenvolvido e uma larga faixa prostática ocorrem em M. lorentzianus (Scott, 1939); M. riopretensis e M. mogianensis (Simone \& Leme, 1998). 
Em todas as espécies o espermoviduto (eo) apresentou o padrão estabelecido por Leme (1971-1973) para os Megalobulimíneos com a presença da glândula genital acessória (e.g., Fig: 158: gg).

Todas as espécies estudadas apresentam o apêndice vaginal (e.g., Fig. 117: av) no oviduto livre, que apresenta internamente largas pregas longitudinais que se continuam como pregas mais discretas na vagina. Somente em M. abbreviatus as pregas estão direcionadas para o óstio do ducto da bursa copulatrix (Fig. 120), como registrado para as espécies do "complexo M. oblongus", M. riopretensis e M. mogianensis (Simone \& Leme, 1998).

O ducto da bursa é de secção arredondada e uniforme em todas as espécies, com exceção do $M$. aff. gummatus que o apresenta largo e achatado. Tanto o ducto como a parede da bursa copulatrix apresenta pregas musculares (Fig. 56), com exceção de $M$. cf. haemastomus, que apresenta uma parede delgada e fina com alta capacidade de distensão (Fig. 187). Para comparação na literatura, as espécies do "complexo $M$. oblongus” como M. lorentzianus (Scott, 1939), M. proclivis (Leme \& Indrusiak, 1995), M. riopretensis e M. mogianensis (Simone \& Leme, 1998), sempre apresentam um apêndice vaginal desenvolvido, em contraste com $M$ parafragilior, que apresenta um discreto apêndice vaginal (Leme \& Indrusiak, 1990), que esta totalmente ausente no “complexo M. ovatus", como M. lopesi (Leme, 1989) e M. auritus (Leme, 1993).

No ramo masculino, um corpo peniano cilíndrico e uniforme ocorre em $M$. granulosus (Fig. 86: pi), M. paranaguensis (Figs. 61, 62) e M. aff. gummatus (Figs. 152, 153), sendo que nas duas últimas espécies o pênis se encontra tracionado pelo ducto deferente, com uma postura convoluta em $M$. aff. gummatus devido ao seu maior comprimento. Um pênis em forma de bastão foi observado em $M$. abbreviatus e $M$. cf. haemastomus. O epifalo não apresenta flagelos em M. paranaguensis e M. granulosus, e dois flagelos são distinguíveis em $M$. aff. gummatus (Fig. 154), M. abbreviatus e $M$. cf. haemastomus, sendo mais longos e desiguais nesta última espécie. Internamente ao ápice do pênis, uma prega transversal (pv) não nodulosa ocorre em $M$. paranaguensis (Fig. 63) e em M. aff. gummatus (Fig. 155), enquanto a uma forma nodulosa é encontrada em M. granulosus (Fig. 90), M. abbreviatus (Fig. 123) e M. cf. haemastomus (Fig. 190). Comparativamente a literatura registra para M. lopesi um pênis em forma de bastão com epifalo curto e sem flagelos (Leme, 1989); um pênis e 
epifalo alongados com um único flagelo curto e largo em M. parafragilior (Leme \& Indrusiak, 1990); um pênis alongado e convoluto com um único flagelo em M. auritus (Leme, 1993); um pênis em forma de bastão com um epifalo longo e com um flagelo em M. riopretensis, ou sem o flagelo em M. mogianensis (Simone \& Leme, 1998). Uma prega transversal do pênis nodulosa foi registrada apenas nas espécies $M$. riopretensis e M. mogianensis (Simone, 1995). 
1.) Os caracteres conquiliológicos utilizados na definição das subespécies de Megalobulimus granulosus por Bequaert (1948) e mantidos para o "complexo $M$. granulosus" não são exclusivos do grupo, e não foram encontrados combinações de caracteres nos tecidos moles nas suas espécies para embasamento morfológico do complexo, sendo portanto, sem validade ou aplicação taxonômica. Do ponto biogeográfico, as espécies do "complexo M. granulosus" distribuem-se, com exceção do M. foreli, de forma contígua entre o litoral sul do Estado de São Paulo e do Paraná (M. paranaguensis), litoral de Santa Catarina (M. granulosus e M. abbreviatus) e nordeste do Rio Grande do Sul (M. abbreviatus).

2.) As cinco espécies que foram estudadas anatomicamente apresentaram um combinação de caracteres dos tecidos moles que as individualizam plenamente;

3.) As espécies $M$. paranaguensis e $M$. aff. gummatus, de distribuição atual simpátrica no litoral sul de São Paulo e região do Vale do Ribeira, apresentaram similaridade na anatomia interna incluindo um rim triangular com cauda; fundo da cavidade palial curto limitado a volta-do-corpo; estômago com canais esofágico e intestinal; próstata não destacável; pregas internas do oviduto livre não direcionadas para o óstio da bursa copulatrix; e uma prega transversal discreta e não nodular do pênis, inferindo tratar-se de espécies-irmãs. Diferencia-se o $M$. paranaguensis pela origem comum de $c 1$ e $c 2$ no vaso pericárdico, e o $M$. aff. gummatus pelo longo pênis convoluto e o ducto da bursa achatado;

4.) A espécie $M$. foreli, com distribuição restrita nos "campos gerais" do segundo planalto paranaense, estudada sem anatomia interna, esta fortemente relacionada conquiliologicamente (biometria e esculturação) com o "complexo M. sanctipauli", de distribuição geográfica no oeste paulista e paranaense (principalmente no planalto basáltico), inferindo a sua relocação para este complexo;

5.) A espécie M. abbreviatus com distribuição ao sudeste de Santa Catarina e nordeste do Rio Grande do Sul, também possui caracteres conquiliológicos de esculturação similares aos observados em $M$. sanctipauli, sendo igualmente inferida sua 
relocação no "complexo M. sanctipauli". Os caracteres anatômicos que em conjunto são exclusivos desta espécie incluem a presença de uma prega transversal nodulosa no pênis; origem da artéria radular diretamente da artéria cefálica; e pregas $p 7$ paralelas a p6;

6.) A espécie $M$. granulosus, com distribuição geográfica na planície litorânea de Santa Catarina, não apresenta similaridade conquiliológica com as outras espécies estudadas, embora compartilhe caracteres anatômicos com o M. abbreviatus como um rim estreito e alongado, prega peniana, e um hilo proximal no carrefour, Diferencia-se desta por apresentar um ducto bipartido da glândula digestiva anterior e um espaçamento proporcionalmente maior entre as pregas intestinais $p 1$ e $p 2$;

7.) Embora o M. cf. haemastomus, com distribuição geográfica pela depressão central do Rio Grande do Sul e Uruguai, apresente similaridades conquiliológicas que possam dificultar a diferenciação com o M. abbreviatus, anatomicamente é distinguida pela formação de um canal de excreção na borda do manto, um estômago de paredes finas e uma bursa copulatrix igualmente fina e sem pregas;

8.) Amostras provisoriamente identificadas como $M$. aff. gummatus, confrontada conquiliologicamente com $M$. gummatus revelaram tratar-se de uma espécie independente com distribuição geográfica na região do Vale do Ribeira e o sul da planície costeira de São Paulo. 
Neste estudo foram comparadas anatomicamente as espécies de gastrópodes terrestres pertencentes ao "complexo Megalobulimus paranaguensis" (M. paranaguensis, M. granulosus, M. abbreviatus, e $M$. foreli) e as espécies $M$. cf. haemastomus e $M$. aff. gummatus, utilizadas como comparativo externo. Todas foram comparadas conquiliologicamente entre si e com M. ovatus, M. sanctipauli, M. yporanganus, e $M$. gummatus. O complexo apresenta uma distribuição geográfica contígua entre o litoral sul de São Paulo e o nordeste do Rio Grande do Sul, mas não possuem embasamento morfológico que o sustente. Todas as espécies possuem um conjunto exclusivo de caracteres que as individualizam. M. paranaguensis e a simpátrica $M$. aff. gummatus compartilham caracteres na cavidade palial, sistema digestivo e reprodutivo, diferenciando-se morfologicamente das demais espécies e consideradas como espéciesirmãs. A esculturação de $M$. foreli e $M$. abbreviatus similares a $M$. sanctipauli infere que estas espécies sejam transferidas para o complexo homônimo. M. granulosus, com ocorrência para o litoral de Santa Catarina, possui uma concha singular, mas apresenta uma anatomia interna similar a $M$. abbreviatus. $M$. cf. haemastomus distribuiu-se pela depressão central do Rio Grande do Sul e Uruguai, com simpatria na região de Porto Alegre com M. abbreviatus diferenciando-se por caracteres na borda do manto e sistemas digestivo e reprodutivo. O confronto de $M$. aff. gummatus, com ocorrência no Vale do Ribeira em São Paulo, e M. gummatus de distribuição no Rio de Janeiro, evidenciou que a primeira é uma espécie independente.

Palavras-chaves: Megalobuliminae, “complexo Megalobulimus granulosus", anatomia, taxonomia, distribuição geográfica. 
This study compares anatomically species of the terrestrial gastropods belonging to the "complex Megalobulimus paranaguensis" (M. paranaguensis, M. granulosus, M. abbreviatus and M. foreli). M. aff. gummatus and M. cf. haemastomus was analyzed as outgroup. They also were conchologically compared with M. ovatus, M. sanctipauli, M. yporanganus and $M$. gummatus. The complex has a contiguous geographical distribution, between the south of São Paulo and northeastern Rio Grande do Sul States, but lacks morphological foundation supports. The species of the complex have a unique set of characters that individualizes it. M. paranaguensis and sympatric $M$. aff. gummatus share characters in the palial cavity, digestive and reproductive systems, differing morphologically from other species, they are regarded as sister species. The shell sculpture of $M$. foreli and M. abbreviatus is similar to $M$. sanctipauli, infering that these species may be transferred to the complex $M$ sanctipauli. The M. granulosus, occurring in Santa Catarina coastal zone, has a singular shell, but presents an internal anatomy similar to M. abbreviatus. The M. cf. haemastomus, distributed in the central depression of the Rio Grande do Sul State and Uruguay, sympatric in the region of Porto Alegre with $M$. abbreviatus, possesses different characters on the edge of the mantle and digestive and reproductive systems. The confrontation of M. aff. gummatus, occurring in Vale do Ribeira, São Paulo, with M. gummatus, from Rio de Janeiro, showed that the first is an independent species.

Palavras-chaves: Megalobuliminae, "complex Megalobulimus granulosus", anatomy, taxonomy, geographical distribution. 
Agudo, A. I. 2008. First registration of continental mollusks in the "Extreme West region” of Santa Catarina's State, SC, Southern Brazil. Ellipsaria 10(2): 10-11.

Bequaert, J.C. 1948. Monograph of the Strophocheilidae, a neotropical family of terrestrial mollusks. Bulletin of the Museum of Comparative Zoology 100 (1): $210 \mathrm{pp}+32$ pls.

Bouchet P., Rocroi J.P., Frýda J., Hausdorf, B.; Ponder, W.; Valdés, Á. \& Warén, A. 2005. Classification and nomenclator of gastropod families. Malacologia: 47 (1-2): 1-397.

Breure, A.S.H. 1979. Systematics, phylogeny and zoogeography of Bulimulinae (Mollusca). Zoologische Verhandelingen Leiden 168: 1-215.

Bruschi-Figueró, G. \& Veitenheimer-Mendes, I.L. 2002. Moluscos em área de horticultura no município de Porto Alegre, Rio Grande do Sul, Brasil. Revista Brasileira de Zoologia 19 (Suplemento 2): 31-37.

Buckup, L. \& Buckup, E.H. 1957. Catálogo dos moluscos do Museu Rio-Grandense de Ciências Naturais. Iheringia, Série Zoologia 1: 1-40.

Cáceres, C.E. 1997. Dormancy in Invertebrates. Invertebrate Biology 116 (4): 371-383.

Chase, R. \& Robinson, D.G. 2001. The uncertain history of land snails on Barbados: implications for conservation. Malacologia 43 (1-2): 33-57.

Colley, E. 2008. Taxonomia dos gastrópodes terrestres do litoral e Serra do Mar do Estado do Paraná. Dissertação de Mestrado em Zoologia do Museu Nacional. Universidade Federal do Rio de Janeiro: 263 pp.

Colley, E. \& Fischer, M.L. 2009. Avaliação dos problemas enfrentados no manejo do caramujo gigante africano Achatina fulica (Gastropoda: Pulmonata) no Brasil. Zoologia 26 (4): 674-683. 
Dieter, M. 1998. O litoral brasileiro e sua compartimentação. Pp. 273-349 in: Cunha, S.B da \& Guerra, A.J.T. (eds). Geomorfologia do Brasil. Rio de janeiro: Bertrand Brasil.

Dimitriadis V. K. 2001. Structure and Function of the Digestive System in Stylommpatophora. Pp 237-257 in: Barker, G. M. (ed) (2001) The Biology of Terrestrial Molluscs. Cromwell Press: Trowbridge.

Felippone, F. \& Barattini, L.P. 1938. Los moluscos uruguayos. Boletin del Servicio Oceanografico y de Pesca 1: 37-63.

Fischer, M.L. \& Colley, E. 2005. Espécie invasora em reservas naturais: caracterização da população de Achatina fulica Bowdich, 1822 (Mollusca - Achatinidae) na ilha Rasa, Guaraqueçaba, Paraná, Brasil. Biota Neotropica 5(1): 127-144.

Fontenelle, J.H. 2011. O uso da espessura do lábio externo para estimativa da idade em Megalobulimus paranaguensis (Pilsbry \& Ihering, 1900) (Gastropoda, Pulmonata). In: XXII Encontro Brasileiro de Malacologia, Fortaleza, CE. Livro de resumos XXII Ebram, p. 132.

Hanazaki, N.; Alves, R.R.N. \&Begossi, A. 2009. Hunting and use of terrestrial fauna used by Caiçaras from the Atlantic Forest cost (Brazil). Journal of Ethnobiology and Ethnomedicine 5: 36. (www.ethnobiomed.com/content/5/1/36). Acessado em 26/11/2009.

Groh, K. 2005. On a gerontic Megalobulimus from Mato Grosso, Brasil (Gastropoda: Strophocheilidae). Visaya 1 (3): 55-57.

Hidalgo, J.G. 1869. Moluscos del viaje al Pacífico - univalves terrestres. $152 \mathrm{pp}+8$ pls.

Hidalgo, J.G. 1870. Catálogue des coquilles terrestres recueillies par les naturalistes de la commission scientifique espagnole sur divers points d l'Amerique mérionale. Journal de Conchuliologie 10: 27-70 
Horn, A.C.M.; Achaval, M. \& Zancan, D.M. 2005. The annual reproductive cycle of the snail Megalobulimus abbreviatus (Bequaert, 1948) (Gastropoda, Pulmonata). Brazilian Journal of Biology 65 (3): 459-467.

Ihering, R.V. 1968. Dicionário dos Animais do Brasil. Brasília, UnB, 790 pp.

IBAMA . 2003. Lista nacional das espécies da fauna brasileira ameaçadas de extinção. In: Ministério do Meio Ambiente. Instrução Normativa no 3 de 27 de maio de 2003. (www.mma.gov.br/estruturas/179/_arquivos/179_05122008034002.pdf). Acessado em 16/09/2012.

Jacinavicius, F.C.; Rios, F.R. \& Molina, F.B. 2004. A maturidade sexual em Megalobulimus aff. ovatus. (Gastropoda, Pulmonata, Megalobulimidae). Arquivos do Instituto Biológico 71 (supl.): 651-653.

Latoski, N.M. \& Fischer, M.L. 2010. Avaliação dos aspectos relacionados às interações interespecíficas entre Megalobulimus paranaguensis Pilsbry \& Ihering, 1900 e Achatina fulica Bowdich, 1822: colonização de substratos. In XXVII Congresso Brasileiro de Zoologia, Curitiba, PR. Livro de resumos, $\mathrm{P} 2341$.

Leme, J.L.M. 1971. Anatomia e posição sistemática dos Strophocheiloidea neotropicais, coma descrição de uma nova família de Gastropoda Pulmonata. Tese de Doutoramento do Instituto de Biociências da USP São Paulo: 67 pp + 54 figs. +4 maps.

Leme, J.L.M. 1973. Anatomy and systematics of the neotropical Strophocheiloidea (Gastropoda, Pulmonata) with the description of a new family. Arquivos de Zoologia de São Paulo 23 (5): 295-337.

Leme, J.L.M. 1975. A fauna malacológica do material recolhido pela missão arqueológica franco-brasileira em Lagoa Santa, Minas Gerais. Arquivos do Museu Nacional 55 (nov.): 174.

Leme, J.L.M. 1989. Megalobulimus lopesi sp. n., uma nova espécie de Pulmonata terrestre da Mata Atlântica brasileira (Mollusca, Gastropoda, Megalobulimidae). Memórias do Instituto Oswaldo Cruz 84 (Suplemento 4): 313-318. 
Leme, J.L.M. 1993. Estudo anatômico sobre Megalobulimus auritus (Sowerby, 1838) (Gastropoda, Megalobulimidae). Papéis Avulso de Zoologia 38(7): 95-105.

Leme, J.L.M. \& Indrusiak, L.F. 1990. Megalobulimus parfragilior sp. n., uma nova espécie de Pulmonata terrestre da serra do mar (Gastrooda, Megalobulimidae). Papeis Avulsos de Zoologia 37(5): 97-105.

Leme, J.L.M. \& Indrusiak, L.F. 1995. Anatomia e considerações sobre o megalobulimus proclivis (Martens, 1888) (Gastropda, Megalobulimidae). Iheringia, Série Zoologia 78: 19-27.

Lydeard, C.; Cowie, R.H.; Ponder, W.F.; Bogan, A.E; Bouchet, P.; Clark, S.A.; Cummings, K.S.; Frest, T.J.; Gargominy, O.; Herbert, D.G.; Hershler, R.; Perez, K.E.; Roth, B.; Seddon, M.; Strong, E.E.; Thompson, F.G. 2004. The Global Decline of Nonmarine Mollusks. BioScience 54 (4): 321-330.

Mansur, M.C.D. \& Leme, J.L.M. 1996. The endangered Megalobulimus from the Atlantic Forest of Brazil. Tentacle 6: 14-15.

Mayr, E. 1977. Populações, espécies e evolução. São Paulo, Edusp, 485 pp.

Myers, N.; Mittermeier, R.A.; Mittermeier, C.G.; Fonseca, A.B. da. \& Kent, J. 2000. Biodiversity hotspots for conservation priorities. Nature 43: 853-858.

Monge-Nájera, J. 2003. Introducción: un vistazo a la historia natural de los moluscos. Revista de Biologia Tropical 51 (Suplemento 3): 1-3.

Morretes, F.L. de. 1949. Ensaio de catálogo dos moluscos do Brasil. Arquivos do Museu Paranaense 7: 5-216

Morretes, F.L. de. 1952. Novas espécies brasileiras da família Strophocheilidae. Arquivos de Zoologia de São Paulo 8 (4): 109-128.

Morretes, F.L. de. 1953. Adenda e corrigenda ao ensaio de catálogo dos moluscos do Brasil. Arquivos do Museu Paranaense 10 (1): 37-76.

Oliveira, M.P. \& Castro, G.A. 1979. Adenda ao ensaio de moluscos do Brasil de 
Frederico Lange de Morretes. Comunicações Malacológicas n. 11. Boletim do Instituto de Ciências Biológicas e Geociências 26, 8 pp.

Oliveira, M.P.; Resende, G.J.R.; Castro, G.A. 1981. Catálogo de moluscos da Universidade Federal de Juiz de Fora, UFJF, 520 pp.

Oliveira, M.P.; Rezende, G.J.R.; Castro, G.A. 1984. Contribuição à biologia do Megalobulimus (Phaiopharus) granulosus Rang, 1831 (Gastropoda, Pulmonata, Stylommatophora, Strophocheilidae). Boletim do Instituto de Ciências Biológicas e Geociências 37 (janeiro), 18 pp.

Pfeiffer, P.L. 1848. Monographia Heliceorum Viventium $2^{\circ}$ vol. 594 pp.

Pilsbry, H.A. 1894. Tryon's manual of conchology, second series: pulmonates 9, XLVIII + $366 \mathrm{pp}+62 \mathrm{pls}$.

Pilsbry, H.A. 1896. Tryon's manual of conchology, second series: pulmonates 10, 212 $\mathrm{pp}+51$ pls.

Pilsbry, H.A. \& Ihering, H.V. 1900. New south american land snail. Proceedings of the Academy of Natural Science of Philadelphia 52: 385-394.

Pilsbry, H.A. 1901. Tryon's manual of conchology, second series: pulmonates 14, 302p +62 pls.

Pilsbry, H.A. 1902. Tryon's manual of conchology, second series: pulmonates classification of Bulimulidae and index to volumes X-XIV. XCIX pp.

Prous, A. 1992. Arqueologia Brasileira. Brasília: UNB, 605 pp.

Rang, M.S. 1831. Description des Coquilles terrestres recueilles pendant un voyage à la côte occidentale d'Afrique, et au Brésil. Annales des Sciences Naturelles XXIV: 5-130.

Rios, F.R.; Jacinavicius, F.C. \& Molina, F.B. 2004. Taxa de eclosão em ovos de Megalobulimus aff. ovatus (Gastropoda, Pulmonata, Megalobulimidae) 
incubados em laboratório. Arquivos do Instituto Biológico 71 (suplemento): 388390.

Romero, S.M.B. 2004. Growth of Megalobulimus mogianensis (Gastropda: Megalobulimidae) raised in the laboratory from hatching to adulthood. American Malacological Bulletin 18 (1-2): 79-85.

Rosenberg, G. \& Muratov, I.V. 2005. Status report on the terrestril mollusca of Jamaica. Proceeding of the Academy of Natural Sciences of Philadelphia 155: 117-161.

Salgado, N.C. \& Coelho, A.C.S. 2003. Moluscos terrestres do Brasil (Gastrópodes operculados ou não exclusive Veronicellide, Milacidae e Limacidae). Revista de Biologia Tropical 51 (suplemento 3): 149-189.

Sawaya, P. \& Petersen, J.A. 1962. Sobre a ocorrência de Strophocheilidae (Molusco, Gastropode) no Rio Grande do Sul. Faculdade de Filosofia, Ciencias e Letras da Universidade de Sao Paulo (Boletim). Zoologia, 261: 31-41.

Scarabino, F. 2003. Lista sistemática de los Gastropoda terrestres viventes de Uruguay. Comunicaciones de la Sociedad Malacológica del Uruguay 8 (78-79): 203-214.

Scopoli, J.A. 1786. Deliciae florae e faunae insubricae 1: IX +85 pp +25 pl.

Scott, M.I.H. 1939. Estudio anatómico del Borus "Strophocheilus lorentzianus" (Doer.) (Mol. Pulm.) Revista del Museo de la Plata (Zoologia) 1(7): 217-278.

Simone, L.R.L. 1995. Estudo anatômico de amostragem de populações distintas de espécies brasileiras do gênero Megalobulimus Miller, 1898 (Gastropoda, Megalobulimidae). Dissertação de Mestrado do Instituto de Biociências da USP São Paulo: 54 pp + 63 figs.

Simone, L.R.L. \& Leme, J.L.M. 1998. Two new species of Megalobulimidae (Gastropoda, Strophocheiloidea) from north São Paulo, Brazil. Iheringia, Série Zoologia 85: 189-203. 
Simone, L. R. L. 1999. Mollusca Terrestres. Pp 3-8 in: Brandão, R. F.; Cancello, E. M. (eds) (1999). Invertebrados terrestres. Biodiversidade do Estado de São Paulo vol. 5. São Paulo: FAPESP, xviii+279 pp.

Simone, L.R.L. 2006. Land and Freshwater Mollucs of Brazil. São Paulo: EGB Fapesp, 390 pp.

Sobreira, H.B. \& Molina, F.B. 2002. Observações preliminares sobre a biologia reprodutiva de Megalobulimus gummatus (Mollusca, Megalobulimidae) em laboratório. Arquivos do Instituto Biológico 69 (suplemento): 139-141.

Taddei,V.A.; Martins, U.R.; Vivo, M. de \& Percequillo, A.R. 1999 . O acervo das coleções zoológicas do estado de São Paulo. In Joly, C. A.; Bicudo, C. E. M. (org.). Biodiversidade do Estado de São Paulo, Brasil: síntese do conhecimento ao final do século $X X$, 7: Infraestrutura para conservação da biodiversidade. São Paulo: Fapesp. p. 53-67.

Thomé, J.W.; Arruda, J.O.; Silva, L.F. 2007. Moluscos terrestres no cone meridional da América do Sul. Ciência e Ambiente, 35 (2): 9-38.

Thomé, J.W.; Carara, A.E.Q.; Mallmann, M.T.O.; Lopes, P.T.C.; Schneider, V.I. 2004. Manual de aulas práticas de zoologia: Estudo morfo-anatômico de um molusco Gastrópode Mesuretra. Cadernos Edipucrs 5 (Série Zoologia), 32 pp.

Tillier, S. 1989. Comparative morphology, phylogeny and classification of land snails and slugs (Gastropoda: Pulmonata: Stylommatophora). Malacologia 30: 1-303

Valduga, R. 1985. O caçador de caramujos. Bento Gonçalves: ed. do autor, 216 pp.

Wheeler, Q.D. 2008. Undisciplined thinking: morphology and Hennig's unfinished revolution. Systematic Entomology 33: 2-7. 
Apêndice 5.1 Biometria das espécies utilizadas na comparação conquiliológica com o "complexo Megalobulimus granulosus": Tabela 16. M. yporanganus; Tabela 17: $M$. ovatus.

\begin{tabular}{rrrrrr}
\hline & COMP. & LARG. & ALT. & $\begin{array}{c}\text { VOLTAS } \\
\text { PROTOCH. }\end{array}$ & $\begin{array}{c}\text { VOLTAS } \\
\text { TOTAIS }\end{array}$ \\
\hline $\mathbf{n}$ & 110 & 109 & 109 & 101 & 102 \\
$\mathbf{m a x}$ & 94 & 50 & 42 & 3.8 & 5.6 \\
$\mathbf{m i n}$ & 52 & 22 & 17 & 3.1 & 4.9 \\
$\mathbf{a m p l}$ & 42 & 28 & 25 & 0.6 & 0.8 \\
$\boldsymbol{\mu}$ & 72 & 33 & 28 & 3.4 & 5.2 \\
$\mathbf{m}$ & 72 & 31 & 25 & 3.4 & 5.3 \\
$\mathbf{D P}$ & 9 & 7 & 6 & 0.1 & 0.2 \\
$\mathbf{C V}(\boldsymbol{\%})$ & $12.0 \%$ & $20.5 \%$ & $22.8 \%$ & $3.8 \%$ & $3.6 \%$ \\
$\mathbf{p}$ & 0.7429 & 0.0261 & 0.0242 & 0.1873 & 0.3863 \\
\hline
\end{tabular}

Tabela 16. Biometria da concha de Megalobulimus yporanganus. Legenda: n: tamanho da amostra; max: valor máximo; min: valor mínimo; ampl: amplitude; $\mu$ : média aritmética; m: mediana; DP: desvio padrão; CV (\%): coeficiente de variação em porcentagem; p: teste de normalidade de D’Agostino-Pearson (distribuição normal nos valores de $\mathrm{p}>0,05$ ).

\begin{tabular}{rrrrrr}
\hline & COMP. & LARG. & ALT. & $\begin{array}{c}\text { VOLTAS } \\
\text { PROTOCH. }\end{array}$ & $\begin{array}{c}\text { VOLTAS } \\
\text { TOTAIS }\end{array}$ \\
\hline $\mathbf{n}$ & 38 & 35 & 35 & 35 & 33 \\
$\mathbf{m a x}$ & 125 & 67 & 60 & 3.6 & 5.6 \\
$\mathbf{m i n}$ & 98 & 54 & 52 & 3.0 & 5.0 \\
$\mathbf{a m p l}$ & 27 & 13 & 8 & 0.6 & 0.6 \\
$\boldsymbol{\mu}$ & 114 & 63 & 55 & 3.5 & 5.4 \\
$\mathbf{m}$ & 114 & 63 & 55 & 3.5 & 5.4 \\
$\mathbf{D P}$ & 5 & 2 & 2 & 0.1 & 0.1 \\
\hline $\mathbf{C V}(\boldsymbol{\%})$ & $4.7 \%$ & $4.0 \%$ & $3.3 \%$ & $3.5 \%$ & $2.7 \%$ \\
$\mathbf{p}$ & 0.1480 & 0.3522 & 0.5274 & 0.3387 & 0.3803 \\
\hline
\end{tabular}

Tabela 17. Biometria da concha de Megalobulimus ovatus (São Paulo). Legenda: n: tamanho da amostra; max: valor máximo; min: valor mínimo; ampl: amplitude; $\mu$ : média aritmética; m: mediana; DP: desvio padrão; CV $(\%)$ : coeficiente de variação em porcentagem; p: teste de normalidade de D’Agostino-Pearson (distribuição normal nos valores de $\mathrm{p}>0,05$ ). 
Apêndice 5.1 (continuação). Biometria das espécies utilizadas na comparação conquiliológica com o "complexo Megalobulimus granulosus": Tabela 18. M. sanctipauli.

\begin{tabular}{rrrrrr}
\hline & COMP. & LARG. & ALT. & $\begin{array}{r}\text { VOLTAS } \\
\text { PROTOCH. }\end{array}$ & $\begin{array}{r}\text { VOLTAS } \\
\text { TOTAIS }\end{array}$ \\
\hline $\mathbf{n}$ & 132 & 132 & 128 & 92 & 116 \\
$\mathbf{m a x}$ & 104 & 53 & 47 & 4.0 & 6.3 \\
$\mathbf{m i n}$ & 72 & 36 & 30 & 3.3 & 5.3 \\
$\mathbf{a m p l}$ & 32 & 17 & 17 & 0.7 & 1.0 \\
$\mathbf{\mu}$ & 88 & 45 & 41 & 3.7 & 5.8 \\
$\mathbf{m}$ & 89 & 45 & 41 & 3.6 & 5.8 \\
$\mathbf{D P}$ & 7 & 4 & 3 & 0.2 & 0.2 \\
\hline $\mathbf{C V}(\boldsymbol{\%})$ & $8.0 \%$ & $8.8 \%$ & $8.0 \%$ & $4.1 \%$ & $4.0 \%$ \\
$\mathbf{p}$ & 0.2356 & 0.4590 & 0.0196 & 0.1934 & 0.1539 \\
\hline
\end{tabular}

Tabela 18. Biometria da concha de Megalobulimus sanctipauli. Legenda: n: tamanho da amostra; max: valor máximo; min: valor mínimo; ampl: amplitude; $\mu$ : média aritmética; m: mediana; DP: desvio padrão; CV (\%): coeficiente de variação em porcentagem; p: teste de normalidade de D’Agostino-Pearson (distribuição normal nos valores de $\mathrm{p}>0,05$ ). 
Apêndice 5.2. Teste $T$ de Student para as medidas e sua relações em espécies do "complexo M. granulosus" e espécies externas

\begin{tabular}{|c|c|c|c|c|c|c|c|c|c|c|}
\hline M. granulosus & $<0,0001$ & 0,0053 & & $<0,0001$ & $<0,0001$ & $<0,0001$ & $<0,0001$ & $<0,0001$ & $<0,0001$ & $<0,0001$ \\
\hline M. abbreviatus & $<0,0001$ & $<0,0001$ & $<0,0001$ & & $<0,0001$ & $<0,0001$ & $<0,0001$ & $<0,0001$ & $<0,0001$ & $<0,0001$ \\
\hline M. chionostoma & $<0,0001$ & $<0,0001$ & $<0,0001$ & $<0,0001$ & & 0,4470 & $<0,0001$ & 0,6698 & $<0,0001$ & $<0,0001$ \\
\hline M. ovatus & $<0,0001$ & $<0,0001$ & $<0,0001$ & $<0,0001$ & 0,4470 & & $<0,0001$ & 0,7522 & $<0,0001$ & $<0,0001$ \\
\hline M. haemastomus & $<0,0001$ & $<0,0001$ & $<0,0001$ & $<0,0001$ & $<0,0001$ & $<0,0001$ & 0,0011 & $<0,0001$ & $<0,0001$ & \\
\hline
\end{tabular}

Tabela 19. Comprimento da concha das espécies estudadas comparadas pelo Teste $\boldsymbol{T}$ de Student $(\boldsymbol{p}<0,05)$. Na linha superior as espécies com a média e o desvio-padrão em milímetros; os valores em negrito indicam não haver diferença significativa entre as espécies comparadas. 
Apêndice 5.2. (continuação) Teste $T$ de Student para as medidas e suas relações em espécies do "complexo M. granulosus" e espécies externas utilizados na construção da Tabela 13.

\begin{tabular}{|c|c|c|c|c|c|c|c|c|c|c|}
\hline M. granulosus & $<0,0001$ & $<0,0001$ & & $<0,0001$ & $<0,0001$ & $<0,0001$ & $<0,0001$ & $<0,0001$ & $<0,0001$ & $<0,0001$ \\
\hline M. abbreviatus & $<0,0001$ & 0,0022 & $<0,0001$ & & $<0,0001$ & $<0,0001$ & $<0,0001$ & $<0,0001$ & $<0,0001$ & $<0,0001$ \\
\hline M. chionostoma & $<0,0001$ & $<0,0001$ & $<0,0001$ & $<0,0001$ & & 0,0633 & $<0,0001$ & 0,6586 & $<0,0001$ & $<0,0001$ \\
\hline M. ovatus & $<0,0001$ & $<0,0001$ & $<0,0001$ & $<0,0001$ & 0,0633 & & $<0,0001$ & 0,0010 & $<0,0001$ & $<0,0001$ \\
\hline M. haemastomus & $<0,0001$ & $<0,0001$ & $<0,0001$ & $<0,0001$ & $<0,0001$ & $<0,0001$ & $<0,0001$ & $<0,0001$ & $<0,0001$ & \\
\hline
\end{tabular}

Tabela 20. Largura da concha das espécies estudadas comparadas pelo Teste $\boldsymbol{T}$ de Student $(\boldsymbol{p}<\mathbf{0 , 0 5})$. Na linha superior as espécies com a média e o desvio-padrão em milímetros; os valores em negrito indicam não haver diferença significativa entre as espécies comparadas. 
Apêndice 5.2. (continuação) Teste $T$ de Student para as medidas e suas relações em espécies do "complexo M. granulosus" e espécies externas utilizados na construção da Tabela 13.

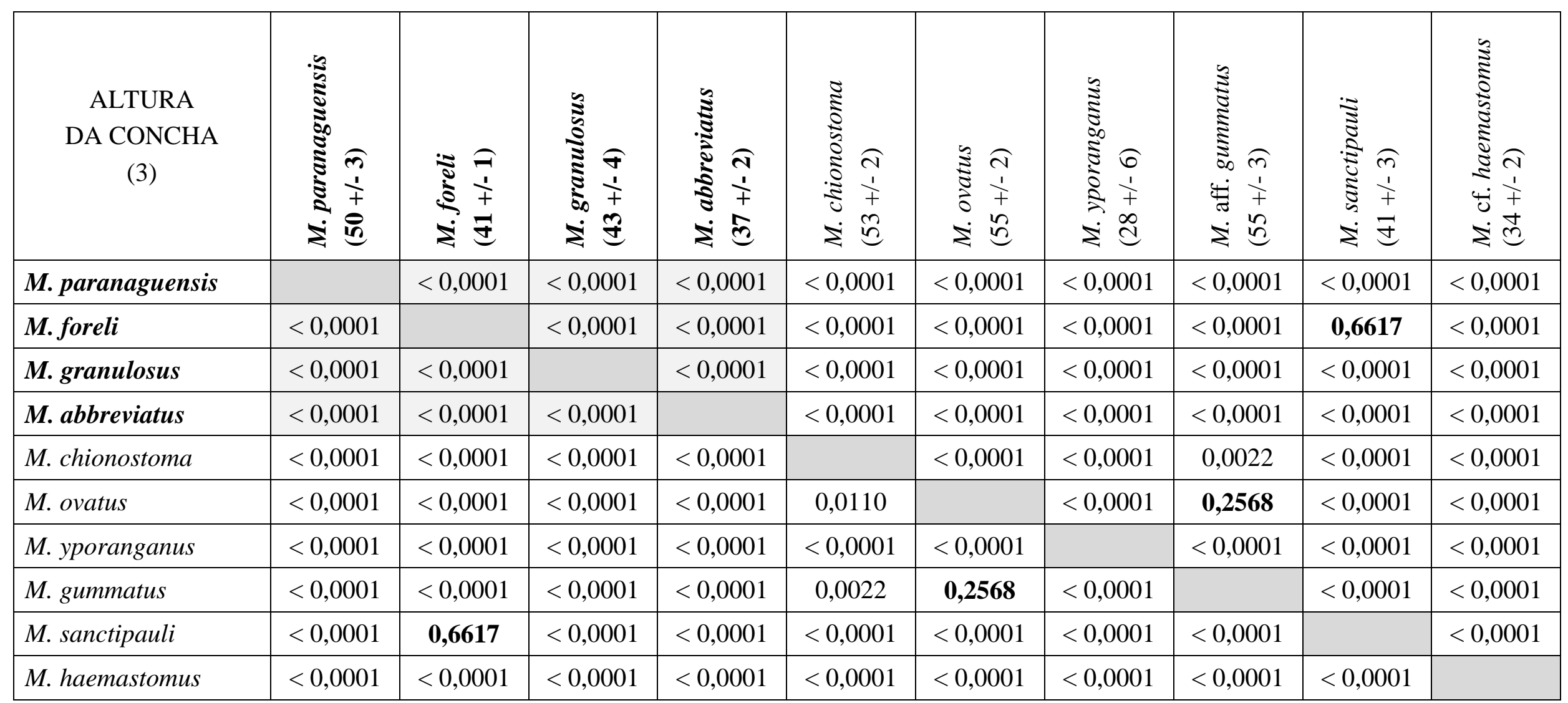

Tabela 21. Altura da concha das espécies estudadas comparadas pelo Teste $\boldsymbol{T}$ de Student $(\boldsymbol{p}<\mathbf{0 , 0 5})$. Na linha superior as espécies com a média e o desvio-padrão em milímetros; os valores em negrito indicam não haver diferença significativa entre as espécies comparadas. 
Apêndice 5.2. (continuação) Teste $T$ de Student para as medidas e suas relações em espécies do "complexo M. granulosus" e espécies externas utilizados na construção da Tabela 13.

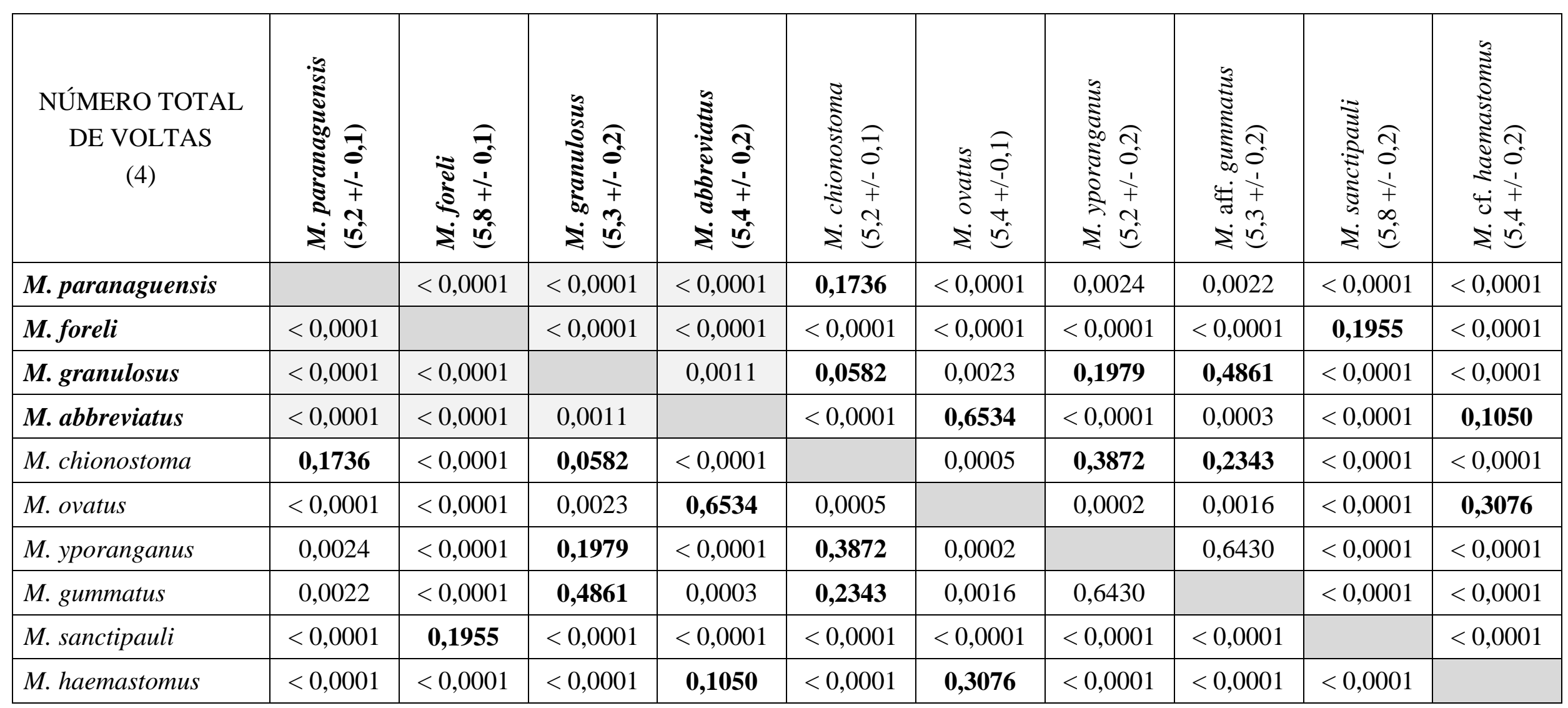

Tabela 22. Número de voltas totais da concha das espécies estudadas comparadas pelo Teste $T$ de Student $(p<0,05)$. Na linha superior as espécies com a média e o desvio-padrão; os valores em negrito indicam não haver diferença significativa entre as espécies comparadas. 
Apêndice 5.2. (continuação) Teste $T$ de Student para as medidas e suas relações em espécies do "complexo M. granulosus" e espécies externas utilizados na construção da Tabela 13.

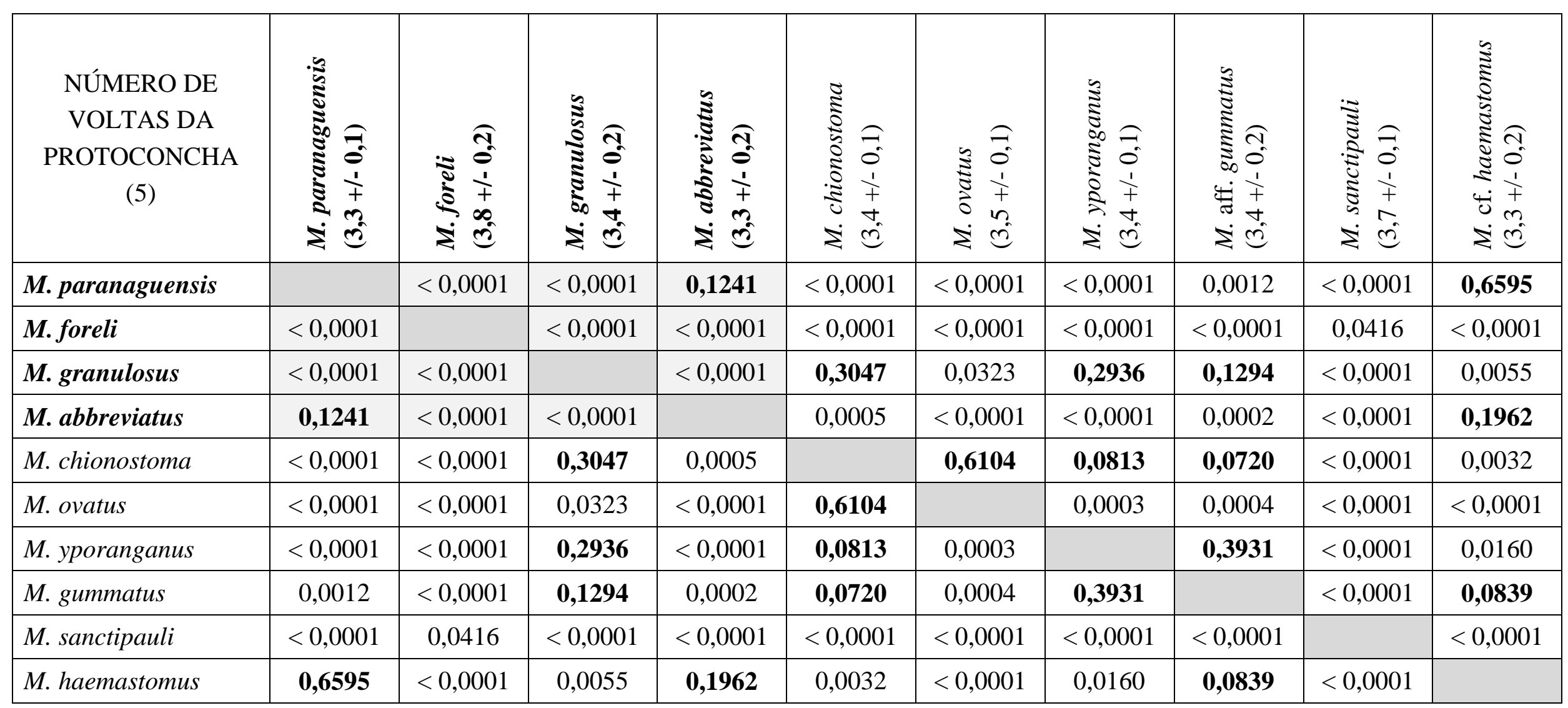

Tabela 23. Número de voltas da protoconcha das espécies estudadas comparadas pelo Teste $T$ de Student $(p<0,05)$. Na linha superior as espécies com a média e o desvio-padrão; os valores em negrito indicam não haver diferença significativa entre as espécies comparadas. 
Apêndice 5.2. (continuação) Teste $T$ de Student para as medidas e suas relações em espécies do "complexo M. granulosus" e espécies externas utilizada na construção da Tabela 13.

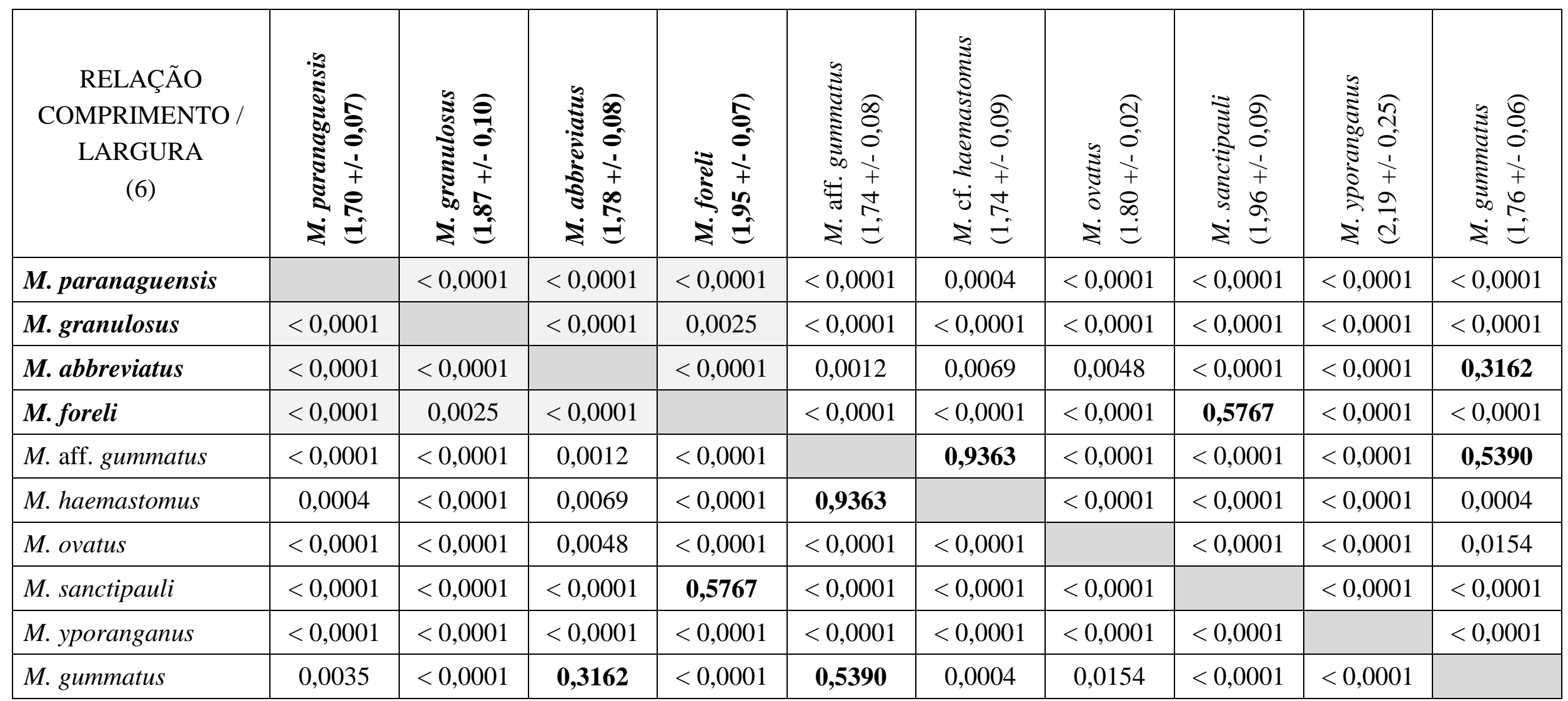

Tabela 24. Relação comprimento/largura da concha das espécies estudadas comparadas pelo Teste $T$ de Student $(p<0,05)$. Na linha superior as espécies com a média e o desvio-padrão; os valores em negrito indicam não haver diferença significativa entre as espécies comparadas. 
Apêndice 5.2. (continuação) Teste $T$ de Student para as medidas e suas relações em espécies do "complexo M. granulosus" e espécies externas utilizada na construção da Tabela 13.

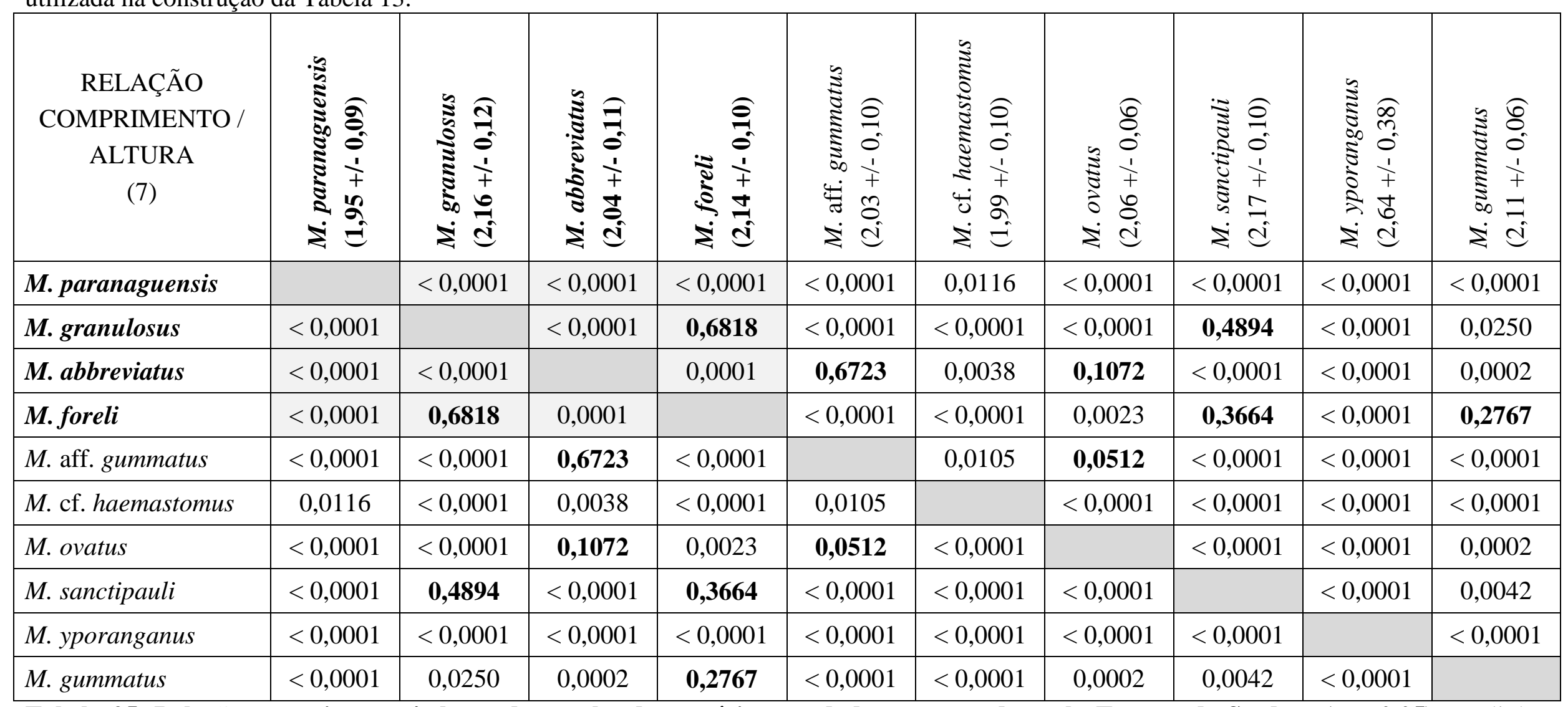

Tabela 25. Relação comprimento / altura da concha das espécies estudadas comparadas pelo Teste $T$ de Student $(p<0,05)$. Na linha superior as espécies com a média e o desvio-padrão; os valores em negrito indicam não haver diferença significativa entre as espécies comparadas. 
Apêndice 5.2. (continuação) Teste $T$ de Student para as medidas e suas relações em espécies do "complexo M. granulosus" e espécies externas utilizadas na construção da Tabela 13.

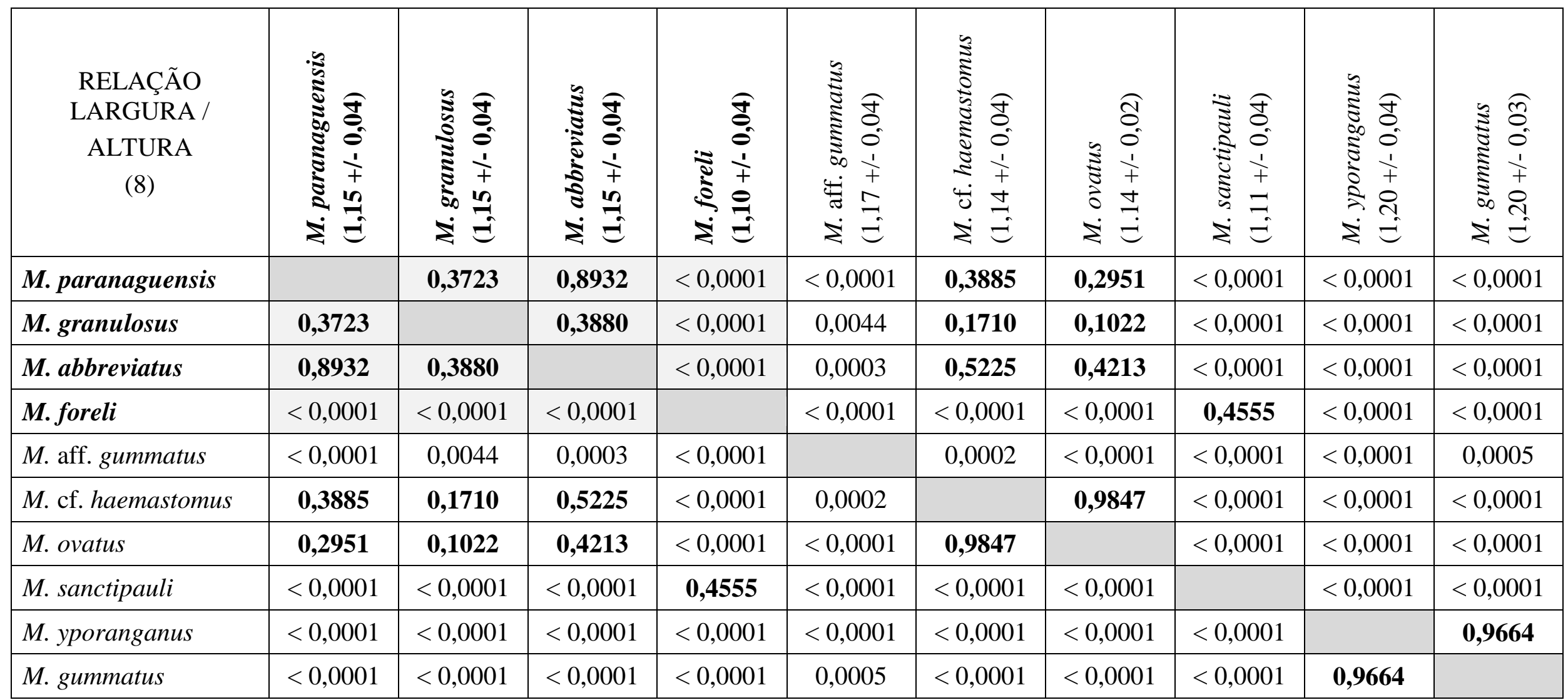

Tabela 26. Relação largura / altura da concha das espécies estudadas comparadas pelo Teste $T$ de Student $(p<0,05)$. Na linha superior as espécies com a média e o desvio-padrão; os valores em negrito indicam não haver diferença significativa entre as espécies comparadas. 